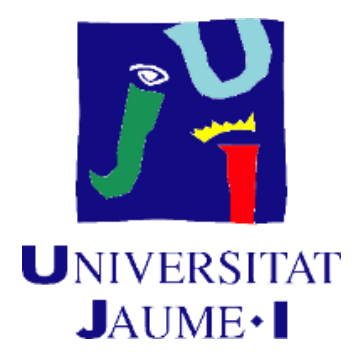

EVALUACIÓN DE UN MODELO DE INTERVENCIÓN SOCIAL PARA LA PROMOCIÓN DE RESILIENCIA CON NIÑOS Y NIÑAS VÍCTIMAS DEL CONFLICTO ARMADO COLOMBIANO

"AUNQUE BEIS CRECIÓ EN LA GUERRA: JUEGA, CREA, SUEÑA"

Doctoranda: Cindy Tatiana Carrero Torres

Directoras: Dra. Sandra Milena Alvarán López y Dra. Raquel Flores Buils

Julio de 2020 


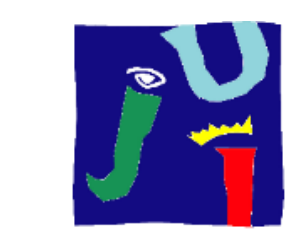

$\mathbf{U}_{\text {NIVERSITAT }}$

JAUME+I

Programa de Doctorado en Desarrollo Local y Cooperación Internacional

Escuela de Doctorado de la Universitat Jaume I

\title{
EVALUACIÓN DE UN MODELO DE INTERVENCIÓN SOCIAL PARA LA PROMOCIÓN DE RESILIENCIA CON NIÑOS Y NIÑAS VÍCTIMAS DEL CONFLICTO ARMADO COLOMBIANO
}

AUNQUE BEIS CRECIÓ EN LA GUERRA: JUEGA, CREA, SUEÑA

\begin{abstract}
Memoria presentada por Cindy Tatiana Carrero Torres para optar al Grado de Doctora por la Universitat Jaume I
\end{abstract}

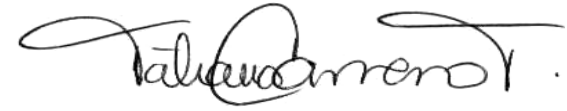

Cindy Tatiana Carrero Torres

Nombre y apellidos del doctorando/a

y FIRMA original

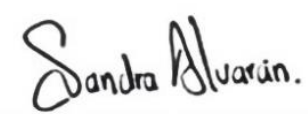

Sandra Milena Alvarán López

Nombre y apellidos del director/a o directores/as de la tesis y FIRMA original

RAQUEL Firmado

|FLORES| $\left.\right|_{\text {Buils }} ^{\text {RAOU }}$

BUILS Fecha: 2020.07.30

Raquel Flores Buils

Nombre y apellidos del director/a o directores/as de la tesis y FIRMA original 


\section{DEDICATORIA}

"Tú serás para mí único en el mundo, yo seré para ti único en el mundo". El Principito- Antoine de Saint-Exupéry

A mi Julián, porque has motivado esta investigación que tiene casi tu edad.

Porque al elegirme como mamá, me retaste a repensarme y a repensar el país que quisiera heredarte. Por invitarme a jugar con "Beis" Por "domesticarme"

A Juan Ángel y Mario Andrés. A los niños y niñas colombianos. 


\section{AGRADECIMIENTOS}

Lograr este producto lleno de pasiones y reflexión, me permite reafirmar mi compromiso con la infancia de mi país. Y por ello quiero extender mis agradecimientos a quienes han hecho parte de este camino, que de seguro, aquí continúa.

A mi esposo Carlos Hernando, por su inagotable amor, su confianza su entrega y su apoyo permanente en este proceso. Por ser el compañero perfecto en la distancia y en la cercanía y ser el mejor coequipero de la vida y un oportuno asistente de investigación.

A mi hermano Carlos Andrés, mi principal tutor de resiliencia en toda la vida, porque ha sido motor, orgullo, apoyo, con pocas palabras y muchos actos de fe y amor. A mis hermanos, por su ternura, sonrisa, porque con ellos empecé a comprender diferente las infancias.

A mis padres y a mi abuelita, por ser mis dadores de vida y por ser los escuchas activos, los consejeros, los motivadores de los caminos que he decidido emprender.

A Catherine, porque desde el colegaje, la hermandad y las pasiones conjuntas, hemos hilado nuestros caminos y nos hemos puestos zapatos una y otra vez, ayudándonos a caminar.

A Heidy y Roberto, amigos, colegas, compañeros de doctorado, su incondicionalidad incomparable. Por el apoyo, las disertaciones, las comprensiones conjuntas, las lágrimas y las carcajadas.

A Sandra Alvarán, Raquel Flores, Antonio Caballer por su motivación, su apoyo permanente, su camaradería y confianza. Por enseñarme la rigurosidad de la investigación.

A Lorena, una gran colega, por su rigurosidad y sus disertaciones como auxiliar de investigación.

A la Corporación Universitaria Minuto de Dios -Uniminuto- y a la Universidad de Antioquia, por el respaldo académico, de crecimiento, de debate y confrontación para crecer en la investigación. 
A la Corporación Juego y Niñez, por enamorarme de la infancia y del juego, porque allá crecí.

A la empresa Lúdica Desarrollo Humano y al Colegio CEDID Ciudad Bolívar sede Tanque Laguna, por permitirme jugar con ellos y desarrollar mi proceso de trabajo de campo.

A la Fundación La Niñez Primero, a Probúsqueda y a la Universidad de El Salvador, porque gracias a mi estancia predoctoral en El Salvador tuve comprensiones académicas y metodológicas en atención a la infancia desde el juego y el conflicto armado en Latinoamérica.

A mis tías, tíos, primos, primas, sobrinos, sobrinas, suegras, cuñados y en general a toda la familia extensa que siempre con sonrisas, amor y comida, me demuestran su amor, respaldo y confianza. 
Índice de contenido

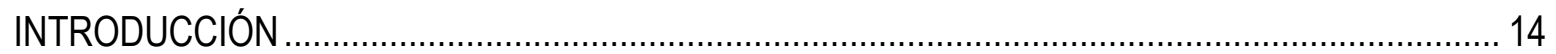

CAPITULO 1: EFECTOS PSICOSOCIALES DEL CONFLICTO ARMADO COLOMBIANO EN LOS NIÑOS Y NIÑAS.

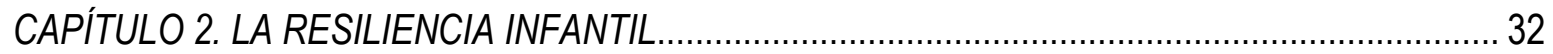

2.1. Las fuentes ontosistémicas de la resiliencia infantil ..................................................... 36

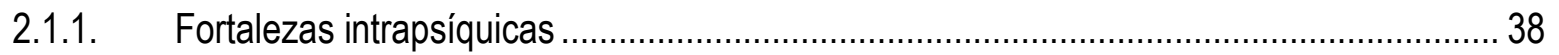

2.1.2. Habilidades para la acción ................................................................................ 40

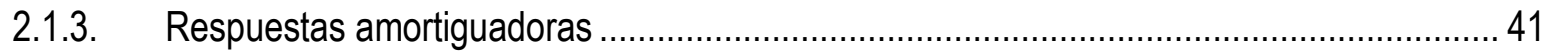

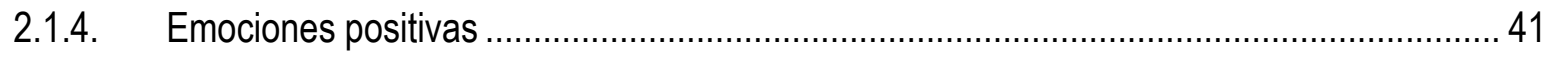

2.2. Las fuentes microsistémicas de la resiliencia infantil ..................................................... 44

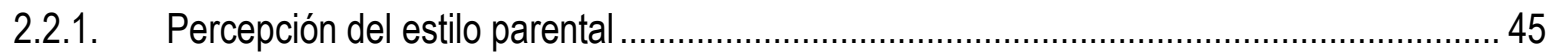

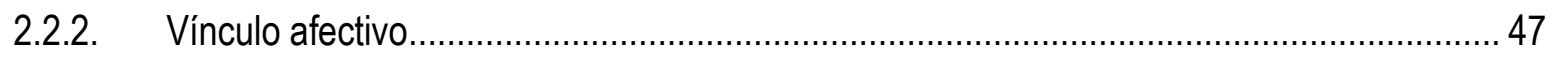

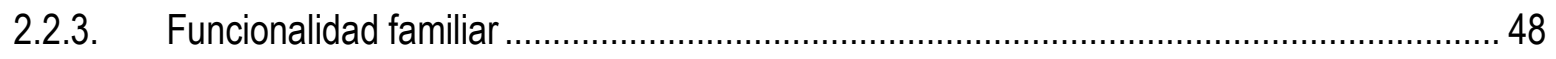

2.3. Las fuentes macrosistémicas de la resiliencia infantil ..................................................... 49

CAPITULO 3. EL JUEGO

3.1. El homo ludens 0 la acción humana de jugar .............................................................. 54

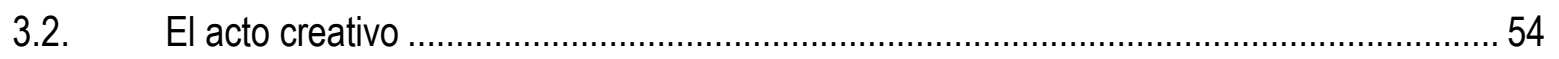

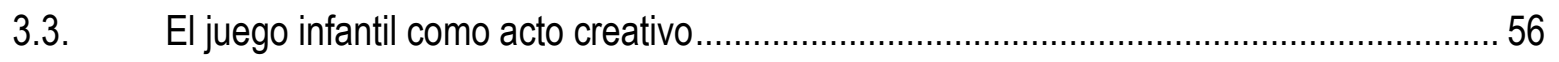

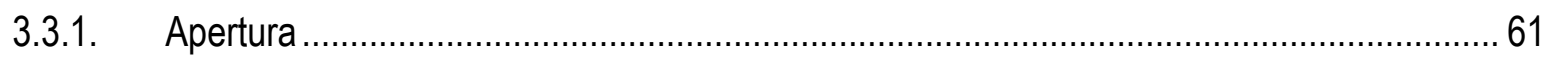

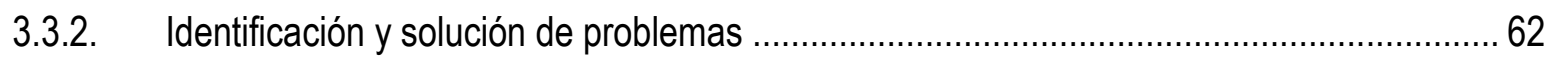

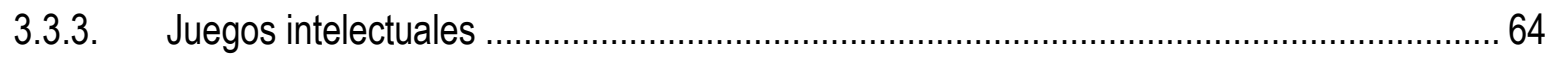

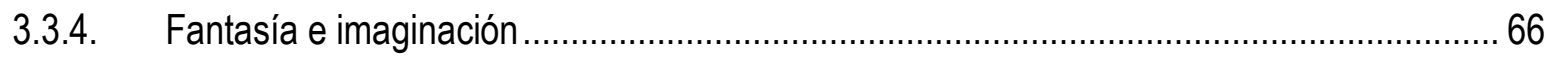

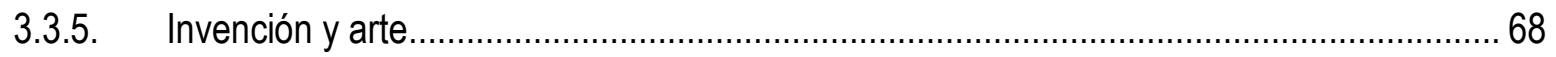

4. CAPÍTULO 4. MODELO DE PROMOCIÓN DE LA RESILIENCIA DESDE EL JUEGO .........73

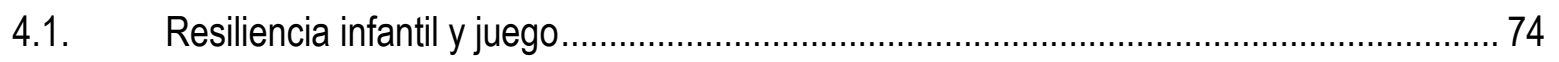

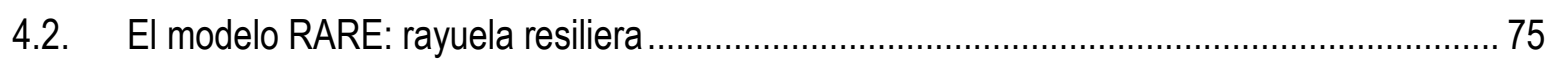

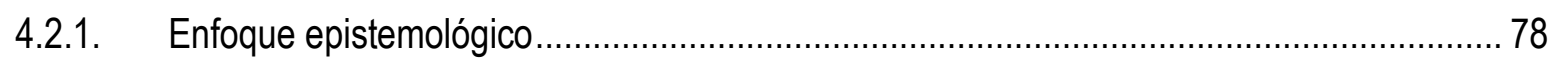




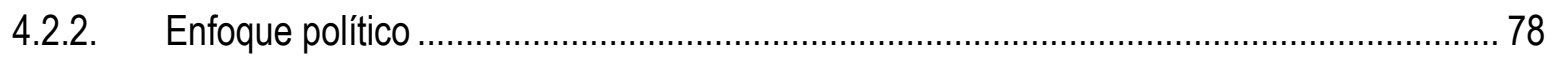

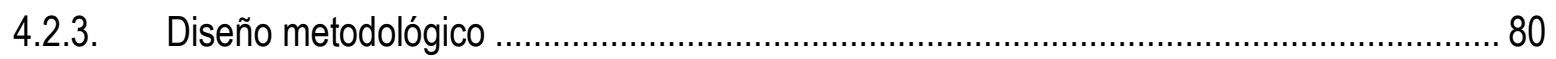

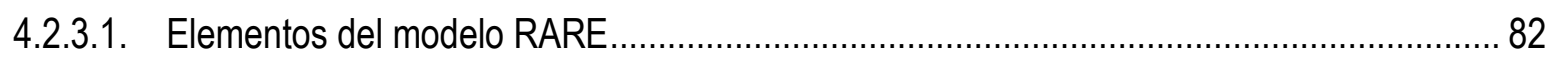

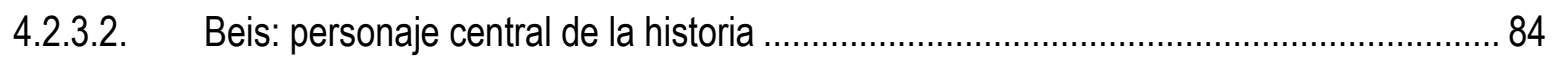

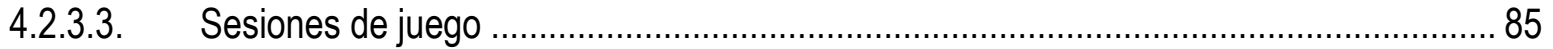

5. CAPÍTULO 5. ESTUDIO CUASI- EXPERIMENTAL PARA LA EVALUACIÓN DE UN MODELO DE INTERVENCIÓN SOCIAL PARA LA PROMOCIÓN DE RESILIENCIA CON NIÑOS Y NIÑAS VÍCTIMAS DEL CONFLICTO ARMADO COLOMBIANO .................................................................. 88

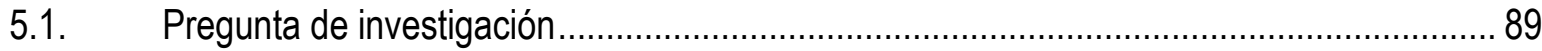

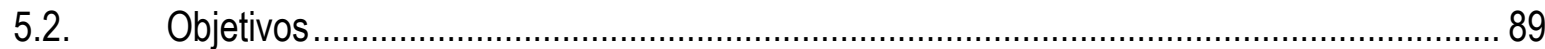

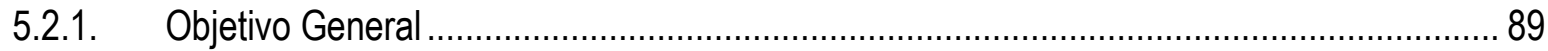

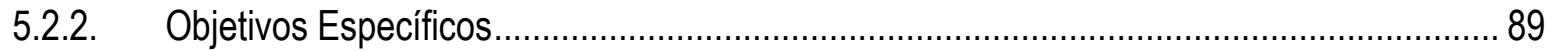

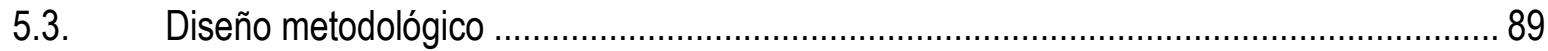

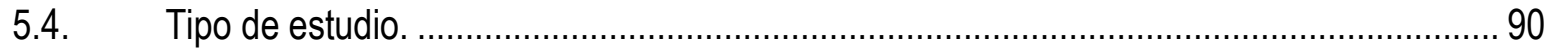

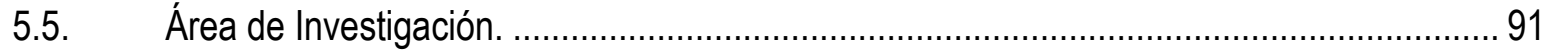

5.6. Población de estudio.............................................................................................. 91

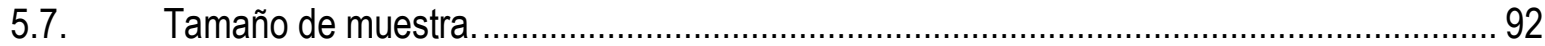

5.8. Criterios de inclusión y exclusión. ............................................................................. 92

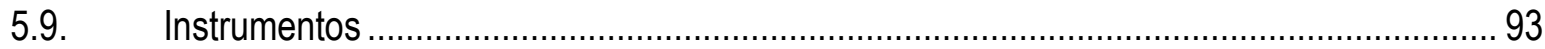

5.9.1.1. Instrumento de medición de resiliencia (JJ63) ........................................................... 93

5.9.1.2. Instrumento de estilos parentales ........................................................................ 94

5.9.1.3. Instrumento de personalidad Creadora......................................................................... 95

5.9.1.4. Cuestionario de Emociones Positivas ...................................................................... 96

5.10. Operacionalización de las variables y preguntas orientadoras …………………….......... 96

5.11. Proceso de recolección de Información ..................................................................... 98

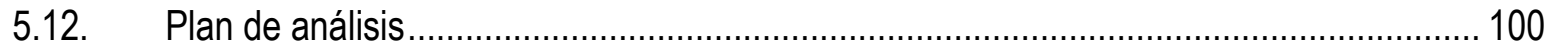

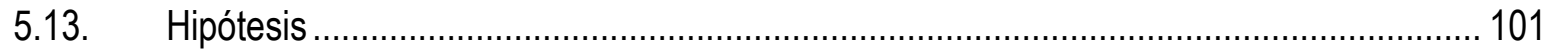

5.14. Identificación y control de potenciales sesgos ………………..................................... 101

5.15. Manejo de los datos en forma detallada .................................................................. 102

5.16. Técnicas y programas utilizados ................................................................................ 103

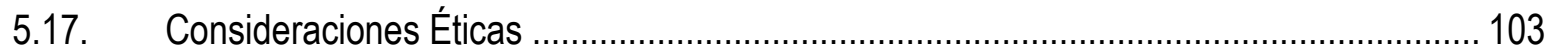


6. CAPÍTULO 6. RESULTADOS DE LA APLICACIÓN DEL MODELO DE PROMOCIÓN DE

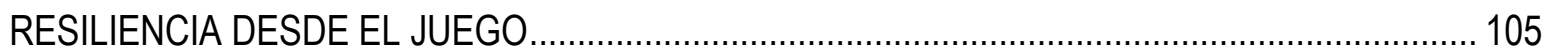

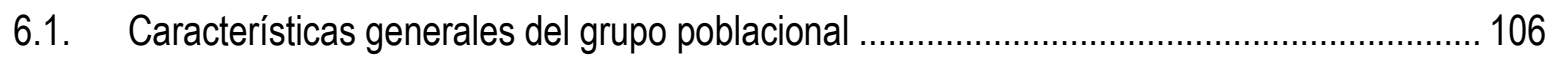

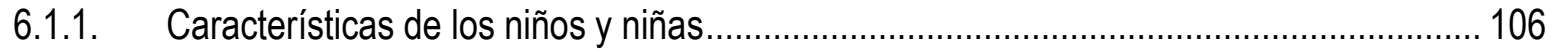

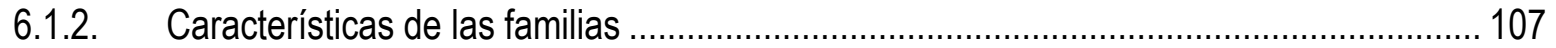

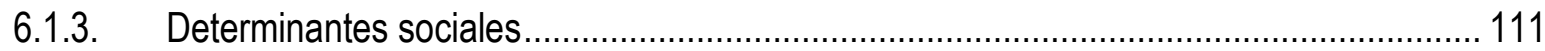

6.2. Análisis de correspondencias múltiples entre las diferentes fuentes o constructos de resiliencia

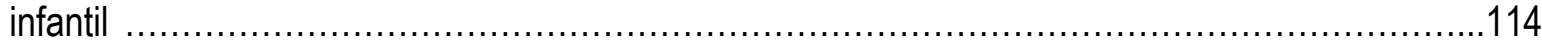

6.3. Niveles de resiliencia infantil antes y después del modelo de intervención ...................... 119

6.4. Resultados comparativos entre los grados cuartos (control) y quinto (caso) para el pos - test de resiliencia infantil...................................................................................................... 128

6.5. Resultados comparativos de las diferentes variables utilizadas en el estudio en relación con la resiliencia infantil (variable dependiente) y el juego (variable independiente) ............................ 132

7. CAPITULO 7. PROPUESTA DE INTERVENCIÓN BASADA EN EL JUEGO ….................. 143

7.1. Taller $\mathrm{N}^{\circ}$ 1: Caracterización y construcción de historia y personaje .............................. 145

7.2. Taller $\mathrm{N}^{\circ}$ 2: Reciprocidad y construcción de confianza............................................. 147

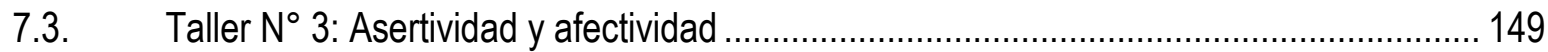

7.4. Taller $\mathrm{N}^{\circ}$ 4: Autoestima, autoconcepto y resistencia................................................ 152

7.5. Taller $\mathrm{N}^{\circ}$ 5: Interdependencia e impulsividad ......................................................... 154

7.6. Taller $\mathrm{N}^{\circ}$ 6: Pensamiento crítico y sentido del humor ................................................ 156

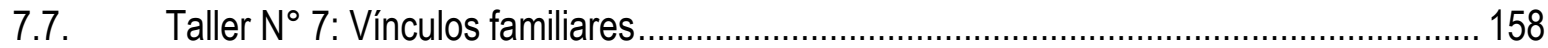

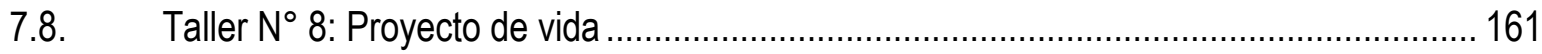

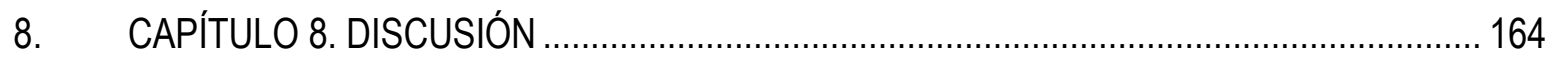

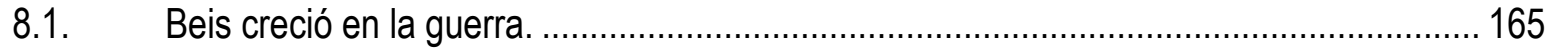

8.2. Para que Beis juegue, cree y sueñe ..................................................................... 169

8.3. El modelo de promoción de la resiliencia desde el juego: intervención psicosocial para la construcción de paz. 171

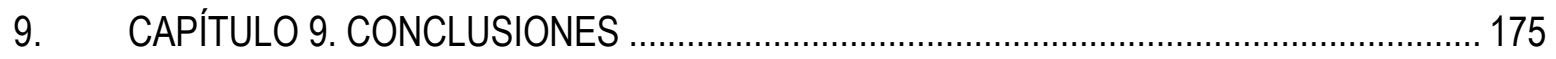

9.1. Intervención psicosocial desde el juego y para el juego. Inversión pública en juego y como efecto colateral: la resiliencia.............................................................................................. 177

9.2. Desarrollo local desde la infancia para la construcción de paz...................................... 179 


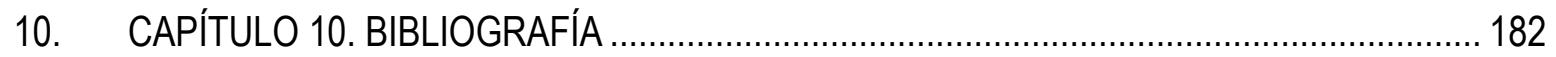

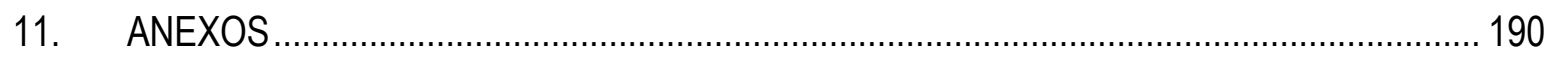




\section{Índice de tablas}

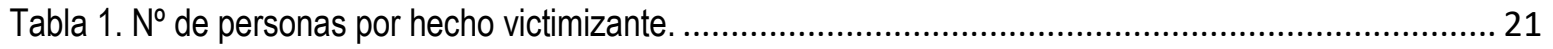

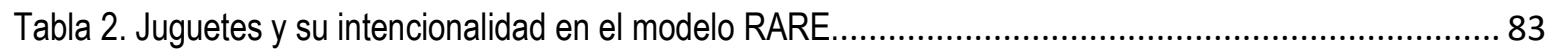

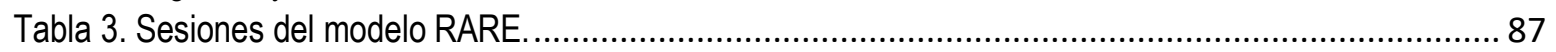

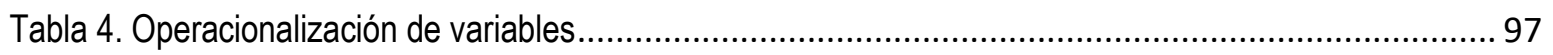

Tabla 5. Porcentajes de algunas características individuales de los estudiantes de cuarto y quinto de primaria la institución educativa Colegio CEDID Ciudad Bolívar, 2019........................................................... 106 Tabla 6. Porcentajes de algunas determinantes de los estudiantes de cuarto y quinto de primaria la institución educativa Colegio CEDID Ciudad Bolívar, 2019 .............................................................................. 111 Tabla 7. Medianas y variabilidad de cada una de las dimensiones de emociones positivas antes y después de la intervención de los estudiantes del Colegio CEDID Ciudad Bolívar 2019....................................... 121

Tabla 8. Promedios y variabilidad de cada una de las dimensiones del constructo de juego antes y después de la intervención de los estudiantes del Colegio CEDID Ciudad Bolívar 2019............................................ 123 Tabla 9. Medianas y variabilidad de cada una de las dimensiones de instrumento de personalidad creadora antes y después de la intervención de los estudiantes del Colegio CEDID Ciudad Bolívar 2019............... 123 Tabla 10. Medianas y variabilidad de cada una de las dimensiones del instrumento de la Escala de Estilos Parentales antes y después de la intervención de los estudiantes del Colegio CEDID Ciudad Bolívar 2019.125 Tabla 11. Medianas y variabilidad de cada una de las dimensiones de la resiliencia antes y después de la intervención de los estudiantes del Colegio CEDID Ciudad Bolívar 2019.

Tabla 12. Cálculo del estadístico de $U$ de Mann Whitney para comparar las dimensiones del pos-test del instrumento JJ63 aplicado a los niños y niñas de grado cuarto y quinto de primaria del colegio CEDID Ciudad Bolívar, 2019

Tabla 13. Cálculo del estadístico de U de Mann Whitney para comparar las dimensiones del pos-test del instrumento de Emociones Positivas aplicado a los niños y niñas de grado cuarto y quinto de primaria del colegio CEDID Ciudad Bolívar, 2019.

Tabla 14. Cálculo del estadístico de U de Mann Whitney para comparar las dimensiones del pos-test del instrumento de Personalidad Creadora aplicado a los niños y niñas de grado cuarto y quinto de primaria del colegio CEDID Ciudad Bolívar, 2019.

Tabla 15. Cálculo del estadístico de $U$ de Mann Whitney para comparar las dimensiones del pos-test del instrumento de Escala de Estilos Parentales aplicado a los niños y niñas de grado cuarto y quinto de primaria del colegio CEDID Ciudad Bolívar, 2019. 132 Tabla 16. Estadístico de Chi- cuadrado de cada una de las categorías de resiliencia pre-test y post-test y su asociación con variables de demográficas, familiares e instrumentos medidos en los niños y niñas del colegio CEDI, cuidad Bolívar 2019. Parte 1

Tabla 17. Estadístico de Chi- cuadrado de cada una de las categorías de resiliencia pre-test y post-test y su asociación con variables de demográficas, familiares e instrumentos medidos en los niños y niñas del colegio CEDI, cuidad Bolívar 2019. Parte 2 .

Tabla 18. Promedios, distribución normal y variabilidad de cada una de las categorías de la resiliencia y valoración de la diferencia de las variables cuantitativas de los niños y niñas de cuarto y quinto de primaria del Colegio CEDID Ciudad Bolívar, 2019. 136 Tabla 19. Estadístico de Chi-cuadrado de cada una de las categorías de resiliencia post-test y post-test y su asociación con las dimensiones del instrumento de personalidad creadora post-test medido en los niños y niñas del colegio CEDI, Ciudad Bolívar 2019. 
Tabla 20. Estadístico de Chi- cuadrado de cada una de las categorías de resiliencia post-test y post -test y su asociación con las dimensiones del instrumento de personalidad creadora pre -test medido en los niños y niñas del colegio CEDID Ciudad Bolívar 2018

Tabla 21. Estadístico de Chi- cuadrado de cada una de las categorías de juego y su asociación con variables de demográficas, familiares e instrumentos medidos en los niños y niñas del colegio CEDI, cuidad, Bolívar 2019.

Tabla 22. Estadístico de Chi- cuadrado de cada una de las categorías de juego y su asociación con variables de demográficas, familiares e instrumentos medidos en los niños y niñas del colegio CEDI, cuidad, Bolívar 2019.

Tabla 23. Tabla de transformación de puntuaciones directas en percentiles para varones y mujeres en la escala de personalidad creadora EPC 


\section{Lista de Figuras.}

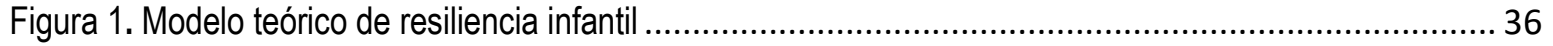

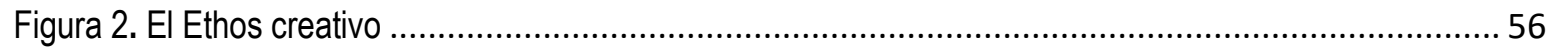

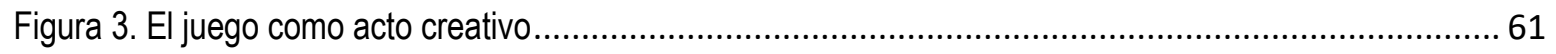

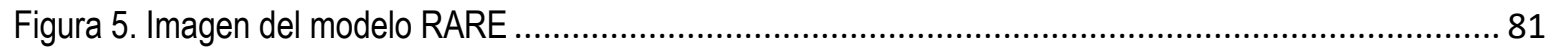

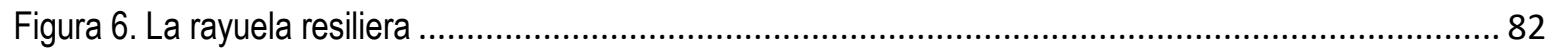

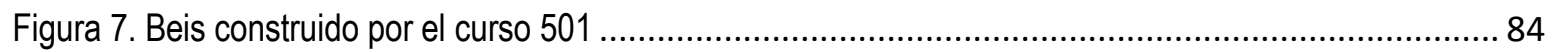

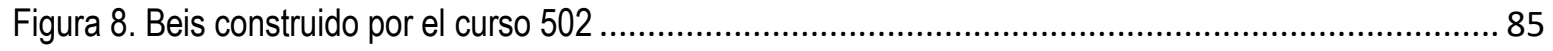

Figura 9. Grado en curso de los estudiantes del Colegio CEDID Ciudad Bolívar 2019. .......................... 107

Figura 10. Tipo de familia de los estudiantes de cuarto y quinto de primaria de la institución educativa Colegio

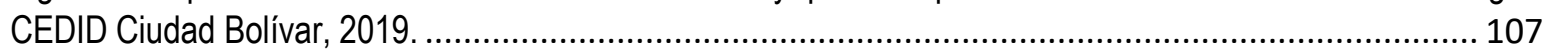

Figura 11. Ingreso mensual promedio del hogar de los estudiantes cuarto y quinto de primaria la institución

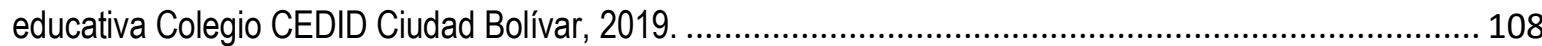

Figura 12. Parentesco de quien diligencia la encuesta de los estudiantes del grado cuarto y quinto del Colegio

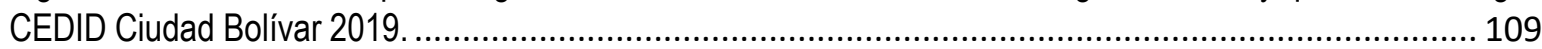

Figura 13. Lugar de nacimiento del adulto que diligencia la encuesta de los estudiantes del Colegio CEDID

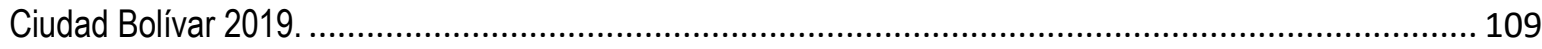

Figura 14. Número de horas dedicadas por el adulto a los estudiantes del Colegio CEDID Ciudad Bolívar

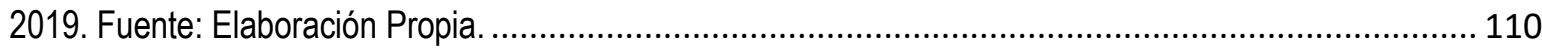

Figura 15. Actividades que realizó el adulto durante la última semana con el niño o la niña del Colegio CEDID

Ciudad Bolívar 2019. Fuente: Elaboración Propia....................................................................... 110

Figura 16. Cantidad de miembros que conforman el hogar de los estudiantes del Colegio CEDID Ciudad

Bolívar 2019. Fuente: Elaboración Propia............................................................................... 112

Figura 17. Cuantos aportan al ingreso del hogar de los estudiantes del Colegio CEDID Ciudad Bolívar 2019.

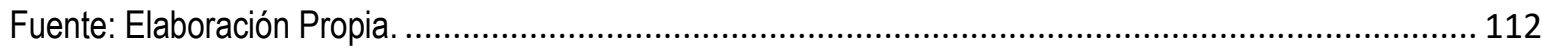

Figura 18. De dónde provienen los ingresos del hogar de los estudiantes del Colegio CEDID Ciudad Bolívar

2019. Fuente: Elaboración Propia. ........................................................................................... 113

Figura 19. Tiempo que lleva el hogar viviendo en la Ciudad y el barrio de los estudiantes del Colegio CEDID

Ciudad Bolívar 2019.Fuente: Elaboración Propia.......................................................................... 113

Figura 20. Mayor y menor nivel educativo aprobado por algún miembro del hogar de los estudiantes del

Colegio CEDID Ciudad Bolívar 2019. Fuente: Elaboración Propia................................................... 114

Figura 21. Conjunto de puntos de categoría de grado y acompañamiento de la familia en las actividades

lúdicos recreativas de los estudiantes del Colegio CEDID Ciudad Bolívar 2019........................................ 115

Figura 22. Conjunto de puntos de categoría de grado y dimensiones de resiliencia después de la intervención

de los estudiantes del Colegio CEDID Ciudad Bolívar 2019. Fuente: Elaboración Propia........................ 116

Figura 23. Conjunto de puntos del grado y las dimensiones funcionalidad Familiar, autoestima, asertividad y adaptabilidad a situaciones nuevas, después de la intervención de los estudiantes del Colegio CEDID Ciudad

Bolivar 2019. Fuente: Elaboración Propia.

Figura 24. Conjunto de puntos del grado y las dimensiones capacidad de pensamiento crítico, impulsividad, afectividad y resiliencia general, después de la intervención de los estudiantes del Colegio CEDID Ciudad

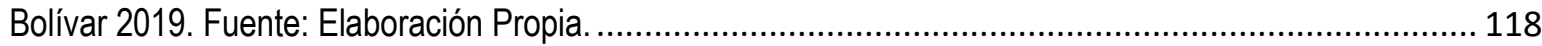

Figura 25. Conjunto de puntos del grado y emociones positivas, después de la intervención de los estudiantes del Colegio CEDID Ciudad Bolívar 2018. Fuente: Elaboración Propia. ............................................... 119

Figura 26. Mediana de cada uno de los constructos de emociones positivas ....................................... 120 
Figura 27. Mediana de cada una de las dimensiones antes y después de la intervención que conforman el constructo de juego de los estudiantes del Colegio CEDID Ciudad Bolívar 2019. Fuente: Elaboración Propia.

Figura 28. Mediana de cada una de las dimensiones de Estilos Parentales antes y después de la intervención de los estudiantes del Colegio CEDID Ciudad Bolívar 2019. Fuente: Elaboración Propia.

Figura 29. Mediana de cada una de las dimensiones de la resiliencia antes y después de la intervención de los estudiantes del Colegio CEDID Ciudad Bolívar 2019. Fuente: Elaboración Propia. 


\section{Lista de anexos}

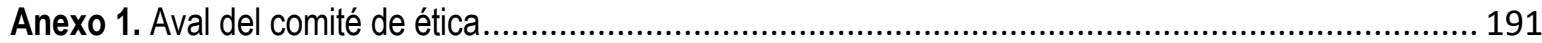

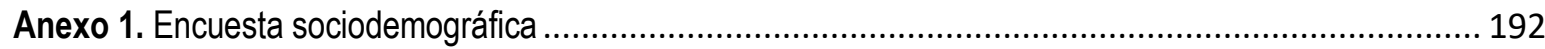

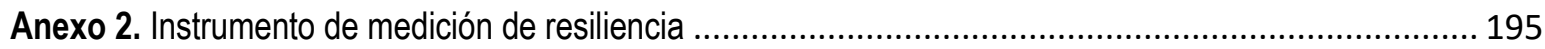

Anexo 3. Autorización del autor para la utilización del instrumento de medición de resiliencia................... 197

Anexo 4. Instrumento de percepción de estilos parentales.............................................................. 198

Anexo 5. Autorización de la autora para la utilización del instrumento de percepción de estilos parentales 199

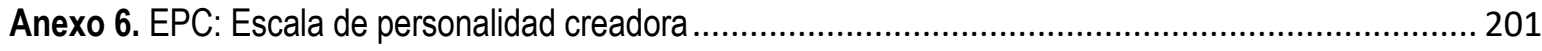

Anexo 7. Autorización de la autora para la utilización de la EPC: Escala de personalidad creadora........... 203

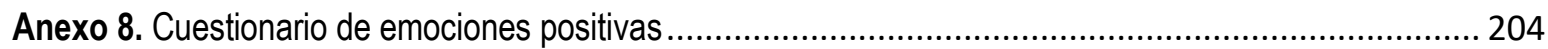

Anexo 9. Autorización de la autora para la utilización del cuestionario de emociones positivas ................ 205

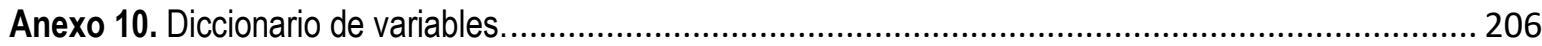

Anexo 7. Consentimiento informado para los padres y asentimiento informado ..................................... 228 
INTRODUCCIÓN 
La República de Colombia al ratificar la Convención de los Derechos del Niño (por medio de la Ley 12 de 1991) se comprometió con el imperativo de proteger de manera integral a los niños, niñas y adolescentes, así como con la satisfacción plena de todos sus derechos de forma prioritaria sobre los de cualquier otro grupo poblacional en consideración a su interés superior. Tal como lo afirma el informe de la Defensoría del Pueblo, "es obligación y deber de toda sociedad democrática e incluyente, visibilizar a los niños y niñas como las víctimas más sensibles del conflicto armado, pues son sujetos de múltiples formas de violencia como el reclutamiento ilicito, la violencia sexual, el homicidio, el secuestro, lesiones y graves infracciones al Derecho Internacional Humanitario, entre otras" (Defensoría del pueblo, 2014).

Es fundamental partir del principio del interés superior del niño y de la niña, consagrado en la Convención de los Derechos del Niño, de la que Colombia hace parte desde $1991^{1}$ es decir, los derechos de los niños y niñas prevalecen sobre los derechos de los demás.

En Colombia, las personas que nacieron entre los años 1950 y 1994, si bien ahora son personas adultas, su infancia transcurrió en el marco del conflicto armado de manera directa 0 indirecta, quedado instalados, en las relaciones consigo mismos y con los demás, elementos culturales como la reproducción de patrones de violencia.

Por ello, entre otras razones, identificar las afectaciones a varias generaciones de niños y niñas que han nacido en medio del conflicto armado en Colombia, sería ver también las afectaciones de quienes hoy son adultos o de las familias de quienes nunca llegaron a serlo, y eso supone un ejercicio de memoria histórica que ayude a la sociedad, en su conjunto, a revisar las causas que han permitido esta situación y a vislumbrar las alternativas y los pasos que se deben dar para garantizar que cesen las violaciones y se logre vivir en dignidad y ejercicio pleno de los derechos humanos desde la niñez.

En el informe de la Defensoría del Pueblo de Colombia manifiesta que "son precisamente los niños y niñas que nacieron de 1995 en adelante, las personas que conforman uno de los sectores poblacionales de mayor vulnerabilidad y exposición a los impactos del conflicto armado (...)" (Defensoría del pueblo, 2014). En muchos casos se arrebata la vida tanto física como emocional. En ocasiones, los niños y niñas ven menoscabados sus derechos a la educación, a la alimentación, a un ambiente sano $o$ una vivienda digna, y las familias, para protegerlos, en truncadas las posibilidades de construir y llevar a cabo sus proyectos de vida en sus territorios originarios.

Por tanto, haber vivido la guerra de manera directa o indirecta supone para los niños y niñas víctimas del conflicto armado interno colombiano, diferentes efectos psicosociales como la pérdida de sus casas y tierras poner el despojo formado de tierras, lesiones personales físicas y psicológicas

\footnotetext{
${ }^{1}$ Constitución Política de Colombia (1991). Título II. De los Derechos, las Garantías y los Deberes. Capítulo 2. De los derechos sociales, económicos y culturales. Artículo 44.
} 
Al ubicar a los niños y niñas en condición de víctimas se están reconociendo los efectos traumáticos que causó la exposición al conflicto y, por ende, en esta condición están implícitos los efectos emocionales, donde los niños y niñas están desamparados y en la mayoría de los casos, no logran desarrollar capacidad de respuesta, pues la exposición al conflicto fue sorpresiva, intensa y en exceso, que deja huellas duraderas en sus condiciones emocionales.

Tales efectos emocionales hacen referencia a heridas abiertas, heridas que no se logran cerrar y que se mantienen incluso hasta la vida adulta, como un choque violento sobre su yo y su construcción de subjetividad, de su construcción de relación con el otro y con el entorno, pues causaron miedo, confusión, falta de confianza en sí mismo y en el otro.

Sin embargo, los efectos emocionales de la guerra son diferentes en cada niño y niña, pues como afirma Carmen Lucía Díaz en su ponencia que "depende de los determinantes históricos del sujeto, de sus fortalezas yoicas y defensas particulares, de la misma vulnerabilidad y terror frente al acto, de las mediaciones que pueda anteponer, de la significación de los acontecimientos, así como de la distancia o cercanía física o emocional frente a los hechos" (Universidad Nacional de Colombia Sede Bogotá, 2003).

Los niños y niñas víctimas del conflicto armado están sometidos a espacios físicos completamente diferentes a los que tenían antes. Las posibilidades de correr y jugar libremente se reducen, se exponen a condiciones de hacinamiento y se modifica drásticamente el entorno social. Para ayudar económicamente a sus padres, o a la mujer que es cabeza de familia, terminan vinculados al comercio informal 0 a trabajos como ayudantes de construcción. En el caso de las niñas, se vinculan al servicio doméstico y, en algunas ocasiones, en situaciones son víctimas de la explotación sexual comercial infantil.

Los niños y niñas se ven obligados a vivir en lugares que no escogieron, en situaciones que nunca soñaron, con personas que nunca conocieron, ya que el desplazamiento forzado les arranca de sus cotidianidades. En la Convención de los Derechos del Niño (CDN), que es el tratado internacional de mayor aceptación puesto que ha sido ratificado por casi todos los Estados, se hace un llamado de atención al mundo entero frente la importancia de los niños, reconociéndolos como sujetos plenos de derechos.

Gracias a la Ley 1448 de 2011 de víctimas y restitución de tierras, el factor psicosocial transversaliza el proceso de atención institucional, desde la declaración de los hechos que hace el afectado hasta la restitución, que incluye una carta de perdón que pide el Estado. Como dice Bello (2014):

"El término psicosocial permite una lectura más amplia de los impactos que causa la guerra. No es lo mismo vivir los efectos de un desastre natural o de una acción de la delincuencia común (...). El enfoque psicosocial busca superar la mirada solo clínica de los impactos y si 
bien identifica los daños asociados a traumas o a enfermedades mentales, los sitúa en un contexto y en el marco de complejas relaciones (...), para así identificar acciones reparativas que vayan más allá de una prescripción médica y que obligan respuestas de orden social y político" (Bello, 2014).

Así como lo afirma Alvarán "estas experiencias son vividas particularmente por los niños, porque los monstruos con los que se suelen asustar todos los seres humanos cuando son pequeños son imaginarios, sin embargo, aquellos monstruos para los niños víctimas del desplazamiento forzado son reales. Pueden irrumpir en la noche o en la madrugada y son monstruos reales que no solamente amenazan, sino que concretan sus acciones porque desaparecerán sus padres, asesinarán a sus amigos, asesinarán figuras representativas que han tenido especial significado para los niños" (Alvarán, 2013).

Con base en lo anterior, y desde el reconocimiento de las cifras que arrojan informes como el impacto del conflicto armado en el estado psicosocial de los niños y niñas y adolescentes realizado en 2014 por el Instituto Colombiano de Bienestar Familiar, con la ejecución de la presente investigación se busca diseñar, ejecutar y evaluar un modelo de promoción de la resiliencia desde el juego, que oriente a los profesionales de las ciencias humanas y sociales, de las ciencias de la educación, de las ciencias médicas, a las autoridades públicas y entidades privadas, frente a los procesos de intervención con niños y niñas víctimas de la violencia socio-política del país. No se puede pensar en modelos únicos para los diferentes contextos, no se pueden seguir pensando propuestas de intervención desde Bogotá (capital de la República), sin tener en cuenta los contextos de cada región, cada barrio, cada cuadra. Las cifras frente a la afectación emocional del conflicto armado en los niños y niñas siguen siendo globales, pero esas cifras aún no dialogan con los sentires, las emociones y la piel de los niños y niñas.

A propósito de esto, el diario El País de Cali (Valle del Cauca, Colombia), publicó en enero de 2015 un artículo titulado "Las huellas del conflicto armado en los niños y adolescentes colombianos" donde evocan la entrevista realizada a una experta en impactos psicosociales a los niños y niñas víctimas de conflicto armado; allí, se manifiesta que los niños y niñas superan los traumas más rápido que los adultos, dada su capacidad de resiliencia, de imaginación. (Montiel, 2015)

La resiliencia, esa aptitud que tienen las personas para sobreponerse a las más severas adversidades es más fuerte en los niños, explicó la magister en Arteterapia de la Universidad de Sury, Londres (Montiel, 2015), porque ellos tienen la capacidad de reprimir más rápido que los adultos la presencia de traumas y miedos "Ellos por su imaginación disminuyen la sensación de impotencia y amenaza (...)".

Generalmente, dijo Kaplansky en su ponencia, basada en estudios y en su experiencia de más de 25 años, "los niños que han sido afectados directamente por la violencia vuelven a su vida 
normal en dos, máximo tres meses. Pero si no reciben tratamiento pueden quedar con secuelas para toda la vida" (Montiel, 2015).

Para Ingrid Rusinque Osorio, directora nacional de protección del ICBF, "el hecho de que el $90 \%$ de los menores víctimas de la guerra pueda superar los traumas es una cifra esperanzadora, ya que los niños tienen gran capacidad de resiliencia y si están en un entorno que los favorece: van al colegio, cuentan con el cariño y acompañamiento de sus padres, de sus familias y la sociedad los acoge, seguro pueden salir adelante" (Montiel, 2015).

En el estudio colombiano, en el tema de resiliencia, en el que se midieron variables como la perseverancia, la confianza en sí mismos, el manejo de la soledad y la satisfacción personal, comenta Guarnizo, se encontró que los que más se tienen confianza son los niños víctimas de minas antipersonas y en segundo lugar, los desvinculados del conflicto (Montiel, 2015).

Y es allí donde se centra mi interés como investigadora, como madre de un niño en primera infancia, como ciudadana política y éticamente comprometida con los niños, niñas y adolescentes, donde recojo mi experiencia y trayectoria profesional en el acompañamiento de diferentes proyectos que promueven la garantía de los derechos de las infancias, el presente del país; radico mi interés en investigar las afectaciones que ha tenido la violencia del país, reconocer las capacidades de los niños y niñas de sobreponerse, de adaptarse, de resignificar y de imaginar mundos posibles, y sobre todo, reconocer el juego como estrategia de intervención, donde los niños sueñan, crean, confrontan y hablan desde sus lenguajes naturales y universales.

Así pues, en el capítulo uno se hace una presentación de los efectos psicosociales que ha dejado el conflicto armado colombiano a partir de una revisión de fuentes secundarias como lo son investigaciones que han realizado instituciones nacionales e internacionales, identificando secuelas importantes en la salud mental de los niños y niñas.

En el capítulo dos se ahonda en uno de los ejes de esta investigación, como lo es la resiliencia infantil, donde se propone un modelo teórico para comprenderla, a partir de la concepción de un proceso sistémico que se alimenta de fuentes ontosistémicas, microsistémicas y macrosistémicas.

En el capítulo tres se presenta una disertación teórico-metodológica sobre el segundo eje que moviliza esta investigación: el juego. Allí se conversa acerca de la acción humana de jugar y la movilización del Ethos creativo en el juego infantil.

Por otro lado, en el capítulo cuarto se abordará el desarrollo metodológico de la investigación, ahondando en los objetivos, las preguntas, las hipótesis y diseño metodológico sobre el cual se soporta, que redunda en la operacionalización de categorías, dimensiones y constructos para el análisis de la realidad estudiada. Este es un estudio cuasi experimental, con mediciones pre y postratamiento, de corte descriptivo. 
En el capítulo quinto, se presenta una propuesta de intervención psicosocial para niños y niñas víctimas del conflicto armado colombiano, denominado modelo RARE (Rayuela Resiliera), un ejercicio de autoría de la investigadora que, a partir de la revisión teórica de las categorías de resiliencia infantil y juego, propone un abordaje metodológico para realizar con niños y niñas entre los 8 y los 12 años de edad.

Este modelo tuvo una fase de experimentación empírica que se desarrolló con niños y niñas del colegio CEDID Ciudad Bolívar, sede Escuela Tanque Laguna, del quinto grado de primaria y contó con un grupo no expuesto de la misma institución, pero del grado cuarto. Este proceso de experimentación empírica se condensó en una sistematización de experiencia que se presenta en el capítulo seis.

Por su parte, en el capítulo siete se presentan los resultados estadísticos de la aplicación del modelo RARE, donde se identifican los aportes que se hacen a las fuentes ontosistémicas de la resiliencia infantil y cómo el juego ayuda a su promoción.

Los resultados estadísticos más las impresiones de la investigadora frente a la promoción de resiliencia observados en los niños y niñas, se discuten en el capítulo ocho, donde además, se identifican las oportunidades de mejora y los desafíos para realizar intervención psicosocial con niños y niñas víctimas del conflicto armado.

En el último capítulo se presentan las conclusiones de este trabajo de investigación doctoral, donde se propone un debate alrededor de los desafíos que enfrenta el desarrollo local en las actuales condiciones de Colombia. 


\section{CAPÍTULO 1: EFECTOS PSICOSOCIALES DEL CONFLICTO ARMADO COLOMBIANO EN LOS NIÑOS Y NIÑAS}


Las cifras oficiales informan que en Colombia se encuentran 8.944.137 víctimas registradas en el Registro Único de Víctimas - RUV (Unidad de Atención y Reparación Integral a Víctimas, s.f.), (Recuperado en abril 2020), es decir, cerca del $18.5 \%$ de la población total del país han sido víctimas de la violencia, de las cuales:

- 8.553.416 manifestaron en su declaración, ser victimizadas por hechos en el marco del conflicto armado en Colombia y 6.916.918 son víctimas sujetas de atención y 1.636.498 víctimas directas de desaparición forzada, homicidio, fallecidas y no activos para la atención²

- 390.721 personas son "víctimas en sentencia"3

En 2011 el gobierno colombiano promulga la Ley de 1448 de 2011, que representó para el país un avance en términos de reconocimiento y dignificación de las víctimas a través de la materialización de sus derechos constitucionales, para lo cual el gobierno nacional en un marco de justicia transicional establece un conjunto de medidas judiciales, administrativas, sociales y económicas, individuales y colectivas, en beneficio de las víctimas de la violencia. Dicha Ley reconoce diferentes hechos victimizantes, siendo el desplazamiento forzado el que mayor número de víctimas arroja. Según el Reporte Único de Víctimas al mes de abril de 2020 se encuentran las siguientes cifras (ver Tabla 1):

Tabla 1. $N^{0}$ de personas por hecho victimizante.

\begin{tabular}{l|r}
\multicolumn{1}{c}{ HECHO } & PERSONAS \\
\hline Abandono o despojo forzado de tierras & 21.149 \\
Acto terrorista/atentados/combates/ hostigamientos & 82.767 \\
Amenaza & 427.585 \\
Delitos contra la libertad y la integridad sexual & 29.622 \\
Desaparición forzada & 178.064 \\
Desplazamiento & 7.585 .536 \\
Homicidio & 1.018 .860 \\
Minas antipersonal/munición sin explotar/artefacto explosivo & 11.608 \\
Perdida de bienes muebles o inmuebles & 116.124 \\
Secuestro & 37.050 \\
Tortura & 10.582 \\
Vinculación de niños niñas y adolescentes & 7.984 \\
\multicolumn{1}{c}{ Fuente: Registro único de víctimas, 2020 }
\end{tabular}

\footnotetext{
${ }^{2}$ Víctimas que por distintas circunstancias no pueden acceder efectivamente a las medidas de atención y reparación. En este grupo se incluyen las víctimas fallecidas a causa del hecho victimizante o que han sido reportadas como fallecidas en otras fuentes de información. También se incluyen las personas sin documento de identificación o con números de documento no válidos. Además se clasifican como no activas para la atención, las personas víctimas de desplazamiento forzado que no han solicitado ayuda humanitaria (Unidad de Atención y Reparación Integral a Víctimas, s.f.)

${ }^{3}$ Víctimas incluidas en cumplimiento de la Sentencia C280 y Auto 119 de 2013
} 
Y frente a estas cifras globales surge la pregunta, ¿cuántos niños y niñas están registrados como víctimas del conflicto armado?

La defensoría del Pueblo citando a la UARIV informó que:

"Para 2014, 2.237.048 son o eran niños y niñas en el momento de la violación de sus derechos, 10 que equivale al 29,88 \% del total de las víctimas. Es decir, en Colombia, alrededor del 13,4 $\%$ de la niñez y la adolescencia ha sido víctima del conflicto armado. El 94,36 \% de los niños y niñas víctimas tuvo que desplazarse, mientras que el cinco por ciento restantes fue víctima de otros crímenes (...). Se evidencia que los hechos registrados más comunes son las amenazas, los homicidios y los actos terroristas o combates" (Defensoría del pueblo, 2014).

Por su parte, el informe "Basta Ya" del Centro Nacional de Memoria Histórica manifiesta que "La violencia del conflicto armado tiene una dimensión no letal que acarrea consecuencias igualmente graves. Al 31 de marzo del 2013, el Reporte Único de Víctimas -RUV4- reportó 25.007 desaparecidos, 1.754 víctimas de violencia sexual, 6.421 niños, niñas y adolescentes reclutados por grupos. El Grupo de Memoria Histórica pudo identificar 405 niños, niñas y adolescentes entre las víctimas de los actores armados, lo que representa el 3,4\% de los casos documentados para el periodo 1980-2012. De hecho, atacar a los niños, niñas y adolescentes en las masacres se convirtió en una acción intencionalmente infligida para devastar a los sobrevivientes y comunicar a los enemigos el colapso de cualquier límite moral en el conflicto armado (Centro Nacional de Memoria Histórica, 2013).

En este sentido, es común ver que el Derecho Internacional Humanitario se viola permanentemente en el marco del conflicto armado colombiano, en especial el principio de distinción que supone necesariamente la protección de la población civil, especialmente de las mujeres y los niños y niñas respecto de los efectos de la confrontación armada, siendo un factor determinante que marca la afectación que sufren la población infantil y sus terribles consecuencias, siendo recurrente la vinculación de los niños y niñas de manera indirecta o directa a la violencia socio política del país.

\footnotetext{
${ }^{4}$ Creado por el decreto 4800 de 2011, para el registro de víctimas del conflicto armado enmarcado en la Ley 1448 de 2011, que incluye también otros mecanismos de registro anteriores como el SIPOD (Ley 387 de 1997 y decreto 2569 de 2000) y las víctimas reconocidas en el marco de la Ley 975 de 2005 (decreto 1290)
} 
Dentro de los riesgos que afrontan los niños y niñas generados por el conflicto armado está la violación de los derechos a la vida e integridad personal, ya que los hechos y los datos oficiales reflejan que los niños y niñas han sido víctimas de crímenes tales como homicidios, torturas y desapariciones forzadas de personas de esta población.

Así pues, el homicidio es el tercer hecho victimizante más frecuente en el registro único de víctimas (RUV), relacionado con la desaparición forzada y la muerte en combate de niños y niñas reclutados por grupos armados, y en muchos casos, no se esclarece el destino final de los cuerpos de los niños y niñas víctimas de este hecho. El Informe Anual del Secretario General de las Naciones Unidas sobre niños y conflictos armados, durante el año 2013, como consecuencia de ataques de grupos armados y enfrentamientos, murieron 43 menores de 18 años y 93 más resultaron mutilados (Organización de las Naciones Unidas, 2014) y frente a esta cifra, el Instituto Nacional de Medicina Legal, registró la muerte de 12.628 niños y niñas entre enero de 2002 y agosto de 2014, en incursiones armadas.

La Defensoría del Pueblo, citando el RUV, manifiesta que "por lo menos 47.577 niños y niñas han sido víctimas directas o indirectas de homicidio desde 1985 hasta 2014, como consecuencia de acciones de actores armados estatales y no estatales, de los cuales 24.266 son niños y adolescentes varones, 22.881 son niñas y adolescentes mujeres y 5 LGBTI". (Defensoría del pueblo, 2014). Las víctimas indirectas son los padres, cónyuges, hijos e hijas de la persona asesinada o desparecida en casos de homicidio y desaparición forzada.

El Programa Presidencial de Acción contra Minas, informó que entre 1991 y 2013 murieron 2.188 niños y niñas como consecuencias de minas antipersonal y municiones sin explosionar, y como consecuencia de estos dispositivos, 973 niños y niñas resultaron lesionados, de los cuales $8,2 \%$ pertenece a la población indígena.

El RUV también registra que 57.135 niños y niñas han sido víctimas de amenazas entre 1985 y 2014 bajo estrategias como las llamadas "limpiezas sociales", una forma de amenaza colectiva, principalmente en zonas urbanas periféricas, de las cuales los adolescentes y jóvenes son las principales víctimas. 
Frente a la tortura, el RUV cuenta 347 niños y niñas de los cuales 190 son niños y 153 son niñas, siendo una forma frecuente e invisible que atenta contra la integridad y la dignidad humana, de acuerdo con la Coalición Colombiana contra la tortura en un $71 \%$ los paramilitares son los presuntos responsables, $17 \%$ la fuerza pública y $12 \%$ la guerrilla, entre 1998 y 2003 y entre 2003 y 2008, siendo la tortura utilizada como coacción, sometimiento, castigo y obtención de información, de acuerdo con las corporaciones Vínculos y AVRE.

De otro lado, las cifras del RUV indican que entre 1985 y 2014, por lo menos 8.601 NIÑOS Y NIÑAS fueron víctimas de desaparición forzada de manera directa e indirecta. El Instituto Nacional de Medicina Legal indica que hasta 2014 no se había logrado identificar por lo menos 4.210 personas menores de 18 años, mientras que la Fiscalía General de la Nación cuenta con un reporte de 14.181 infantes desaparecidos, durante el mismo periodo. Frente a las violaciones a la libertad de los niños y niñas, la corte constitucional advirtió que esta población se encuentra en riesgo de persecución por las estrategias de control coercitivo del comportamiento público y privado de las personas implantadas por actores armados en extensas áreas del territorio nacional.

Por otro lado, y según el Instituto Colombiano de Bienestar Familiar (ICBF), entre 1999 y 2013 un total de 2.379 niños y niñas fueron secuestrados, con mayor incidencia en los primeros 5 años del periodo reportado, de los cuales el $50.23 \%$ de las víctimas era niñas y adolescentes mujeres, mientras el $48,77 \%$ fueron niños y adolescentes varones. Siendo los principales responsables los grupos de delincuencia común (51,05\% de los casos), las FARC- EP (16,56\%), los familiares (10,46\%), el ELN $(6,34 \%)$ y las Autodefensas Unidas de Colombia (3,86\%).

Y sumado a lo anterior, el desplazamiento forzado es el hecho victimizante más visible pues lo ha padecido cerca del $80 \%$ de las personas víctimas reconocidas con el RUV, de los cuales el $94,36 \%$ son niños y niñas, es decir, 2.110 .832 personas víctimas fueron menores de 18 años en el momento del desplazamiento.

Como indica Alvarán, "La situación de la infancia en Colombia es preocupante, basta con leer el Auto $N^{\circ} 251$ de 2008, donde la Corte Constitucional en uso de sus facultades, expone la situación 
de los derechos fundamentales de los niños, niñas y adolescentes desplazados por el conflicto armado en el país" (Alvarán, 2013)

En este auto se exhorta al Estado Colombiano a tomar medidas urgentes para garantizar el goce efectivo de derechos y la reparación integral de los niños, niñas y adolescentes desplazados, al plantear que:

"Los niños, niñas y adolescentes colombianos en situación de desplazamiento forzado son las víctimas más débiles e indefensas del conjunto de la población desplazada por el conflicto armado en el país, y al mismo tiempo, son duramente golpeados por crímenes y condiciones estructurales de existencia que escapan por completo tanto a su control y su responsabilidad como a su capacidad de resistir o de responder, marcándolos de por vida al incidir negativamente sobre su proceso de desarrollo individual (Art. 1)".

Muchos de los niños colombianos nacen y otros han pasado la mayoría de su infancia como desplazados. Para ellos, esta situación se convirtió en un estilo de vida en el que las salidas son poco alentadoras de cara a un Estado que no garantiza los derechos básicos de este tipo de población que requiere de una atención prioritaria. Las cifras no dejan de ser alarmantes y escandalosas en un país democrático (Alvarán, 2013).

Los niños y niñas son vinculados de manera activa o pasiva al conflicto armado, como mencionan (Bello \& Ruiz Ceballo, 2002) , puesto que dicha vinculación va ligada a la obligatoriedad o no, es decir, la vinculación directa en el caso de los niños y niñas combatientes y de los colaboradores de los grupos armados y, por otro lado, la vinculación como víctimas de modo directo o indirecto de algún hecho victimizante.

También, los niños y las niñas han sido utilizados por todos los actores armados para perpetuar la guerra en Colombia. Sin embargo, como lo dice la Defensoría del Pueblo (2014) "la diferencia entre el reclutamiento y otras violaciones a los derechos de los niños y niñas es el impacto específico que tiene en las construcciones sociales de la niñez y la adolescencia, en los planes de vida, en la reproducción de la guerra y especialmente en la asignación de roles que solo los adultos 
deberían asumir. Es de vital importancia entender que el reclutamiento o utilización de los niños y niñas por parte de actores armados es forzado e ilegal. Independientemente de las edades establecidas por el DIH, el interés superior del niño y de la niña supone que se aplique la norma más favorable, en este caso los 18 años."

De acuerdo con la información del RUV, hasta el año 2014 se encuentran incluidos 7.675 niños y niñas, sin embargo, al 31 de julio de 2013, del 83 por ciento de las personas que declararon haber sido víctimas de vinculación como niños y niñas a grupos armados, en el marco de la Ley 1448 de 2011, no fueron incluidos en el RUV, y el 69 \% del total eran menores de 18 años.

Por su parte el Instituto Colombiano de Bienestar Familiar (ICBF) reporta que:

"Entre 1999 a 31 de octubre de 2014, 5.645 niños y niñas han pasado por el programa especializado para la atención a niños y niñas desvinculados de grupos armados no estatales. Para el año 2013, de conformidad con el Informe Global del SGNU sobre niños y conflictos armados (2014), el ICBF recuperó 342 menores de 18 años (114 niñas y 228 niños), en el mismo el SGNU evidencia un incremento con respecto a los 264 niños separados de grupos armados en 2012. Asimismo, de los niños y niñas recuperados en 2013, el 76 \% había sido reclutado por las FARC-EP, el $19 \%$ por el ELN, el 4,3 \% por grupos pos- desmovilización, y el 0,29\% por el EPL." (Defensoría del pueblo, 2014).

En cualquiera de los casos, la vinculación de los niños y niñas al conflicto armado es obligada puesto que no hay voluntariedad en el ser víctima, como tampoco en la no posibilidad de escoger cuando el medio no ofrece nada distinto para hacer, es difícil construir un proyecto de vida distinto, además de las amenazas o pagos por ser parte o no del conflicto. Como lo dice Ruiz-Ceballos (2002), vale la pena aclarar que se reconoce a los niños y niñas como sujetos de derechos y con voluntad propia, pero también existe en el marco del conflicto armado una vulneración permanente de sus derechos y no existen condiciones de escogencia que les permita el ejercicio pleno y goce efectivo de esos derechos. 
Ahora bien, la violencia sexual ha sido otra estrategia utilizada en diferentes conflictos armados como arma de guerra. La Corte Constitucional advirtió del riesgo que corren las niñas de ser víctimas de este tipo de violencia, siendo causa directa de desplazamiento forzado de personas, familias y comunidades enteras, utilizada por actores armados tanto estatales como ilegales. "La militarización de muchas regiones y la presencia prolongada de actores armados propiciaron que muchas niñas y adolescentes se involucraran en relaciones afectivas y sexuales con miembros de los grupos armados" (Centro Nacional de Memoria Histórica, 2013, pág. 317).

Según en el informe del Instituto Nacional de Medicina Legal, entre 2004 y 2014 por lo menos 163.216 niños y niñas fueron víctimas de violencia sexual en el país, mientras el RUV informa que entre 1985 y 2014 , un total de 575 niños y niñas han sido víctimas de este hecho victimizante, que obedece a la falta de información de parte de las víctimas.

En el marco de los escenarios de reclutamiento, otras violaciones se dan contra niños y niñas; la violencia sexual contra las niñas está asociada no solamente a la violación, la utilización emocional o abuso sexual que se mencionaban en el capítulo correspondiente. Las prácticas asociadas al control reproductivo como la implantación forzada de dispositivos para planificar, el aborto forzado y en otros casos, la separación de madres e hijos concebidos en estos escenarios. De acuerdo con la información disponible en los informes de campo de la Defensoría del Pueblo, estas últimas violaciones referidas no solo se presentan en el marco de ocurrencia del reclutamiento, también se dan como parte de la violencia sexual contra niñas y adolescentes que no hacen parte de las filas.

De otro lado, también es importante reconocer las niños y niñas víctimas indirectas del conflicto armado colombiano, como los huérfanos y huérfanas y en algunos casos, viudas y viudas menores de 18 años, que como lo menciona el informe "Basta Ya" del Centro Nacional de memoria Histórica (2013):

"La experiencia de la orfandad en los niños, niñas y adolescentes tiene un especial impacto. De los datos del ICBF sobre niños, niñas y adolescentes huérfanos en el conflicto armado en tres departamentos (526 en Antioquia, 360 en Nariño y 65 en Casanare), se podría extrapolar que la cifra nacional mostraría una realidad preocupante acerca de miles de niños y niñas. 
En algunos casos, especialmente en huérfanos y huérfanas, se han registrado condiciones de dependencia, apego, vulnerabilidad y sensación de abandono. Una de las situaciones que afecta la vida cotidiana y las posibilidades de desarrollo de niños, niñas, adolescentes y jóvenes es el riesgo y la práctica del reclutamiento ilícito por los grupos armados, relacionada directamente con la dinámica del conflicto armado y las estrategias de guerra de los armados." (Centro Nacional de Memoria Histórica, 2013).

$Y$ frente a estos crudos y duros datos de los impactos directos que tiene el conflicto armado en los niños y niñas, se evidencia un país devastado, que muestra pocas opciones de futuro para la infancia, por tanto, esta tesis doctoral entra a dialogar con la pregunta, ¿Cuáles son las afectaciones psicosociales que deja el conflicto armado en los niños y niñas?

Los niños y niñas que padecen directamente de la intensidad de la violencia colombiana están expuestos a diferentes efectos como la condición de impotencia y desamparo, además, de exponerse a la agresividad del actor armado, acompañado de actos de crueldad y sevicia. Sin embargo, esta victimización también logra ser indirecta para todo el pueblo colombiano, puesto que se reproduce la zozobra, el dolor y el desconcierto ante la muerte y destrucción de la estructura social.

"El miedo intenso, la alteración del sueño, la apatía, la rebeldía, la rabia y los sentimientos de venganza son solo algunos de los impactos que más reiteran padres, madres y docentes (...). Se observan problemas de concentración, memoria y aprendizaje; episodios de pánico repentinos, alteraciones graves del sueño, dificultades de lenguaje y comunicación, agresividad e hiperactividad (...) Estas experiencias dejaron huellas físicas y emocionales, y afectaron su capacidad de confiar en otros, su valoración de sí mismas y la posibilidad de entablar relaciones basadas en el respeto y que resulten placenteras" (Centro Nacional de Memoria Histórica, 2013).

Uno de los factores estructurales asociados con la invisibilidad de los impactos del conflicto armado sobre los niños y niñas, está relacionado con la normalización de las violencias que de este se derivan. La militarización de la vida civil, como consecuencia de un conflicto armado de más de medio siglo, y la incorporación de los actores armados estatales y no estatales, así como de la violencia 
armada en la vida cotidiana de la poblaciones rurales y urbanas, ha generado no solo la normalización de situaciones que en otros contextos serían consideradas graves, sino además, el control armado de las prácticas sociales, culturales e incluso familiares. Deconstruir este tipo de impactos en la vida de las comunidades colombianas requiere grandes esfuerzos articulados de toda la población, entidades y el Estado.

Como lo dice Ruiz-Ceballos (2002), el lenguaje, los juegos, la forma de relación y de conocer el mundo de los niños, las niñas y los adolescentes víctimas del conflicto armado están condicionados por la simbología y las expresiones de los hechos de violencia que se dan en medio de la guerra. Esto implica, que además de las pérdidas humanas, económicas, ambientales, materiales, culturales y sociales que deja la guerra, la violencia política produce en los niños y niñas profundos impactos psicosociales, pues estamos frente a un conflicto en el cual los niños y las niñas son obligados, no solo a sufrir las consecuencias como víctima, sino a involucrarse activamente, en las dinámicas propias del conflicto (Universidad Nacional de Colombia Sede Bogotá, 2003).

A los niños y niñas colombianos se les cierra la probabilidad de desarrollarse en ambientes adecuados que les garanticen el ejercicio efectivo de sus derechos, pues el conflicto armado se impone frente a su vida cotidiana desde el miedo, la hostilidad, la venganza, el odio y la desesperanza, frustración, ausencia de apuestas de futuro, y lo más grave, existe una alta tendencia a desarrollar conductas delincuenciales y a continuar en la promoción y reproducción de la guerra como única salida y proyecto de vida.

Como lo indica Alvarán (2013), "es importante describir los datos estadísticos frente a las situaciones que se presentan en un determinado espacio, contexto o situación, ya que esta cuantificación permite avizorar la magnitud, sin embargo, en muchas ocasiones la cuantificación del dolor y del sufrimiento humano se quedan al margen de los números, ya que no hay expresión cuántica posible que englobe el sentimiento de pérdida, de vulnerabilidad, de desprotección y de abandono".

"Este escenario de dolores, de pérdidas, desarraigos, muertes y sufrimientos, impacta de manera particular a la infancia (...) La situación de Colombia hace que millones de niños sobrevivan en condiciones de miseria ofensivas para la dignidad de cualquier ser humano. La infancia 
colombiana se está desarrollando en un contexto de barbarie donde la guerra es su medio socializador, la muerte, la venganza, el odio, son expresiones naturalizadas en la infancia, puesto que no conocen otro mundo posible más que el que les permite ver la guerra. Los niños colombianos asimilan en silencio el dolor de los adultos y acumulan sus propias pérdidas, sus propios desarraigos. Esta situación que en ocasiones desalienta, debe convertirse en un llamado de atención ya que día a día crece la deuda con la infancia colombiana" (Alvarán, 2013).

El país se encuentra en proceso de implementación del Acuerdo de Paz firmado con las FARCEP (Fuerzas Armadas Revolucionarias de Colombia - Ejército del Pueblo) en septiembre del 2016, así como se realizó el proceso de desmovilización de las Autodefensas Unidas de Colombia en el 2006, sin embargo, se tiene la necesidad imperativa de construir condiciones para una paz estable y duradera que permita a su nación dejar de ser la sumatoria de generaciones nacidas en la guerra. Por tanto, se deben garantizar condiciones para que los adultos (padres, madres, cuidadores, familias, etc.) sean corresponsables con la generación y consolidación de entornos seguros y protectores para las infancias, es decir, promover condiciones óptimas para su desarrollo y crecer en escenarios de inclusión, de participación activa y de reconocimiento de todos los sectores de la sociedad, imperativos para una paz duradera. Esta no depende exclusivamente de las negociaciones con los grupos armados no estatales, sino de la participación de todas las personas colombianas desde la cotidianidad (Defensoría del pueblo, 2014).

De tal manera, dichas posibilidades de construcción de paz con la participación activa de la niñez y la adolescencia requieren el lugar del juego, ya que los procesos de intervención desde el juego suponen hablar desde el lenguaje común y universal de los niños y niñas, hablar desde las acciones naturales, desde la cotidianidad, a pesar de los efectos del conflicto los niños y niñas siguen jugando, siguen soñando y siguen imaginando mundos posibles y dichos mundos pueden convertirse en aportes frente a la construcción de nuevas realidades.

El poder de los niños y niñas es el de construir realidades con el tiempo (que se reduce para las personas adultas) y justamente por esta razón es fundamental transformar los imaginarios y las realidades de quienes han sido afectados de directa 0 indirectamente por el conflicto armado, reconociendo y reparando de manera transformadora los daños causados a sus vidas. 
La paz para Colombia se construirá desde la cotidianidad de las relaciones, en las casas, en las calles, con las familias, con los vecinos. Esta tesis doctoral brindará un aporte en la construcción de procesos de intervención a escala de los niños y niñas víctimas, para que ellos y ellas puedan reconstruir un presente, desde su lenguaje cotidiano, como aporte a la construcción de paz. 


\section{CAPÍTULO 2. LA RESILIENCIA INFANTIL}

"Los niños son inherentemente vulnerables, sin embargo, a la vez son fuertes en su determinación a sobrevivir y crecer"

(Radke- Yarrow, 1992) 
El concepto de resiliencia ha sido ampliamente abordado por diferentes teóricos y ramas de investigación, entendiéndose como concepto para representar las adaptaciones positivas a pesar de la adversidad (Klotiarenco, 2000). La resiliencia es un proceso dinámico, constructivo, de origen interactivo, sociocultural, que conduce a la optimización de los recursos propios del ser humano y que le permite sobreponerse a las situaciones adversas (Klotiarenco, Cáceres, \& Fontecilla, 1997), que se caracteriza por encontrarse inmerso en un conjunto de procesos sociales y psicológicos que a lo largo del tiempo posibilitan tener una vida sana a pesar de haber enfrentado situaciones adversas.

Teóricos como Grotberg (1995), Vanistendael (2005), Cyrulnik (2005), Alvarán (2013), entre otros, vienen estudiando el concepto de resiliencia, donde ha pasado de ser una habilidad del individuo, a ser una capacidad que se puede desarrollar o no en la persona. Para Cyrulnik (2005) la resiliencia es una condición propia de la infancia y se considera dicha etapa indispensable para el desarrollo de la capacidad en la persona adulta.

La resiliencia, puede definirse como la capacidad y el proceso que surge de cada persona en la medida en que esta se enfrenta a situaciones que puedan representar adversidad o vulnerabilidad, y frente a ellas, el individuo pone en marcha y se apoya en distintas habilidades o recursos internos y externos, que permiten que este pueda considerarse capaz de enfrentar y trascender de una forma positiva, ante el momento "estresor" en concreto. De aquí, que la resiliencia se entienda como una potencialidad y una posibilidad universal que permite a personas, grupos y comunidades hacer frente a las adversidades, utilizando sus aptitudes personales como un escudo protector.

Para Vanistandael la resiliencia es una capacidad para desarrollarse de manera positiva, a pesar del estrés que provoca una adversidad o un resultado negativo (Poletti \& Dobbs, 2005, pág. 16) y para (Alvarán, 2013) la resiliencia es la capacidad y/o habilidad que pueden llegar a desarrollar 0 potenciar las personas que se han visto expuestas a situaciones traumáticas constantes, que se puede desarrollar en cualquier etapa de la vida, con la participación de factores protectores (biológicos, psicológicos, sociales, culturales y ecológicos).

Por su parte Grotberg (1997) indica que los factores de la resiliencia son condiciones que fortalecen y promueven la construcción de la resiliencia en todas las personas, pero que 
particularmente interesa potenciar en niños y niñas para superar adecuadamente el estrés y la adversidad. Por lo cual dice Grotberg que la resiliencia es la capacidad humana universal para hacer frente a las adversidades de la vida, siendo un proceso evolutivo que debe ser promovido desde la niñez.

Se podría decir entonces que la resiliencia es una habilidad que puede ser adquirida durante la vida, en la que confluyen capacidades y fortalezas, que gracias a estas se pueden lograr cambios positivos individuales o grupales; así pues, sería lo mismo decir que la resiliencia es la capacidad de enfrentarse y adaptarse a las adversidades en medio de dicho enfrentamiento, desarrollar nuevas competencias.

La resiliencia en los niños y las niñas está constituida por diversos procesos sociales, personales y culturales, construidos y promovidos, a través de las relaciones efectuadas entre el niño y su contexto más próximo, en el que se encuentran un entramado de sensaciones, vínculos y conexiones que en cierta medida determinan y configuran el posible ver, actuar y sentir del infante frente a situaciones específicas. Ello, refiere a que la resiliencia infantil, no puede visualizarse como algo solamente innato, sino que trata de un proceso de intercambios entre el medio y los niños; más claramente, referiría entonces a una capacidad que adquieren durante las distintas etapas de desarrollo (Carrero \& Pinilla, 2018).

Para Vanistendael, citado por (Rodríguez, Guzmán, \& Yela, 2012), la resiliencia está mediada por el desarrollo del yo (personalidad), el cual logra su surgimiento por los efectos educativos propios del medio en el que se desarrolla un individuo, es decir, se entiende la resiliencia no como un elemento de la personalidad sino como una construcción hecha por la persona a partir de su relación con el medio, los individuos y sus acontecimientos. Es por esto que la resiliencia se entiende la resiliencia como un proceso que se construye con ayuda de externos y no es el niño o la niña quienes autónomamente forjan la misma, entendiendo que el microsistema (la familia) es el primer lugar que promociona la capacidad resiliente: las prácticas de cuidado, los niveles de expresión de afecto, involucramiento y orientación positiva en los niños y las niñas, por lo que se da cuenta de la influencia de la familia en el desarrollo de niñas y niños resilientes. 
"La resiliencia infantil da cuenta de capacidades resultado de la interacción social, no niega ni excluye que puede haber una parte que depende de aspectos constitutivos de los niños. Pero aun así, si bien es cierto que los factores innatos determinan la estructura individual y sus límites, no es menos cierto que estos están ampliamente influenciados por el entorno, a tal punto que la organización cerebral de un niño o niña depende de la existencia de los cuidados y la estimulación que reciben de parte de los adultos significativos, especialmente de sus padres" (Barudy \& Dantagnan, 2008, pág. 14).

La resiliencia puede ser inherente al ser humano, es necesario ser potencializada por el contexto, especialmente por las condiciones sociales (Morelato, 2014), que posiblemente, pueden estar asociadas, a políticas públicas y las relaciones sujeto-estado (macrosistema), haciendo de la resiliencia un proceso individual (ontosistema) y colectivo (microsistema).

Así como lo afirma Morelato (2014) el contexto en que se desarrolla el niño y la niña aporta o limita su proceso de aprendizaje y formación, en términos de lo que él mismo determina como el microsistema, el mesosistema, el exosistema y el macrosistema, determina o promociona la resiliencia, dependiendo de las relaciones y vínculos sociales, directos e indirectos, que influyen en el desarrollo de los niños.

En este orden de ideas, para esta investigación se considera la resiliencia infantil como un producto ecosistémico que emerge como resultado de las siguientes fuentes (ver Figura 1):

- Las fuentes ontosistémicas (individuales) o lo que sería lo mismo, la personalidad del niño y de la niña

- Las fuentes microsistémicas o la familia en la cual crece el niño o la niña

- Las fuentes macrosistémicas o el contexto socio- cultural en el cual se desarrolla el niño o la niña (sus amigos, la comunidad y el Estado como garante de derechos). 


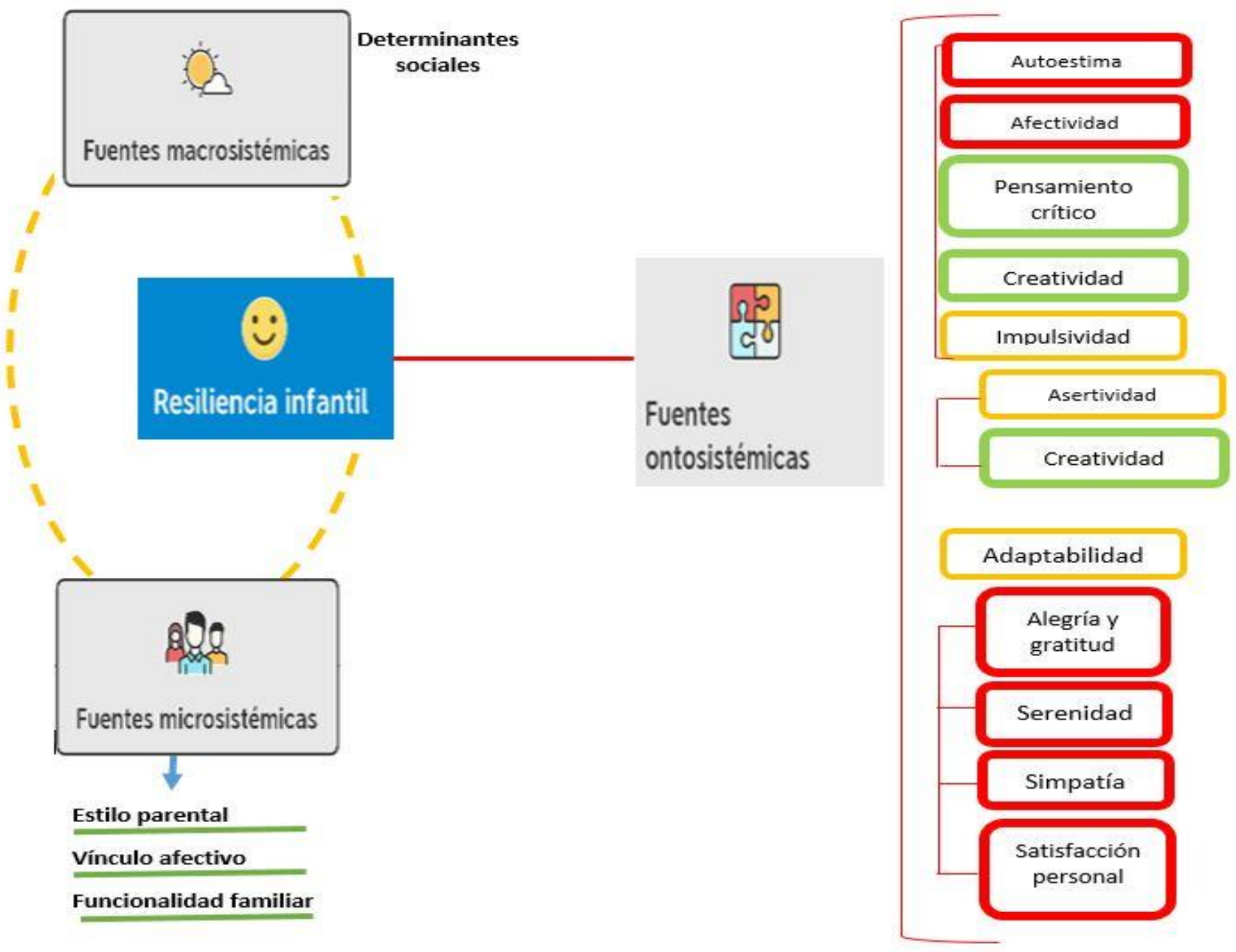

Figura 1. Modelo teórico de resiliencia infantil

Fuente: Construcción propia

\subsection{Las fuentes ontosistémicas de la resiliencia infantil}

La resiliencia depende de los recursos internos o fortalezas intrapsíquicas (cognitivas y emocionales), físicas y sociales de la persona, así como los factores protectores que rodean a las personas durante la infancia. Así mismo, no es una capacidad exclusiva de la individualidad, sino que también se puede desarrollar en contextos familiares, grupales y comunitarios, que presentan momentos de mayor debilidad, pero que logran demostrar resistencia, adaptación y superación de obstáculos. 
La resiliencia no solo se presenta durante circunstancias desfavorables, sino que se desarrolla en la cotidianidad de los niños y niñas dentro de contextos "normales" para el desarrollo, como un factor de protección (Grotberg, 2006) lo cual implica adicionalmente potenciar características personales de los niños y niñas tales como: habilidades emocionales y de control de impulsos, auto constructos (autoestima, autonomía, autocuidado, etc.), empatía (capacidad de ponerse en la posición del otro para comprenderlo), reflexión, asertividad, habilidades comunicativas, entre otras.

Aunque la resiliencia es una habilidad que se da en los individuos, también puede caracterizarse en comunidades y grupos sociales que adoptan posturas de aprendizaje y afrontamiento a la adversidad (Aguirre, 2010). Es así como para Aguirre el autoconcepto y la autoevaluación, la autoestima, la autonomía, la empatía, el humor y la creatividad adecuados son las características más comunes en los niños y las niñas resilientes. La edad y el género son dos variables que influyen en el desarrollo de tales características: desde las investigaciones estudiadas por Aguirre se evidenció que las niñas tienen mayores puntajes en los factores resilientes, por lo que es posible considerar que las mujeres y niñas tienen más posibilidades de desarrollar capacidades para afrontar la adversidad, especialmente, cuando se fomenta el factor de la autoestima, como uno de los elementos más influyentes para el desarrollo de la misma, y en contraste, Aguirre analiza que los factores personales de empatía y autonomía, característicos de las actitudes resilientes, presentan niveles bajos en la población de niñas y niños.

En este sentido, los factores implicados en el desarrollo de la resiliencia provienen de tres niveles diferentes: apoyos externos, la fuerza interior y los factores interpersonales, todos lo que puede ser promovidos por separado y los organizó en, YO SOY (fuerza interior), YO TENGO (Apoyo externo), YO PUEDO (Capacidades interpersonales y resolución de conflictos) (Grotberg, 2006).

Con relación a los factores internos éstos juegan un papel fundamental para promover la resiliencia, puesto que, aquí se evidencia el apoyo familiar y las redes de apoyo que poseen los niños y niñas 
"Ante la diversidad de definiciones, resulta difícil pensar en una sola concepción de resiliencia, por lo que, partiendo de la consideración de que ésta se sustenta en la interacción entre el individuo y el entorno, en esta investigación se entiende que la resiliencia es el resultado de la combinación o interacción entre los atributos del individuo (internos) y su ambiente familiar, social y cultural (externos) que lo capacitan para superar el riesgo y la adversidad de forma constructiva" (González, Valdez, \& Zavala, 2008).

A continuación, se analizan cuatro factores claves en las fuentes individuales que emergen la resiliencia infantil:

- las fortalezas intrapsíquicas

- las habilidades para la acción

- las respuestas amortiguadoras

- Las emociones positivas.

\subsubsection{Fortalezas intrapsíquicas}

Las fortalezas intrapsíquicas o recursos internos de la personalidad resiliente son el conjunto de características estables, ya sean innatas o adquiridas por el individuo "las fortalezas intrapsíquicas son aquellos recursos internos de cada persona que pueden ser fortalecidos en su interacción con el ambiente, que conforman su personalidad y lo protegen frente a la adversidad" (Puig \& Rubio, 2013)

Según Puig y Rubio, citando a Maddi y Khoshaba, indican que el patrón de personalidad resiliente consiste en una serie de actitudes y acciones que ayudan a transformar las situaciones estresantes de potenciales desastres a oportunidades de crecimiento. Como lo dirían estos mismos autores, las fortalezas intrapsíquicas son los recursos internos de cada persona, lo que conforma su personalidad, o lo que Cyrulnik (2005) Ilamaría "Cimientos de la Resiliencia".

Así pues, estos recursos internos son características genéticas y temperamentales (Puig \& Rubio, 2013) que confluyen en lo que Grotberg llamaría el "Yo soy". 
Para esta investigación, se han considerado las siguientes fortalezas intrapsíquicas o recursos internos:

- Impulsividad: ésta es la conducta irreflexiva conducente a actos de riesgo. La impulsividad es considerada como la emoción básica y son aquellas emociones que el ser humano posee por instinto como son los sentimientos de supervivencia, el miedo natural, la convivencia grupal o comunal, etc. La impulsividad tiene un significado emocional de los eventos externos e internos que hacen que tengamos una conducta aversiva con su respectiva respuesta sentimental y motora según el factor estresor presente, siendo conductas de defensa y afrontamiento (Jaramillo J. , 2012)

- Autoestima: o capacidad de autovaloración, tiene dos componentes: la valía personal y el sentimiento de capacidad personal. La primera expresa la forma en la cual el adolescente se autovalora, mientras que la segunda utiliza a lo que la gente es capaz de ser en el futuro y todas las expectativas que tiene hacia sí mismo. (Jaramillo, Pozo, Quezada, \& Quispillo, 2011). La autoestima como una variable que se relaciona con la resiliencia en la medida en que permite lograr mayor resistencia a sucumbir a los mensajes negativos de las experiencias de maltrato. Los niños con alta autoestima podrían establecer mejores procesos atribucionales de las razones del maltrato que reciben, evitando la internalización de autopercepciones negativas.

- Capacidad de pensamiento crítico: Expresión de valores, iniciativa y solidaridad.

- Creatividad: Cualidad cognoscitiva y afectiva conducente a resolución de eventos de forma propia y novedosa. (Jaramillo J. , 2012). La personalidad creadora está asociada a la originalidad, novedad, transformación, entre otros, que se refiere a la persona con un alto potencial creativo pero que no ha sido desarrollado plenamente. (Garaigordobil \& Pérez, 2005). La creatividad como factor protector y pilar de la resiliencia, pues da al individuo la capacidad de pensar sobre sus propios pensamientos, generar ideas y nuevas posibilidades de acción ante las situaciones adversas. La creatividad es un potencial que ayuda al individuo a afrontar las situaciones presentes y futuras, mejorando la capacidad de adaptación del sujeto a diferentes entornos (Fuentes \& Torbay, 2004). Los niños y las niñas están en un 
constante proceso creativo para hacer frente a los desafíos del desarrollo y las dificultades de su entorno de la vida (Barudy \& Dantagnan, 2008).

- Afectividad: Capacidad de mostrar emociones, sentimientos y pasiones de forma adecuada a la cultura a la cual el sujeto pertenece. El vínculo afectivo es considerado el factor protector más importante en el desarrollo de las personas, proveyendo al individuo de un vínculo estable que permita que el niño/niña afronte de manera correcta las crisis inesperadas e imprevisibles. Esto le permite al adolescente y al adulto mantener relaciones estables con personas hacia las que tiene sentimientos encontrados o ambivalentes. (Jaramillo, Pozo, Quezada, \& Quispillo, 2011)

\subsubsection{Habilidades para la acción}

Las habilidades para la acción son los recursos interpersonales o sociales, que se orientan a la acción y que entran en juego en la interacción (con lo otro, con el otro, con los otros), es decir, son las manifestaciones de los recursos internos o pilares de la resiliencia, lo que implica que sean observables y susceptibles de ser fortalecidos, toda vez que dependen del contexto y del momento del desarrollo del niño o de la niña. (Puig \& Rubio, 2013)

Para esta investigación se han considerado las siguientes habilidades para la acción:

- Asertividad: Capacidad de sentir, pensar y actuar inmediatamente acorde a las situaciones evitando el uso de mecanismos de defensa (Jaramillo J. , 2012). La asertividad también se puede entender como un conjunto de pensamientos, sentimientos y acciones que logran alcanzar un desarrollo socialmente aceptable, es decir poder alcanzar una meta sin agredir o ser agredido, siendo también importante la forma en la cual el individuo es capaz de pedir ayuda y de aceptarla en un momento oportuno (Jaramillo, Pozo, Quezada, \& Quispillo, 2011).

- Creatividad: esta habilidad vuelve aparecer, puesto que no solamente tiene que ver con los recursos internos, sino que también se favorece en la interacción con los otros. La creatividad, dirían Garaigordobil y Pérez citando a Czikszentmihalyi, es el resultado 
de la interacción de tres elementos como lo son el campo de conocimiento, la persona y el ámbito de realización. (Garaigordobil \& Pérez, 2005)

\subsubsection{Respuestas amortiguadoras}

Las respuestas amortiguadoras son mecanismos de protección específicos que se activan en la persona como consecuencia de la situación estresante concreta o suceso potencialmente traumático. (Puig \& Rubio, 2013).

En esta investigación, se han considerado los siguientes aspectos como respuestas amortiguadoras:

- Adaptabilidad: Uso de mecanismos cognitivos para aceptar y ser aceptado socialmente. Se define como la capacidad de involucrase con el entorno lograr simbiosis con el mismo logrando disponer a ambos el uno del otro, asumiendo una forma nueva de supervivencia con una interrelación que produzca frutos para la persona y el entorno. (Jaramillo J. , 2012)

\subsubsection{Emociones positivas}

Se podría decir que la literatura en resiliencia sugiere la importancia de trabajar por la promoción de los factores resilientes específicos, pero es importante avanzar en la investigación y elaboración de teorías que expliquen cómo estos factores específicos interactúan entre sí en el entorno del individuo permitiendo el proceso de adaptación resiliente. El humor, la fantasía, el afecto, la aceptación de sí mismo, la ilusión, la alegría, el amor, la generosidad, el optimismo realista, la esperanza, son destrezas que pueden ser enseñadas, aprendidas y desarrolladas (Manciaux, 2003)

Greco, Morelato e Isón citan a Csiksentmihalyi (1998) al describir las emociones positivas como el "flow" que en castellano podría traducirse como "flujo de conciencia" definido como un estado en el 
que la persona se encuentra completamente absorta en una actividad para su propio placer y disfrute durante la cual pierde la noción del tiempo y experimenta una enorme satisfacción.

De esta manera, Greco, Morelato, \& Ison (2007), Citando a James Averill ha precisado que una emoción es positiva si cumple alguna de las condiciones siguientes:

- El sentimiento provocado por la emoción se percibe como agradable.

- El objeto de la emoción se valora como bueno.

- La conducta que se realiza mientras se experimenta esa emoción se evalúa de forma favorable y las consecuencias de la emoción son beneficiosas.

Experimentar emociones positivas permiten al niño 0 a la niña desarrollar una capacidad diferente de afrontar, en tanto sus procesos cognitivos le permitirán ver de un modo diferente las adversidades que se le van presentando en la vida:

"Experimentar emociones positivas favorece el pensamiento creativo para la solución de problemas interpersonales, promueve la flexibilidad cognitiva, posibilita la toma de decisiones asertivas, desarrolla respuestas de generosidad y altruismo, aumenta los recursos intelectuales y contrarresta las tendencias depresivas entre otras". (Greco, Morelato, \& Ison, 2007, pág. 81)

En la misma línea los autores que exploran la resiliencia destacan que algunas de las características de los niños resilientes están relacionadas con la flexibilidad cognitiva, la capacidad creativa, la habilidad para resolver problemas interpersonales, el buen nivel de autoconcepto y los vínculos de apego que hayan forjado. (Greco, Morelato, \& Ison, 2007, pág. 84)

De esta manera, para esta investigación se han considerado las siguientes emociones positivas como claves en el proceso resiliente infantil -tomado de (Oros, 2014, pág. 523):

- La alegría es una intensa emoción positiva desencadenada por situaciones de vida satisfactorias y por progresos significativos en dirección a las metas personales. Se 
refiere a un estado general de contentamiento, diversión y regocijo, cuya máxima expresión es la risa.

- La gratitud es una emoción empática de gran relevancia social. Se experimenta gratitud cuando: (a) se obtiene un beneficio que es evaluado como positivo, (b) ese beneficio no se ha conseguido por el esfuerzo propio, sino que (c) ha sido otorgado intencionalmente por un benefactor. El sentimiento genuino de gratitud retroalimenta las conductas prosociales, puesto que una persona agradecida sentirá deseos de retribuir a su benefactor, quien ha mostrado altruismo y prosocialidad antes.

- La serenidad es una emoción profunda que involucra paz y confianza. Puede experimentarse independientemente de los eventos externos, incluso en situaciones de adversidad. La serenidad facilita el afrontamiento al estrés y permite tomar distancia de aquellos pensamientos que generan inquietud y/o angustia. La regulación emocional y la capacidad de relajación constituyen elementos clave de la habilidad para serenarse.

- La simpatía constituye el componente afectivo de la empatía. Envuelve la capacidad de sintonizar con la emoción de los demás y la inclinación a ayudar. La simpatía es una reacción emocional vicaria basada en la preocupación por la condición emocional del otro, que involucra sentimientos de pena e interés y comprende el deseo de que el otro se sienta mejor. Éste es un concepto intercambiable con el de compasión.

- La satisfacción personal, también llamada orgullo, es la emoción positiva que acompaña los procesos de valoración, promoción del self y autoatribución de méritos valiosos. Es una respuesta afectiva relacionada a la conformidad y a la aceptación de uno mismo. En este sentido, el concepto de satisfacción personal está estrechamente ligado al de autoestima. Entendida así, la satisfacción personal se diferencia del concepto de satisfacción con la vida, el cual es un componente principalmente cognitivo del bienestar subjetivo, y se refiere al juicio global acerca de la vida. 


\subsection{Las fuentes microsistémicas de la resiliencia infantil}

Las investigaciones en torno a la resiliencia familiar coinciden en afirmar que un ambiente familiar afectivo, estable, con reglas y límites adecuados y claros, resultado de la acción de adultos competentes y muchas veces resilientes, permite y facilita que niños y niñas, al recibir buenos tratos de una forma natural y permanente, desarrollen esta capacidad. (Barudy \& Dantagnan, 2008, pág. 16)

La cohesión familiar, dicen Carrero y Pinilla, representado en las capacidades parentales, refiere a un factor de protección en la medida en que la presencia significativa de un padre/madre, cuidador, o tutor, nutre los procesos de resiliencia individual del niño, pues una relación estrecha y afectiva con alguno de ellos, permite que los impactos ante adversidades puedan verse minimizados

y se evidencie la existencia de una red de apoyo, cuidado y reparación, reconociendo los límites y posibilidades sin caer en el proteccionismo (Carrero \& Pinilla, 2018).

"La primera condición es la estructura y reglas claras dentro del hogar, el apoyo entre los cónyuges; las estrategias familiares de afrontamiento eficaces, las prácticas de cuidado y crianza efectivas, la interacción y apego entre padres e hijos (la presencia de una relación cálida, nutricia y de apoyo al menos con uno de los padres, protege o mitiga los efectos nocivos de un medio adverso)" (Vanegas, Bolívar, \& Camacho, 2011)

Para esta investigación, la vinculación de la familia como fuente microsistémica de la resiliencia infantil, se puede identificar a partir de los siguientes indicadores:

- Percepción del estilo parental

- Vínculo afectivo

- Funcionalidad familiar

- Condiciones familiares 


\subsubsection{Percepción del estilo parental}

Como lo indica Richaud de Minzi la percepción de la relación contenedora de parte de los padres es uno de los mayores recursos de que dispone el niño (y la niña), por lo que es de la mayor importancia el desarrollo de un adecuado estilo parental y de que el mismo sea percibido como tal por el niño.

"En un estudio con niños de 6, 9 y 12 años, se ha encontrado que la mayor fuente de percepción de amenaza durante la infancia provenía de la percepción de la falta de apoyo por parte de los padres" (Richaud de Minzi, 2007)

Cuando los niños identifican que sus padres los aman y los aceptan, les es más fácil adaptarse a situaciones nuevas, mientras que cuando perciben relaciones inapropiadas con ellos desarrollan afrontamientos desadaptativos y experimentan sentimientos de soledad y depresión.

Como lo menciona Richaud citando a Baumrind, los padres autoritarios son más eficaces en la enseñanza de conductas sociales deseables y son más afectivos, sus castigos son más consistentes y tienen mayor compromiso. Los padres permisivos son ambivalentes y suelen anular el efecto del castigo, lo cual no favorece el comportamiento autoasertivo. En esta última categoría también se encuentran los padres indulgentes, que se basan en la confianza, la democracia y la permisividad. Sin embargo, dice Richaud, que los estilos autoritarios tienen efectos adversos en el desarrollo psicosocial del niño pues restringen la independencia, pero actúa como barrera frente a comportamientos desviados. Mientras que los niños criados de manera indulgente tienen un mayor desarrollo psicosocial pero tienen altos niveles de conducta desviada.

Por lo anterior, dice Richaud citando a Schaefer, que se entiende que la percepción que tiene el niño o la niña acerca del comportamiento de su padre o madre está más relacionada con su capacidad de adaptación que el comportamiento "real" de los mismos.

Para clasificar la percepción de los estilos parentales, se retoma la definición hecha por Richaud de Minzi en 2007: 
- Aceptación: se refiere a la aceptación centrada en el niño, como expresión de afecto manifiesto y apoyo emocional, a la aceptación de la individuación como la promoción del intercambio y la comunicación abierta, la libertad para expresarse y para ejercer un pensamiento independiente, y la implicación positiva como ser sensible ante las necesidades del niño.

- Control aceptado: Incluye la puesta de límites y el establecimiento de normas que son percibidos como cuidado por el niño.

- Control estricto: Incluye una puesta de límites y establecimiento de normas con una supervisión parental estrecha que es percibida por el niño como imposición.

- Control Patológico: Incluye varias formas de control excesivo: ser intrusivo, controlar a través de la culpa, aplicar normas estrictas, usar castigo y retos, evaluar negativamente al hijo o a la hija y alejar a través del rechazo.

- Autonomía Extrema: Se refiere a permisividad extrema.

- Control parental laxo en el que se da al hijo total libertad sin imposición de reglas 0 establecimiento de límites. Generalmente es percibido por el hijo como negligencia e ignorancia en el comportamiento de sus padres al atender sus necesidades. (Richaud de Minzi, 2007)

Vanistendael y Lecomte (2005) afirman que "la resiliencia como un proceso que se construye con ayuda de externos y no es el niño o la niña quienes autónomamente forjan la misma". De igual modo, estos autores no desligan el contexto de los niños y niñas pues al tejer resiliencia se es más efectivo cuando hay un acompañamiento hacia los infantes por parte de los padres de familia, tal y como lo argumentan los autores citando a Greenspan (1996) en donde enumera una serie de condiciones familiares que favorecen la resiliencia entre los niños.

"La promoción de características resilientes en etapas como la niñez y adolescencia son fundamentales para el futuro desarrollo saludable de la persona, pues la infancia se constituye la base emocional del niño la cual sigue activa durante el resto de la vida de la persona ya sea desde sus experiencias de dolor o experiencias positivas. Las decisiones que como adulto se 
toman, las conductas y pautas de relación son movidas por esa base emocional que desde niño se establece a la que se denomina el niño interior". (Ospina \& Sarmiento, 2010)

Además, la personalidad resiliente tiene una relación existente con las prácticas de crianza en las dimensiones de apoyo afectivo y regulación de comportamiento tales como: Expresiones de afecto, orientación positiva, involucramiento, prácticas de cuidado, sensibilización e inducción (Aguirre, 2010).

\subsubsection{Vínculo afectivo}

Cuando el niño se encuentra en su primera infancia, siendo un bebé, recibe de quienes lo rodean, mensajes a través de los gestos, del lenguaje no verbal (ceños fruncidos, sonrisas, mimos). Todas estas expresiones de la emoción el niño las va aprehendiendo de los adultos y pares que le rodean y moldean su carácter, así como va comprendiendo la forma de expresar dicha emoción. (Cyrulnik, 2005). Un niño que recibe mensajes positivos seguramente construirá una mejor autoestima, lo que le permitirá tener relaciones más efectivas con sus pares. Esto quiere decir, que el niño está influenciado por la cultura en la que crece, la condición de guerra o paz que se viva en su territorio, la presencia de un cuidador responsable y la expresión de afecto que se presencie en su lugar de habitación y, sobre todo, el bienestar emocional de dichas personas y del lugar en que habiten.

"El vínculo afectivo es considerado el factor protector más importante en el desarrollo de las personas, proveyendo al individuo de un vínculo estable que permita que el niño/niña afronte de manera correcta las crisis inesperadas e imprevisibles. Esto le permite al adolescente y al adulto mantener relaciones estables con personas hacia las que tiene sentimientos encontrados o ambivalentes, además al crecer ayudará a la persona a afrontar situaciones adversas como la perdida de algún familiar cercano y aceptar los diferentes aspectos positivos y negativos de una persona sin desvalorizarlos" (Pozo, Quezada, \& Quispillo, 2011).

El vínculo afectivo puede ser definido como la creación de relaciones entre las personas mediadas por procesos de interacción entre padres, madres e hijos y entre cuidadores y niños y niñas. (Corporación juego y niñez, 2014) 
La resiliencia, como proceso sistémico, resulta de la interacción de los individuos con su entorno. Así pues, la resiliencia resultaría de la presencia de un adulto significativo que teja una vinculación desde el amor, el cuidado, la protección y la acogida.

"Una relación en la que el niño se siente seguro, aceptado y en confianza, le permite construir una imagen saludable de sí mismo, así como generar un sentimiento de pertenencia y el desarrollo de sus capacidades para dar y recibir con la finalidad de construir una red social y afectiva en la cual muestre interés por explorar su entorno y vivir situaciones novedosas. Así, el vínculo afectivo promueve la adquisición de recursos internos que fomentan la construcción de la resiliencia". (Fundación Carlos Slim, 2020)

Entre los factores determinantes, podrían expresarse los atributos promovidos en primera medida, por las relaciones con el sistema más cercano, referente a la familia, pues desde ellas (más específicamente con la figura materna), se inicia la formación del primer vínculo de apego seguro, que vendría siendo esencial para el desarrollo socio afectivo del niño o niña, teniendo en cuenta que este lazo, hace parte de un "nicho sensorial", el cual, tutoriza y envuelve los procesos de desarrollo en la infancia, con el objetivo de formular una buena competencia social y brindar seguridad.

En concordancia a lo anterior, Grotberg expone que "la resiliencia es parte del proceso evolutivo y debe ser promovida desde la niñez. Así, vemos cómo se comienza a plantear la importancia de los factores protectores para el desarrollo sano de la infancia" (Grotberg E. , 1995), permitiendo precisar, en la existencia de mecanismos de protección viables para hacer de la resiliencia infantil un hecho más concreto. Estos "factores" o "mecanismos de protección", permiten que el niño o niña, desarrolle potencialidades de las que pueda salir fortalecido ante situaciones que podrían considerarse aniquiladoras, y a su vez, puedan efectuar un ejercicio de enfrentamiento efectivo y adaptabilidad como una fuerza motivacional significativa de superación.

\subsubsection{Funcionalidad familiar}

La funcionalidad familiar es la capacidad que tienen las familias para afrontar y superar todas las etapas del ciclo vitar familiar, refiriéndose específicamente a la posibilidad de organizarse para 
cumplir con cada una de las tareas que le demanda el atravesar por los diferentes ciclos (Jaramillo, Pozo, Quezada, \& Quispillo, 2011).

Se considera como funcional aquella familia que responde abiertamente a los cambios, retos y demandas de cada uno de los ciclos vitales y que no sufre mayores irrupciones en su cotidianidad, más allá de conflictos leves y que son solucionables.

"Actualmente la familia representa el primer contexto referencial para sus integrantes, especialmente los niños y adolescentes, los cuales generan sus primeros vínculos emocionales, afectivos. Además, permite forjar su propia identidad y trasmitirles valores socioculturales, que a través de su curso de vida le permitirá afrontar las situaciones adversas. Por ello, resulta relevante conocer aquellas capacidades que le permiten hacer frente a ellos y seguir mirando hacia el futuro, denominándose a ello, resiliencia”. (Pérez, Guevara, Canales, \& Matta, 2018)

Así pues, la funcionalidad familiar tendría una importante relación con el incremento de la resiliencia, que, como lo mencionan Arriagada, Jara y Luengo "se podría inferir que la funcionalidad familiar estaría relacionada con la capacidad de los individuos en salir adelante a pesar de la adversidad, lo que coincide con otros estudios. Al parecer, ser resiliente se relaciona directamente con la funcionalidad familiar percibida..., potenciando la capacidad de los individuos para recuperarse a pesar de la adversidad. (Arriagada, Jara, \& Luengo, 2017)

\subsection{Las fuentes macrosistémicas de la resiliencia infantil}

Si bien los niños y las niñas son resilientes y se forja a lo largo de su proceso de crecimiento, la relación con su entorno o el contexto social en el que crecen, podrían condicionar el sostenimiento no de su capacidad resiliente. Factores como la pobreza, hambre, violencia, desestructuración familiar.

Se ha encontrado que las condiciones del entorno social y familiar pueden ser facilitadores para el desarrollo de la resiliencia infantil "la seguridad de una expresión afectiva recibida por encima de todas las circunstancias y no condicionada a las conductas ni a ningún otro aspecto de la persona; 
la relación de aceptación incondicional por parte de un adulto significativo; y la extensión de redes informales de apoyo" (Asociación Centro de Desarrollo y Consultoría psicosocial Taller de vida, 2010).

Hablar de la resiliencia infantil es reconocer que, como lo menciona Cyrulnik, el niño y la niña nace resiliente y esta habilidad se va mejorando de acuerdo con el contexto en el cual crece el niño. Desde el momento de gestación el niño recibe mensajes de quienes lo rodean, pero es su madre la que trasmite la forma de manejar o de afrontar las emociones.

Así pues, la resiliencia infantil depende del contexto en que crece y se desarrolla el infante: su propio desarrollo, la condición en que se dio su concepción y gestación, la salud mental de su madre y de los cuidadores (adultos que los rodean), la condición del territorio donde crece.

Los niños resilientes son pues, quienes logran enfrentarse adecuadamente a los problemas de su cotidianidad y dicho enfrentamiento se realiza en condiciones flexibles, autónomas, sociales, racionales. Son hijos de familias que a pesar de sufrir adversidades (económicas, sociales, entre otras) logran tener una autoestima alta, unos niveles importantes de autonomía, se enfrenta sin miedo a sus propios errores, es empático. (Morelato, 2014, pág. 1473)

Se puede denotar que la resiliencia infantil, refiere a capacidades, personales/sociales, que se nutren con el tiempo, en concordancia a las relaciones con el medio o contexto social, cultural o familiar, en los que a pesar de impartir dinámicas estresoras, o encontrarse rodeado de factores de riesgo y vulnerabilidad, puede el menor recurrir a sus recursos internos que le permiten alcanzar un renacer psicológico y del alma, que reconfigura las percepciones del trauma, del sufrimiento, por reconstrucción, sabiduría, y fortaleza (Carrero \& Pinilla, 2018).

Así pues, existen algunos determinantes sociales para la resiliencia infantil entre los cuales se resalta la sobrecarga de responsabilidades, maltrato físico y psicológico, falta de atención médica, marginación y situación de pobreza extrema. Los niños que están en mayor situación de vulnerabilidad, son aquellos que están expuestos a factores acumulados de riesgo, ya sea por dificultades económicas, enfermedad mental de alguno de los padres, prácticas de crianza inadecuadas, abuso, conflicto familiar o armado. Es decir, un contexto material y psicosocial empobrecido (Fergusson, Horwood, \& Suniya S. , 2003). No obstante, aquellos determinantes 
sociales no deben visualizarse como "verdades lapidarias", en relación a maneras de visualizar o intentar predecir un posible desarrollo de patologías como la vulnerabilidad emocional, respecto al haber vivenciado o experimentado una situación consideraba devastadora.

La situación actual de los niños que viven en condiciones desfavorables desde el punto de vista social y económico se desarrolla en un contexto signado por problemas políticos, económicos y sociales que desembocan en la progresiva pobreza. Escenario en el que circula una serie de pérdidas sociales, familiares y personales, así como dificultades en la inserción laboral, incremento de las desigualdades, crecimiento de la exclusión social, condiciones laborales desfavorables, pérdida de recursos y condiciones económicas, deserción escolar y violencia familiar, entre otras. Estas circunstancias aumentan el grado de vulnerabilidad de los niños/as y sus familias. (Greco, Morelato, \& Ison, 2007)

Siguiendo con Greco Morelato e Ison, cuando citan a Castel (1991) indican que la zona de vulnerabilidad se caracteriza por trabajo precario y fragilidad de los soportes relacionales, constituyendo un espacio social de turbulencias e inestabilidad. Los niños y sus familias que viven en situación de pobreza están expuestos, a menudo, a condiciones precarias que atentan contra la salud mental y física, a problemas conductuales y de aprendizaje (Klotiarenco, Cáceres, \& Fontecilla, 1997) y con mayor frecuencia presentan enfermedades físicas, estrés familiar, apoyo social insuficiente y depresión parental. (Greco, Morelato, \& Ison, 2007, pág. 83); así pues, los determinantes sociales podrían ubicarse tanto en el microsistema (ej. maltrato infantil), en el mesosistema (ej.: lo institucional, laboral, dificultades en la relación escolar, poco acceso a redes de apoyo) o en el exosistema (ej.: pobreza, desocupación u otro facto de la comunidad que implique riesgo social). Finalmente, a nivel macro se ubicarían factores de riesgo como por ej. falta de políticas sociales con respecto a la niñez y adolescencia más el entorno de valores sociales y culturales. (Greco, Morelato, \& Ison, 2007, pág. 89)

Por tanto, la resiliencia también puede ser fomentada individualmente por la relación entablada consigo mismo, integrando así la salud mental de cada individuo. Igualmente, puede suponerse que las condiciones de vulnerabilidad inciden en el fomento de la resiliencia, sin embargo, ésta no es exclusiva de los contextos marginales, los estratos socioeconómicos bajos o la pobreza. 
Así pues, Jaramillo habla que los determinantes sociales son las condiciones sociales en que las personas viven y trabajan, que impactan sobre la salud o también lo frasea como "las características sociales en que la vida se desarrolla" y considera que estos determinantes son: el entorno físico familiar, el entorno físico social, el entorno físico ecológico, hábitos personales de salud mental, estilo de vida, acceso a servicios de salud (Jaramillo, 2015). 


\section{CAPITULO 3. EL JUEGO}

"El hombre es un animal que está Agradablemente condenado a jugar".

(Huizinga, 1990) 


\subsection{El homo ludens o la acción humana de jugar}

El juego es una actividad que ha acompañado al hombre durante su proceso histórico y evolutivo, fundamental e inherente en el desarrollo del individuo. Ha atravesado la cultura, el crecimiento de las comunidades, y la humanidad.

Johan Huizinga en su texto "Homo Ludens" intenta demostrar que la cultura humana brota del juego: "... no se trata... del lugar que al juego corresponda entre las demás manifestaciones de la cultura, sino en qué grado la cultura misma ofrece un carácter de juego" (Huizinga, 1968).

Para Huizinga (1990) el "Homo Ludens" (hombre que juega) expresa una función tan esencial como el "Homo faber" (el hombre que fabrica) y el "Homo Sapiens" (hombre que piensa) y trata de buscar los orígenes del juego y de la cultura al cuestionarse si el juego surge en la cultura o si por el contrario, la cultura surge de la actividad de juego: "la cultura brota del juego, como juego, y allí se desarrolla", así el juego visto de esa manera, es una de las principales bases de la civilización, un factor importante del mundo social.

Huizinga además amplia la noción de juego más allá de la niñez, hasta el conjunto de las manifestaciones humanas y ve en él las relaciones con las competencias, la máscara, los mitos, los intercambios, etc. Igualmente, establece una relación profunda con la estética, el arte, la fantasía y lo que podría denominarse la ruptura del ser, fuera de s arraigo natural o social. Otro aspecto esencial que propone Huizinga es que atribuye al juego una serie de características fundamentales, a saber:

\subsection{El acto creativo}

"Toda la vida del ser humano, desde el nacimiento hasta la muerte, es una creación" (Tirado, 1998), pues el sujeto se debate permanentemente a la pregunta o inquietud en torno a sí mismo, para poder luego preguntarse por los fenómenos que lo rodean y le permiten buscar su propia representación y comprensión de si y del mundo, pues dicha comprensión se produce gracias a la creación. 
La creatividad es una permanente construcción o acto transformador que solo puede expresarse en un hombre capaz de asumir una actitud de apertura sensible y racional frente a sí y frente al mundo, y apertura significa estar de cara a la dimensión de lo posible. La creatividad es una búsqueda incansable, entusiasmo, asombro, libertad, construcción permanente, y en suma, es una particular manera de intentar comprender-se un poco más (Tirado, 1998).

La creatividad suele confundirse con recursividad, habilidad o técnica, sin embargo, la creatividad se encuentra en los actos humanos y en la sumatoria de sensibilidad y racionalidad, siendo un puente entre ambas formas de experiencia humana. En palabras de Tirado, este acto creador debe comprenderse como un acto transformador de un sujeto que es capaz de asumir una actitud de apertura sensible y racional frente a sí y frente al mundo y apertura significa estar de cara a la dimensión de lo posible (Tirado, 1998).

Para que alguien desarrolle su capacidad creativa, es necesario desarrollar el "Ethos creativo" en su triple conceptualización (ver Figura 2): como morada interior (postura vital), como hábito (actitudes, valores, acciones), y como cogito (modo de pensar: movimientos, habilidades, características e imaginación ética) (Lucas, 2012):

- El Ethos como morada interior es un continuo movimiento, en una constante construcción del lugar interno desde donde deben enfrentarse los retos del mundo y es la capacidad creativa la que nos permite comprender la vida como una obra de arte y la humanidad como un proyecto; así, es enfrentarse a la vida con armonía, equilibrio y esperar lo inesperado. Esto implica que la morada interior es un acto ético- estético que se muestra en las acciones de los que asumen ese reto. Los aspectos que representan esto ethos, son: autoimagen, autoestima, autoconocimiento y proyección del yo ideal.

- El Ethos como hábito es actitudinal que se aprende y se fomenta, sumados a su desarrollo ético (morada interior), que una vez formados y en disposición de actuar, se convierten en un hábito; como valor se encuentra: libertad, dignidad, justicia, respeto mutuo, reciprocidad. De otro lado, la lista de actitudes para fomentar, que expone Lucas, es la siguiente: voluntad de crecer y autodisciplina para lograrlo, perseverancia ante los 
obstáculos y la frustración, apertura a la experiencia, manejo de la ambigüedad, voluntad de asumir riesgos, autoconfianza y coraje con las propias ideas, independencia y cierto nivel de desinterés por la aprobación social, perseverancia para el diálogo constante, aceptación del otro y empatía; respeto, crítica y creación de reglas.

- El Ethos como cogito tiene que ver con el pensamiento creativo, hace énfasis en el papel de la imaginación, que significa imagen y visión, imaginar es percibir mentalmente, tener una idea sobre algo que no está presente realmente, es decir, cuando imaginamos transcendemos la experiencia con sus datos y hechos.

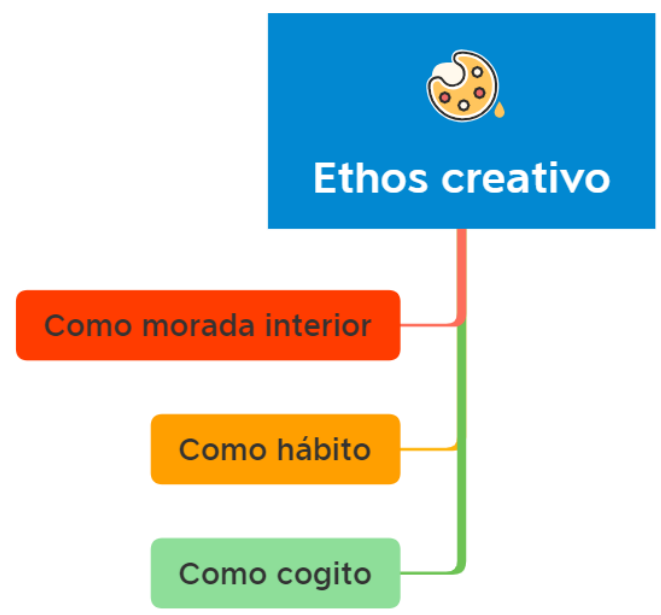

Figura 2. El Ethos creativo

Fuente: Lucas (2012)

\subsection{El juego infantil como acto creativo}

Gracias a Vigotsky, Egan, Harris, Gardner y Bruner desentrañamos la importancia vital de las experiencias al servicio de la imaginación a partir del juego simbólico, principalmente en los primeros años de vida y como, los mecanismos que subyacen a la imaginación y al juego simbólico propician los "esquemas" necesarios, y las condiciones vitales sobre las que se engrana el desarrollo social y cognitivo del ser humano. Evidentemente el juego simbólico pasa de ser visto como una cosa "ridícula", tonta, sin importancia y que se acaba en la niñez, a ser una etapa decisiva en el desarrollo infantil y, por ende, en la formación del humano, en general. Se posiciona igualmente la importancia meta representativa del juego, para construir alternativas de realidad que le permite alcanzar una mayor 
comprensión del mundo que los rodea y resaltan la importancia de los social, de las interacciones, de lo afectivo que hace parte del desarrollo cognitivo.

Gran variedad de recreacionistas, "expertos" en juego y recreación, han posicionado al juego como una actividad que en muchos casos se siente obligatoria, en la que la diversión a cualquier precio (sin importar el respeto al otro), es un imperativo. Aquí recalca Huizinga que la libertad se convierte en una característica indispensable en el juego, sin ella no podría existir. No a todos nos gustan todos los juegos, nadie juega por obligación, si alguien juega obligado, simplemente no es juego para él o ella, es otra cosa. En concordancia con esa libertad, Huizinga menciona que el juego es un escape de la vida corriente, se actúa "como si...". El juego es una "...actividad que transcurre dentro de sí misma y se practica debido a la satisfacción de su misma práctica, sin que haya en ella ningún interés material ni se obtenga en ella provecho alguno) (Huizinga, 1968).

De otro lado, para Huizinga, el juego necesita de una orden. Todas sus acciones están reguladas y la desviación más pequeña estropea el juego, la hace perder su carácter y lo anula. Produce además tensión, emoción y misterio. Existe incertidumbre sobre lo que va a ocurrir. Esta característica, junto con la del orden hace que se tengan que considerar las reglas del juego "las reglas del juego, de cada juego, son obligatorias y no permiten duda alguna” (Huizinga, 1968)

Ahora, se relacionan un segundo grupo de autores que resaltan la importancia relacional, afectiva y liberadora del juego: Donald Winnicott y Graciela Montes.

El juego es una actividad universal, incierta y libertaria, que se desarrolla en una zona de distensión o neutra, una zona potencial o "tercera zona". La primera experiencia de juego se da entre la madre y el bebé, pero se extiende entre el niño y la familia, entre el individuo y la sociedad. Cuando entre esta diada se genera confianza, se abre un espacio potencial, que puede convertirse en una zona infinita de separación. Esta separación, producto de la confianza, significa que la madre ofrece la oportunidad de pasar de la dependencia de la autonomía y que el bebé, el niño, el adolescente, el joven y el adulto, puedan llenar de juego en forma creadora. En esta tercera zona habita el juego, es decir que, en el acto de jugar, se confunde el "adentro" y el "afuera" desarrollando libremente una zona intermedia. En esta zona no existe el tiempo ni el espacio, tal como se concibe culturalmente, lo que 
sucede allí no tiene una duración ni conexión con lo real, aunque se apoya en los objetos del contexto con que se cuenta, pues el verdadero juego, no se encuentra sujeto a las regulaciones internas, ni externas, sino que fabrica sus propias reglas por la capacidad de autorregulación y de auto organización que produce. El lugar de ubicación de la cultura es justamente esta tercera zona, en permanente creación y cuya manifestación es el juego (Winnicott , 1991).

Montes (1999) retoma esa tercera zona, denominándola como "frontera indómita", que sería el espacio entre el adentro y el afuera, donde habita el juego, la literatura, las artes, que permiten que se amplíe la imaginación y la creatividad. Una frontera indómita que "...no se hace de una vez para siempre, se trata de un territorio en constante conquista, nunca conquistado del todo, siempre en elaboración, en permanente hacerse" (Montes, 1999). La infancia entonces para Montes es más que un periodo biológico, es un estadio determinado culturalmente en el que la frontera indómita gracias al papel que desempeña la dicotomía fantasía/ realidad, posibilita o inhibe determinadas experiencias. Experiencias en las que la imaginación es trascendental.

Estos dos autores, nuevamente señalan el importante papel del juego en la cultura, el afecto y la confianza necesarios para que se genere una tercera zona o frontera indómita, en la que los seres humanos podamos ser realmente libres y en las que las experiencias y la imaginación proporcionan (o posibilitan) un ensanchamiento de esta frontera.

Es común encontrar en los juegos de los niños y las niñas situaciones que muestran ejemplos de las más auténtica y verdadera creación como por ejemplo "el niño que se imagina que va a caballo cuando monta sobre un palo; la niña que se imagina madre al jugar con sus muñecas; o el que en un juego se transforma de bandido, soldado o marinero" (Vigotsky, 1999). Tales situaciones planteadas permiten concretar que uno de los aspectos que está implícito dentro de los juegos infantiles, es la habilidad de los niños para dejar de lado la parte objetiva de la realidad e involucrarse en la construcción de diferentes episodios simulatorios, a través de los cuales les es posible crear diferentes episodios simulatorios, a través de los cuales es posible crear diferentes objetos, acciones, eventos 0 sucesos imaginarios que dan cena de su capacidad imaginativa. 
El juego, como actividad primigenia en el ser humano, es en donde están los orígenes de la fantasía y la creación, y "solo en la medida en que el hombre pueda jugar puede crear y sólo en la medida en que se abre a un juego creador puede acceder entonces a la experiencia de la obra de arte" (Tirado, 1998).

El acto de jugar de los humanos se distingue de las diferentes acepciones del verbo, en tanto es una actividad libre y sin fronteras, sin reglas aparentes, que da lugar a la fantasía y la creación, por lo cual, la palabra juego, es usado para nombrar experiencias y actividades que no tienen un orden definido. En el idioma inglés distingue dos palabras, a propósito: game y play. El game corresponde a los juegos de reglas determinadas, impuestas 0 autoimpuestas y con una finalidad, se juega para alcanzar un objetivo. El play es lo que muchos hemos llamado el juego libre, donde hay ausencia de fronteras en el espacio y el tiempo, sin reglas y finalidad conscientemente determinadas.

Aquí el juego es una actuación ubicada bajo el orden simbólico, en el que se re- crea el mundo, que como lo diría Tirado el sujeto que juega elige y determina una ordenación particular de los movimientos del juego y elige a su vez el espacio de su acto lúdico. (Tirado, 1998, pág. 53), lo que llamaría Huizinga el "como si" y en el que, como diría Gadamer (1991), el jugador se abandona de tal modo a su actividad lúdica que casi podría decirse que es otro y es suficiente saberlo, solo por el deleite de jugar. Es en este carácter de "ser jugado" donde se evidencia su comportamiento lúdico, que se traduce en encuentro con su propia libertad, autonomía de su propia voluntad, someterse al vaivén y a la gratuidad que el juego plantea, es decir, el juego como representante del Ethos creativo (ethos como hábito).

Para Tirado (1998), el arte es la misma expresión del juego humano, pues es en este carácter de "ser jugado" donde encontramos la fantasía, la imaginación y la libertad, como los hilos que tejen la red entre el juego y la experiencia artística, donde el juego humano alcanza su máxima perfección en el arte, donde la conciencia subjetiva se pierde y el juego se juega con el hombre, es decir, el juego juega con el hombre, pues sólo el sujeto humano juega entre las dos dimensiones: game y play. El jugar humano es una forma de autorepresentación. Lo que sería la representación del Ethos como morada interior y Ethos como cogito. 
Por lo anterior, para esta investigación el juego infantil es un acto creativo, es decir, el juego de los niños y niñas es uno con el Ethos creativo, donde el jugador se "abandona" de manera consciente a jugar, donde interpreta la imaginación, juega con las reglas y fantasea con las mismas, en su modo de ser, bajo el vínculo indescriptible entre el juego y la belleza, entre el juego y el arte, donde el juego- la vida es esa obra de arte.

"El verdadero ser del juego radica en que la identidad del jugador se "diluye" para que la representación pueda llevarse a cabo... Si por ejemplo, un niño al jugar no se toma en serio el como si, de su propia representación lúdica... verdaderamente fuera baquero, pianista o héroe..., entonces podrá pasar muy fácilmente las frágiles fronteras que existen entre lo lúdico y lo no lúdico de su propia realidad. Aquí no se trata de ser otro, sino de explorarse a sí mismo como si fuera otro, pero otro que nunca duda que se trata de un despliegue incesante de su propia mismidad". (Tirado, 1998, pág. 66)

Por lo anterior, el juego como acto creativo lleva a proponer los siguientes indicadores de la personalidad creadora de los niños y niñas (ver Figura 3), desde un modelo interaccionista, basada en la teoría de la inversión de Sternberg y Lubart y el modelo sistémico de Csikszentmihalyi. (Garaigordobil \& Pérez, 2005):

- Apertura

- Identificación y solución de problemas

- Juegos intelectuales

- Fantasía e imaginación

- Invención y arte 


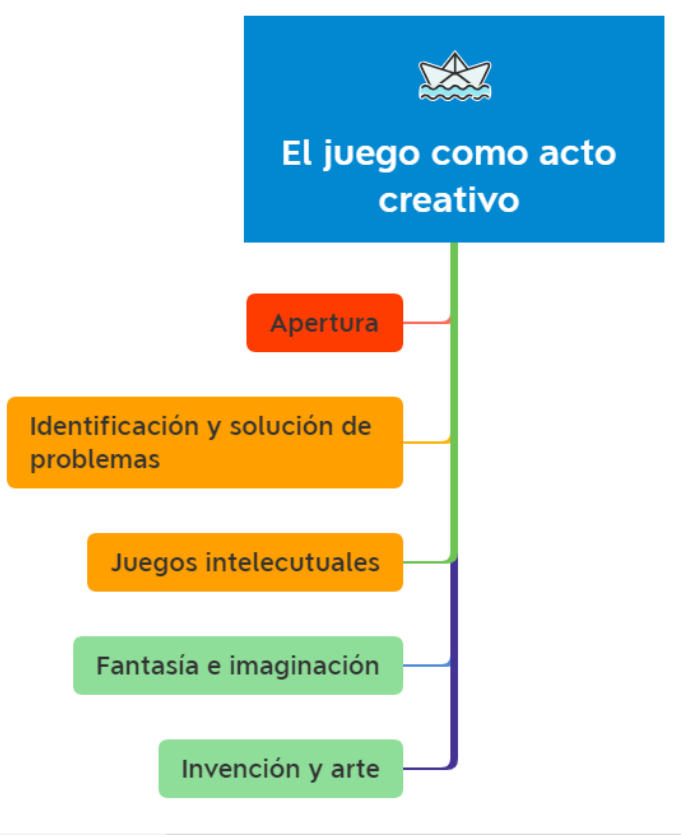

Figura 3. El juego como acto creativo

Fuente: elaboración propia

\subsubsection{Apertura}

Piaget señala que "los juegos de los niños constituyen admirables instituciones sociales" (Piaget, 1932), por ello estudiar y observar a los niños y las niñas es muy interesante, pertinente y relevante. Posteriormente señala que la moral está directamente relacionada con las reglas "toda moral consiste en un sistema de reglas y la esencia de cualquier moralidad hay que buscarla en el respeto que el individuo adquiere hacia estas reglas" y la forma de acceder "naturalmente" a esas reglas en los niños y las niñas, es a través de los juegos infantiles.

El autor referencia observaciones, interrogaciones y conversaciones con niños de Ginebra y Neuchatel, particularmente sobre el juego de las canicas. Piaget identifica que este juego de canicas comporta un muy completo sistema de reglas, es decir, todo un código y una jurisprudencia. Reglas que normalmente recibe de un adulto, de sus mayores o sus pares, y al igual que en lo moral, las reglas del juego de las canicas se transmiten de generación en generación y se mantienen gracias al respeto por parte de los niños. 
En las reglas del juego según Piaget (1932), se deben estudiar los dos fenómenos, la práctica de las reglas, es decir, la manera como los niños de las distintas edades aplican efectivamente las reglas y la conciencia de la regla o la manera en que los niños de las distintas edades se representan el carácter obligatorio, sagrado o decisorio, la heteronomía o la autonomía propias de las reglas de juego. La pregunta que guía el primer fenómeno sería ¿cómo se adaptan poco a poco los individuos a las reglas, es decir, como observan las reglas en función de su edad y su desarrollo mental? Y la pregunta que guía el segundo fenómeno sería ¿cómo adquieren conciencia de la regla, es decir, qué tipos de obligaciones resultan para ellos, según las edades, del dominio progresivo de la regla?

\subsubsection{Identificación y solución de problemas}

Es común encontrar en los juegos de los niños y las niñas situaciones que muestran ejemplos de las más auténtica y verdadera creación como por ejemplo "el niño que se imagina que va a caballo cuando monta sobre un palo; la niña que se imagina madre al jugar con sus muñecas; o el que en un juego se transforma de bandido, soldado o marinero" (Vigotsky, 1999). Tales situaciones planteadas permiten concretar que uno de los aspectos que está implícito dentro de los juegos infantiles, es la habilidad de los niños para dejar de lado la parte objetiva de la realidad e involucrarse en la construcción de diferentes episodios simulatorios, a través de los cuales les es posible crear diferentes episodios simulatorios, a través de los cuales es posible crear diferentes objetos, acciones, eventos 0 sucesos imaginarios que dan cuenta de su capacidad imaginativa.

Otra característica enunciada por Huizinga (1990) es que el juego tiene límites de tiempo y de espacio. Sin embargo, una vez que se ha jugado, el juego permanece en el recuerdo como creación, pudiendo ser transmitido como tradición para que se juegue inmediatamente o transcurrido algún tiempo, cobrando una sólida estructura como forma cultural. No es raro incluso encontrar niños que retoman un juego horas, días, o semanas después, en el punto exacto donde lo dejaron la última vez que jugaron.

En consecuencia, para Huizinga (1990) el juego tiene reglas. El juego, como la vida social, estimula el "saber hacer" y se introduce y perfecciona en competencias, virtudes y pasiones humanas en un marco de reglas. Todos los juegos, más allá de su variedad y diversidad, tienen en común el 
estar formados por reglas, reglas que les permiten ser jugados y a la vez los delimitan. Las reglas, en cada juego, definen un espacio a partir del cual, los jugadores pueden desarrollar libremente sus estrategias y sus acciones. Las reglas son límites y a la vez el estímulo para la acción y la libertad.

Cercano a Huizinga y su afirmación de que el juego se practica por mera satisfacción, sin que haya en ello ningún interés, Callois (1986) plantea que el juego es un fin en sí mismo, no un medio para otras cosas, sino que su propio interés es suficiente. Retoma además el considerar al juego como una actividad libre a la cual el jugador no podría estar obligado sin que el juego perdiera al punto su naturaleza de diversión atractiva y alegre y que la convierte en una actividad incierta e improductiva simultáneamente: Incierta porque su desarrollo no podría estar determinado ni el resultado dado de antemano, por dejarse obligatoriamente a la iniciativa del jugador cierta libertad en la necesidad de inventar. Improductiva porque no crea bienes, ni riqueza, salvo desplazamiento de propiedad en el círculo de los jugadores, porque se llega a una situación idéntica a la del principio de la partida.

Igualmente, Callois (1986) reconoce al juego circunscrito en límites de espacio y de tiempo, y como actividad reglamentada. Es decir, el juego es sometido a convenciones que suspendan las leyes ordinarias e instauran momentáneamente una nueva legislación, que es la única que cuenta.

Finalmente, reconoce en el juego una característica de ficción "... ir acompañada de una franca irrealidad en comparación con la vida corriente" (Callois, 1986), característica muy interesante y que después retomaremos a partir de atores que trabajan la imaginación como Vigotsky y Harris.

Otro de los autores clásicos en torno al juego es Duvignaud. Para este autor la libertad del juego y su influencia en la cultura son esenciales, al igual que para Huizinga. Pero va un poco más allá al mencionar que al juego lo componen el teatro, la creación artística, la fiesta, los sueños y lo imaginario (factor en que estaría la raíz de la libertad del juego). La cercanía para Duvignaud (1997) del juego con el arte, con lo estético es evidente y por ello la relación entre juego y cultura también.

El juego es para este autor una región intermedia entre creencias y prácticas. Las máscaras, la charla, la palabrería, que se da en cualquier tiempo o lugar, mitos, leyendas, fábulas, literatura e incluso, expresiones sexuales en algunas culturas, son fruto de esta mediación. Lo importante es 
comprender lo que implican esos comportamientos, es decir que, en su origen, no tienen intencionalidad.

La estética y el arte, hacen una ruptura en el ser fuera de su arraigo natural o social. El juego clasifica al arte, lo jerarquiza, le pone ataduras, le pone reglas. En ese sentido, Duvignaud plantea una paradoja "el juego permite la inmersión del hombre en la cultura, pero simultáneamente lo libera de ella" (Duvignaud, 1997).

En general estos tres autores Huizinga, Callois y Duvignaud comparten algunos elementos esenciales del juego: la libertad como condición inherente del juego, la satisfacción que genera, la posibilidad de ser una actividad con un fin en sí misma, contar con límites espacio- temporales, el ser una actividad con un orden, organizada, sus imbricaciones con la cultura y la presencia de las reglas sin importar la clase de juego o s complejidad, elementos centrales para que el ser humano acceda a la sociedad.

\subsubsection{Juegos intelectuales}

Bruner (1997), en concordancia con los autores anteriores (Vigotsky, Harris, Egan, Gardner) que reconocen la importancia del juego cognitivo o juego intelectual, resalta las interacciones que se presentan en el juego. Bruner inicialmente menciona que jugar para el niño y para el adulto es una forma de utilizar la mente e incluso, una actitud sobre cómo utilizar la mente. Es un marco en el que ponen a prueba las cosas, donde se da la posibilidad de combinar pensamiento, lenguaje y fantasía. Pero Bruner (1997) va más allá, pues da lugar especial a la interacción como elemento fundamental de la dinamización de los procesos de enseñanza- aprendizaje, pues la relación entre pares permite que se desarrolle un "jalonamiento" cognitivo como camino de acceso a niveles superiores de desarrollo o de estructuras del pensamiento, a partir de la interacción con otro que haya logrado ese nivel de desarrollo, pues le brinda las herramientas o un andamiaje para acceder a eses nivel, lo que se puede observar en las relaciones de niños y niñas con una diferencia de edad no muy lejana.

Aquí el juego se convierte en un elemento catalizador o potencializador del desarrollo de estructuras más avanzadas, en el que, a través de la realización conjunta de operaciones frente a 
diferente tipo de situaciones problemáticas, los niños y las niñas identifican, prueban y asumen estrategias, instrumentos y herramientas para adaptarse a la situación.

Sin embargo, la interacción no solo y exclusivamente permite el desarrollo cognitivo, sino en otras dimensiones humanas como el afecto, la estética y las relaciones sociales, en las que se transmiten diferentes tipos de valores, costumbres, deseos, ideologías, prejuicios, conocimientos, saberes y en general, todo aquello que hace parte de la vida cotidiana y que es el legado de la civilización y la cultura.

Piaget considera el juego como elemento importante para potenciar la lógica y la racionalidad, como elemento de la inteligencia, entendida como la facultad de adaptarse de la mejor forma a la realidad o al contexto. Los trabajos de Piaget valorizan al juego como instrumento de la evolución intelectual. En ese sentido, el juego es una forma poderosa de actividad que tiene la actividad constructiva del niño, pero adicionalmente es importante para la vida social. El juego posibilita la creación de un puente entre el pensamiento concreto y el pensamiento abstracto, entre la percepción y la representación. Incluso la "adquisición del lenguaje está subordinado al ejercicio de una función simbólica que se apoya en el desarrollo de la imitación y del juego..." (Piaget, 1961).

Para Piaget el juego evoluciona en tres tipos generales: ejercicio, símbolos y reglas, con un cuarto tipo que es transversal, el de Ensamblaje. Inicialmente el niño utiliza cosas en actividades que tienen un fin en sí mismas, allí el juego se confunde con las conductas sensoriomotoras. Esta exploración de los objetos, del cuerpo a través de los sentidos, constituye lo que Piaget denomina "juego de ejercicio"; pero este juego de ejercicio que aparece muy frecuentemente entre los 0 y los 2 años, no es exclusivo de esta edad, reaparecen durante toda la infancia, aunque tienden a desaparecer. La manipulación directa de los objetos, la paulatina apropiación y dominio de los objetos y de la realidad en que se vive, primero individual y posteriormente en relación con los otros y en interlocución con los mimos, se posibilita y se da a través y en el juego, según Piaget. Posteriormente, gracias a la aparición de la función simbólica, aparece la imaginación que somete las cosas de la propia actividad. Como ya se había mencionado, para Piaget el juego simbólico va desapareciendo con el tiempo, mientras que para Harris continua solo que, modificándose en la vida adulta. Con la 
socialización del niño en el juego adquiere reglas o adapta la imaginación simbólica a los requerimientos de la realidad.

La tesis de Piaget de que las funciones del juego difieren con la variación de edad cronológica, de la cual fundamentó su clasificación del juego, permitió igualmente establecer las relaciones entre el juego, las reglas y el desarrollo moral. Es decir que el papel del juego de reglas y de las reglas en general, no solo tienen implicaciones cognitivas, sino altamente sociales y morales.

\subsubsection{Fantasía e imaginación}

La experiencia y la imaginación, factores ineludibles en el juego infantil, son trabajados decisivamente por Vigotsky. Para este autor ruso el juego es, ante todo, una de las principales o incluso la principal actividad del niño. El juego en Vigotsky es una de las maneras de participar del niño en la cultura, es su actividad cultural típica, como lo será luego, de adulto, el trabajo. Es decir, según la perspectiva dada, el juego resulta una actividad cultural. Pero la participación del juego en la cultura se da en gran medida a través de la imaginación. "la imaginación es una función vital y necesaria, una actividad que además de combinar, crea y contribuir a la formación de una imagen, es la base de toda actividad creadora" (Vigotsky, 1999). Afirma además que todo lo que lo rodea y ha sido creado por la mano del hombre es producto de la imaginación, la cual depende directamente de la riqueza y de la diversidad de la experiencia del hombre; es decir, que mientras más rica sea la experiencia, más rica debe ser en iguales condiciones, la imaginación.

Para este psicólogo ruso, a través de la imaginación los seres humanos no sólo pueden conservar y reproducir sus experiencias anteriores, sino que también pueden extraer de estos elementos que

podrán ser transformados y combinados para construir con ellos nuevas ideas y formas diferentes de interpretar su realidad. De esta manera, la imaginación tal y como lo propone Vigotsky es "un proceso mental consiente en el que se evocan ideas o imágenes de objetos, sucesos, relaciones y atributos, asi como otros nunca antes experimentados ni percibidos, en el que se producen imágenes de sucesos o de objetos poco o nada relacionados con la realidad pasada y presente, mientras simultáneamente se incluye la renovación o la "re- experimentación "de lo ya vivido" (Vigotsky, 1999). 
Con base en lo anterior, la imaginación puede concebirse como una función psíquica que posibilita que la mente vaya más allá de lo tomado de la realidad, pero siempre utilizando materiales derivados de la experiencia. Esto permite retomar las dos orientaciones bajo las cuales se manifiesta la imaginación y que fueron expuestas por Vigotsky. Para este autor, la imaginación entendida como la fuente de la creación, Fomenta el surgimiento de dos impulsos creadores, estos son el impulso reproductor o reproductivo y el impulso creador o combinador.

El primero hace referencia al proceso de creación que se da a partir de la reproducción de hechos, impresiones o experiencias vividas por cada ser humano y el segundo, se entiende como el proceso de creación que realizan los individuos en el que no solo retoman elementos de sus experiencias pasadas para originar algo nuevo; sino que se modifican, asocian y combinan dichos elementos de una manera distinta para construir nuevas ideas y nuevas interpretaciones de la realidad.

De igual manera, Egan, en consonancia con lo planteado por Vigotsky, reconoce que dentro del proceso imaginativo juegan un papel muy importante todas las vivencias de los individuos y afirma que "la imaginación se sitúa en una especie de cruce donde se interceptan e interactúan la percepción la memoria, la generación de ideas, la emoción, la metáfora y sin duda, otros importantes aspectos de nuestra vida. Algunas de las imágenes que experimentamos parecen "ecos" de lo que hemos percibido, aunque podamos modificarlas, combinarlas, manejarlas hasta que ya no se asemejen a nada que hayamos percibido (Egan, 1992).

Todo lo anterior, permite contemplar a la imaginación como una capacidad fundamental en el desarrollo de los individuos, que se alimenta de las experiencias de éstos y que la motiva a transformar su realidad inmediata en cada momento de su vida, ya sea durante la época de infancia, adolescencia 0 adultez.

Además, es necesario reconocer que la imaginación en la infancia puede ser visualizada a través de las creaciones que hacen los niños en sus juegos infantiles, pues tal y como lo manifiesta Vigotsky, es en los juegos en donde se puede apreciar mejor los procesos de creación que desarrollan los niños, ya que en éstos ellos pueden llegar a reproducir mucho de lo que han visto y escuchado en su contexto, pero estas experiencias nunca son reproducidas absolutamente igual a como se 
presentaron en la realidad; también en los juegos, los niños realizan una transformación creadora de las impresiones vividas, en la medida que son capaces de combinarlas y organizarlas para la formación de una nueva realidad, que responda a las exigencias e inclinaciones del propio niño.

\subsubsection{Invención y arte}

Así pues, al hablar de la habilidad de los niños para crear situaciones simuladas dentro de sus juegos, exige toca una clase de juego en esencia, como lo es el juego de simulación denominado así por Harris (2005) o también llamado "juego simbólico" o "juego fingido" para autores como Piaget (1961) y Gardner (1993).

Según Harris (2005) el juego de simulación es uno de los indicadores más tempranos y evidentes de la imaginación de los niños, ya que les permite a estos construir una nueva realidad, pues es en el juego de simulación donde el mundo real retrocede y es reemplazado por un paisaje simulado y por la experiencia de la que dispondría el protagonista.

Harris considera que el juego de simulación no desaparece con el desarrollo de los individuos (como si lo planteó Piaget), sino que, por el contrario, se va sofisticando a medida que estos crecen. Así mismo, el autor expresa que cuando los niños se comprometen dentro de un juego de simulación, pueden considerar formas alternativas de la realidad a partir de la evaluación que ellos mismos ya han hecho de ésta, lo que en lugar de alejarlos del desarrollo de un pensamiento objetivo (como lo plantea Piaget), los acerca a éste (Harris, 2005):

"Si se tiene en cuenta la disposición de los niños a comprometerse emocionalmente en un mundo imaginario como un índice de inmadurez cognitiva, se debería arribar a conclusiones semejantes con respecto a dicha disposición de los adultos. Sin embargo, la mayoría de los adultos se dejan absorber por novelas, películas u obras de teatro. En la medida en que esta atracción por la ficción no es un fenómeno transitorio de la niñez sino una característica que dura de por vida, es apropiado preguntarse qué representa para la conformación cognitiva y emocional de los seres humanos, ya que los empuja a comprometerse tan intensamente en la vida de otras personas (incluida la vida de personajes ficticios)" (Harris, 2005). 
El juego de simulación para Harris se concibe como la actividad que les permite a los niños de manera individual o colectiva, usar su imaginación para dejar de lado o transformar la realidad cotidiana, involucrando principalmente el entorno físico y/o la incorporación de seres animados. Es decir, cuando los niños participan en un juego de simulación, modifican su realidad inmediata a partir del uso creativo de los objetos que se encuentran en su entorno y de la afluencia de situaciones 0 suceso imaginarios que parten de las experiencias de cada individuo y de su capacidad para asociar y combinar todas sus ideas, motivándose por el deseo de jugar:

"La simulación no es una distorsión de la realidad sino una exploración de mundos posibles, en la medida en que varios objetos son puestos como sustento de un uso creativo. En un nivel más profundo ofrece una vía para imaginar, explorar y conversar acerca de las posibilidades inherentes a la realidad" (Harris, 2005).

Es así como dentro de los juegos de simulación, los niños tienen la posibilidad de usar objetos presentes en el contexto inmediato, con la libertad de otorgarles una nueva entidad, la cual hace parte del proceso de materialización de la imaginación que realiza cada niño, quien además de esto, da rienda suelta a la combinación de sus experiencias para construir una serie de sucesos y eventos imaginarios, que lo hacen olvidar la verdad objetiva de la realidad, para sumergirse en una nueva realidad que es totalmente imaginaria.

De la misma manera, la realidad no solo se trasforma cuando los niños juegan con los objetos presentes en su entorno, otorgándoles nuevas entidades, sino que también se dan transformaciones en la realidad a partir de la incorporación de seres animados, es decir, cada vez que los niños dentro del juego hacen uso de su capacidad de imaginar y actuar el rol de una persona o criatura, utilizando acciones simuladas y expresiones que son apropiadas, tanto para el rol representado como para el juego.

Frente a esto Harris plantea que la creación de seres animados activa dentro de la simulación un juego de rol, el cual: 
"Se produce durante una simulación solitaria, o junto a un compañero adulto, pero el contexto más frecuente es con otros niños, hermanos o familiares cercanos". Así mismo, este autor afirma que la incorporación de personajes animados al juego "incluye casos en los que el niño adopta un rol o identidad para sí mismo, dejando de lado su propia identidad, o el niño que crea y actúa un rol pero en lugar de asignarse ese rol a sí mismo, lo proyecta en otro objeto y el niño que inventa una criatura o persona que no necesita para su soporte ningún objeto" (Harris, 2005).

Harris plantea que cuando los niños participan en un juego de simulación describen que está sucediendo en el mundo imaginario y evitan las referencias literales a los movimientos y objetos usados para construir esa realidad imaginaria. Es decir, que el juego de simulación les permite a los niños apartarse del mundo real, pero sin desconocer los poderes causales de ese mundo, ya que las entidades imaginarias que crean durante el juego de simulación estarán sujetas a los mismos principios casales que sus equivalentes en el mundo real. De esta manera, cuando los niños se involucran en un juego de simulación son capaces de construir todo un episodio simulatorio, pero éste termina los niños vuelven a procesar la realidad normalmente de manera literal. Al respecto, Harris afirma que "una vez que la postura de simulación es abandonada, las referencias y la información que ellas codifican dejan de guiar las reacciones del niño y este vuelve a procesar la realidad de manera normal" (Harris, 2005).

De otra parte, Harris plantea que el juego de simulación tiene cuatro componentes o rasgos que son las reglas de la simulación, los poderes causales, la suspensión de la verdad objetiva y el encadenamiento causal desplegado:

- Las reglas de simulación son las posibilidades que se tienen en el juego de otorgar a las cosas una nueva entidad temporaria y existencia pública; por ejemplo, una caja de cartón es una bañera y un pedazo de madera es un jabón. Estas reglas son introducidas por cada jugador y se consideran temporales porque son mantenidas solo durante un episodio simulatorio y públicas porque son conocidas y respetadas por todos los jugadores que participen en dicho episodio. 
- Los poderes causales son los poderes que poseen las entidades imaginarias creadas para generar o causar acciones. Por ejemplo, el agua puede salir de un grifo imaginario y un jabón imaginario puede usarse para bañar a un oso de peluche. Estos poderes causales son equivalentes a los poderes de los objetos reales que representan. En relación a esto Harris indica que "los niños desde los 2 años no solamente entienden las reglas de simulación, sino que también entienden los poderes causales asociados con una entidad estipulada". (Harris, 2005)

- La suspensión de la verdad objetiva consiste en dejar de lado dicha verdad para comprometerse en la creación de una verdad simulada o imaginaria a través del desarrollo de un juego de simulación. Esta suspensión se da en el momento en que por ejemplo al retirar un oso de una bañera imaginaria se dice "el oso este todo mojado", aun sabiendo que el oso está evidentemente seco. El obviar la verdad objetiva de la realidad permite que cada jugador pueda describir lo que está sucediendo en su imaginación.

- El encadenamiento causal desplegado es la unión causal de una acción con otra dentro de un episodio simulatorio que se enlazan con una estructura parecida a la narrativa. Por ejemplo, al abrir el grifo imaginario se llena la bañera, al sentar un oso en la bañera éste se moja y será necesario secarlos con una toalla.

Por todo esto, el juego de simulación se puede llegar a considerar tal y como lo plantea Harris, como un instrumento a través del cual los niños describen con sus acciones y expresiones verbales, corporales, etc., lo que está ocurriendo en su mundo imaginario.

En este mismo sentido, de resaltar la importancia del juego en general y del juego simbólico en particular, a nivel cognitivo se encuentra Gardner (1993) quien manifiesta que el juego fingido, como él lo denomina, les permite a los niños involucrarse en una actividad mental de meta representación, a través de la cual los niños evocan o producen diferentes cosas o situaciones de manera fingida, ignorando el estado real de los objetos que están involucrados en el juego, es así como Gardner señala que:

"En un juego fingido se pueden encontrar diferentes órdenes meta representativos como: tratar un objeto como si fuera otro (un plátano es un teléfono), tratar nada como si fuera algo 
(quiere beber el té esta taza- aunque de hecho la taza este vacía-, tratar algo como si fuera nada (hablaré de Susie, como si no estuviera aquí); se puede deformar una propiedad hasta el punto de tratarla como otra propiedad (haré como si el cabello corto fuera largo y lo llevaré recogido como una cola de caballo" (Gardner, 1993).

En otras palabras, para Gardner en el juego fingido los niños hacen uso de su imaginación para adoptar posturas diferentes respecto a la realidad cotidiana, logrando tal y como lo afirma este autor, ser capaces de imaginar el estado de cosas contrario al que perciben los sentidos, captando esa actividad imaginativa en una forma simbólica pública, muy en sintonía con los aportes de Harris.

Por consiguiente, se reconoce que los juegos de simulación son una herramienta que hace evidente la imaginación de los niños, en la medida en que estos construyen dentro del juego una nueva realidad, ayudados por la libertad que tiene cada jugador para combinar sus ideas y experiencias; dando lugar a la creación de nuevas cosas a partir del cambio temporal de las entidades de los objetos presentes en la realidad y que han sido representados en el juego.

Igualmente, dichos juegos admiten que los niños imaginen y creen personajes animados ya sea representándolos en ellos mismos o delegando la personificación en otros objetos presentes en su rol de contexto, lo cual implica que los niños simulen acciones y expresiones acordes tanto para el rol representado como para el episodio simulado. 
4. CAPÍTULO 4. MODELO DE PROMOCIÓN DE LA RESILIENCIA DESDE EL JUEGO 


\subsection{Resiliencia infantil y juego}

La resiliencia infantil es un proceso sistémico que, como tal, se entrecruza y depende de diferentes sistemas. Como se mencionó en el capítulo dos, la resiliencia infantil requiere de la interacción de tres de sus fuentes: ontosistémicas, microsistémicas y macrosistémicas.

Hablar de la promoción de la resiliencia desde el juego, implica un encuentro con los niños y niñas desde su lenguaje universal; para Vigotsky (1999) el juego es, ante todo, una de las principales o incluso la principal actividad del niño, es una de las maneras de participar del niño en la cultura, es una actividad cultural típica, como lo será luego, de adulto, el trabajo. Es decir, según la perspectiva dada, el juego resulta una actividad cultural. Pero la participación del juego en la cultura se da en gran medida a través de la imaginación. "La imaginación es una función vital y necesaria, una actividad que además de combinar, crea y contribuir a la formación de una imagen, es la base de toda actividad creadora" (Vigotsky, 1999)

Para este autor, a través de la imaginación los seres humanos no sólo pueden conservar y reproducir sus experiencias anteriores, sino que también pueden extraer de estos elementos que podrán ser transformados y combinados para construir con ellos nuevas ideas y formas diferentes de interpretar su realidad. De esta manera, la imaginación tal y como lo propone Vigotsky es "un proceso mental consiente en el que se evocan ideas o imágenes de objetos, sucesos, relaciones y atributos, así como otros nunca antes experimentados ni percibidos, en el que se producen imágenes de sucesos o de objetos poco o nada relacionados con la realidad pasada y presente, mientras simultáneamente se incluye la renovación o la "re- experimentación "de lo ya vivido" (Vigotsky, 1999).

Así pues, al hablar de la habilidad de los niños para crear situaciones simuladas dentro de sus juegos, exige toda una clase de juego en esencia, como lo es el juego de simulación denominado así por Harris (2005) o también llamado "juego simbólico" o "juego fingido" para autores como Piaget (1961) y Gardner (1993).

Y es en el juego infantil donde se desarrollan principalmente las diferentes bases para el desarrollo de la resiliencia como la autonomía, la confianza en sí mismo y en el entorno, y la competencia social, 
por tanto desde los procesos de intervención se debe estimular la generación de escenarios de respeto, diálogo, reconocimiento de sí mismos y del otro, de acceso a la ayuda, verbalizaciones positivas y empáticas, resolución pacífica de conflictos, entre otros aspectos, para que desde allí se fortalezca la apropiación de estos factores como elementos cotidianos en la vida de los participantes, pues "la posesión de estas atribuciones verbales puede considerarse como una fuente generadora de resiliencia". (Munist, Santos, Kotliarenco, Suárez, \& Grotberg, 1998).

Es necesario promover experiencias que permitan a los niños y niñas involucrarse en los asuntos comunes, tolerancia y respeto por la diferencia, expresar adecuadamente sus ideas, establecer comunicaciones a partir de intereses opiniones y deseos de acuerdo con el momento de desarrollo en el que se encuentre; así como fomentar la negociación y la empatía.

\subsection{El modelo RARE: rayuela resiliera}

Realizar procesos de acción psicosocial desde el juego supone hablar desde el lenguaje común y universal de los niños y las niñas, hablar desde las acciones naturales, desde la cotidianidad. A pesar de los efectos directos e indirectos del conflicto armado en Colombia, los niños y niñas siguen jugando, siguen soñando y siguen imaginando mundos posibles y dichos mundos pueden convertirse en aportes frente a la construcción de nuevas realidades.

El modelo de atención psicosocial "RARE: Rayuela Resiliera" busca fortalecer las fuentes ontosistémicas de la resiliencia infantil desde un ámbito eminentemente lúdico, generando aprendizajes acerca del autocuidado, reconocimiento del otro, exploración del entorno, entre otras.

El modelo RARE se fundamenta teóricamente en los capítulos dos y tres de este documento. En primer lugar, el paradigma de la resiliencia infantil, que resulta de un proceso sistémico: interacción entre tres sistemas: el ontosistema, el microsistema y el macrosistema (ver Figura 6).

Sin embargo, es de aclarar que el modelo RARE aporta principalmente a las fuentes ontosistémicas de la resiliencia, es decir, el modelo busca movilizar en los niños y niñas sus formas de ser y estar en su relación con el otro. Para ello, el modelo RARE busca potenciar en los niños sus 
fortalezas intrapsíquicas, sus habilidades para la acción, sus respuestas amortiguadoras y sus emociones positivas.

De esta manera, el modelo RARE basa su accionar en las potencialidades del juego como un acto creativo, es decir, del juego que potencia el Ethos creativo del jugador y comprendiendo la creatividad como el principal movilizador de las fuentes ontosistémicas de la resiliencia infantil.

Así pues, las fortalezas intrapsíquicas, como características innatas o adquiridas por el niño y la niña, que se potenciarán principalmente serán la autoestima y la afectividad y las emociones positivas. Éstas hacen parte de la morada interior (lugar interno) del Ethos creativo, que permite contemplar la belleza, la vida como obra de arte y permite la apertura o la disposición para esperar lo inesperado, para disponerse a los retos, en un acto ético- estético, pues permiten equilibrio y armonía, acompañado de emociones positivas.

Otra fortaleza intrapsíquica que se trabajará bajo la aplicación del modelo RARE será la impulsividad, vinculada al Ethos como hábito, es decir, como la actitud que se aprende y se fomenta. Alli aparecen la identificación y solución de problemas y los juegos intelectuales, como una posibilidad de fomentar actitudes para enfrentarse a los riesgos y para asumir las propias ideas.

De otro lado, frente al Ethos creativo como cogito (modo de pensar) se potenciará el pensamiento crítico y la creatividad, que en la acción de jugar serían la fantasía y la imaginación, la invención y el arte, en donde se visiona la realidad, donde aparece el juego imaginario, simbólico o el "como si", donde el niño y la niña juega a la realidad que sueña.

Frente a las habilidades para la acción, el modelo RARE comprende que la creatividad misma (como cogito) y la asertividad (como hábito).

A continuación, se presenta la gráfica que explica el modelo. 


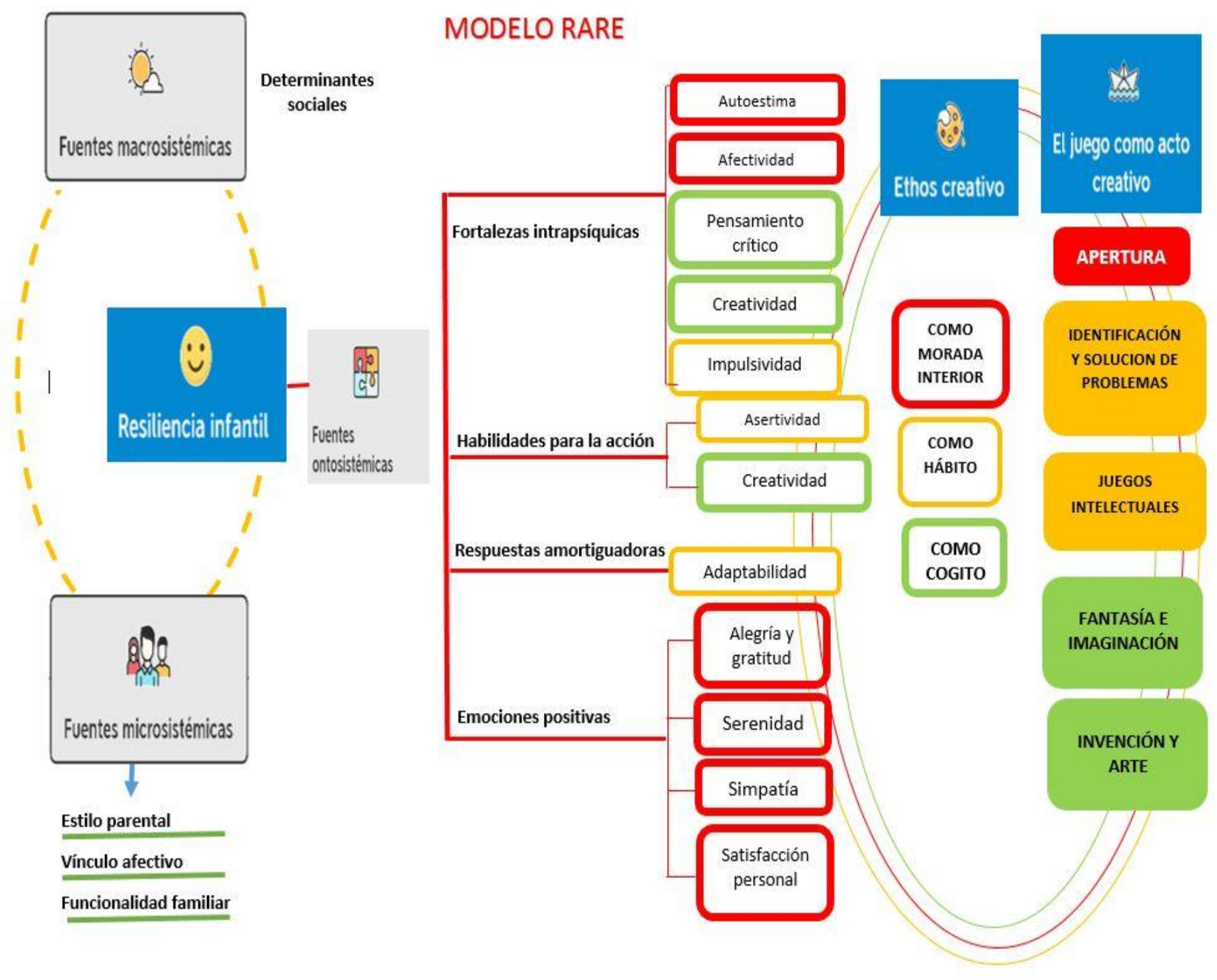

Figura 6. Diseño teórico del modelo RARE

Fuente: elaboración propia 


\subsubsection{Enfoque epistemológico}

Fundamentado en la teoría de sistemas, el enfoque sistémico define este como un todo que es más que la suma de sus partes, como un conjunto de elementos que se relacionan entre ellos y toman una unidad frente al medio externo; aquí la familia se considera como un todo organizado y las partes que la conforman son independientes. El individuo se comprende como un ser en interacción dentro de una red compleja de relaciones de la que él hace parte. Este sistema social cumple con el desarrollo del individuo a través de funciones intransferibles a otras instituciones, como sistema afectado por cada unidad que la integra.

Este enfoque permite la intervención en el sistema familia, mediante la exploración de las relaciones interpersonales y con otros sistemas, de ahí que se considere fundamental tener en cuenta le funcionamiento familiar en conjunto y no solamente con el niño.

Tiene por objetivo mejorar las relaciones, la comunicación y clarificar los roles dentro del sistema familiar, así como sensibilizar al individuo de su pertenencia al sistema y la influencia de su forma de comportamiento en él.

\subsubsection{Enfoque político}

El enfoque de acción sin daño, y el enfoque diferencial son transversales al Modelo RARE, ya que establecen un enfoque político de abordaje y relacionamiento con los actores que participan y cocrean el modelo en su diseño, implementación y evaluación. De manera específica estos dos enfoques orientan el posicionamiento desde el cual los adultos facilitan el juego para promocionar la resiliencia, por tanto, supone una postura de relación, reconocimiento, de respeto frente al lugar de ser niño y niña como sujeto de derecho, titular de mecanismos de protección y con particularidades desde la construcción de su infancia.

- Enfoque de acción sin daño (ASD): Este enfoque tienen sus bases en los postulados de la ética médica de "no hacer daño" y la obligación moral de actuar en beneficio del otro, para ello se requiere tener como fundamento la ética del trabajador que refiere a "Hacer bien una 
actividad y hacer el bien a otros mediante esa actividad bien hecha" (Rodríguez, 2010, pág. 34). De tal manera, estos aportes han alimentado a los procesos de acompañamiento e intervención en las ciencias sociales, principalmente en programas humanitarios, de desarrollo, y de construcción de paz, para ello se han analizado los distintos tipos de daño en los conflictos sociales y los contextos, planteando que en estos campos quienes intervienen tiene una relación directa con quienes interactúan en las problemáticas sociales, por tanto su postura ética debe ser claramente mediada por el enfoque de acción sin daño el cual posibilita que los ejecutores, en este caso los adultos que agencien el modelo RARE, brinden orientaciones adecuadas a los y las niñas velando por su mayor bienestar y que no se lleven a cabo acciones nocivas, también se deben reconocer los aprendizajes previos de los y las participantes, se debe realizar una toma de decisiones pertinentes ante cualquier situación que no revictimizar y no cause un daño más, a partir de la intervención realizada.

En conclusión "el enfoque de ASD se trata entonces, no sólo de reconocer y analizar los daños que ocasionan las situaciones de conflictos, sino de prevenir y estar atentos a no incrementar con las propias acciones, esos efectos y sí en cambio, tratar de reducirlos". (Rodríguez, 2010, pág. 38)

- Enfoque Diferencial: Partiendo de los lineamientos del enfoque de derechos, el cual determina la libertad sobre la base de la dignidad humana, la igualdad inalienable y la no discriminación, surge la referencia a un principio del derecho a la equidad que plantea dar a cada sujeto social lo que le corresponde acorde a sus necesidades y particularidades. Esto implica el desarrollo del enfoque diferencial, el cual garantiza como instrumento jurídico que el ejercicio pleno y efectivo de los derechos tenga en cuenta las condiciones físicas, culturales, contextuales, e históricas de grupos sociales y sujetos, en pro de prevenir cualquier acto de discriminación y dar la garantía de un derecho con pertinencia. Por tanto este enfoque identifica las particularidades de grupos poblacionales como: pueblos étnicos (Afrodescendientes, indígenas, palenqueros, raizales y Rrom), víctimas del conflicto armado, personas con discapacidad, grupos con orientaciones sexuales e identidades de género diversas y la diferenciación de los grupos etarios por ciclo vital, dando prioridad a los sujetos de mayor protección (Niños, niñas, mujeres en embarazo y adultos mayores), con el fin de que la atención, la protección y la participación de dichos sujetos en estrategias de 
intervención, acompañamiento o investigación, sean previstas desde de sus condiciones y contextos.

De manera tal que el enfoque diferencial es "la forma de análisis y actuación social y política que, por una parte identifica y reconoce las diferencias" y a partir del reconocimiento de estas, el enfoque diferencial "busca la transformación o supresión de las inequidades y de sus expresiones de subordinación, discriminación y exclusión social" (Unidad administrativa especial de gestión de restitución de tierras despojadas, 2016, pág. 5) a las que históricamente han estado supeditadas estas poblaciones.

Por tanto, en el modelo RARE el enfoque diferencial es preliminar, ya que la diversidad presente en los y las niñas participantes es alta, e implica abordar dichas diferencias para una implementación acorde a cada una de las personas que vivencian el modelo.

\subsubsection{Diseño metodológico}

El modelo de promoción de la resiliencia infantil RARE está diseñado para niños y niñas entre los 8 y los 12 años de edad, colombianos, escolarizados y que han sido víctimas del conflicto armado.

El modelo aborda ocho componentes, es una particular manera de intentar comprenderse un poco más, como lo diría Tirado (1998), donde se promoverán los hábitos y la morada interior de los niños y las niñas. Dada su estructura, al finalizar se evaluará si la rayuela cumplió su efecto. 


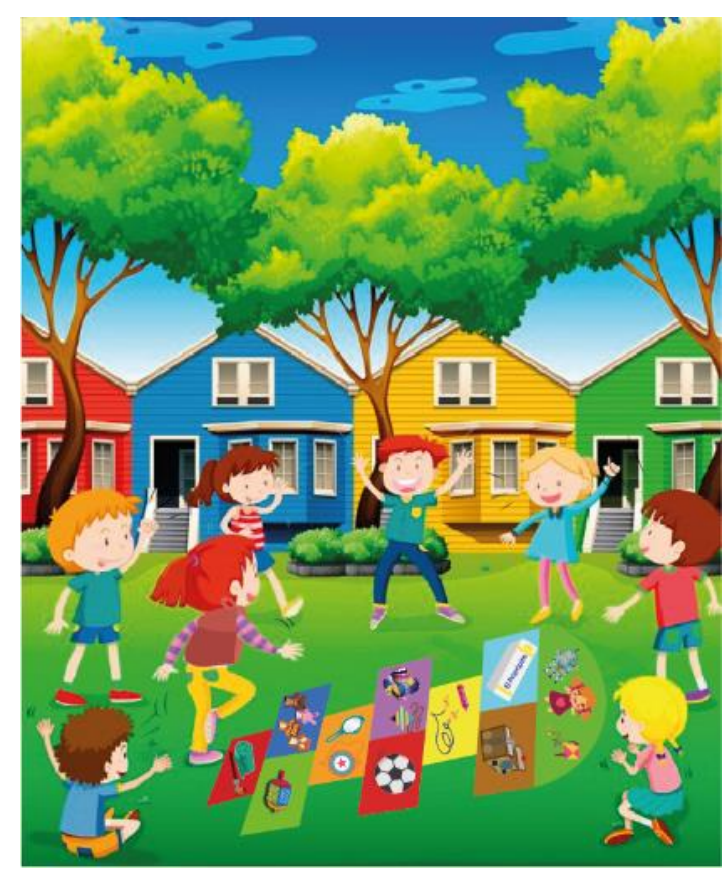

Figura 4. Imagen del modelo RARE Fuente: elaboración propia

Para el trabajo con los niños y las niñas, la imagen del modelo está en la Figura 5 que representa los diferentes componentes que se vinculan en él:

1. La rayuela, que será el camino que se recorre durante el modelo.

2. Beis, el personaje central del modelo, un niño o niña que cada participante lo imagina de alguna manera, representa el amigo imaginario

3. La mochila resiliente, donde se van guardando las construcciones y comprensiones que van sucediendo en cada momento de juego

4. Los juguetes, elementos vinculantes para jugar

5. "Los otros", los pares, amigos, o tutores de resiliencia

6. Las casas, que representan las fuentes micro y macro sistémicas, que, aunque no se vinculan en la intervención del modelo, si se depende de ellas para el sostenimiento de las habilidades resilientes. 


\subsubsection{Elementos del modelo RARE}

- Rayuela: Para amenizar los procesos resilientes se utilizará un juego que ha sido utilizado y jugado en diferentes culturas en el mundo: La rayuela, golosa, avión o peregrina, que para este modelo de promoción de la resiliencia que se juega para que como niño o niñas (sujeto), pueda identificar mis vínculos, mis emociones, mi afrontamiento, reencontrarme con mis juegos, es un encuentro consigo mismo. La rayuela representa el proceso individual para enfrentar la vida misma, donde se avanza o se retrocede, donde se cae y se vuelve a levantar para volver a empezar, donde se ponen a prueba su personalidad resiliente (ver Figura 6). En cada escalón de rayuela, se irá recogiendo un juguete, un juguete con sentido y significado.

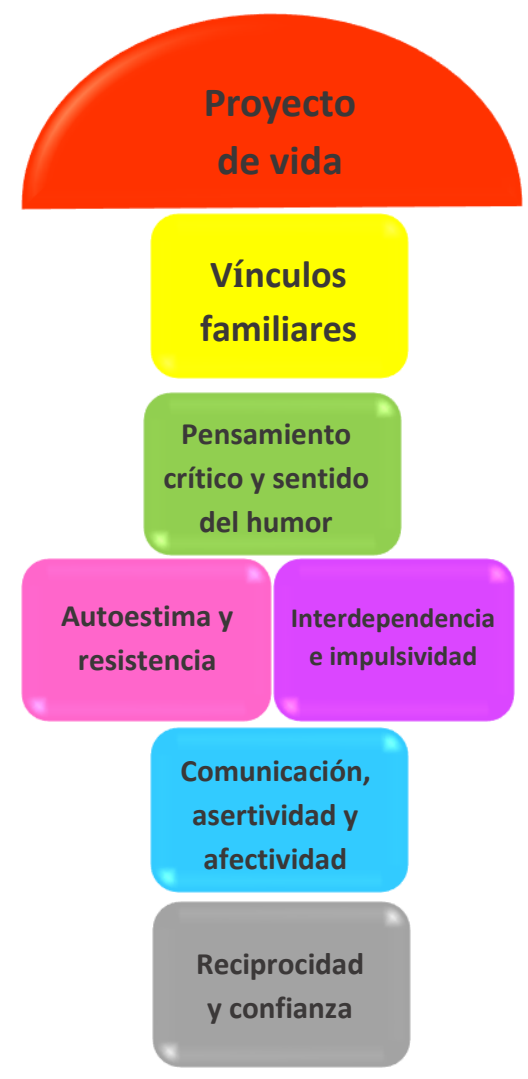

Figura 5. La rayuela resiliera Fuente: elaboración propia

La rayuela implica un proceso, donde Beis arranca con la mochila vacía y cuando finalice el juego de la rayuela estará llena de condiciones individuales para enfrentar su vida; también implica un proceso de devolverse, volver a empezar, analizar por qué se devolvió y con nueva actitud, emprender un nuevo viaje.

- Juguetes: Los juguetes son elementos vinculantes para jugar. Los juguetes incluidos en este modelo hacen parte de la cotidianidad de los niños y niñas, además de seleccionarse porque se pueden construir con ellos y ellas en las sesiones y con este ejercicio de construcción, se espera lograr una mayor adherencia a la propuesta de intervención, pues cuando los niños construyen sus propios juguetes, estos adquieren una mayor pertenencia e identidad con ellos. La mochila de Beis será tejida por las familias de los niños y niñas y con ello se espera no solamente que las familias se involucren en el proceso, sino, adicionalmente, la mochila representa los valores que vienen de casa y que 
entrega la familia.

Los juguetes son los objetos físicos y simbólicos para el juego y su presencia es necesaria en la construcción de los espacios de juego.

La construcción de juguetes es fundamental en este modelo para conseguir los objetivos perseguidos, para ello se deben considerar hacer elaboraciones inspiradas en la cotidianidad de los niños y las niñas. Por ello los juguetes escogidos son propios de la cultura colombiana y se podrán realizar con materiales del entorno, pues así se logra un contenido significativo (ver Tabla 2).

Tabla 2. Juguetes y su intencionalidad en el modelo RARE.

\begin{tabular}{|c|c|c|}
\hline Juguete & Juguete & Sentido \\
\hline & $\begin{array}{l}\text { 1. Mochila } \\
\text { 2. Cobija caliente }\end{array}$ & Vínculos familiares \\
\hline & 3. Caballito de madera & Asumir riesgos \\
\hline & 4. Pirinola & $\begin{array}{l}\text { Apertura a la experiencia, } \\
\text { independencia, autonomía }\end{array}$ \\
\hline & 5. Títeres & Sentido del humor \\
\hline & $\begin{array}{l}\text { 6. Espejo } \\
\text { Yoyo }\end{array}$ & $\begin{array}{l}\text { Auto- imagen, auto estima, } \\
\text { autoconocimiento, yo ideal, } \\
\text { identidad }\end{array}$ \\
\hline & 7. Balón & Confianza \\
\hline & $\begin{array}{l}\text { 8. Trompo y canicas } \\
\text { Lazo }\end{array}$ & $\begin{array}{l}\text { Reciprocidad, altruismo, respeto } \\
\text { por el otro, interacción }\end{array}$ \\
\hline & 9. Carro en caja de cartón & Iniciativa \\
\hline$\varepsilon Q B r i$ & 10. Cuento "El Principito" & Libertad, justicia \\
\hline
\end{tabular}




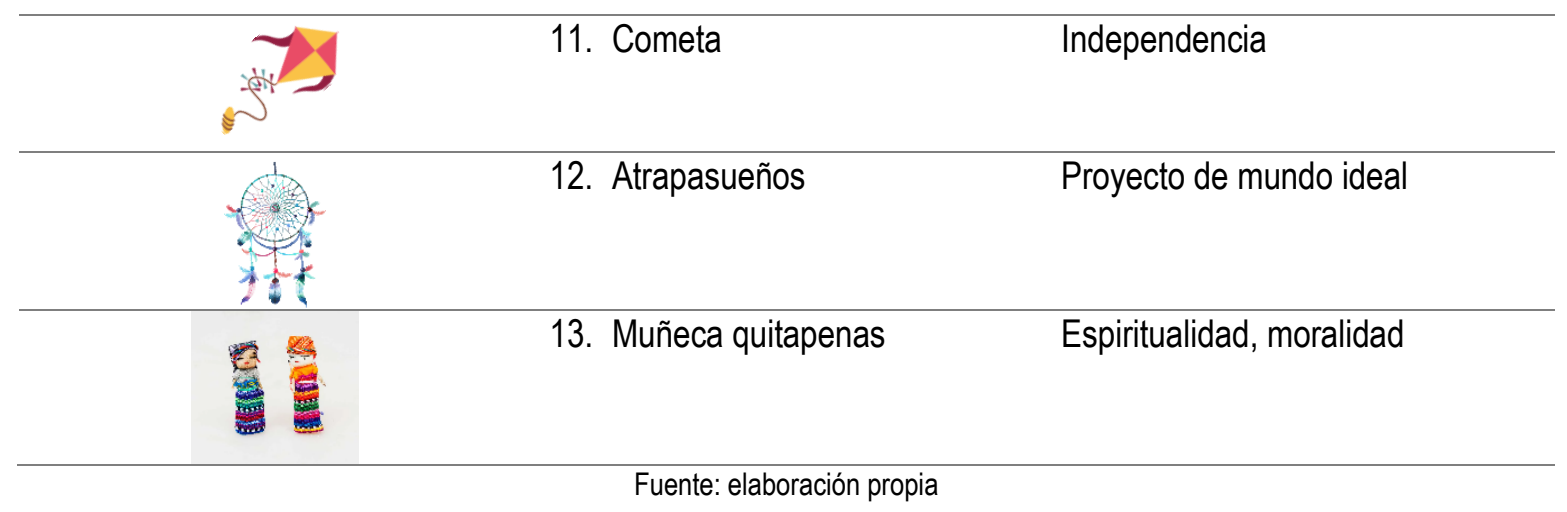

\subsubsection{Beis: personaje central de la historia}

En el centro del modelo está el personaje "Beis", el amigx imaginarix, ese que tiene un lugar, una forma u otro nombre en cada niño y niña (ver Figuras 7 y 8 ). El que ha jugado, ha llorado, ha dormido, ha corrido, en aparente silencio para el mundo, pero en grandes voces que toman forma. Que se desenvuelve en consonancia, en camaradería, en complicidad con cada niño y niña. Ese con el que cada niño y niña crea un mundo imaginario.

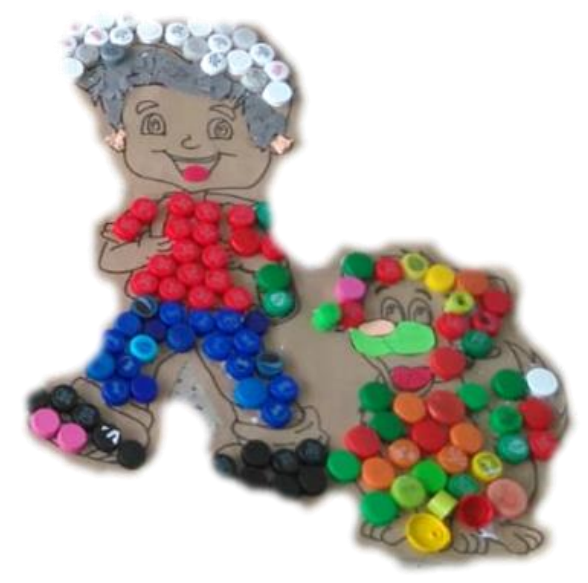

Figura 6. Beis construido por el curso 501

Fuente: elaboración de niños y niñas del curso 501 Colegio CEDID Ciudad Bolívar 
Beis lleva en su espalda una mochila que representa su personalidad resiliente, el ser humano como tal, donde guarda todas sus habilidades, experiencias y en últimas, es el equipaje con el que nace cada persona, pero que se va llenando con los aportes de la familia. Esa mochila se lleva a lo largo de la vida para enfrentar los retos de la adolescencia, la juventud y la adultez. La mochila es entregada a Beis por su familia, pues representa los vínculos familiares y la formación de valores y hábitos que se aprenden en familia.

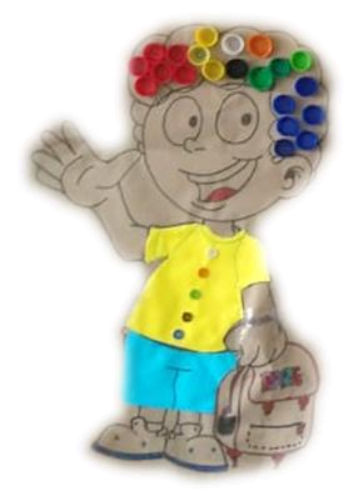

Figura 7. Beis construido por el curso 502

Fuente: elaboración de niños y niñas del curso 502 Colegio CEDID Ciudad Bolívar

\subsubsection{Sesiones de juego}

Una condición que debe estar presente en las sesiones con los niños y las niñas es que el juego es la experiencia a través de la cual se busca promover en los niños un aprendizaje de manera natural. Por ello, es importante reconocer las formas en que se expresa el juego en cada momento de la vida de los niños, con el fin de construir escenarios de aprendizaje enriquecidos que faciliten la exploración, la construcción, la interacción con los juguetes, con las personas y con el entorno próximo del cual hace parte.

Así pues, las sesiones de juego como escenario de aprendizaje significativo deben propiciar experiencias sensoriales, comunicativas, afectivas, motrices, creativas y de conocimientos (ver Tabla 3). 
Teniendo en cuenta los objetivos planteados que apuntan a la validación de un modelo psicosocial para la promoción de la resiliencia basado en el juego para niños y niñas, se llevan a cabo una serie de talleres que posibilitan la comprensión de las dinámicas individuales, grupales y sociales que los y las estudiantes experimentan en su día a día, y cómo a través del juego, el diálogo, la experiencia y la reflexión se desarrollan habilidades en cuanto al control de emociones y acciones frente adversidades y problemáticas que los y las aquejan.

Las sesiones de trabajo planteadas se realizaron bajo la metodología del taller reflexivo con un enfoque diferencial e intercultural, los cuales invitan a los y las participantes a aprender de diferentes culturas a través de juegos modernos y tradicionales, en donde encuentran retos, análisis y obstáculos que los involucra en la búsqueda de soluciones y alternativas resilientes ante lo adverso. Por ende, los talleres desarrollados se emplean como un medio de capacitación y sensibilización que integra el hacer, el sentir y el pensar, facilitando de esta manera el aprendizaje.

Así mismo, se buscó desarrollar destrezas, habilidades y actitudes resilientes con el fin de brindar y posibilitar herramientas de carácter actitudinal en los niños y niñas que les sean útiles para enfrentar diversas problemáticas y situaciones cotidianas como la adolescencia y sus cambios, el paso hacia nuevas etapas escolares, las separaciones o pérdidas de familiares y seres queridos, entre otros; y otras como los efectos primarios y secundarios de situaciones sociales y culturales como la violencia, la desigualdad y el posconflicto, donde, dadas las características sociales en que crecen y viven los y las estudiantes, se ven forzados a ser más fuertes y resistente en sus contexto para poder generar espacios y momentos de vida más dignos y prósperos, por tanto, se espera que cada participante asuma sus propias reflexiones y conclusiones de acuerdo con su propia subjetividad para así aplicar los aprendizajes en su vida diaria y entornos cercanos. 
Tabla 3. Sesiones del modelo RARE.

\begin{tabular}{l|l}
\multicolumn{1}{c}{ NOMBRE DE LA SESIÓN } & \multicolumn{1}{c}{ CONSTRUCTO PARA PROMOVER } \\
\hline ENTRADA & $\begin{array}{l}\text { Aplicación de encuestas Pre y Caracterización } \\
\text { Reconocimiento del otro- reciprocidad }\end{array}$ \\
$\begin{array}{l}\text { 1. YO Y EL OTRO } \\
\text { 2. YO AMO, YO ME AMO, YO LOS AMO }\end{array}$ & $\begin{array}{l}\text { Asertividad - Afectividad } \\
\text { Independencia- Impulsividad }\end{array}$ \\
3. YO PUEDO & $\begin{array}{l}\text { Resistencia- Autoestima- Autoconocimiento- (Duelo- } \\
\text { 4. YO CREO }\end{array}$ \\
\begin{tabular}{ll} 
5. LOS ADULTOS & Vínculos familiares \\
6. YO ESTOY & Pensamiento crítico- Sentido del humor \\
7. YO PUEDO SER & Proyecto de vida- flexibilidad- Creatividad \\
8. VÍNCULOS FAMILIARES & Vínculo familiar \\
SALIDA & Aplicación de encuestas post \\
& Fuente: elaboración propia \\
\hline
\end{tabular}
\end{tabular}


5. CAPÍTULO 5. ESTUDIO CUASIEXPERIMENTAL PARA LA EVALUACIÓN DE UN MODELO DE INTERVENCIÓN SOCIAL PARA LA PROMOCIÓN DE RESILIENCIA CON NIÑOS Y NIÑAS VÍCTIMAS DEL CONFLICTO ARMADO COLOMBIANO 


\subsection{Pregunta de investigación}

¿Es efectivo el modelo de atención psicosocial basado en el juego, para la promoción de la resiliencia en población infantil afectada por el conflicto armado en una zona de Colombia?

\subsection{Objetivos}

\subsubsection{Objetivo General}

Evaluar la efectividad de un modelo psicosocial para la promoción de la resiliencia basado en el juego para niños y niñas víctimas del conflicto armado de la localidad de Ciudad Bolívar en Bogotá, Colombia.

\subsubsection{Objetivos Específicos}

1. Realizar línea base de las capacidades resilientes de los niños y niñas antes de la implementación de un modelo de atención psicosocial.

2. Diseñar e implementar un modelo de atención psicosocial para la promoción de la resiliencia basado en el juego.

3. Evaluar los cambios obtenidos en los niños y niñas que participaron en la implementación del modelo de atención psicosocial basado en el juego.

4. Proponer a la comunidad científica un modelo de atención psicosocial que contenga los ajustes sugeridos por la validación del modelo.

\subsection{Diseño metodológico}

Esta investigación doctoral estuvo basada en el paradigma o escuela de pensamiento pospositivista el cual:

[...] examina la causa y como diferentes causas interactúan y/o influyen en los resultados. El paradigma pos-positivista adopta la filosofía en el cual la realidad puede ser descubierta imperfectamente y de forma probabilística. El enfoque es típicamente deductivo - 
donde la mayor parte de las ideas o conceptos se reducen a variables, y las relaciones entre ellas son sometidas a test. El conocimiento resultante es basado en la observación, medición e interpretación cuidadosa de la realidad objetiva (Sousa, Driessnack \& Costa, 2007).

Así pues, el presente estudio es de enfoque cuantitativo, ya que se centra fundamentalmente en los aspectos observables y susceptibles de cuantificación (Hernández, Fernández, \& Baptista, 2010). Utiliza la recolección de los datos para probar hipótesis, con base en la numeración numérica y análisis estadístico, para establecer patrones de comportamiento y probar teorías (Calderón \& Piñeiro, 2003), por ello, la investigación se basó en el paradigma pos-positivista de tipo probabilístico pues pretende comprender qué pasa cuando los niños y las niñas víctimas juegan, si el juego aporta a su capacidad resiliente.

\subsection{Tipo de estudio.}

Estudio cuasi-experimental sobre los aportes del juego a la promoción de la resiliencia en la infancia víctima del conflicto armado.

Como diseño cuasi-experimental se analizó los cambios entre el pre test y post test en cada uno de los grupos evaluados, grados cuarto y quinto, posteriormente se estableció un grupo control donde se examinó relaciones de causa y efecto entre las variables independiente y dependiente, este modelo cuasi experimental será útil para probar la efectividad de la intervención desde el juego, a través de la comparación entre el grupo sin intervención, y el grupo control expuesto al tratamiento.

Este proyecto de investigación aplica una intervención basada en el juego, buscando el favorecimiento de las variables de la resiliencia en estudio. También se establecerán las dimensiones que se van a promover y se va a usar este conocimiento desde un modelo hipotético para fortalecer y evaluar sistemáticamente la modulación o cambio logrado atribuible a la intervención. Los elementos traslacionales estarán en:

- La literatura que se usa para establecer los procesos o dimensiones del comportamiento que se pretende cambiar o favorecer 
- Para establecer las estrategias metodológicas, sensibles al cambio, que servirán para mapear si se logró lo que se propuso

- Para seleccionar las pruebas desde lo cualitativo, pero también desde lo cuantitativo para capturar estos cambios

- Para establecer cómo se seleccionarán los controles y que se hará con el grupo que no participe en la intervención, esto para garantizar que los cambios no sean productos del azar

- Para interpretar los resultados, asumiendo los cambios a promover, por lo que es necesario saber cómo están las variables propuestas en un momento determinado para aplicar la intervención de la manera más sistemática posible (documentando detalladamente que se hizo) y midiendo el cambio en las variables que se postularon originalmente al finalizar la intervención.

\section{5.Área de Investigación.}

La investigación se realizará con niños y niñas víctimas del conflicto armado que se encuentran escolarizados en Colegio CEDID Ciudad Bolívar, sede Tanque Laguna, Localidad de Ciudad Bolívar de Bogotá, Colombia.

\subsection{Población de estudio.}

- Población objeto:

Estudiantes de 8 a 12 años, de cuarto y quinto de primaria, del Colegio CEDID Ciudad Bolívar, sede Tanque Laguna, jornada mañana, el número total de estudiantes equivalentes con las características descritas anteriormente es de 114 estudiantes matriculados (48 del grado cuarto) y (66 grado quinto). 
- Unidad de observación:

De los 114 Estudiantes de 8 a 12 años de cuarto y quinto de primaria del Colegio CEDID Ciudad Bolívar, sede Tanque Laguna, jornada mañana, 94 participaron del estudio (54 estudiantes de quinto grado) y (40 del grado cuarto) y cumplieron todos los criterios de elegibilidad.

\subsection{Tamaño de muestra.}

La selección de la muestra será intencionada. El grupo expuesto al tratamiento serán 54 niños y niñas de 8 a 12 años, del grado quinto de primaria del Colegio CEDID Ciudad Bolívar, sede Tanque Laguna, jornada mañana. El grupo no expuesto serán 40 niños y niñas de 8 a 12 años, del grado cuarto de primaria del Colegio CEDID Ciudad Bolívar, sede Tanque Laguna, jornada mañana.

\subsection{Criterios de inclusión y exclusión.}

- Criterios de Inclusión.

Se incluirán a los niños y niñas que se encuentren matriculados en el Colegio CEDID Ciudad Bolívar, sede Tanque Laguna, que tengan edades entre los 8 y los 12 años, que hayan completado el asentimiento y consentimiento informado.

El consentimiento informado se hará llegar a los padres de los niños y niñas un sobre cerrado que contenga el consentimiento informado, asegurándoles el anonimato y la confidencialidad de la información obtenida. Una vez cumplimentado, los estudiantes devuelven el consentimiento al centro.

- Criterios de Exclusión.

Se excluirán a los/as estudiantes que no entren dentro del grupo de edad mencionado en los criterios de inclusión y que hayan tenido negativa a participar en el estudio, o que sus familias no se auto reconozcan como víctimas del conflicto armado; así mismo, se excluirán los cuestionarios que no se encuentren completamente diligenciados. 


\subsection{Instrumentos}

Los instrumentos aplicados que permiten identificar el nivel de resiliencia antes y después de la intervención son:

\subsubsection{Instrumento de medición de resiliencia (JJ63)}

Es un instrumento construido por doctor Julio Alfredo Jaramillo Oyervide, investigador de la Facultad de Ciencias Médicas de la Universidad de Cuenca para evaluar cuanti -cualitativamente la resiliencia adolescente (Jaramillo Oyervide, 2010), el cual mide los siguientes ejes:

- Funcionalidad familiar: Dinámica relacional sistemática que se da a través de: cohesión, armonía, roles, comunicación, permeabilidad, y adaptabilidad; todos estos aspectos intrafamiliares.

- Autoestima: Capacidad de auto-valoración

- Asertividad: Capacidad de sentir, pensar y actuar inmediatamente acorde a las situaciones evitando el uso de mecanismos de defensa.

- Impulsividad: Conducta irreflexiva conducente a actos de riesgo.

- Afectividad: Capacidad de mostrar emociones, sentimientos y pasiones de forma adecuada a la cultura a la cual el sujeto pertenece.

- Adaptabilidad a situaciones nuevas: Uso de mecanismos cognitivos para aceptar y ser aceptado socialmente.

- Tareas adolescentes: Definición escalonada durante las etapas de la adolescencia de independencia, autonomía, identidad sexual, y proyecto de vida.

- Creatividad: Cualidad cognoscitiva y afectiva conducente a resolución de eventos de forma propia y novedosa.

- Capacidad de pensamiento crítico: Expresión de valores, iniciativa y solidaridad. 
Tras la validación realizada para la población colombiana por (Alvarán López, Rueda, Vieco, \& Gaviria, 2019), el instrumento original de 63 ítems fue resumido en un brief scale de 46 ítems de fácil aplicación y comprensión para población infantil y juvenil de Colombia, además de estar agrupados en ocho constructos 1. Funcionalidad familiar, 2. Autoestima, 3. Asertividad, 4. Adaptabilidad a situaciones nuevas, 5. Creatividad, 6. Capacidad de pensamiento crítico, 7. Impulsividad, 8. Afectividad. Los datos psicométricos reportados para Colombia, presenta un alfa de Crohbach global de 0,875 . Las preguntas generales del JJ46 se detallan en la sección B del cuestionario anexo.

El permiso del autor Jaramillo, para la utilización del instrumento, se encuentra en el anexo 3.

\subsubsection{Instrumento de estilos parentales}

Es una escala de percepción de la relación con los padres para niños basada en el modelo Schaefer, de Richaud de Minzi (2007), definiendo 5 factores: 1) aceptación, 2) control aceptado, 3) control estricto, 4) control patológico y 5) autonomía extrema. La escala contiene 32 preguntas para responder en "sí, no, algunas veces" (Ver anexo 4).

- Aceptación: se refiere a la aceptación centrada en el niño, como expresión de afecto manifiesto y apoyo emocional, a la aceptación de la individuación como la promoción del intercambio y la comunicación abierta, la libertad para expresarse y para ejercer un pensamiento independiente, y la implicación positiva como ser sensible ante las necesidades del niño

- Control aceptado: incluye la puesta de límites y el establecimiento de normas que son percibidos como cuidado del niño

- Control estricto: incluye una puesta de límites y el establecimiento de normas con una supervisión parental estrecha que es percibida por el niño como imposición

- Control patológico: incluye varias formas de control excesivo: ser intrusivo, controlar a través de la culpa, aplicar normas estrictas, usar castigos y retos, evaluar negativamente la hijo o a la hija y alejar a través del rechazo. 
- Autonomía extrema: se refiere a permisividad extrema. Control parental laxo en el que se da al hijo total libertad sin imposición de reglas o establecimiento de límites. Generalmente es percibido por le hijo como negligencia e ignorancia en el comportamiento de sus padres al atender sus necesidades.

La fiabilidad, medida por el coeficiente de alfa de Cronbach, en la muestra de adolescentes de Buenos Aires, Argentina, fluctuó entre 0.62 y 0.92 (Richaud de Minzi, 2007).

\subsubsection{Instrumento de personalidad Creadora}

Escala de personalidad creadora EPC, de Maite Garaigondobil y José Ignacio Pérez: "la EPC evalúa la creatividad infantil explorando conductas y rasgos de personalidad creadora. La escala contiene 21 frases 0 afirmaciones sobre conductas y rasgos de personalidad creadora, planteados en una escala de estimación con la que se evalúa si la conducta o el rasgo se pueden aplicar a esa persona "nada, algo, bastante o mucho" (Garaigordobil \& Pérez, 2005).

La EPC evalúa 5 factores: Identificación y solución de problemas, Invención y arte, apertura, fantasía e imaginación y juegos intelectuales.

Los coeficientes calculados con una muestra de 139 sujetos (Alpha de Cronbach= 0.87 ) permiten sugerir la consistencia interna de la prueba. (Garaigordobil \& Pérez, 2005).

Para esta investigación se aplicará la versión de autoevaluación, donde cada niño o niña debe reflexionar en qué medida puede aplicarse esas frases a sí mismo (Ver anexo 6). Se estableció contacto con la autora del instrumento para solicitar su permiso para la utilización del instrumento (Ver anexo 7). 


\subsubsection{Cuestionario de Emociones Positivas}

El Cuestionario Infantil de Emociones Positivas (CIEP), fue diseñado y validado por Laura Oros con la finalidad de medir la experiencia emocional positiva en niños de 8 a 12 años de edad. Inicialmente, se conformó un cuestionario con 40 enunciados para operacionalizar la alegría, la serenidad, la simpatía, la satisfacción personal y la gratitud.

El Alpha de Cronbach en la prueba completa indico un índice del 0.90 por lo que se considera confiable mostrando correlación entra cada una de las preguntas (Bojórquez, López, Hernández, \& Jimenez, 2013). En cuanto a la validez de la prueba, teniendo en cuenta que el instrumento fue diseñado y validado por Laura Oros en Argentina, se analizó la claridad de cada uno de los ítems que conforman el cuestionario y la semejanza en el habla hispana para los niños que iban a ser evaluados en este estudio, por lo cual no se consideró necesario realizar una adaptación cultural del Cuestionario Infantil de Emociones Positivas, siendo éste adecuado para las personas a las que se les aplicó. Se tiene en cuenta, además, que el Cuestionario Infantil de Emociones positivas se aplicó evitando improvisaciones, se usó un espacio adecuado libre de ruido o perturbaciones, cómodo y favorable para el desarrollo de la aplicación (Ver anexo 8). La autorización de la autora se encuentra en el anexo 9.

\subsection{Operacionalización de las variables y preguntas orientadoras}

- Preguntas orientadoras

¿Es efectivo el modelo de atención psicosocial basado en el juego, para la promoción de la resiliencia en población infantil afectada por el conflicto armado en una zona de Colombia? 
- Operacionalización de variables (ver Tabla 4).

Tabla 4. Operacionalización de variables

\begin{tabular}{|c|c|c|c|c|}
\hline $\begin{array}{l}\text { TIPO DE } \\
\text { INVESTIGACION }\end{array}$ & CATEGORÍA & VARIABLES & DIMENSIONES & CONSTRUCTO \\
\hline \multirow{33}{*}{$\begin{array}{c}\text { CUANTITATIVA } \\
\text { CON APORTES } \\
\text { CUALITATIVOS } \\
\text { - TIPO } \\
\text { CORRELACION } \\
\text { AL CON } \\
\text { VALOR } \\
\text { DESCRIPTIVO } \\
\text { - DISEÑO } \\
\text { CUASI } \\
\text { EXPERIMENTA } \\
\text { L } \\
\text { - CON GRUPO } \\
\text { CONTROL PRE } \\
\text { Y POS TEST }\end{array}$} & \multirow{33}{*}{$\begin{array}{c}\text { Resiliencia } \\
\text { en los } \\
\text { niños y } \\
\text { niñas } \\
\text { víctimas } \\
\text { del } \\
\text { conflicto } \\
\text { armado }\end{array}$} & \multirow{19}{*}{$\begin{array}{c}\text { Fuentes } \\
\text { ontosistémi } \\
\text { cas }\end{array}$} & \multirow{8}{*}{$\begin{array}{c}\text { Características } \\
\text { de los niños y } \\
\text { niñas }\end{array}$} & A5 - Edad niño/a \\
\hline & & & & A7 - Nacimiento niño/a \\
\hline & & & & A11 - Género niño/a \\
\hline & & & & Calculo Edad \\
\hline & & & & A9 - Lugar nacimiento niño/a \\
\hline & & & & A12 - Niño/a victima conflicto armado \\
\hline & & & & A13 - Discapacidad \\
\hline & & & & A14 - Etnia \\
\hline & & & \multirow{5}{*}{$\begin{array}{c}\text { Fortalezas } \\
\text { intrapsíquicas }\end{array}$} & Impulsividad \\
\hline & & & & Autoestima \\
\hline & & & & Pensamiento crítico \\
\hline & & & & Creatividad \\
\hline & & & & Afectividad \\
\hline & & & $\begin{array}{l}\text { Habilidades para } \\
\text { la acción }\end{array}$ & Asertividad \\
\hline & & & $\begin{array}{l}\text { Respuestas } \\
\text { amortiguadoras }\end{array}$ & Adaptabilidad \\
\hline & & & \multirow{4}{*}{$\begin{array}{c}\text { Emociones } \\
\text { positivas }\end{array}$} & Alegría y Gratitud \\
\hline & & & & Serenidad \\
\hline & & & & Simpatía \\
\hline & & & & Satisfacción personal \\
\hline & & \multirow{14}{*}{$\begin{array}{c}\text { Fuentes } \\
\text { microsistém } \\
\text { icas }\end{array}$} & \multirow[t]{7}{*}{ Estilo parental } & A3 - Parentesco \\
\hline & & & & Aceptación \\
\hline & & & & Control Aceptado \\
\hline & & & & Control estricto \\
\hline & & & & Control Patológico \\
\hline & & & & Autonomía Extrema \\
\hline & & & & Control parental laxo \\
\hline & & & Vínculo afectivo & Afectividad \\
\hline & & & \multirow[t]{6}{*}{$\begin{array}{l}\text { Funcionalidad } \\
\text { familiar }\end{array}$} & $\begin{array}{l}\text { C4 - Horas a la semana } \\
\text { acompañamiento académico }\end{array}$ \\
\hline & & & & $\begin{array}{l}\text { C5 - Horas a la semana actividades } \\
\text { ludo recreativas }\end{array}$ \\
\hline & & & & $\begin{array}{l}\text { C6 - Actividades realizadas durante la } \\
\text { última semana }\end{array}$ \\
\hline & & & & A3 - Parentesco \\
\hline & & & & A4 - Edad adulto \\
\hline & & & & A10 - Género adulto \\
\hline
\end{tabular}




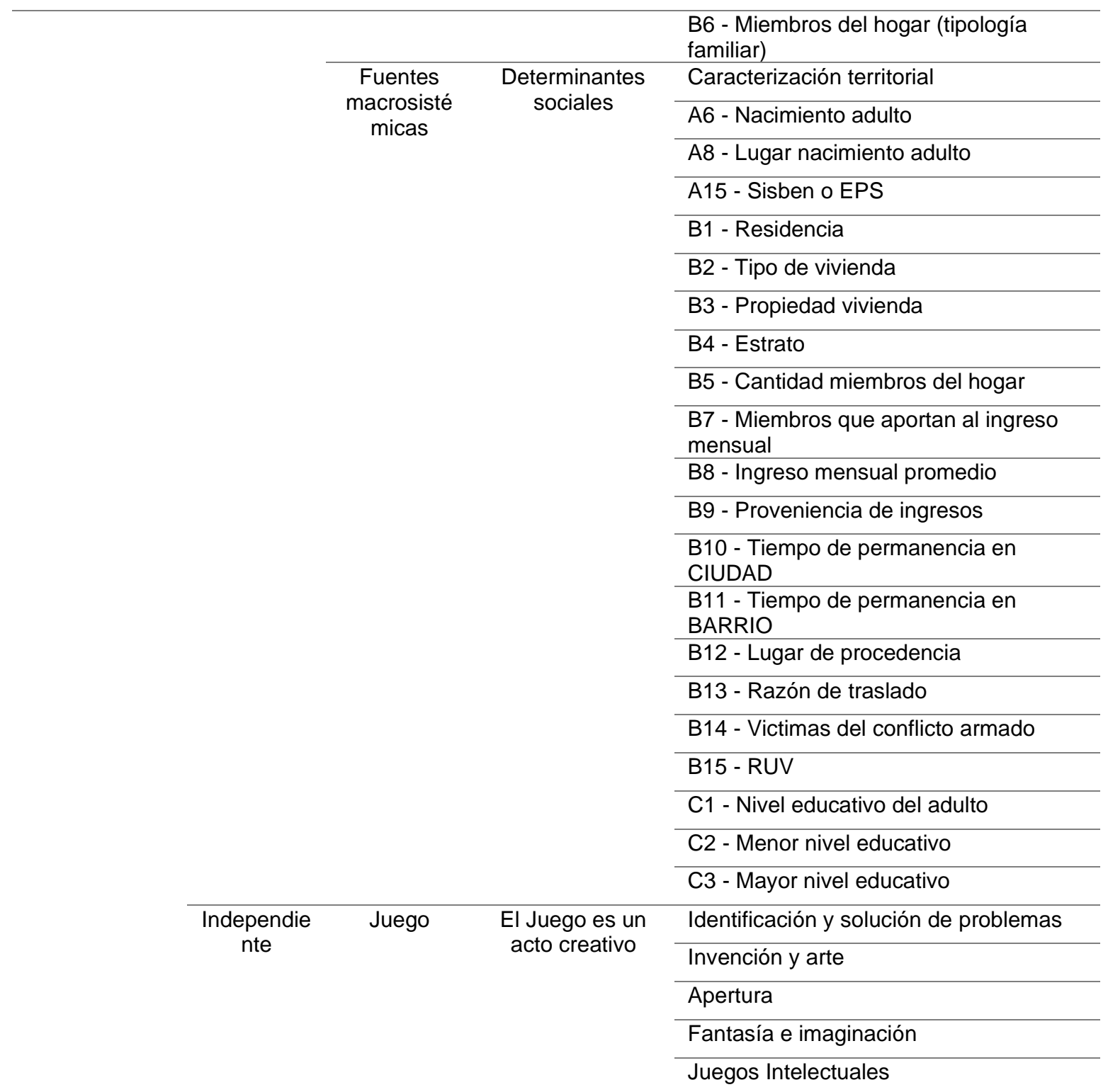

Fuente: Elaboración Propia.

\subsection{Proceso de recolección de Información}

La información fue recolectada por personal capacitado por el investigador principal quienes realizaron la recolección durante los tres meses donde al inicio se realizó la recolección de información y al finalizar el proceso de intervención se aplicó nuevamente los diferentes cuestionarios. 


\section{- Manual del supervisor}

La investigadora y la auxiliar de investigación fueron las profesionales encargadas de coordinar la recolección de la información en el colegio CEDID, y desarrollaron las siguientes actividades:

- Entrega y seguimiento de los consentimientos informados y disentimientos a los estudiantes.

- Capacitar a los encuestadores sobre la aplicación de la encuesta y el trabajo de campo

- Entregar la carga de trabajo diariamente.

- Mantener comunicación permanente con los encuestadores.

- Recibir diariamente las encuestas aplicadas y realizar todo el proceso de revisión-

\section{- Manual del encuestador}

El encuestador (a) fue la persona encargada de aplicar el cuestionario a los estudiantes; las actividades realizadas son las siguientes:

- Asistir a la capacitación de la encuesta

- Recibir retroalimentación

- Cumplir con el plan de trabajo establecido

- Recibir la carga de trabajo diariamente

- Recibir el material de cada día como: consentimiento informado, cuestionarios impresos, lapiceros, listados de asistencia, reglas, etc.

- Proporcionar la información del proyecto al inicio de la recolección, leer el consentimiento informado así cada estudiante llevaría a su casa el consentimiento y disentimiento para decidir con los padres su participación o no y durante la aplicación 0 aclarar dudas de ser necesario. 
- Informar al supervisor cualquier dificultad presentada en campo y entregar al supervisor las encuestas realizadas completas e incompletas diariamente.

El proceso de recolección consistió en solicitar los permisos pertinentes ante la institución educativa, según el rango de edad de aplicación de los instrumentos de medición a los estudiantes, acto para participar del proceso únicamente eran los estudiantes del grado quinto y cuarto del colegio CEDID, a partir de estas condiciones se establece que la población de estudio sean estos dos grados, se solicita al colegio los listados de estudiantes de ambos grados. Con la ayuda del supervisor y los encuestadores se realiza la entrega y envió de un sobre sellado con el consentimiento y disentimiento a los padres de familia quienes aceptaban la participación de su hijo en la investigación, luego los estudiante hacían la devolución de los documentos en un transcurso de 3 días hábiles y se procedía a programar la recolección de información, la cual se realizó a las aulas de clase con cuestionarios que fueron diligenciados a papel y lápiz por cada uno de los estudiantes. Este proceso se realizó tanto al inicio (primer mes), como al final (mes tres) del proceso de recolección.

\subsection{Plan de análisis}

Para el análisis univariado se calcularon los estadísticos descriptivos de las variables sociodemográficas, donde se representó la información en gráficos de pastel, barras y tablas con frecuencias absolutas y relativas, se realizó un análisis de correspondencias múltiples con el fin de conocer las asociaciones de las variables principales con otras variables del estudio, las distancias entre las distintas categorías permite visualizar la relación entre las variables cualitativas (nominales u ordinales).

En el análisis estadístico, se comprobó la normalidad de los puntajes de cada una de las dimensiones presentadas en cada instrumento como son: el JJ63, emociones positivas, estilos parentales y personalidad creadora, tanto para el pre-test como el post-test se aplicó prueba de Shapiro Wilk, donde si las dimensiones que presentaban una distribución normal se les construyeron intervalos de confianza del $95 \%$ para la diferencia de promedios en muestras relacionadas y en los casos donde no se cumplía normalidad se comparaban las muestras relacionadas con el estadístico de Wilcoxon, este análisis se realizó para comparar el pre test de los estudiantes de cuarto grado con su post test y de igual forma para comparar el Pretest y post test del grado quinto. 
Para analizar si existen cambios entre el post test de los estudiantes de cuarto y quinto grado se aplicó el estadístico U Mann Whitney que es una prueba no paramétrica aplicada a dos muestras independientes. Para ver si existe asociación entre la variable dependiente de interés y las demás variables cualitativas se realizó la asociación por medio de la prueba chi-cuadrado, aplicando la prueba de Pearson para variables con más de 2 categorías y sin tener presente otro tipo de correcciones y para las variables dicotómicas se aplica la prueba de chi-cuadrado de Fisher.

\subsection{Hipótesis}

- Cuando los niños o las niñas víctimas del conflicto armado participan en una propuesta de atención psicosocial basada en juego, aumentan su resiliencia en mayor medida con respecto a otras propuestas de intervención.

- El juego promueve la creatividad en los niños y niñas víctimas del conflicto armado colombiano.

- Cuando se promueven las emociones positivas en los niños y niñas, aumenta su capacidad resiliente.

- El estilo parental del padre o la madre del niño o la niña determina la capacidad de resiliencia

\subsection{Identificación y control de potenciales sesgos}

\section{- Sesgos de selección}

La selección de los estudiantes se realizó de manera intencionada. Sin embargo, el estudio presenta un sesgo de selección que se salió del control de la investigación, al ser seleccionados los estudiantes no se contó con que cada uno de los grupos fueran homogéneos al tener el mismo número de estudiantes y tener poblaciones similares a la hora de realizar comparaciones. 


\section{- Sesgos de información}

Debido a los instrumentos: Para garantizar la mayor precisión y calidad en la información se usaron unos instrumentos de medición para identificar resiliencia infantil. Se realizó una prueba piloto para verificar la medición adecuada en las variables, la redacción de las preguntas y términos usados, tiempo promedio de respuesta para identificad los ítems que generaban dificultad, para lo cual se entrenó al personal encuestador en la lectura guiada de estas preguntas.

Debido al observado: Se garantizó el anonimato en la participación y se tuvo en cuenta que la comprensión lectora de los estudiantes más pequeños no era muy adecuada.

Debido al observador: Para controlar los errores generados por el observador, se realizó durante una semana la estandarización del personal y capacitación relacionada con la captación de los datos y la utilización de estrategias de la lectura guiada del cuestionario.

\subsection{Manejo de los datos en forma detallada}

Se procedió a observar en la base de datos y en los cuestionarios físicos los registros que no fueron diligenciados en su totalidad, estos registros fueron identificados fácilmente porque no tenían el total de registros o podrían aparecer en blanco. Dentro de los criterios de exclusión las encuestas que no están diligenciadas en su totalidad no son tenidas en cuenta, por tal razón las encuestas que tuvieron en su registro valores en blanco, fueron eliminadas de la base de datos. Dentro de los criterios de depuración de la base de datos se tuvieron en cuenta los siguientes aspectos:

- Eliminar encuestas no finalizadas, teniendo en cuenta que era un criterio de exclusión en la investigación, este proceso se realizó por filtros a cada una de las variables y los formularios

- Verificar que cada registro coincidiera en cada una de las hojas de cálculo donde se alojó cada uno de los instrumentos utilizados. 


\section{- Recategorización de variables}

Para poder exportar la base de datos al programa estadístico SPSS fue necesario recategorizar algunas variables, presentado la suma de las puntuaciones para el cálculo de las dimensiones de cada cuestionario.

\section{- Cuantificación de puntajes del instrumento}

En Excel se calcularon las puntuaciones totales para cada dimensión de los instrumentos. Para este proceso se realizaron sumatorias, cálculo de promedios y porcentajes acorde a los manuales de cada instrumento. Al final se obtiene la base de datos lista para ser llevada al programa estadístico SPSS, acompañado del diccionario de datos y poder generar los análisis estadísticos definidos en el plan de análisis (Ver anexo 6 de diccionario de variables).

\subsection{Técnicas y programas utilizados}

El procesamiento de la información se realizó en el programa estadístico SPSS versión 22 y el programa Epidat versión 3.1. Los informes se realizaron utilizando las herramientas de Microsoft Office como el Excel, Word y power point.

\subsection{Consideraciones Éticas}

Se solicitó la aprobación del Comité de Ética de la Facultad Nacional de Salud Pública de la Universidad de Antioquia, como Universidad que respalda a la directora de esta tesis, además por estar presente en el mismo contexto donde se desarrolló este proyecto (ver anexo 1). Se buscó el permiso correspondiente de las autoridades de la Fundación Lúdica Desarrollo Humano y del Colegio CEDID Ciudad Bolívar. También se gestionó la firma del consentimiento y asentimiento informado por parte de los/as participantes y sus padres o cuidadores responsables. 
La investigación es considerada de riesgo mínimo que cumple con las normas científicas y administrativas que rigen el desarrollo de la investigación, tal como lo estipula la Resolución 8430 de 1993 en sus artículos 5-22 y 45-46. Se garantiza en la investigación los principios bienestar, seguridad, privacidad, dignidad, protección, y contó con el consentimiento informado del sujeto de investigación. Se garantizó la privacidad como sujetos de investigación, identificándolo solo cuando los resultados lo requieran y se cumpla con el permiso adecuado, solo pueden tener acceso a los resultados individuales el investigador principal.

En toda investigación existe una mínima probabilidad de que el sujeto de investigación sufra algún daño como consecuencia inmediata o tardía del estudio, este estudio garantizó la asistencia necesaria en caso de ser requerida. Es obligación de los investigadores suspender la investigación en el caso que la misma ocasione daños para la salud de los participantes. Se respetaron los principios éticos recogidos en la Declaración de Helsinki y los establecidos por el habeas data.

El manejo y custodia de la investigación estuvo a cargo del personal experto, garantizando su confidencialidad. En el caso de la custodia, entrega y demás disposiciones de los instrumentos evaluados es obligación del investigador principal garantizar el manejo adecuado de la misma.

Se diligenció el consentimiento informado y el disentimiento, estos documentos contaron con un contenido explicado, de forma completa y clara. Los documentos presentaron información de la justificación, los objetivos, beneficios, metodología y riesgos posibles, se dio a conocer la libertad de retirar su consentimiento en cualquier momento y dejar de participar en el estudio sin que por ello se creen perjuicios para el estudiante. Este estudio no generó gastos o costos que fueran asumidos por los participantes. (Ver anexo 7, consentimiento informado para los padres y asentimiento informado para los menores de 18 años). 


\section{CAPÍTULO 6. RESULTADOS DE LA APLICACIÓN DEL MODELO DE PROMOCIÓN DE RESILIENCIA DESDE EL JUEGO}




\subsection{Características generales del grupo poblacional}

\subsubsection{Características de los niños y niñas}

Los niños y niñas participantes eran 94 estudiantes de cuarto $(57,4 \%)$ y quinto grado de primaria $(42,6 \%)$ de la institución educativa Colegio CEDID Ciudad Bolívar, sede Tanque Laguna, Bogotá, Colombia (ver Figura 9), durante la segunda mitad del año 2018; donde el 53,2\% de los participantes son hombres y el 46,8\% mujeres (ver Tabla 5), y el promedio de la edad fue de 10 años ( $D E=9,54$ años), la cual fue la más frecuente y coincidió con la mediana.

Tabla 5. Porcentajes de algunas características individuales de los estudiantes de cuarto y quinto de primaria la institución educativa Colegio CEDID Ciudad Bolivar, 2019.

\begin{tabular}{|c|c|c|c|c|}
\hline \multirow{2}{*}{ Características individuales } & \multirow{2}{*}{$\mathrm{n}$} & \multirow{2}{*}{$\%$} & \multicolumn{2}{|c|}{ IC (95 para $\left.p^{*}\right)$} \\
\hline & & & inferior & Superior \\
\hline \multicolumn{5}{|l|}{ Sexo } \\
\hline Masculino & 50 & 53,2 & 43,1 & 63,3 \\
\hline Femenino & 44 & 46,8 & 36,7 & 56,9 \\
\hline \multicolumn{5}{|l|}{ Edad } \\
\hline $9-10$ & 40 & 42,6 & 32,6 & 52,5 \\
\hline $11-12$ & 28 & 29,8 & 20,5 & 39,0 \\
\hline $13-14$ & 3 & 3,2 & $-0,4$ & 6,7 \\
\hline Sin información & 23 & 24,5 & 15,8 & 33,2 \\
\hline \multicolumn{5}{|l|}{ Estrato de la vivienda } \\
\hline Uno & 61 & 64,9 & 55,2 & 74,5 \\
\hline Dos & 7 & 7,4 & 2,1 & 12,8 \\
\hline Sin información & 26 & 27,7 & 18,6 & 36,7 \\
\hline \multicolumn{5}{|l|}{ Víctima del conflicto armado } \\
\hline $\mathrm{Si}$ & 3 & 3,2 & $-0,4$ & 6,7 \\
\hline No & 68 & 72,3 & 63,3 & 81,4 \\
\hline Sin información & 23 & 24,5 & 15,8 & 33,2 \\
\hline \multicolumn{5}{|c|}{ Discapacidad, limitación o capacidad diferente: } \\
\hline Si & 1 & 1,1 & $-1,0$ & 3,1 \\
\hline No & 70 & 74,5 & 65,7 & 83,3 \\
\hline Sin información & 23 & 24,5 & 15,8 & 33,2 \\
\hline \multicolumn{5}{|l|}{ Lugar de nacimiento } \\
\hline Bogotá & 57 & 60,6 & 50,7 & 70,5 \\
\hline Otro & 7 & 7,5 & 2,2 & 12,8 \\
\hline Sin información & 30 & 31,9 & 22,5 & 41,3 \\
\hline
\end{tabular}

\footnotetext{
*Intervalo de confianza binomial exacto
} Fuente: Elaboración Propia. 


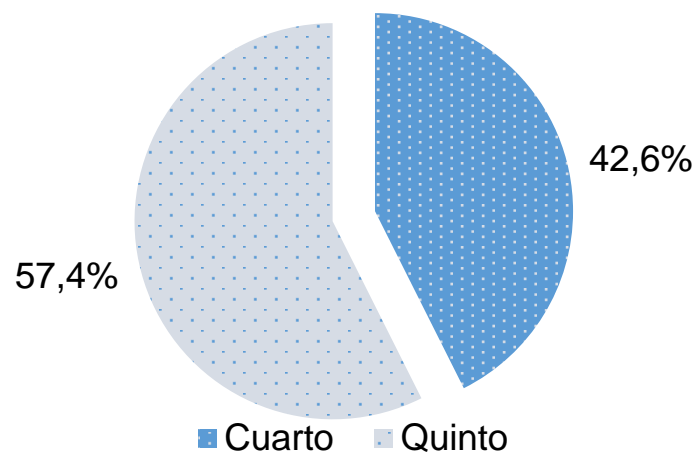

Figura 8. Grado en curso de los estudiantes del Colegio CEDID Ciudad Bolívar 2019.

Fuente: Elaboración Propia.

\subsubsection{Características de las familias}

El 50,0\% de los estudiantes de 4 y 5 de primaria de la institución educativa pertenecen a familias nucleares, definidas como la familia conviviente formada por los miembros de un único núcleo familiar, el grupo formado por los padres y sus hijos. Por otro lado, el 14,9\% de los estudiantes pertenecen a familias monoparentales formadas por un único progenitor con uno o varios hijos a cargo. (Ver Figura 10).

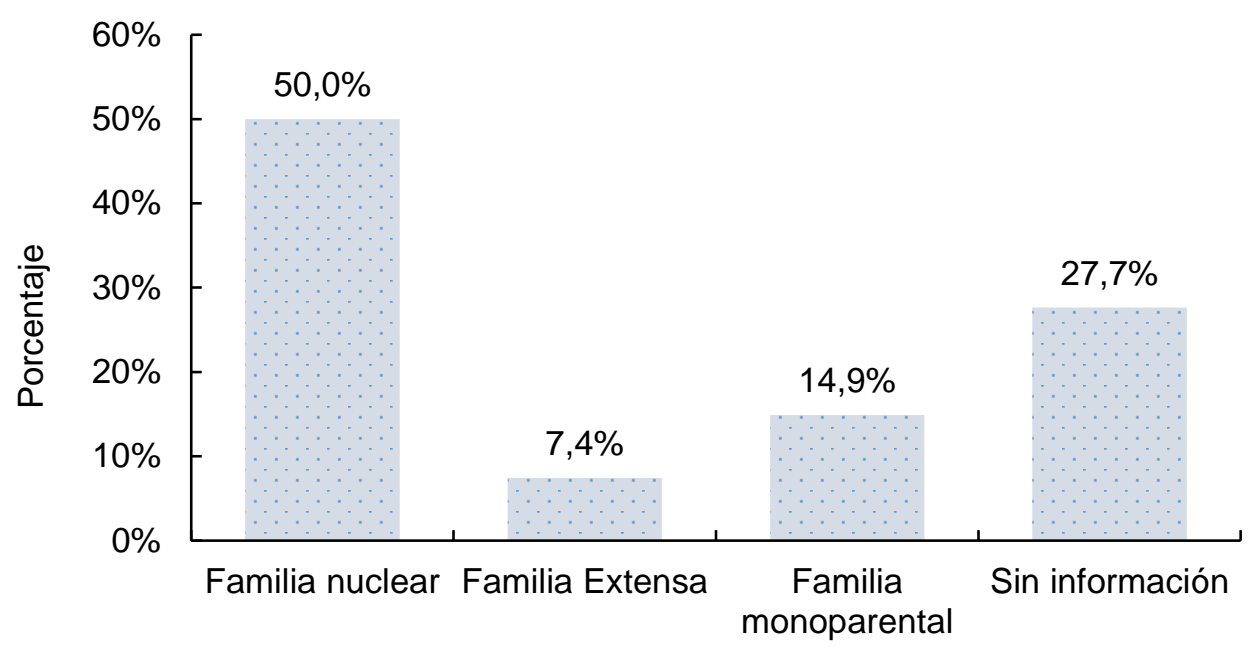

Tipo de familia

Figura 9. Tipo de familia de los estudiantes de cuarto y quinto de primaria de la institución educativa Colegio CEDID Ciudad Bolívar, 2019.

Fuente: Elaboración Propia. 
El ingreso promedio de las familias de los estudiantes se encuentra entre $\$ 350.001$ y $\$ 1.000 .000$ de pesos colombianos (entre 97 y 277 euros) mensual, como indica la jError! No se e ncuentra el origen de la referencia.1; el 56,4 pagan arriendo (ver Tabla 6).

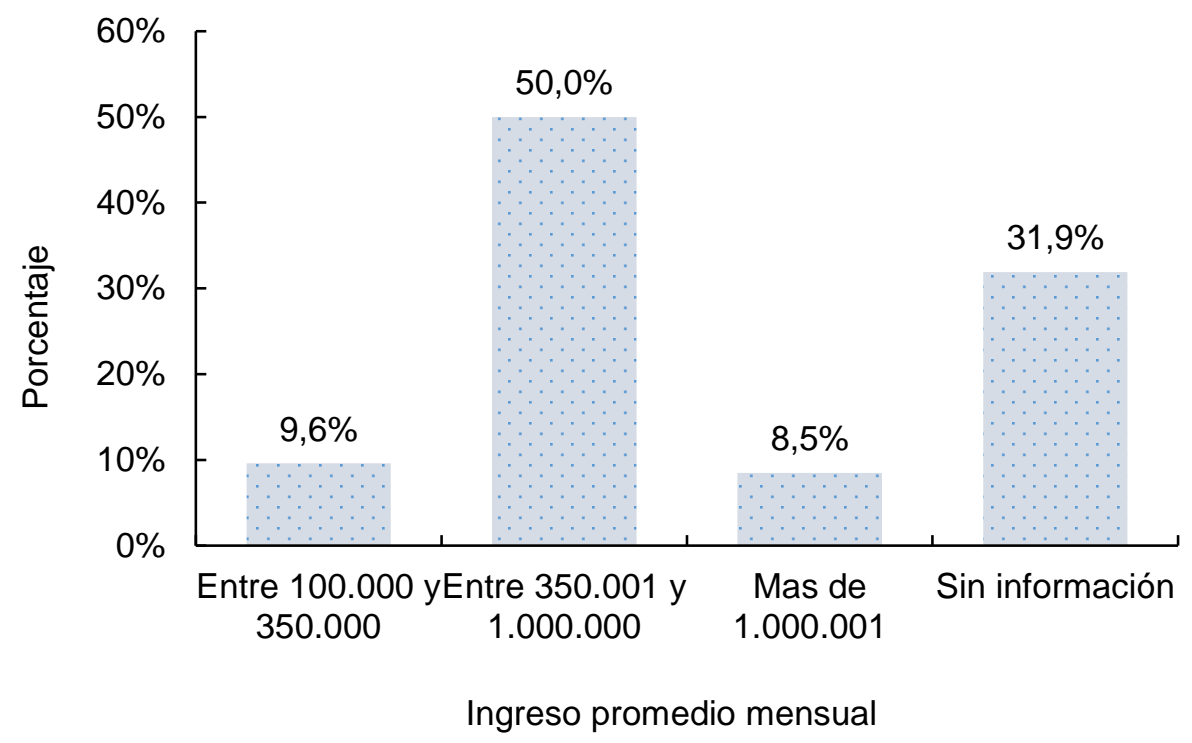

Figura 10. Ingreso mensual promedio del hogar de los estudiantes cuarto y quinto de primaria la institución educativa Colegio CEDID Ciudad Bolívar, 2019.

Fuente: Elaboración Propia.

El $67 \%$ de los adultos que diligenciaron la encuesta son mamás, mientras el $24,5 \%$ (24) de los adultos no se sabe que vinculo tiene con el estudiante (ver Figura 14). 


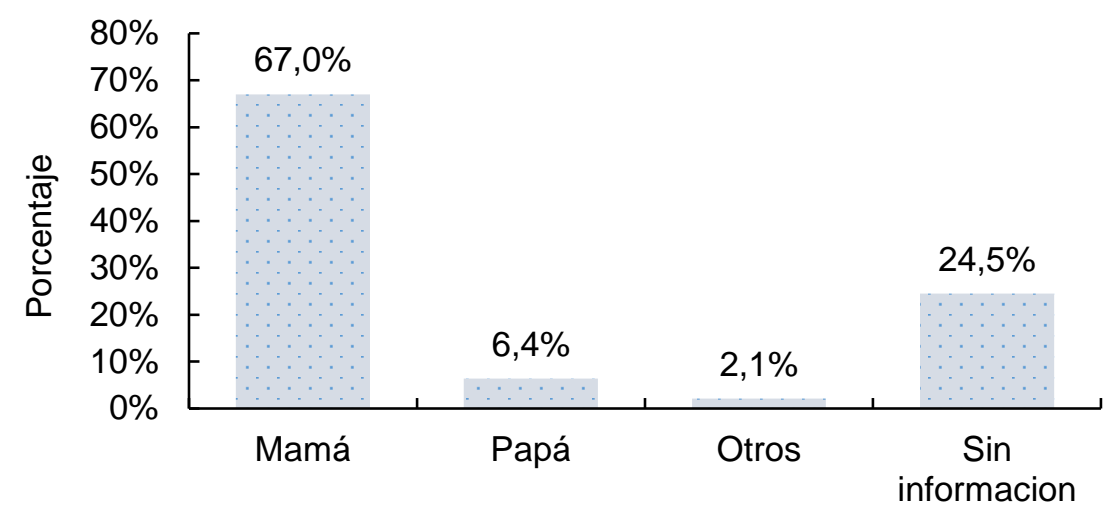

Parentesco

Figura 11. Parentesco de quien diligencia la encuesta de los estudiantes del grado cuarto y quinto del Colegio CEDID Ciudad Bolívar 2019.

Fuente: Elaboración Propia.

El 38,3\% de los adultos nacieron en Bogotá, el $36,2 \%$ en otros departamentos como lo son Magdalena, Antioquia, Bolívar, Tolima y Santander (ver Figura 15).

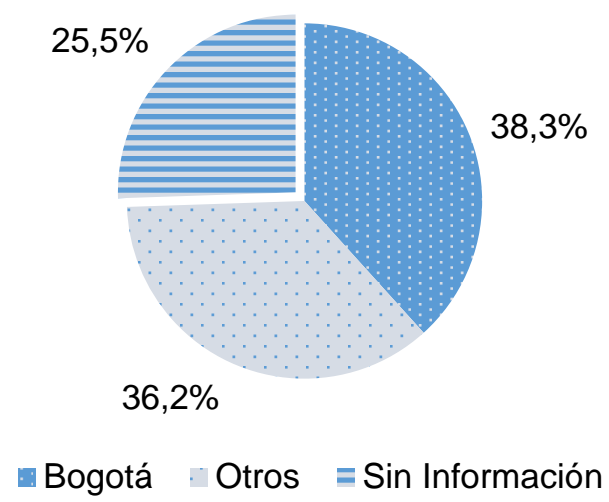

Figura 12. Lugar de nacimiento del adulto que diligencia la encuesta de los estudiantes del Colegio CEDID Ciudad Bolívar 2019.

Fuente: Elaboración Propia.

En cuanto al número de horas que le dedica el padre al acompañamiento y realización de tareas del niño o de la niña destacar que el $37,2 \%$ lo hace de 3 a 6 horas semanales, y que el $27,7 \%$ le dedica al estudiante menos de 3 horas a la semana a las actividades lúdicas y recreativas (como juego y/o deportes), como se evidencia en la Figura 14 a continuación. 


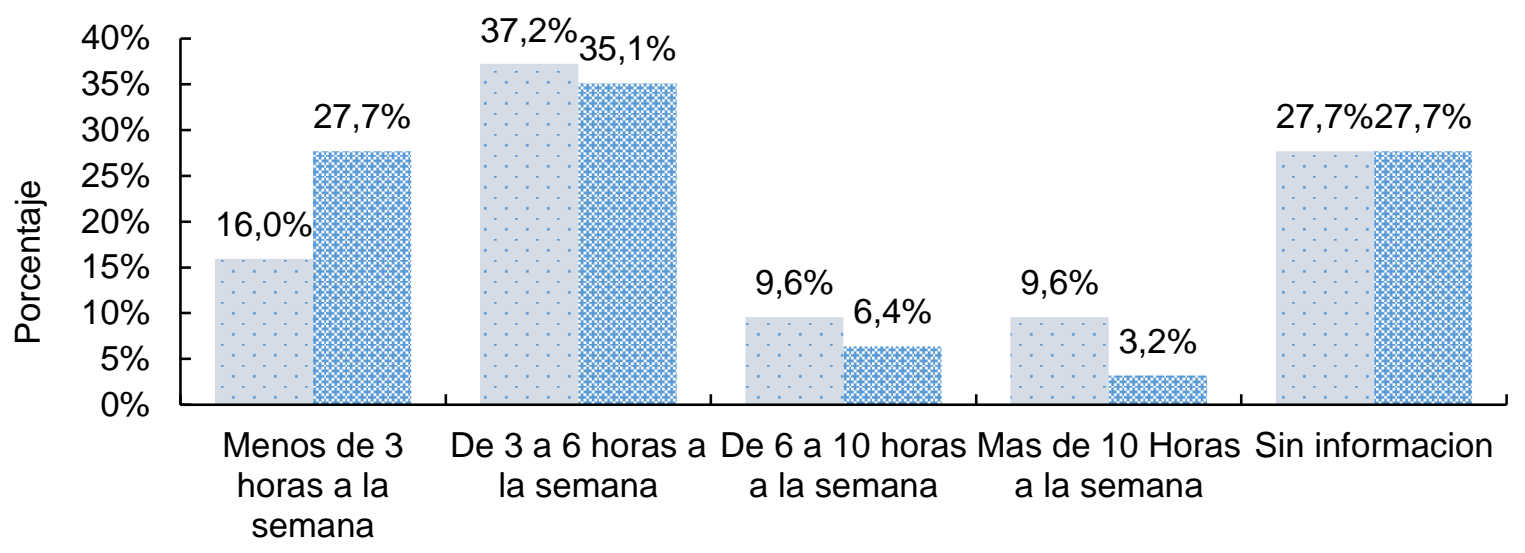

Horas a la semana que usted dedica al acompañamiento y realización de tareas del niño o de la niña

Horas a la semana que usted dedica a actividades lúdicas y recreativas (como juegos y/o deportes) junto al niño o a la niña

Figura 13. Número de horas dedicadas por el adulto a los estudiantes del Colegio CEDID Ciudad Bolívar 2019. Fuente: Elaboración Propia.

En cuanto a las actividades que realizó durante la última semana con el niño o la niña, el $50,0 \%$ de los padres manifestó que realizaron labores académicas (ver Figura 15).

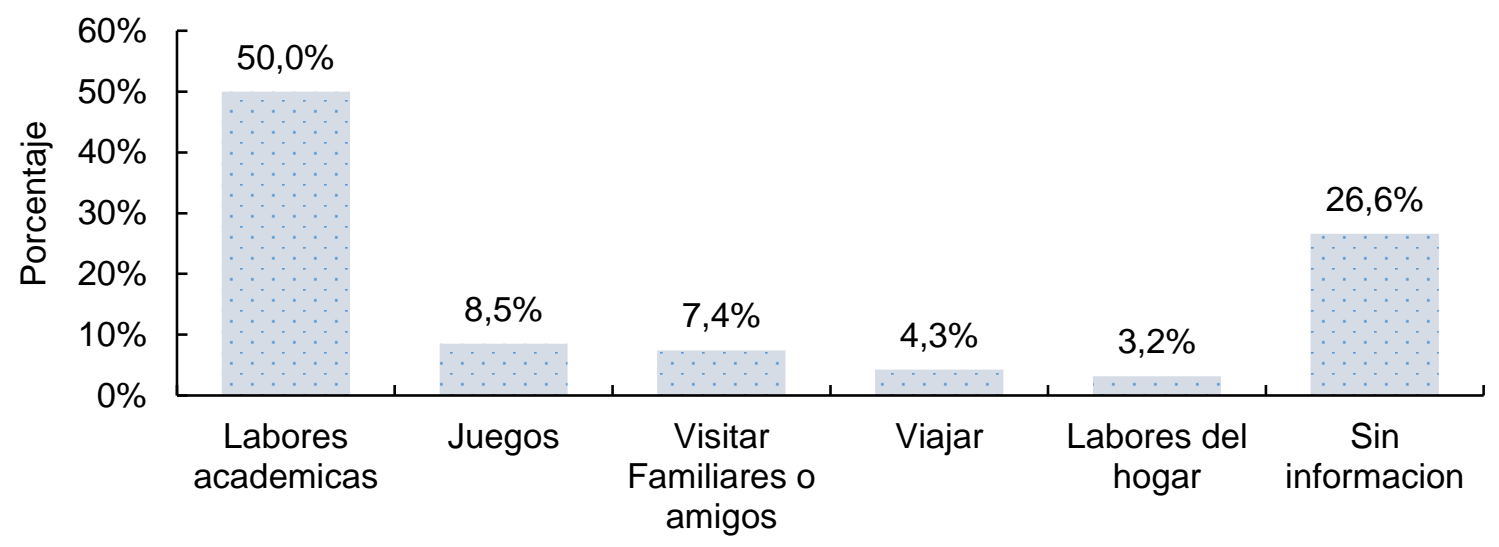

Actividades que usted realizó durante la última semana con el niño o la niña

Figura 14. Actividades que realizó el adulto durante la última semana con el niño o la niña del Colegio CEDID Ciudad Bolívar 2019. Fuente: Elaboración Propia. 


\subsubsection{Determinantes sociales}

Los niños que participaron en este estudio pertenecen en un 64,9\% al estrato uno; el 3,2\% refirió ser víctima del conflicto armado; el 60,6\% nacieron en Bogotá y el porcentaje restante en otros departamentos como lo son Valle del Cauca, Santander y Cesar.

Tabla 6. Porcentajes de algunas determinantes de los estudiantes de cuarto y quinto de primaria la institución educativa Colegio CEDID Ciudad Bolívar, 2019.

\begin{tabular}{|c|c|c|c|c|}
\hline \multirow{2}{*}{ Determinantes sociales } & \multirow{2}{*}{$\mathrm{n}$} & \multirow{2}{*}{$\%$} & \multicolumn{2}{|c|}{ IC (95 para p*) } \\
\hline & & & inferior & Superior \\
\hline \multicolumn{5}{|l|}{ Estrato de la vivienda } \\
\hline Uno & 61 & 64,9 & 55,2 & 74,5 \\
\hline Dos & 7 & 7,4 & 2,1 & 12,8 \\
\hline Sin información & 26 & 27,7 & 18,6 & 36,7 \\
\hline \multicolumn{5}{|l|}{ Lugar de nacimiento } \\
\hline Bogotá & 57 & 60,6 & 50,7 & 70,5 \\
\hline Otro & 7 & 7,5 & 2,2 & 12,8 \\
\hline Sin información & 30 & 31,9 & 22,5 & 41,3 \\
\hline \multicolumn{5}{|l|}{ Tipo de vivienda } \\
\hline Apartamento & 29 & 30,9 & 21,5 & 40,2 \\
\hline Casa & 38 & 40,4 & 30,5 & 50,3 \\
\hline Inquilinato & 4 & 4,3 & 0,2 & 8,3 \\
\hline Sin información & 23 & 24,5 & 15,8 & 33,2 \\
\hline \multicolumn{5}{|c|}{ La vivienda ocupada por este hogar es } \\
\hline Arriendo & 53 & 56,4 & 46,4 & 66,4 \\
\hline Familiar & 4 & 4,3 & 0,2 & 8,3 \\
\hline Propia & 12 & 12,8 & 6,0 & 19,5 \\
\hline Otra & 1 & 1,1 & $-1,0$ & 3,1 \\
\hline Sin información & 24 & 25,5 & 16,7 & 34,3 \\
\hline
\end{tabular}

* Intervalo de confianza binomial exacto

Fuente: Elaboración Propia.

El 47,9\% de los hogares de los estudiantes son conformados por 4 y 5 miembros, típica familia nuclear, mientras el $16 \%$ es conformado por más de 6 miembros (Figura 16). 


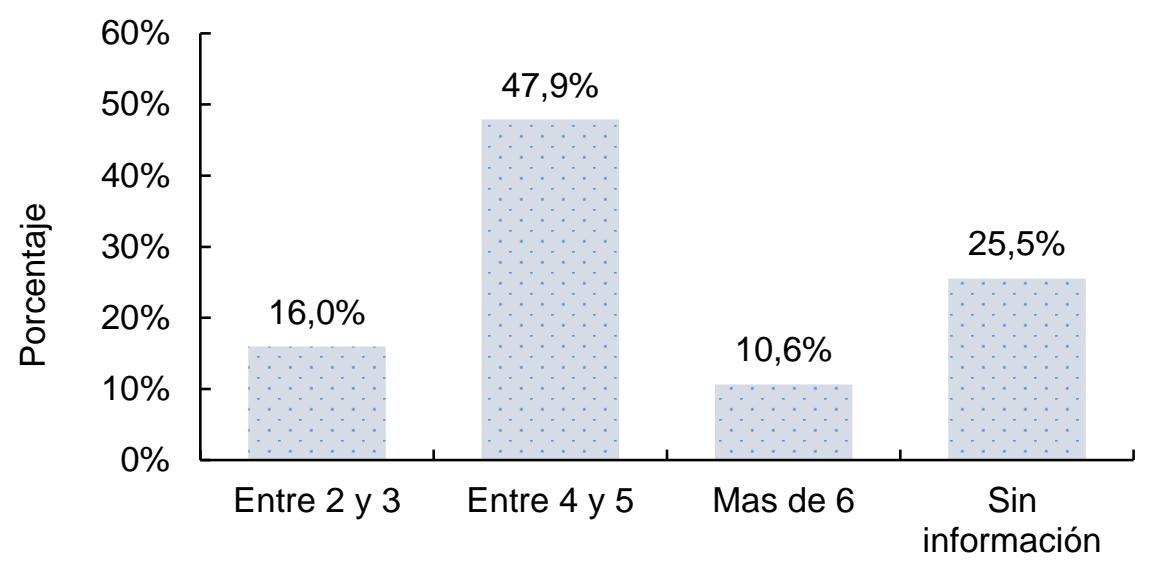

Cantidad de miembros que conforman el hogar

Figura 15. Cantidad de miembros que conforman el hogar de los estudiantes del Colegio CEDID Ciudad Bolívar 2019. Fuente: Elaboración Propia.

Como se evidencia en la Figura 17, dentro del número de personas que aportan al ingreso en el hogar, el $30,9 \%$ refieren que dos y el $20,2 \%$ una persona es la aportante.

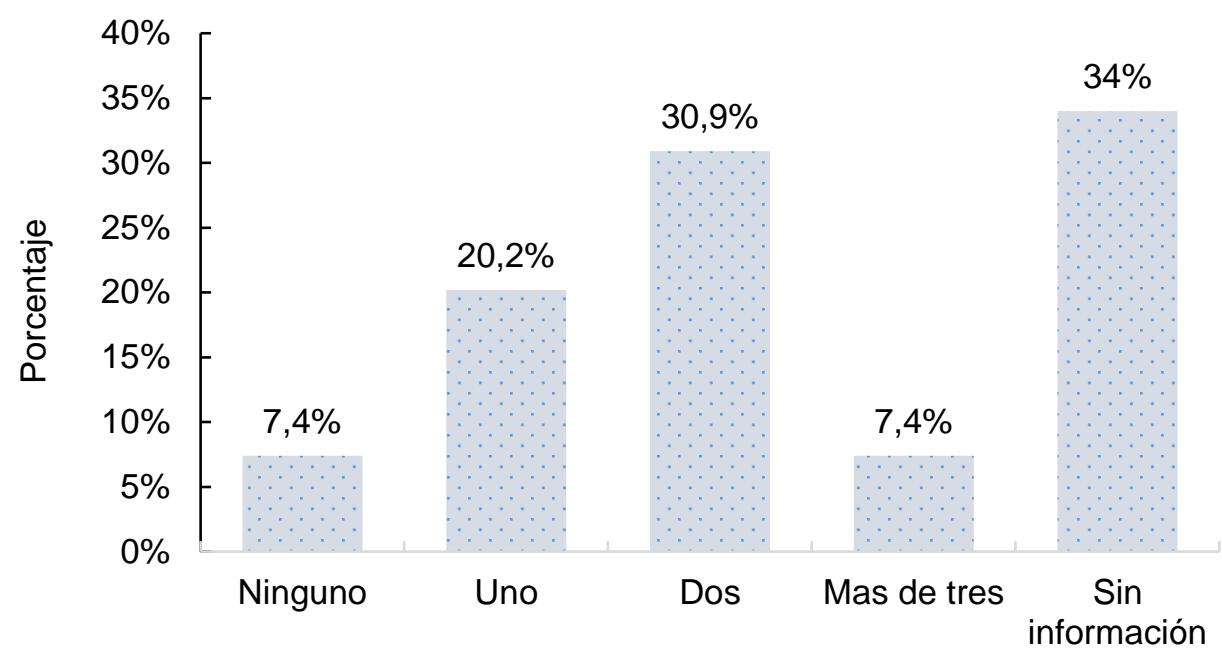

Cuantos aportan al ingreso del hogar

Figura 16. Cuantos aportan al ingreso del hogar de los estudiantes del Colegio CEDID Ciudad Bolívar 2019. Fuente: Elaboración Propia.

Los mayores ingresos provienen del trabajo asalariado e independiente $53,2 \%$ y $16,0 \%$ respectivamente, como lo muestra la Figura 18. 


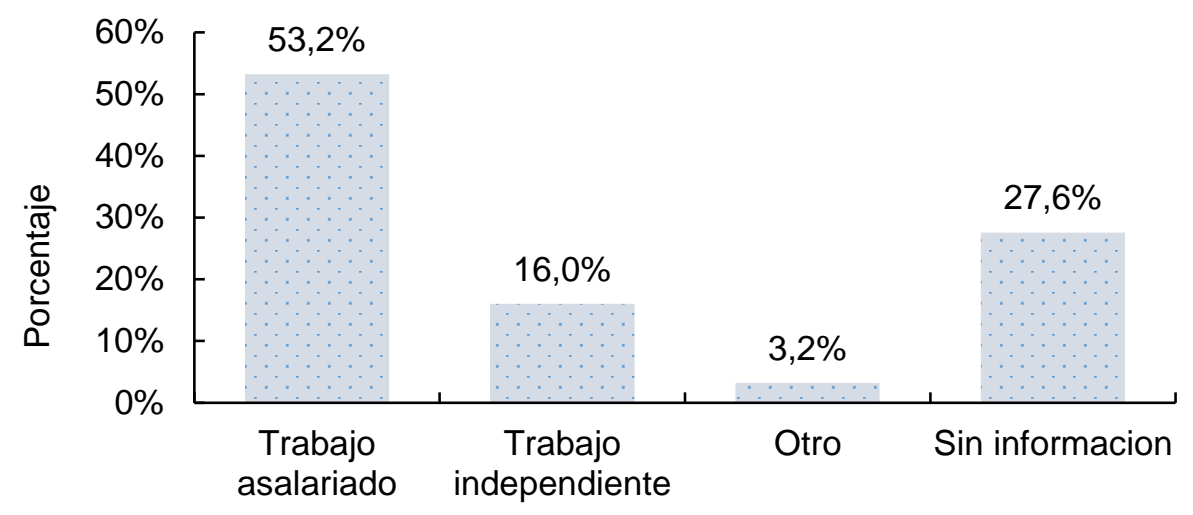

De dónde provienen los ingresos

Figura 17. De dónde provienen los ingresos del hogar de los estudiantes del Colegio CEDID Ciudad Bolívar 2019. Fuente: Elaboración Propia.

El tiempo que lleva el hogar del estudiante viviendo tanto en la ciudad como en el barrio, es más de 5 años para el 64,9\% en la ciudad, y 56,4\% en el Barrio, como se observa en la Figura 19. Entre los hogares que llevan menos de 4 años viviendo, manifestaron que la principal razón de traslado de la familia a su lugar de residencia actual es por trabajo y adquisición de vivienda.

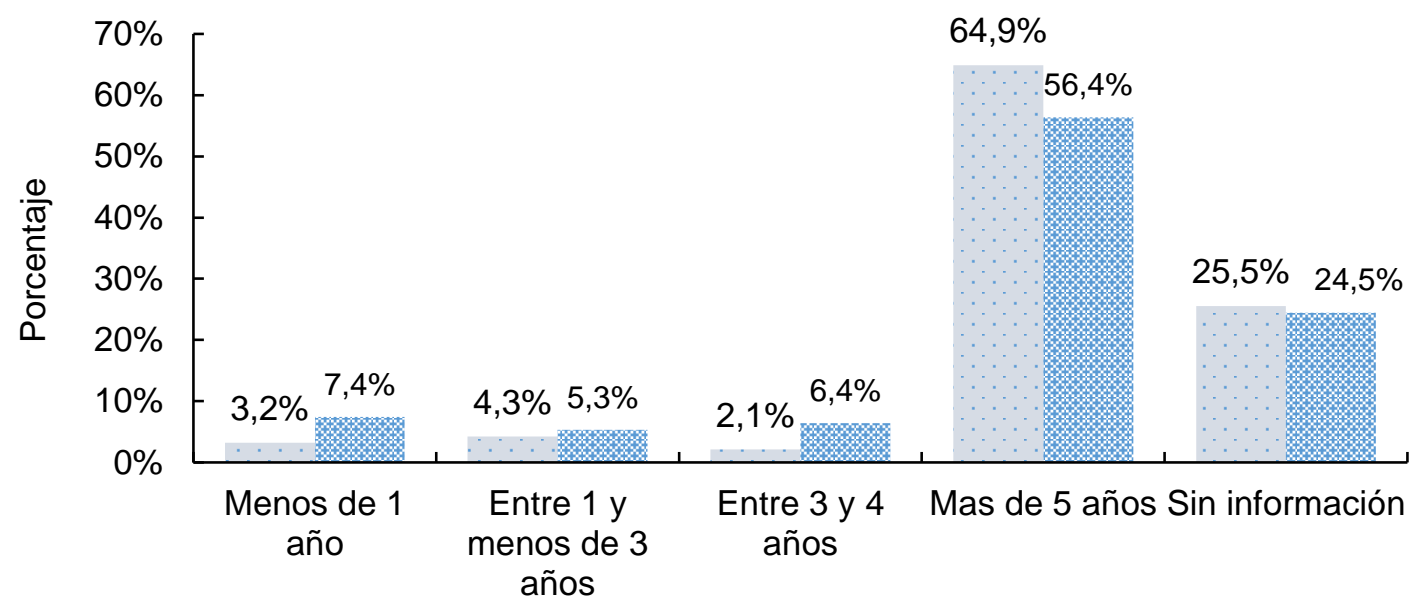

- Tiempo que lleva este hogar viviendo en esta ciudad

婳Tiempo que lleva este hogar viviendo en este barrio

Figura 18. Tiempo que lleva el hogar viviendo en la Ciudad y el barrio de los estudiantes del Colegio CEDID Ciudad Bolívar 2019.Fuente: Elaboración Propia. 
El menor nivel educativo aprobado por algún miembro del hogar que conforma el grupo familiar es primaria el mayor es secundaria $34 \%$ y $35,1 \%$ respectivamente, como se observa en la ¡Error! No s e encuentra el origen de la referencia. 0 .

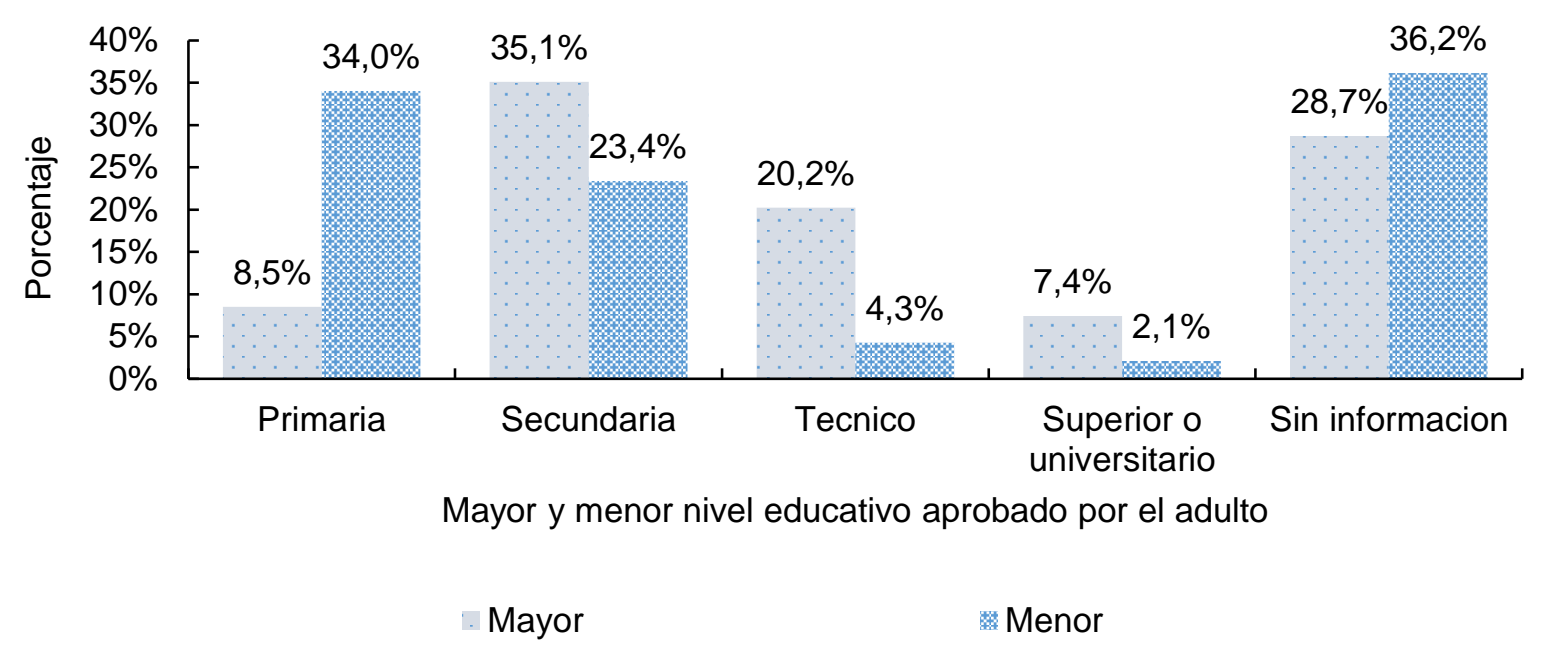

Figura 19. Mayor y menor nivel educativo aprobado por algún miembro del hogar de los estudiantes del Colegio CEDID Ciudad Bolívar 2019. Fuente: Elaboración Propia.

\subsection{Análisis de correspondencias múltiples entre las diferentes} fuentes o constructos de resiliencia infantil

Con el propósito de construir un perfil de los estudiantes resilientes, se realizó un análisis de correspondencias múltiples (ACM) que permita identificar las relaciones entre las categorías 0 modalidades de las variables identificadas como factores relacionados con cada una de las dimensiones o variables de estudio y a través de la observación de las cercanías o lejanías de los puntos de las diferentes modalidades se establecen las relaciones de semejanza existentes entre las modalidades de respuesta; para visualizar la asociación entre los distintos niveles de las variables se presentarán mapas perceptuales.

Al analizar el grado de escolaridad y el acompañamiento de la familia en las actividades lúdicas recreativas de los estudiantes se observa (ver Figura 21): 
- En el perfil uno: estudiantes de cuarto grado, donde el acompañamiento de los padres a la realización de las tareas es de 3 a 6 horas y las actividades lúdicas recreativas de 6 a 10 horas, donde la actividad que realizaron en la última semana fue básicamente labores académicas y en algunas ocasiones juegos;

- Perfil dos: estudiantes de quinto grado, donde el acompañamiento de los padres a la realización de las tareas es menos de 3 horas al igual que en las actividades lúdicas recreativas, donde la actividad que realizaron en la última semana fue viajar y visitar familiares.

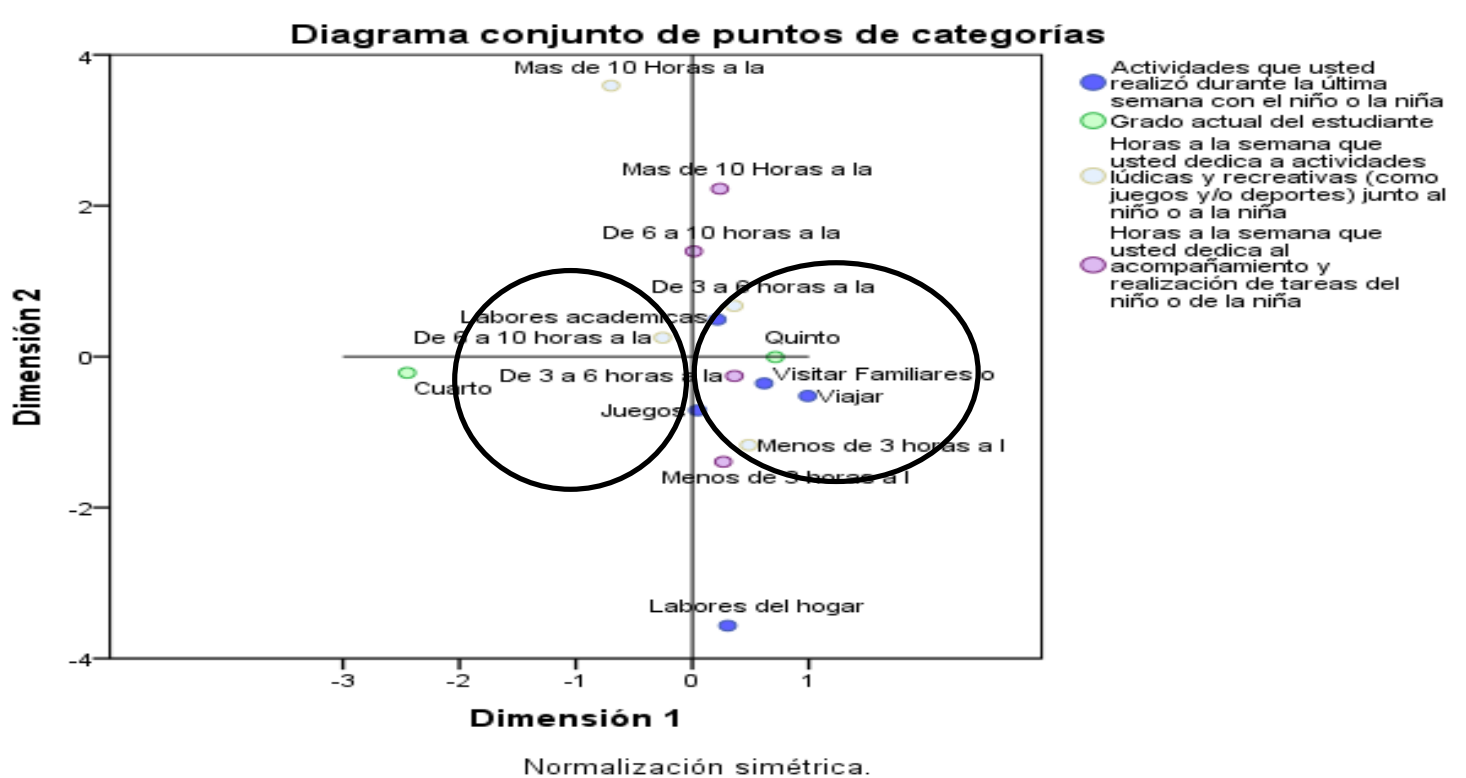

Figura 20. Conjunto de puntos de categoría de grado y acompañamiento de la familia en las actividades lúdicos recreativas de los estudiantes del Colegio CEDID Ciudad Bolívar 2019. Fuente: Elaboración Propia.

Al analizar el grado y las fortalezas intrapsíquicas después de la intervención, se encontró (ver Figura 22):

- Perfil uno: estudiantes del grado cuarto con un pensamiento poco crítico, afectivo ocasional, impulsivo y moderadamente impulsivos,

- Perfil dos: estudiantes del grado quinto con una autoestima y pensamiento moderado y no impulsivo, se puede asimilar a un grado un poco mayor de criticidad a medida que avanza la edad. 


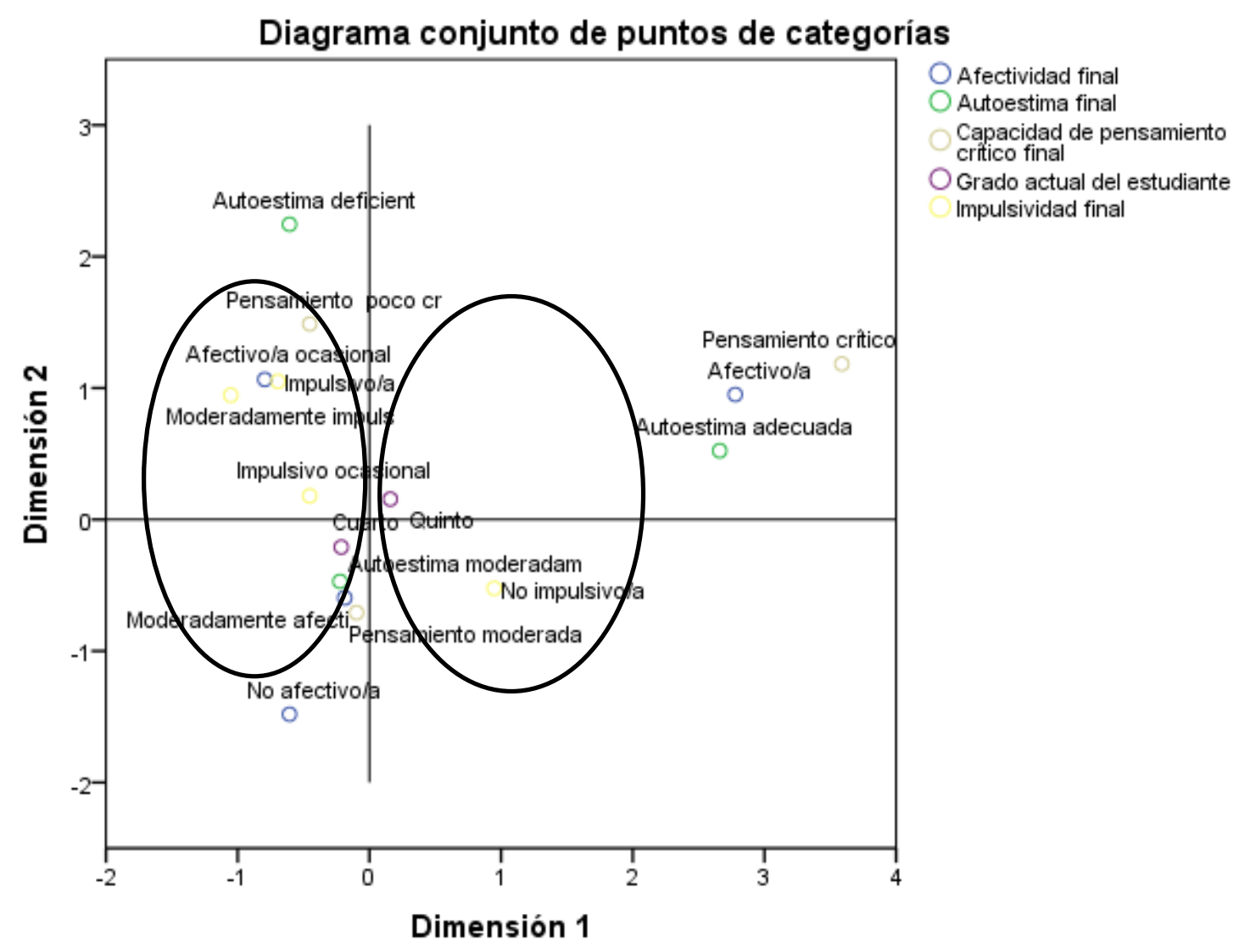

Normalización simétrica.

Figura 21. Conjunto de puntos de categoría de grado y dimensiones de resiliencia después de la intervención de los estudiantes del Colegio CEDID Ciudad Bolívar 2019. Fuente: Elaboración Propia.

Al analizar el grado escolar y las dimensiones funcionalidad familiar, autoestima, asertividad y adaptabilidad a situaciones nuevas, después de la intervención se encontró (ver Figura 23):

- Perfil uno: estudiantes del grado cuarto con una autoestima deficiente, asertivo esporádico, tipo de familia funcional, con una adaptabilidad moderada

- Perfil dos: estudiantes del grado quinto moderadamente asertivos con una autoestima y adaptabilidad adecuada. 


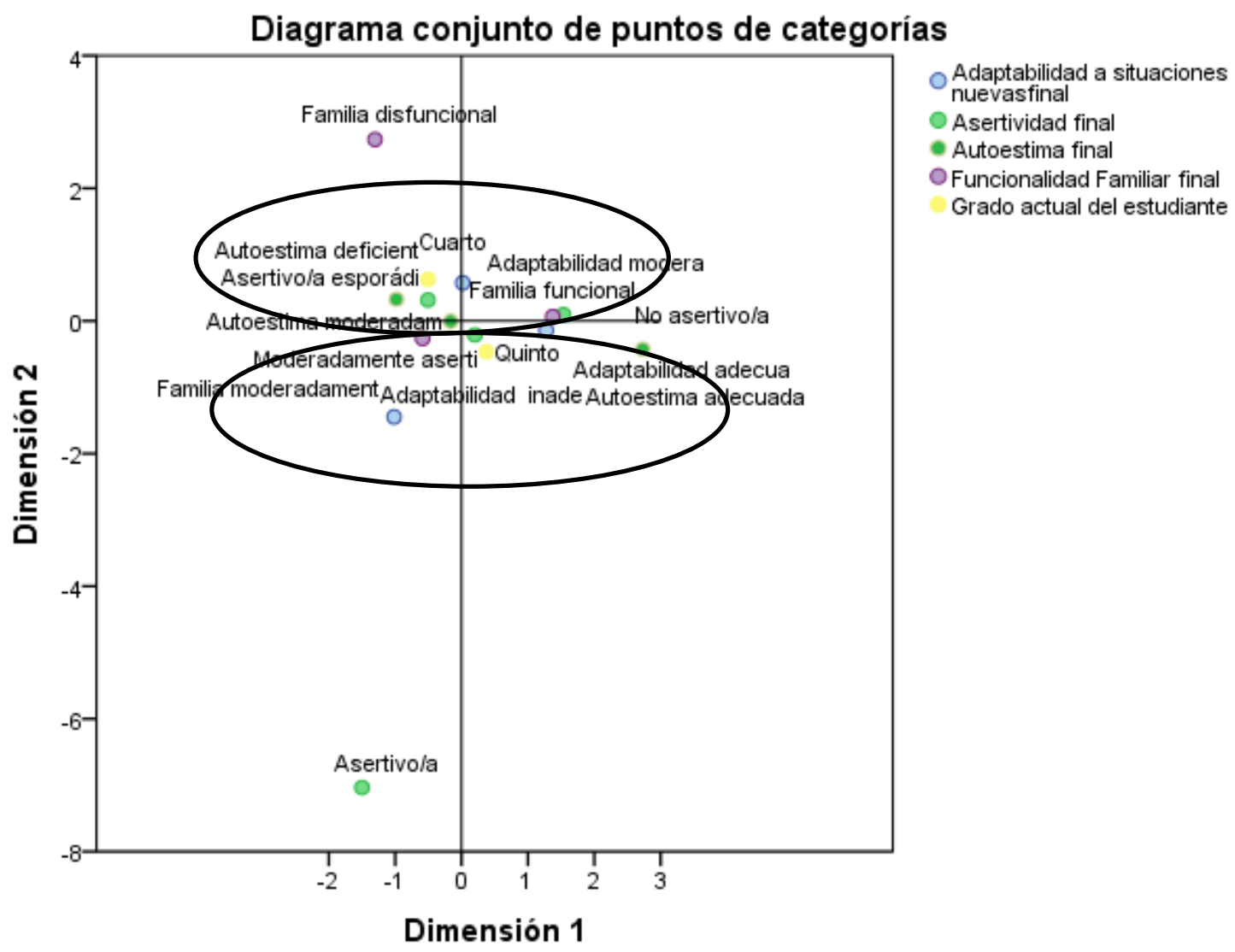

Normalización simétrica.

Figura 22. Conjunto de puntos del grado y las dimensiones funcionalidad Familiar, autoestima, asertividad y adaptabilidad a situaciones nuevas, después de la intervención de los estudiantes del Colegio CEDID Ciudad Bolívar 2019. Fuente: Elaboración Propia.

Al analizar el grado y las dimensiones capacidad de pensamiento crítico, impulsividad, afectividad y resiliencia general, después de la intervención, se encontró (ver Figura 24):

- Perfil uno: estudiantes del grado cuarto no afectivos y levemente resilientes;

- Perfil dos: estudiantes del grado quinto impulsivos ocasionales, no afectivo e impulsivo con un pensamiento crítico moderado, con una familia moderadamente funcional. 


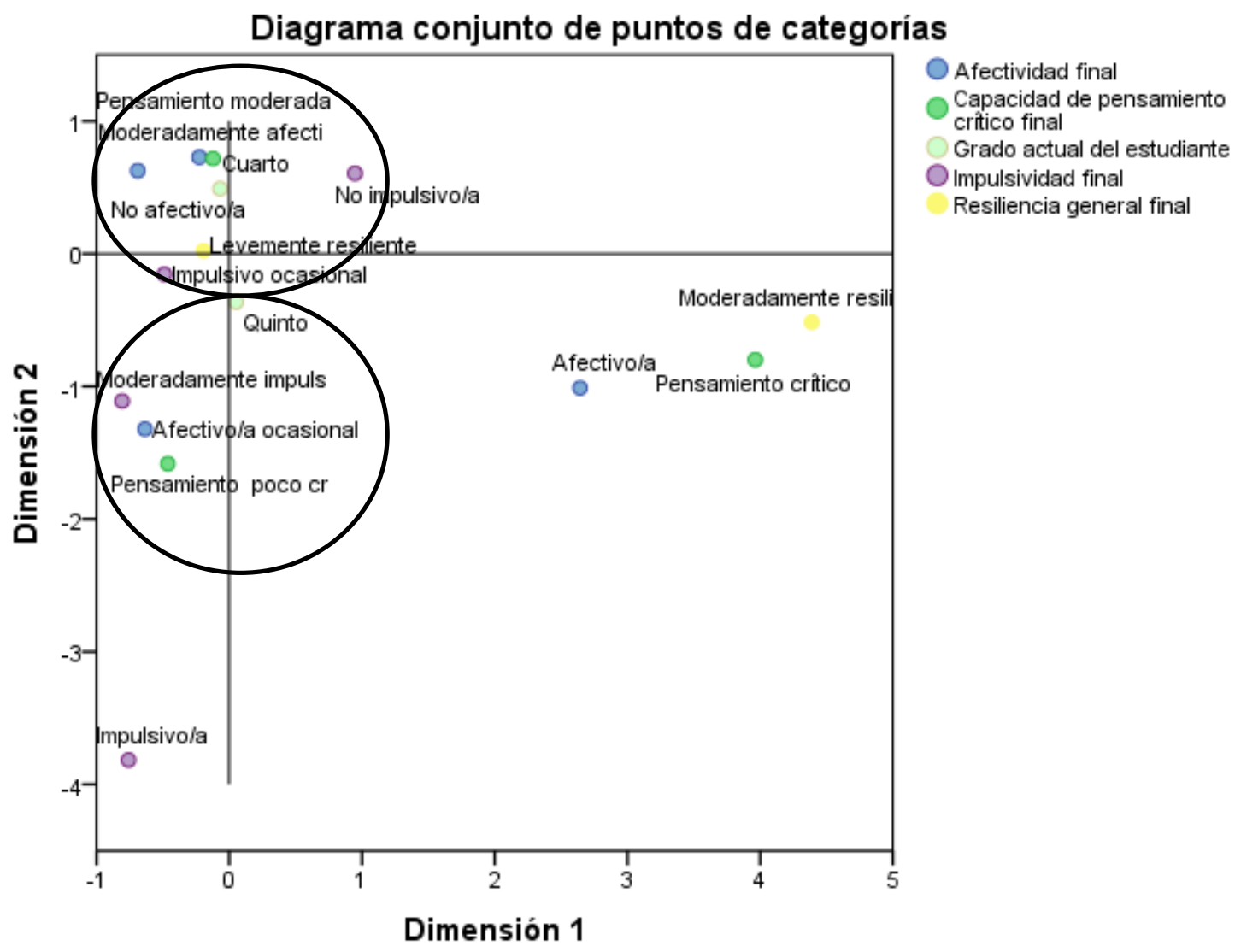

Normalización simétrica.

Figura 23. Conjunto de puntos del grado y las dimensiones capacidad de pensamiento crítico, impulsividad, afectividad y resiliencia general, después de la intervención de los estudiantes del Colegio CEDID Ciudad Bolívar 2019. Fuente: Elaboración Propia.

Al analizar el grado y emociones positivas, después de la intervención se encontró que (ver Figura 25):

- Perfil uno: estudiantes de cuarto se encontró que en cuanto a las emociones positivas están en un nivel medio-bajo

- Perfil dos: estudiantes del grado quinto están en alto. 


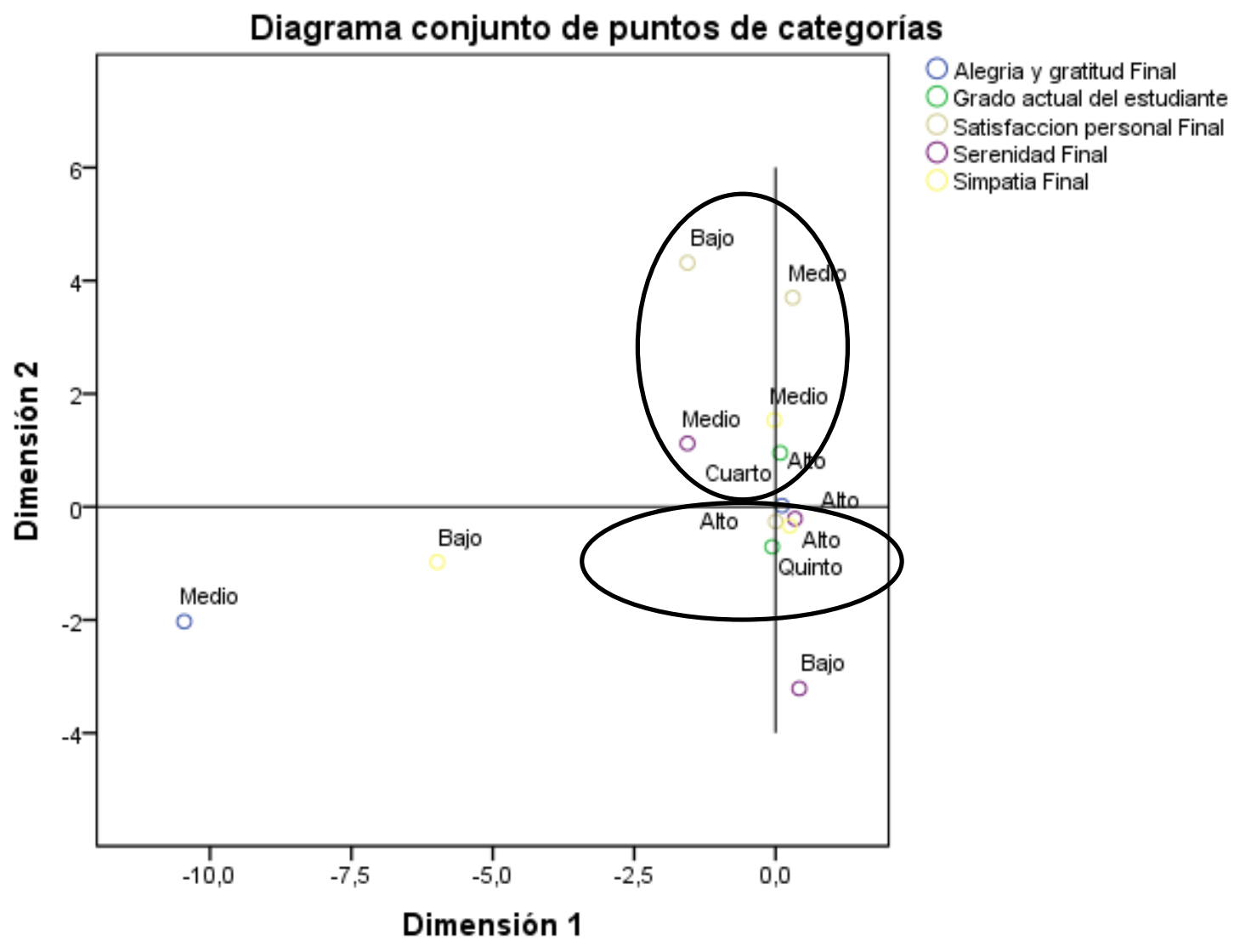

Normalización simétrica.

Figura 24. Conjunto de puntos del grado y emociones positivas, después de la intervención de los estudiantes del Colegio CEDID Ciudad Bolívar 2018. Fuente: Elaboración Propia.

\subsection{Niveles de resiliencia infantil antes y después del modelo de intervención}

A continuación, se realiza un análisis desde cada uno de los instrumentos aplicados para medir la resiliencia infantil y el relacionamiento de las categorías, variables y dimensiones desde las cuales se apalancó el modelo RARE. 
- Emociones positivas:

Frente al instrumento de emociones positivas, al identificar que las variables no se distribuían normal según el estadístico Kolmogorov-Smirnov $p=0,000$ (ver Tabla 7) solo para el caso de serenidad para los niños del grado 4 no sigue una distribución normal, por lo que, en todas sus dimensiones, se sugiere calcular la mediana.

Así pues, la puntuación de las emociones positivas de los estudiantes de cuarto tuvo el efecto esperado, no variaron dado que no se les realizó ninguna intervención; sin embargo, para el caso del grado quinto se empieza a ver un cambio en la mediana de los datos de un estado inicial de la intervención al final en los tres primeros constructos (ver Figura 26).
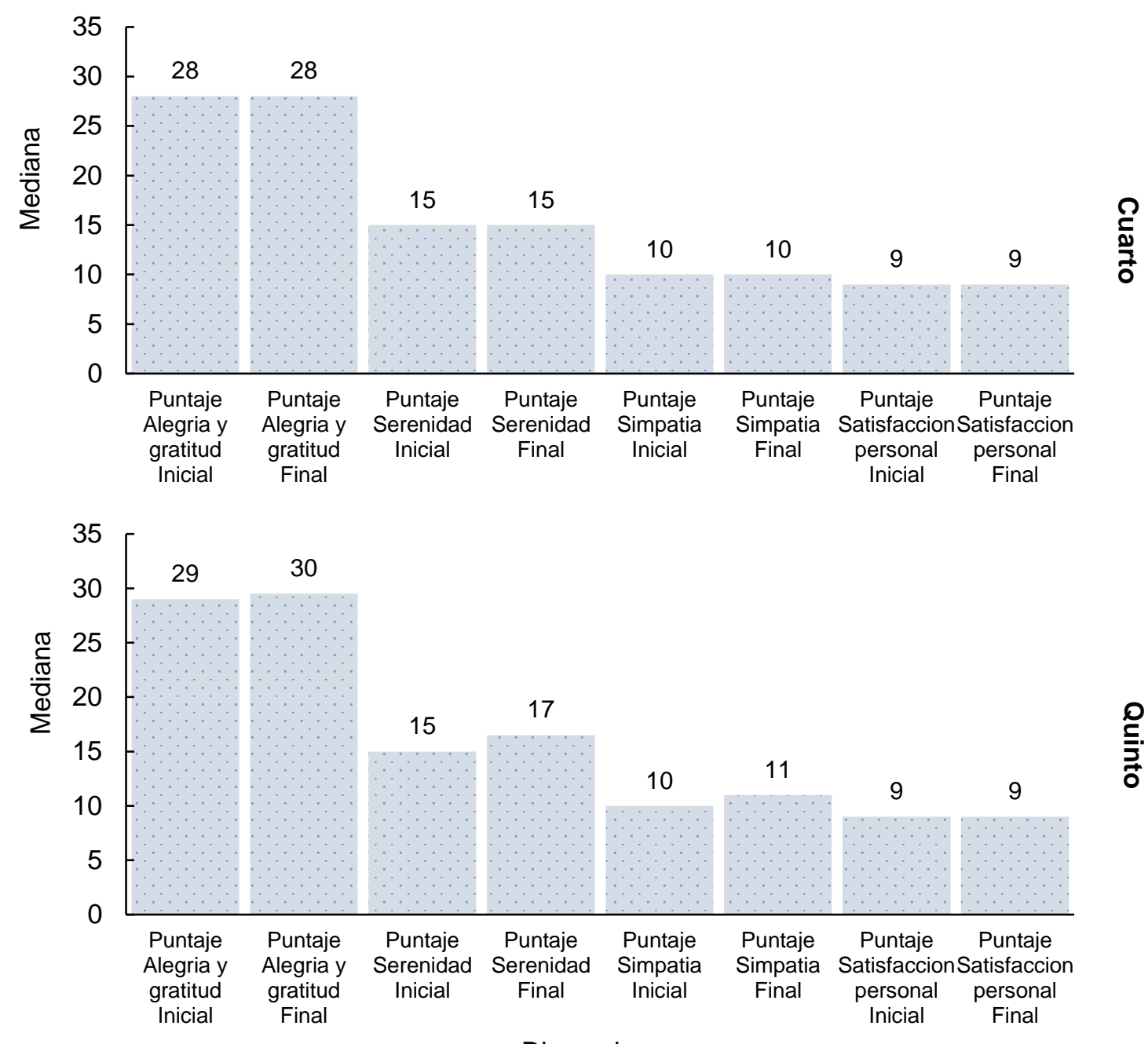

Figura 25. Mediana de cada uno de los constructos de emociones positivas aplicadas a los estudiantes del Colegio CEDID Ciudad Bolívar 2019. Fuente: Elaboración Propia. 
Al analizar estadísticamente en el instrumento de emociones positivas las diferencias en el antes y el después de la aplicación del tratamiento o modelo RARE de los grados cuarto y quinto, se encontró que en los estudiantes del grado cuarto no existen diferencias estadísticas en el antes y después, pero para grado quinto se encontraron diferencias estadísticas en la serenidad en el antes y después de la intervención, pasando de 15 estudiantes en la mediana en el análisis inicial y después de la intervención aumento a 17 estudiantes.

Tabla 7. Medianas y variabilidad de cada una de las dimensiones de emociones positivas antes y después de la intervención de los estudiantes del Colegio CEDID Ciudad Bolívar 2019.

\begin{tabular}{|c|c|c|c|c|c|c|c|c|c|c|}
\hline \multirow{2}{*}{ Puntaje } & \multicolumn{5}{|c|}{ Quinto } & \multicolumn{5}{|c|}{ Cuarto } \\
\hline & $\mathbf{p}^{*}$ & Mediana & Q1 & Q3 & $\mathbf{P}^{\star *}$ & $\mathbf{p}^{*}$ & Mediana & Q1 & Q3 & $\mathbf{P}^{\star *}$ \\
\hline \multicolumn{11}{|c|}{ Puntaje Alegría y gratitud } \\
\hline Inicial & 0,000 & 29,0 & 28,0 & 30,0 & 0,719 & 0,000 & 28 & 27,0 & 30,0 & \multirow{2}{*}{0,388} \\
\hline Final & 0,000 & 29,5 & 28,0 & 30,0 & & 0,000 & 28 & 26,0 & 30,0 & \\
\hline \multicolumn{11}{|l|}{ Serenidad } \\
\hline Inicial & 0,001 & 15,0 & 14,0 & 17,0 & 0,046 & 0,087 & 15 & 13,0 & 16,0 & \multirow{2}{*}{ 0,893+ } \\
\hline Final & 0,000 & 16,5 & 14,0 & 18,0 & & 0,072 & 15 & 13,0 & 16,5 & \\
\hline \multicolumn{11}{|l|}{ Simpatía } \\
\hline Inicial & 0,000 & 10,0 & 9,0 & 12,0 & 0,976 & 0,001 & 10 & 9,0 & 11,0 & \multirow{2}{*}{0,419} \\
\hline Final & 0,000 & 11,0 & 9,0 & 12,0 & & 0,035 & 10 & 9,0 & 11,0 & \\
\hline \multicolumn{11}{|c|}{ Satisfacción personal } \\
\hline Inicial & 0,000 & 9,0 & 8,0 & 9,0 & 0,199 & 0,000 & 9 & 8,0 & 9,0 & \multirow{2}{*}{0,946} \\
\hline Final & 0,000 & 9,0 & 9,0 & 9,0 & & 0,000 & 9 & 8,0 & 9,0 & \\
\hline
\end{tabular}

Para el caso del constructo del juego como acto creativo, se analizaron cinco dimensiones, identidad y solución de problemas, invención y arte, apertura, fantasía e imaginación y por último juegos intelectuales; en general no se evidencian cambios en el antes y después según el 50,0\% de los datos de la intervención para ambos casos (ver Figura 27). 


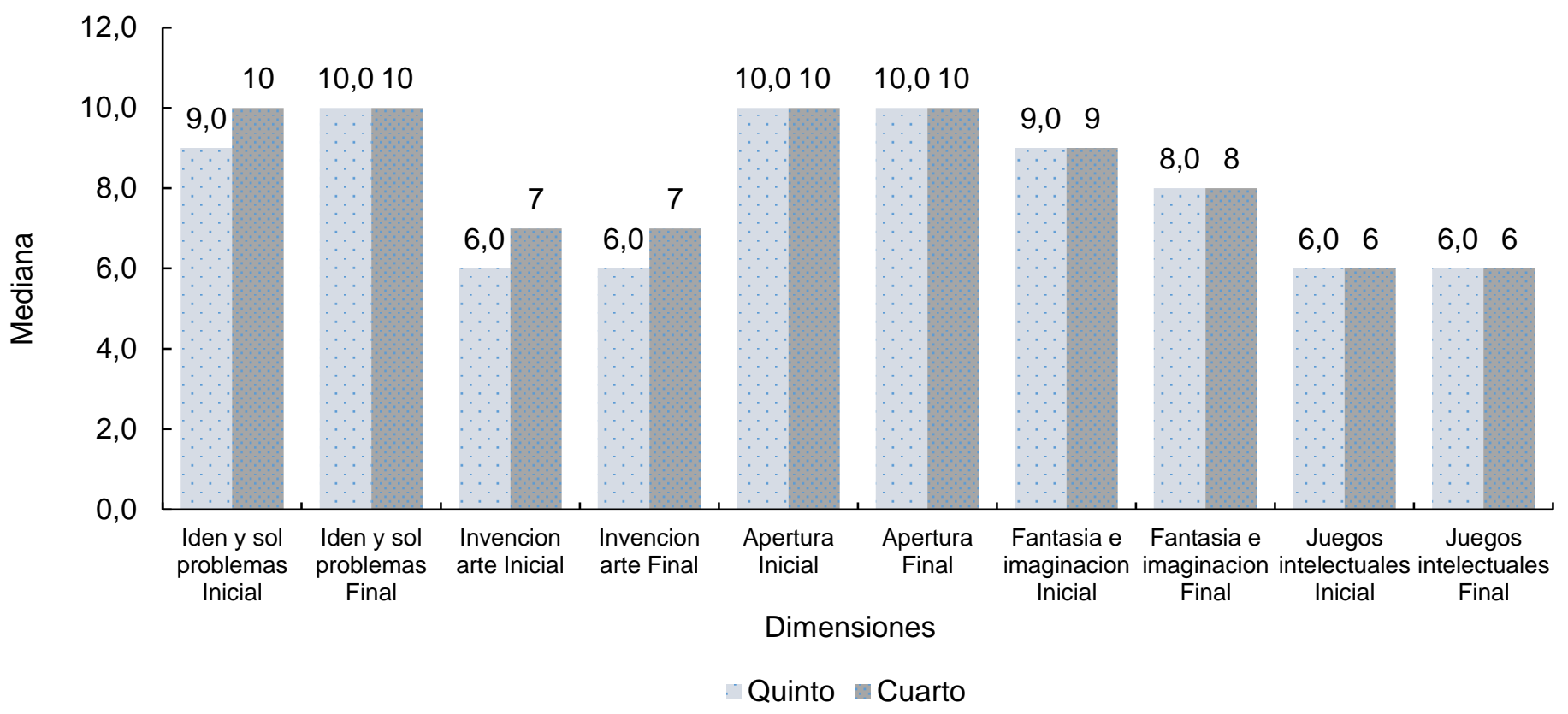

Figura 26. Mediana de cada una de las dimensiones antes y después de la intervención que conforman el constructo de juego de los estudiantes del Colegio CEDID Ciudad Bolívar 2019. Fuente: Elaboración Propia.

Al momento de realizar el análisis por cada una de las dimensiones, con las variables que siguen una distribución normal $p>0,05$ se les aplicó la prueba T para muestras relacionadas, solo para el caso de la identificación y solución de problemas se identificó un leve aumento en el 50,0\% de los datos después de la intervención, y existen diferencias en el antes y después para los constructos de fantasías e imaginación para el caso de los alumnos del grado 4 indicando una leve mejoría antes de la intervención (ver Tabla 8). 
Tabla 8. Promedios y variabilidad de cada una de las dimensiones del constructo de juego antes y después de la intervención de los estudiantes del Colegio CEDID Ciudad Bolívar 2019.

\begin{tabular}{|c|c|c|c|c|c|c|c|c|}
\hline \multirow{2}{*}{ Puntaje } & \multicolumn{4}{|c|}{ Quinto } & \multicolumn{4}{|c|}{ Cuarto } \\
\hline & $\mathbf{p}^{*}$ & Media & DE & $\mathbf{P}^{\star *}$ & $\mathbf{p}^{*}$ & Media & DE & $\mathbf{P}^{\star *}$ \\
\hline \multicolumn{9}{|c|}{ Identificación y solución de problemas } \\
\hline Inicial & 0,200 & 9,2 & 2,9 & \multirow{2}{*}{0,151} & 0,056 & 9,5 & 3,2 & \multirow{2}{*}{0,041} \\
\hline Final & 0,008 & 9,8 & 2,5 & & 0,066 & 9,9 & 2,5 & \\
\hline \multicolumn{9}{|l|}{ Apertura } \\
\hline Inicial & 0,054 & 9,9 & 2,8 & \multirow{2}{*}{0,174} &, $200^{*}$ & 10,2 & 3,0 & \multirow{2}{*}{0,334} \\
\hline Final & 0,020 & 9,4 & 3,3 & & 0,122 & 9,8 & 2,7 & \\
\hline \multicolumn{9}{|c|}{ Fantasía e imaginación } \\
\hline Inicial & 0,000 & 8,3 & 2,5 & \multirow{2}{*}{0,65} & 0,000 & 8,9 & 2,2 & \multirow{2}{*}{0,002} \\
\hline Final & 0,050 & 8,2 & 2,4 & & ,200* & 8,1 & 2,2 & \\
\hline
\end{tabular}

Para el caso de los constructos que siguen una distribución normal $p<0,005$, se identificó relación en el antes y después en los estudiantes del grado cuarto para el constructo de invención y arte siendo menor después de la intervención (ver Tabla 9).

Tabla 9. Medianas y variabilidad de cada una de las dimensiones de instrumento de personalidad creadora antes y después de la intervención de los estudiantes del Colegio CEDID Ciudad Bolívar 2019.

\begin{tabular}{|c|c|c|c|c|c|c|c|c|c|c|}
\hline \multirow{2}{*}{ Puntaje } & \multicolumn{5}{|c|}{ Quinto } & \multicolumn{5}{|c|}{ Cuarto } \\
\hline & $\mathbf{p}^{*}$ & Mediana & Q1 & Q3 & $\mathbf{P}^{\star \star}$ & $\mathbf{p}^{*}$ & Mediana & Q1 & Q3 & $\mathbf{P}^{\star \star}$ \\
\hline \multicolumn{11}{|c|}{ Juegos intelectuales } \\
\hline Inicial & 0,001 & 6,0 & 5,0 & 8,0 & \multirow{2}{*}{0,99} & 0,197 & 6,8 & 6,0 & 8,0 & \multirow{2}{*}{0,309} \\
\hline Final & 0,000 & 6,0 & 5,0 & 8,0 & & 0,014 & 6,4 & 5,0 & 8,0 & \\
\hline \multicolumn{11}{|c|}{ Invención y arte } \\
\hline Inicial & 0,021 & 5,9 & 5,0 & 8,0 & \multirow{2}{*}{0,467} & 0,000 & 6,2 & 5,0 & 7,5 & \multirow{2}{*}{0,032} \\
\hline Final & 0,000 & 5,7 & 5,0 & 7,0 & & 0,001 & 5,3 & 4,0 & 7,0 & \\
\hline
\end{tabular}

- Percepción de estilos parentales

Para la dimensión de estilos parentales (ver Figura 28) se evidencian diferencian en el antes y después de la intervención en algunos casos; por ejemplo, en aceptación los casos presentaron un aumento en la puntuación final, al igual que el factor de aceptación donde paso de un mediana de 20 
a un 22 en el 50,0\% de los casos que se intervinieron; en cuanto al control patológico en el antes y después de la intervención para el caso de los estudiantes del grado 4 disminuyó, pero para el caso de los alumnos del grado quinto este aumentó de un 16 a un 17 en su mediana; llama la atención que los estudiantes de quinto en la dimensión de control estricto en ningún de los dos grupos evaluados y en ninguna de las dos mediciones se presentó un cambio en el antes ni en el después.

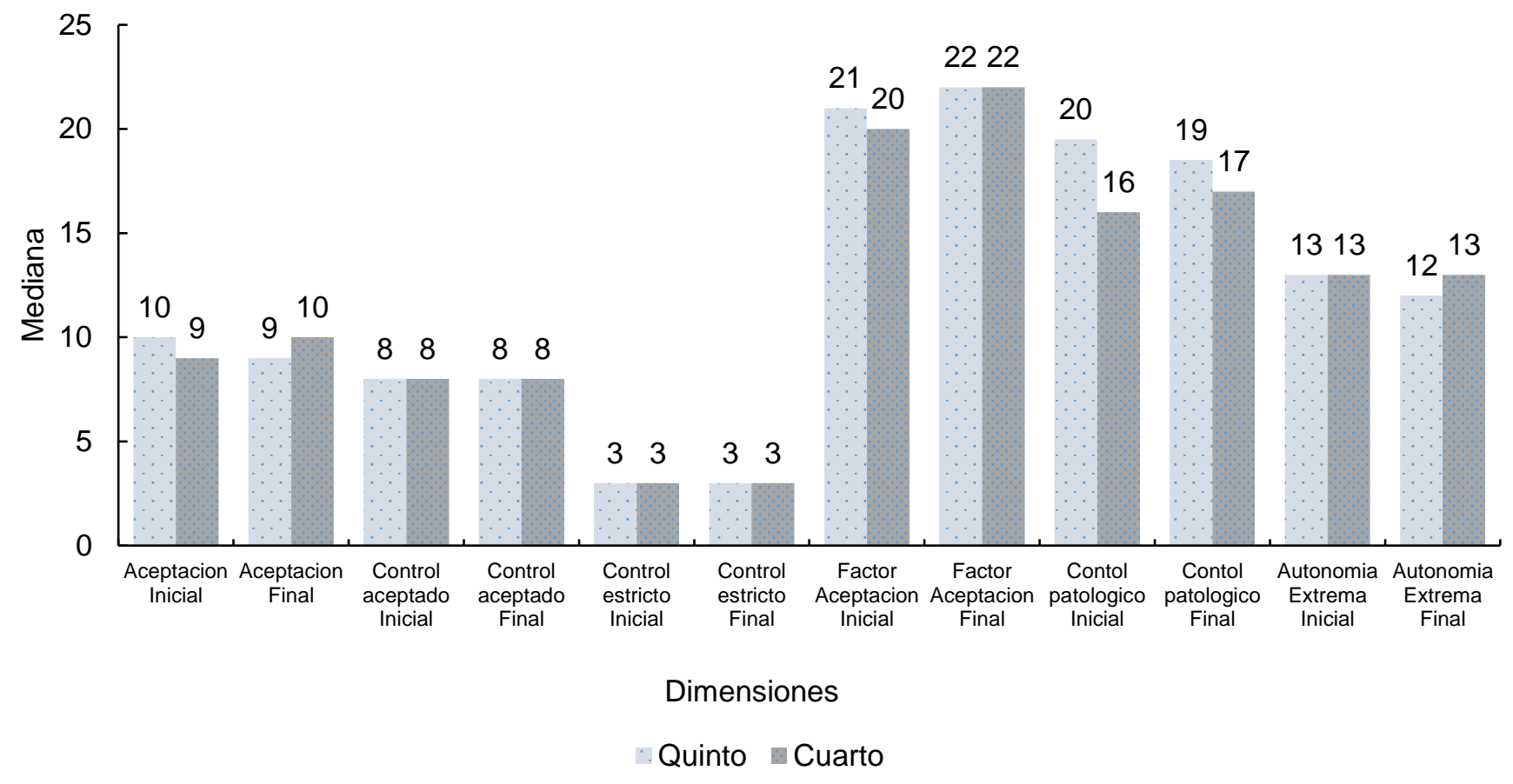

Figura 27. Mediana de cada una de las dimensiones de Estilos Parentales antes y después de la intervención de los estudiantes del Colegio CEDID Ciudad Bolívar 2019. Fuente: Elaboración Propia.

En cuanto a la normalidad de los constructos, sólo el "control patológico" sigue una distribución normal con el valor de $p>0,005$; en cuanto al constructo de "aceptación" en los alumnos de quinto se presentó un aumento de la mediana pasando de 21 a 22 alumnos, y solo fue estadísticamente significativa la relación del antes y después para los estudiantes de cuarto grado en la dimensión de factor de aceptación con un $p<0,005$ indicando una asociación a favor del instrumento final; al igual que la aceptación donde los estudiantes de cuarto presentaron diferencias estadísticas con un valor de $p=0,021$, indicando un aumento en la relación de la intervención inicial con la final (ver Tabla 10). 
Tabla 10. Medianas y variabilidad de cada una de las dimensiones del instrumento de la Escala de Estilos Parentales antes y después de la intervención de los estudiantes del Colegio CEDID Ciudad Bolivar 2019.

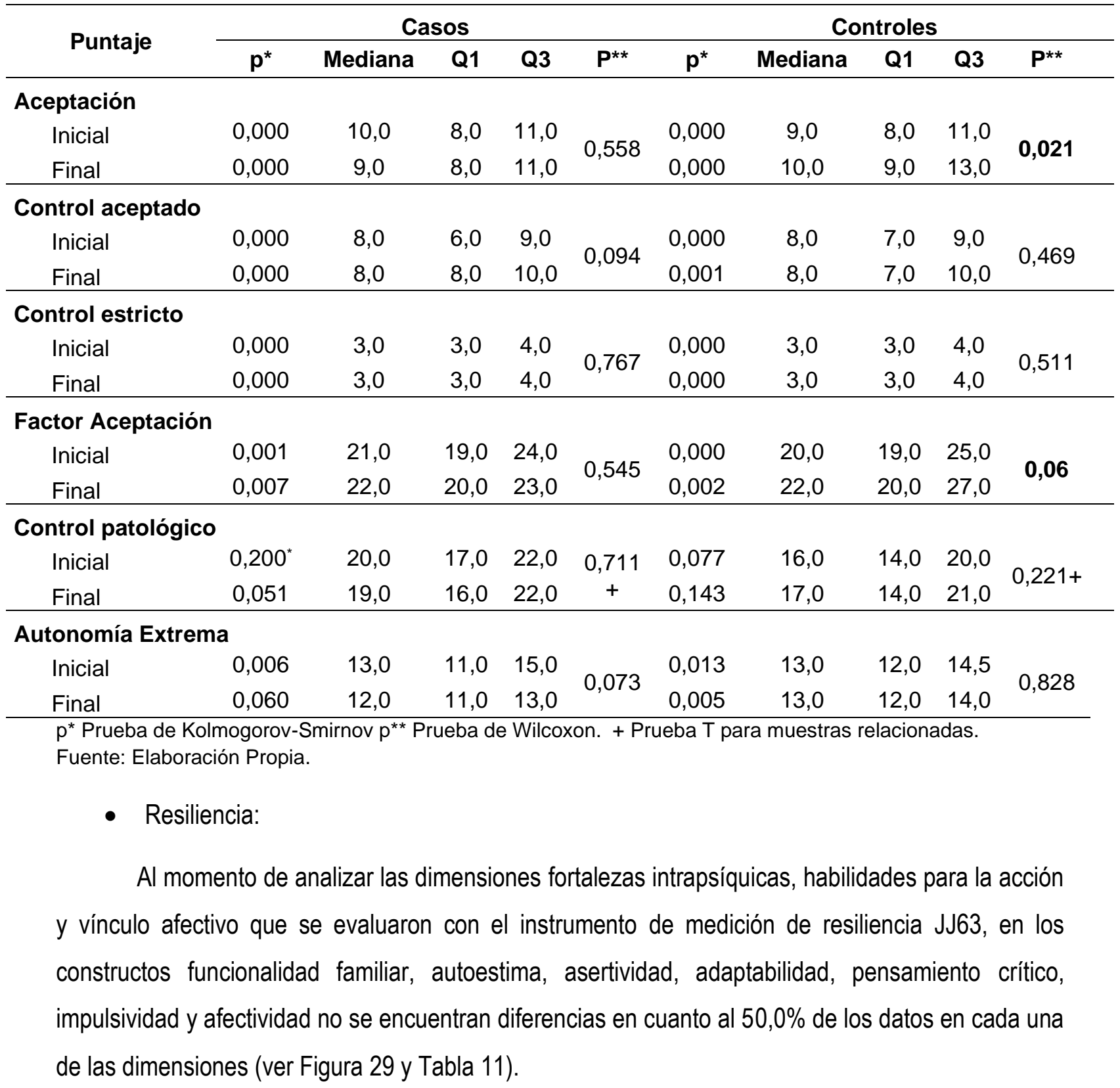




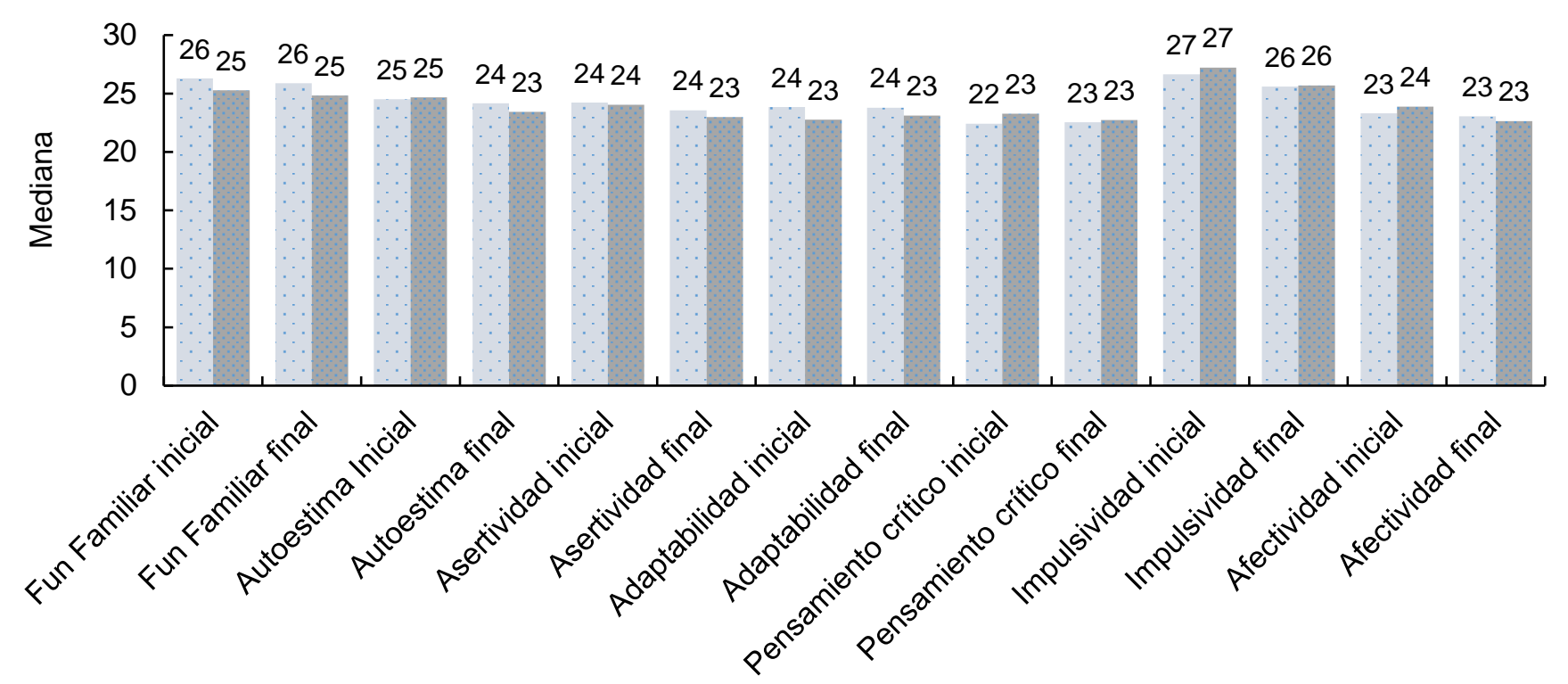

Dimensiones

Quinto Cuarto

Figura 28. Mediana de cada una de las dimensiones de la resiliencia antes y después de la intervención de los estudiantes del Colegio CEDID Ciudad Bolívar 2019. Fuente: Elaboración Propia.

En cuanto a la normalidad de cada una de dichos constructos, para el grado quinto se identificó que siguen una distribución normal, en cuanto a la capacidad de pensamiento crítico se identificó una mejoría en el antes y después de la intervención pasando de 22 alumnos a 23 alumnos según la mediana, en cuanto al grado cuarto se encontraron diferencias estadísticas en autoestima, impulsividad y resiliencia en general, pero con una disminución en el antes de la intervención. 
Tabla 11. Medianas y variabilidad de cada una de las dimensiones de la resiliencia antes y después de la intervención de los estudiantes del Colegio CEDID Ciudad Bolívar 2019.

\begin{tabular}{|c|c|c|c|c|c|c|c|c|}
\hline \multirow{2}{*}{ Puntaje } & \multicolumn{4}{|c|}{ Quinto } & \multicolumn{4}{|c|}{ Cuarto } \\
\hline & $\mathbf{p}^{*}$ & Media & $\mathrm{DE}$ & $\mathbf{P}^{\star \star}$ & $\mathbf{p}^{*}$ & Media & DE & $\mathbf{P}^{\star \star}$ \\
\hline \multicolumn{9}{|c|}{ Funcionalidad Familiar } \\
\hline Inicial & 0,200 & 26,0 & 5,0 & \multirow{2}{*}{0,493} & 0,200 & 25,0 & 5,0 & \multirow{2}{*}{0,553} \\
\hline Final & 0,067 & 26,0 & 4,0 & & 0,200 & 25,0 & 4,0 & \\
\hline \multicolumn{9}{|l|}{ Autoestima } \\
\hline Inicial & 0,200 & 24,5 & 3,5 & \multirow{2}{*}{0,444} & 0,048 & 25,0 & 4,0 & \multirow{2}{*}{0,042} \\
\hline Final & 0,200 & 24,2 & 3,2 & & 0,020 & 23,0 & 3,0 & \\
\hline \multicolumn{9}{|l|}{ Asertividad } \\
\hline Inicial & 0,008 & 24,2 & 4,6 & \multirow{2}{*}{0,362} & 0,200 & 24,0 & 4,0 & \multirow{2}{*}{0,205} \\
\hline Final & 0,200 & 23,6 & 4,8 & & 0,107 & 23,0 & 4,0 & \\
\hline \multicolumn{9}{|c|}{ Adaptabilidad a situaciones nuevas } \\
\hline Inicial & 0,002 & 24,0 & 5,0 & \multirow{2}{*}{0,933} & 0,074 & 23,0 & 4,0 & \multirow{2}{*}{0,606} \\
\hline Final & 0,200 & 24,0 & 4,0 & & 0,025 & 23,0 & 4,0 & \\
\hline \multicolumn{9}{|c|}{ Capacidad de pensamiento crítico } \\
\hline Inicial & 0,091 & 22,0 & 4,0 & \multirow{2}{*}{0,852} & 0,200 & 23,3 & 3,5 & \multirow{2}{*}{0,424} \\
\hline Final &, $200^{*}$ & 23,0 & 3,0 & & 0,153 & 22,7 & 3,6 & \\
\hline \multicolumn{9}{|l|}{ Impulsividad } \\
\hline Inicial & 0,200 & 27,0 & 5,0 & \multirow{2}{*}{0,136} & 0,200 & 27,0 & 4,0 & \multirow{2}{*}{0,046} \\
\hline Final & 0,004 & 26,0 & 4,0 & & 0,020 & 26,0 & 4,0 & \\
\hline \multicolumn{9}{|l|}{ Afectividad } \\
\hline Inicial & 0,007 & 23,3 & 3,6 & \multirow{2}{*}{0,701} & 0,119 & 24,0 & 4,0 & \multirow{2}{*}{0,110} \\
\hline Final & 0,067 & 23,1 & 4,3 & & 0,200 & 23,0 & 3,0 & \\
\hline \multicolumn{9}{|c|}{ Resiliencia general } \\
\hline Inicial & 0,033 & 171,2 & 17,6 & \multirow{2}{*}{0,311} & 0,200 & 171,0 & 21,0 & \multirow[b]{2}{*}{0,045} \\
\hline Final & 0,200 & 168,6 & 16,7 & & 0,200 & 165,0 & 15,0 & \\
\hline
\end{tabular}

Se presentan estos constructos teniendo en cuenta que los constructos "tareas adolescentes" y "creatividad" no tuvieron una carga estadística significativa. Es posible que las preguntas del constructo "tareas adolescentes" no fueran comprendidas por los niños y niñas dada su edad y desarrollo evolutivo y el constructo fue abordado por la prueba de personalidad creadora. 


\subsection{Resultados comparativos entre los grados cuartos (control) y quinto (caso) para el pos - test de resiliencia infantil}

A continuación, se presentan los resultados del post-test de los instrumentos aplicados entre los estudiantes que participaron en el modelo RARE y los que no participaron, tomando como expuestos los registros recolectados en el grado quinto de primaria del Colegio CEDID Ciudad Bolívar, sede Tanque Laguna, jornada mañana; los estudiantes estuvieron expuestos a la implementación del modelo RARE, ejecutando un total de 9 sesiones. Para el grupo de alumnos que no participaron en el modelo se seleccionaron estudiantes del grado cuarto de primaria del Colegio CEDID Ciudad Bolívar, sede Tanque Laguna, jornada mañana, a este grupo no se les aplicó ningún modelo de intervención, únicamente participaron en la recolección de los instrumentos de medición.

Al analizar la dimensión de funcionalidad familiar, se observa que el valor del estadístico de U de Mann Whitney es de 0,038 siendo inferior al valor de alfa de 0,05, indicando que existen diferencias significativas entre los estudiantes de cuarto grado y quinto del colegio CEDID, estas diferencias son significativas a favor de los estudiantes del grado de 5 , ya que el valor de rangos promedios es de 51,9 versus el del grado cuarto que solo alcanza un 41,6 . Esto nos permite concluir que el modelo RARE si influyó en la percepción de los niños del grado quinto sobre el funcionamiento de su familia (ver Tabla 12).

Las otras dimensiones del instrumento de medición de resiliencia JJ63 no presentaron diferencias significativas, como son las dimensiones de autoestima, asertividad, adaptabilidad, creatividad, impulsividad, afectividad y resiliencia, esta información es comprobada porque el valor de $p$ de cada dimensión es superior al valor de alfa de 0,05 . Aquí se puede decir que las dimensiones mencionadas anteriormente no presentan diferencias significativas entre los promedios del puntaje de los estudiantes de cuarto y quinto en cada dimensión, esto lleva a pensar que el impacto de los talleres no es el deseado y que pueden existir otros factores que influencian la efectividad de la intervención, como el tiempo de ejecución y la estrategia implementada. 
Tabla 12. Cálculo del estadístico de U de Mann Whitney para comparar las dimensiones del pos-test del instrumento JJ63 aplicado a los niños y niñas de grado cuarto y quinto de primaria del colegio CEDID Ciudad Bolivar, 2019.

\begin{tabular}{|c|c|c|c|c|c|}
\hline Dimensiones & $\begin{array}{c}\text { Grupo al que } \\
\text { pertenece el } \\
\text { estudiante }\end{array}$ & $\mathbf{N}$ & $\begin{array}{c}\text { Rango } \\
\text { promedio }\end{array}$ & $\begin{array}{l}\text { Suma de } \\
\text { rangos }\end{array}$ & $\mathbf{p}^{\star *}$ \\
\hline \multirow{3}{*}{ Funcionalidad Familiar } & Cuarto & 40 & 41,6 & 1665,0 & \\
\hline & Quinto & 54 & 51,9 & 2800,0 & 0,038 \\
\hline & Total & 94 & & & \\
\hline \multirow{3}{*}{ Autoestima } & Cuarto & 40 & 47,0 & 1881,0 & \\
\hline & Quinto & 54 & 47,9 & 2584,0 & 0,865 \\
\hline & Total & 94 & & & \\
\hline \multirow{3}{*}{ Asertividad } & Cuarto & 40 & 46,5 & 1861,0 & \\
\hline & Quinto & 54 & 48,2 & 2604,0 & 0,726 \\
\hline & Total & 94 & & & \\
\hline \multirow{3}{*}{ Adaptabilidad } & Cuarto & 40 & 44,1 & 1765,0 & \\
\hline & Quinto & 54 & 50,0 & 2700,0 & 0,231 \\
\hline & Total & 94 & & & \\
\hline \multirow{3}{*}{ Creativo } & Cuarto & 40 & 47,3 & 1893,0 & \\
\hline & Quinto & 54 & 47,6 & 2572,0 & 0,951 \\
\hline & Total & 94 & & & \\
\hline \multirow{3}{*}{ Impulsividad } & Cuarto & 40 & 47,7 & 1907,0 & \\
\hline & Quinto & 54 & 47,4 & 2558,0 & 0,951 \\
\hline & Total & 94 & & & \\
\hline \multirow{3}{*}{ Afectividad } & Cuarto & 40 & 46,5 & 1860,0 & \\
\hline & Quinto & 54 & 48,2 & 2605,0 & 0,724 \\
\hline & Total & 94 & & & \\
\hline \multirow{3}{*}{ Resiliencia } & Cuarto & 40 & 45,7 & 1828,0 & \\
\hline & Quinto & 54 & 48,8 & 2637,0 & 0,357 \\
\hline & Total & 94 & & & \\
\hline
\end{tabular}

$\mathrm{P}^{* *}$ : Estadístico U Mann Whitney

Fuente: Elaboración Propia

Frente a las emociones positivas, se evidencia que ninguna de sus dimensiones presentan cambios significativos entre los rangos promedios de puntajes entre los estudiantes de cuarto y quinto de primaria del colegio CEDID, los diferentes valores de $p$ fueron superiores al valor de alfa de 0,05 , alegría y gratitud $(0,114)$, Serenidad $(0,116)$, simpatía $(0,252)$, Satisfacción personal $(0,100)$.Como conclusión se mantiene la hipótesis que los cambios no pueden ser significativos por otros factores como pueden ser las diferencias entre los tamaños de las muestras (ver Tabla 13). 
Tabla 13. Cálculo del estadístico de U de Mann Whitney para comparar las dimensiones del pos-test del instrumento de Emociones Positivas aplicado a los niños y niñas de grado cuarto y quinto de primaria del colegio CEDID Ciudad Bolivar, 2019.

\begin{tabular}{|c|c|c|c|c|c|}
\hline Dimensiones & $\begin{array}{c}\text { Grupo al que } \\
\text { pertenece el } \\
\text { estudiante }\end{array}$ & $\mathbf{N}$ & $\begin{array}{c}\text { Rango } \\
\text { promedio }\end{array}$ & $\begin{array}{l}\text { Suma de } \\
\text { rangos }\end{array}$ & $\mathbf{p}^{\star *}$ \\
\hline \multirow{3}{*}{ Alegría y Gratitud } & Cuarto & 40 & 43,6 & 1742,0 & \\
\hline & Quinto & 54 & 50,4 & 2723,0 & 0,114 \\
\hline & Total & 94 & & & \\
\hline \multirow{3}{*}{ Serenidad } & Cuarto & 40 & 43,9 & 1755,0 & \\
\hline & Quinto & 54 & 50,2 & 2710,0 & 0,116 \\
\hline & Total & 94 & & & \\
\hline \multirow{3}{*}{ Simpatía } & Cuarto & 40 & 44,4 & 1774,0 & \\
\hline & Quinto & 54 & 49,8 & 2691,0 & 0,252 \\
\hline & Total & 94 & & & \\
\hline \multirow{3}{*}{ Satisfacción Personal } & Cuarto & 40 & 43,2 & 1728,0 & \\
\hline & Quinto & 54 & 50,7 & 2737,0 & 0,100 \\
\hline & Total & 94 & & & \\
\hline
\end{tabular}

$\mathrm{P}^{\star *}$ : Estadístico U Mann Whitney

Fuente: Elaboración Propia

En la dimensión de identificación y soluciones de problemas, no se presentaron cambios significativos, esto lo evidencia el valor de $p$ de 0,554 . Lo mismo pasa con la dimensión de invención $y$ arte donde el valor de $p$ demuestra que no existen cambios significativos entre los grados cuarto y quinto del colegio CEDID (valor de p: 0,878) (ver Tabla 14).

Para las dimensiones de apertura, fantasía e imaginación, juegos intelectuales y total personalidad creadora se presenta un valor de $p$ de 0,$958 ; 0,859 ; 0,167 ; 0,764$ respectivamente, estos valores son superiores al valor de alfa de 0,05 indicando que no existen diferencias significativas entre los grados cuarto y quinto de primaria, aunque es importante resaltar que en valor de los rangos promedios si es más alto en los estudiantes de quinto versus los estudiantes de cuarto, principalmente en la dimensiones de juegos intelectuales (cuarto 43,7; Quinto: 50,3), Identificación y solución de problemas (cuarto: 45,9; Quinto: 48,7) y total del constructo de personalidad creadora (cuarto: 46,7; Quinto: 48,1) 
Tabla 14. Cálculo del estadístico de U de Mann Whitney para comparar las dimensiones del pos-test del instrumento de Personalidad Creadora aplicado a los niños y niñas de grado cuarto y quinto de primaria del colegio CEDID Ciudad Bolivar, 2019.

\begin{tabular}{|c|c|c|c|c|c|}
\hline Dimensiones & $\begin{array}{c}\text { Grupo al que } \\
\text { pertenece el } \\
\text { estudiante }\end{array}$ & $\mathbf{N}$ & $\begin{array}{c}\text { Rango } \\
\text { promedio }\end{array}$ & $\begin{array}{l}\text { Suma de } \\
\text { rangos }\end{array}$ & $\mathbf{p}^{\star \star}$ \\
\hline \multirow{3}{*}{$\begin{array}{l}\text { Identificación Solución } \\
\text { Problemas }\end{array}$} & Cuarto & 40 & 45,9 & 1834,0 & \\
\hline & Quinto & 54 & 48,7 & 2631,0 & 0,554 \\
\hline & Total & 94 & & & \\
\hline \multirow{3}{*}{ Invención Arte } & Cuarto & 40 & 47,9 & 1916,0 & \\
\hline & Quinto & 54 & 47,2 & 2549,0 & 0,878 \\
\hline & Total & 94 & & & \\
\hline \multirow{3}{*}{ Apertura } & Cuarto & 40 & 47,7 & 1906,0 & \\
\hline & Quinto & 54 & 47,4 & 2559,0 & 0,958 \\
\hline & Total & 94 & & & \\
\hline \multirow{3}{*}{ Fantasía e Imaginación } & Cuarto & 40 & 47,9 & 1917,0 & \\
\hline & Quinto & 54 & 47,2 & 2548,0 & 0,859 \\
\hline & Total & 94 & & & \\
\hline \multirow{3}{*}{ Juegos Intelectuales } & Cuarto & 40 & 43,7 & 1747,0 & \\
\hline & Quinto & 54 & 50,3 & 2718,0 & 0,167 \\
\hline & Total & 94 & & & \\
\hline \multirow{3}{*}{ Total Personalidad creativa } & Cuarto & 40 & 46,7 & 1866,0 & \\
\hline & Quinto & 54 & 48,1 & 2599,0 & 0,764 \\
\hline & Total & 94 & & & \\
\hline
\end{tabular}

$\mathrm{P}^{\star *}$ : Estadístico U Mann Whitney

Fuente: Elaboración Propia

Al analizar el instrumento de escala de estilos parentales el valor de p para las dimensiones de aceptación control aceptado, control estricto y el total del factor de aceptación vs control estricto, no presenta un valor de $p$ inferior a 0,05 lo que nos lleva concluir que no existen diferencias significativas entre los rangos promedios de los puntajes obtenidos entre los estudiantes de cuarto y quinto del colegio CEDID en cada una de las dimensiones (ver Tabla 15).

Los factores de control patológico y autonomía extrema presentan valores del estadístico de $\mathrm{U}$ de Mann Whitney de 0,032 y 0,006 respectivamente, indicando que, si existen diferencias significativas entre los rangos promedios de los puntajes de las dimensiones presentados por los estudiantes de cuarto versus los de quinto, esto nos lleva a pensar que los talleres aplicados influenciaron positivamente en estas 2 dimensiones. También podemos considerar que los talleres impactaron principalmente factores familiares como el funcionamiento, la autonomía y el control patológico. 
Tabla 15. Cálculo del estadístico de U de Mann Whitney para comparar las dimensiones del pos-test del instrumento de Escala de Estilos Parentales aplicado a los niños y niñas de grado cuarto y quinto de primaria del colegio CEDID Ciudad Bolívar, 2019.

\begin{tabular}{|c|c|c|c|c|c|c|}
\hline Factor & Dimensiones & $\begin{array}{c}\text { Grupo al que } \\
\text { pertenece el } \\
\text { estudiante }\end{array}$ & $\mathbf{N}$ & $\begin{array}{l}\text { Rango } \\
\text { promedio }\end{array}$ & $\begin{array}{l}\text { Suma de } \\
\text { rangos }\end{array}$ & $\mathbf{p}^{\star \star}$ \\
\hline \multirow{12}{*}{$\begin{array}{l}\text { Aceptación vs } \\
\text { Control Estricto }\end{array}$} & \multirow{3}{*}{ Aceptación } & Cuarto & 40 & 50,7 & 2028,0 & \multirow{3}{*}{0,257} \\
\hline & & Quinto & 54 & 45,1 & 2437,0 & \\
\hline & & Total & 94 & & & \\
\hline & \multirow{3}{*}{$\begin{array}{l}\text { control } \\
\text { Aceptado }\end{array}$} & Cuarto & 40 & 43,4 & 1735,0 & \multirow{3}{*}{0,107} \\
\hline & & Quinto & 54 & 50,6 & 2730,0 & \\
\hline & & Total & 94 & & & \\
\hline & \multirow{3}{*}{ Control Estricto } & Cuarto & 40 & 49,5 & 1979,0 & \multirow{3}{*}{0,473} \\
\hline & & Quinto & 54 & 46,0 & 2486,0 & \\
\hline & & Total & 94 & & & \\
\hline & Factor & Cuarto & 40 & 49,0 & 1961,0 & \multirow{3}{*}{0,589} \\
\hline & \multirow{2}{*}{$\begin{array}{l}\text { Aceptación } \\
\text { Control }\end{array}$} & Quinto & 54 & 46,4 & 2504,0 & \\
\hline & & Total & 94 & & & \\
\hline \multirow{3}{*}{\multicolumn{2}{|c|}{ Factor Control Patológico }} & Cuarto & 40 & 41,5 & 1659,0 & \multirow{3}{*}{0,032} \\
\hline & & Quinto & 54 & 52,0 & 2806,0 & \\
\hline & & Total & 94 & & & \\
\hline \multirow{3}{*}{\multicolumn{2}{|c|}{ Factor Autonomía Extrema }} & Cuarto & 40 & 54,8 & 2191,0 & \multirow{3}{*}{0,006} \\
\hline & & Quinto & 54 & 42,1 & 2274,0 & \\
\hline & & Total & 94 & & & \\
\hline
\end{tabular}

$\mathrm{P}^{\star *}$ : Estadístico U Mann Whitney

Fuente: Elaboración Propia

\subsection{Resultados comparativos de las diferentes variables utilizadas en}

el estudio en relación con la resiliencia infantil (variable dependiente) y el juego (variable independiente)

Para ver si existe asociación entre la variable dependiente y sus constructos, se realizó la asociación por medio de la prueba chi-cuadrado; dentro de los resultados obtenidos se puede observar en la Tabla 16 que la resiliencia del pre test solo presenta relación con la variable impulsividad, esta relación, aunque es significativa, no presentó una mejora en la puntuación obtenida en el post test.

Al observar los resultados del post test de resiliencia se presenta relación con 6 de las variables analizadas, donde existe asociación de la resiliencia después de la intervención con la 
variable de impulsividad $(0,001)$ aunque el cambio del pretest al pos-test no fue favorable. Otra variable que presentó relación con la resiliencia después de la intervención es la autoestima $(0,000)$, donde se pasó de 2 estudiantes con autoestima adecuada con resiliencia alta en el pretest a 7 estudiantes con autoestima adecuada y resiliencia alta. La variable de pensamiento crítico presenta asociación con la resiliencia después de la intervención donde se tenía en el pretest 1 estudiante con pensamiento crítico y resiliencia alta y después de la intervención se presentan 3 estudiantes con las mismas condiciones, aprobando así el uso adecuado de la intervención. La afectividad se asocia con la resiliencia y presenta un cambio de 3 estudiantes afectivos y con resiliencia alta a 7 estudiantes con las mismas condiciones después de participar en la intervención.

La asertividad presenta relación con la resiliencia pos-test, aunque existe relación la intervención no presento un cambio favorable del pre-test al post-test. De igual forma, se presenta asociación entre la adaptabilidad a situaciones nuevas con la resiliencia pre-test, este cambio fue positivo porque se pasó de 7 estudiantes con resiliencia alta antes de la intervención a un total de 8 con las mismas condiciones. 
Tabla 16. Estadístico de Chi- cuadrado de cada una de las categorías de resiliencia pre-test y posttest y su asociación con variables de demográficas, familiares e instrumentos medidos en los niños y niñas del colegio CEDI, cuidad Bolivar 2019. Parte 1

\begin{tabular}{|c|c|c|c|c|c|c|c|c|c|c|c|}
\hline \multirow{4}{*}{ Variable } & \multirow{4}{*}{ Categoría } & \multicolumn{10}{|c|}{ Resiliencia } \\
\hline & & \multicolumn{5}{|c|}{ Pre-test } & \multicolumn{5}{|c|}{ Post-test } \\
\hline & & \multicolumn{2}{|c|}{ Bajo } & \multicolumn{2}{|c|}{ Alto } & \multirow{2}{*}{$\mathbf{p}^{\star}$} & \multicolumn{2}{|c|}{ Bajo } & \multicolumn{2}{|c|}{ Alto } & \multirow{2}{*}{$\mathbf{p}^{\star}$} \\
\hline & & $\mathbf{n}$ & $\%$ & $\mathbf{n}$ & $\%$ & & $\mathbf{n}$ & $\%$ & $\mathbf{n}$ & $\%$ & \\
\hline \multirow{4}{*}{$\begin{array}{l}\text { Impulsividad Post- } \\
\text { test }\end{array}$} & No impulsivo/a & 18 & $25,0 \%$ & 16 & $72,7 \%$ & \multirow{4}{*}{0,001} & 23 & $28,4 \%$ & 11 & $84,6 \%$ & \multirow{4}{*}{0,001} \\
\hline & Impulsivo ocasional & 45 & $62,5 \%$ & 6 & $27,3 \%$ & & 49 & $60,5 \%$ & 2 & $15,4 \%$ & \\
\hline & Moderadamente impulsivo & 8 & $11,1 \%$ & 0 & $0,0 \%$ & & 8 & $9,9 \%$ & 0 & $0,0 \%$ & \\
\hline & Impulsivo/a & 1 & $1,4 \%$ & 0 & $0,0 \%$ & & 1 & $1,2 \%$ & 0 & $0,0 \%$ & \\
\hline \multirow{4}{*}{$\begin{array}{l}\text { Autoestima Post- } \\
\text { test }\end{array}$} & Autoestima adecuada & 7 & $9,7 \%$ & 2 & $9,1 \%$ & \multirow{4}{*}{0,093} & 2 & $2,5 \%$ & 7 & $53,8 \%$ & \multirow{4}{*}{0,000} \\
\hline & $\begin{array}{l}\text { Autoestima } \\
\text { moderadamente adecuada }\end{array}$ & 52 & $72,2 \%$ & 20 & $90,9 \%$ & & 66 & $81,5 \%$ & 6 & $46,2 \%$ & \\
\hline & Autoestima deficiente & 13 & $18,1 \%$ & 0 & $0,0 \%$ & & 13 & $16,0 \%$ & 0 & $0,0 \%$ & \\
\hline & $\begin{array}{l}\text { Autoestima severamente } \\
\text { deficiente }\end{array}$ & 0 & $0,0 \%$ & 0 & $0,0 \%$ & & 0 & $0,0 \%$ & 0 & $0,0 \%$ & \\
\hline \multirow{3}{*}{$\begin{array}{c}\text { Capacidad de } \\
\text { pensamiento crítico } \\
\text { Post-test }\end{array}$} & Pensamiento crítico & 4 & $5,6 \%$ & 1 & $4,5 \%$ & \multirow{3}{*}{0,222} & 2 & $2,5 \%$ & 3 & $23,1 \%$ & \multirow{3}{*}{0,007} \\
\hline & $\begin{array}{l}\text { Pensamiento } \\
\text { moderadamente crítico }\end{array}$ & 45 & $62,5 \%$ & 18 & $81,8 \%$ & & 55 & $67,9 \%$ & 8 & $61,5 \%$ & \\
\hline & Pensamiento poco crítico & 23 & $31,9 \%$ & 3 & $13,6 \%$ & & 24 & $29,6 \%$ & 2 & $15,4 \%$ & \\
\hline \multirow{4}{*}{$\begin{array}{l}\text { Afectividad Post- } \\
\text { test }\end{array}$} & Afectivo/a & 8 & $11,1 \%$ & 3 & $13,6 \%$ & \multirow{4}{*}{0,753} & 4 & $4,9 \%$ & 7 & $53,8 \%$ & \multirow{4}{*}{0,000} \\
\hline & Moderadamente afectivo/a & 43 & $59,7 \%$ & 15 & $68,2 \%$ & & 52 & $64,2 \%$ & 6 & $46,2 \%$ & \\
\hline & Afectivo/a ocasional & 20 & $27,8 \%$ & 4 & $18,2 \%$ & & 24 & $29,6 \%$ & 0 & $0,0 \%$ & \\
\hline & No afectivo/a & 1 & $1,4 \%$ & 0 & $0,0 \%$ & & 1 & $1,2 \%$ & 0 & $0,0 \%$ & \\
\hline \multirow{4}{*}{$\begin{array}{l}\text { Asertividad Post- } \\
\text { test }\end{array}$} & Asertivo/a & 1 & $1,4 \%$ & 1 & $4,5 \%$ & \multirow{4}{*}{0,193} & 2 & $2,5 \%$ & 0 & $0,0 \%$ & \multirow{4}{*}{0,000} \\
\hline & Moderadamente asertivo/ & 17 & $23,6 \%$ & 4 & $18,2 \%$ & & 18 & $22,2 \%$ & 3 & $23,1 \%$ & \\
\hline & Asertivo/a esporádico & 44 & $61,1 \%$ & 10 & $45,5 \%$ & & 52 & $64,2 \%$ & 2 & $15,4 \%$ & \\
\hline & No asertivo/a & 10 & $13,9 \%$ & 7 & $31,8 \%$ & & 9 & $11,1 \%$ & 8 & $61,5 \%$ & \\
\hline \multirow{3}{*}{$\begin{array}{c}\text { Adaptabilidad a } \\
\text { situaciones nuevas } \\
\text { Post-test }\end{array}$} & Adaptabilidad adecuada & 9 & $12,5 \%$ & 7 & $31,8 \%$ & \multirow{3}{*}{0,051} & 8 & $9,9 \%$ & 8 & $61,5 \%$ & \multirow{3}{*}{0,000} \\
\hline & $\begin{array}{l}\text { Adaptabilidad } \\
\text { moderadamente adecuada }\end{array}$ & 44 & $61,1 \%$ & 13 & $59,1 \%$ & & 52 & $64,2 \%$ & 5 & $38,5 \%$ & \\
\hline & Adaptabilidad inadecuada & 19 & $26,4 \%$ & 2 & $9,1 \%$ & & 21 & $25,9 \%$ & 0 & $0,0 \%$ & \\
\hline Parentesco de & Madre & 6 & $10,7 \%$ & 0 & $0,0 \%$ & & 5 & $8,1 \%$ & 1 & $11,1 \%$ & \\
\hline quien diligencia la & Padre & 48 & $85,7 \%$ & 15 & $100,0 \%$ & 0,299 & 56 & $90,3 \%$ & 7 & $77,8 \%$ & 0,254 \\
\hline encuesta & Otros & 2 & $3,6 \%$ & 0 & $0,0 \%$ & & 1 & $1,6 \%$ & 1 & $11,1 \%$ & \\
\hline
\end{tabular}

$\mathrm{P}^{*}$ : Chi-cuadrado

Fuente: Elaboración propia

En la Tabla 17 se presenta relación entre la resiliencia post test con la variable de donde provienen los ingresos del hogar, esta asociación presenta un cambio positivo a favor de la categoría ingreso capital pasando de no tener estudiantes con resiliencia alta en el pre test a un estudiante con las mismas condiciones en el post test. Las otras categorías como son trabajo salariado y trabajo independiente presentaron un cambio no favorable después de la intervención, asumiendo que esta relación puede afectar considerablemente estas categorías. 
Tabla 17. Estadístico de Chi- cuadrado de cada una de las categorías de resiliencia pre-test y posttest y su asociación con variables de demográficas, familiares e instrumentos medidos en los niños y niñas del colegio CEDI, cuidad Bolívar 2019. Parte 2.

\begin{tabular}{|c|c|c|c|c|c|c|c|c|c|c|c|}
\hline \multirow{4}{*}{ Variable } & \multirow{4}{*}{ Categoría } & \multicolumn{10}{|c|}{ Resiliencia } \\
\hline & & \multicolumn{5}{|c|}{ Pre-test } & \multicolumn{5}{|c|}{ Post-test } \\
\hline & & \multicolumn{2}{|c|}{ Bajo } & \multicolumn{2}{|c|}{ Alto } & \multirow{2}{*}{$\mathbf{p}^{*}$} & \multicolumn{2}{|c|}{ Bajo } & \multicolumn{2}{|c|}{ Alto } & \multirow{2}{*}{$\mathbf{p}^{*}$} \\
\hline & & $\mathrm{n}$ & $\%$ & $\mathbf{n}$ & $\%$ & & $\mathbf{n}$ & $\%$ & $\mathbf{n}$ & $\%$ & \\
\hline \multirow[b]{2}{*}{ Género del adulto } & Masculino & 6 & $10,9 \%$ & 0 & $0,0 \%$ & \multirow[b]{2}{*}{0,181} & 5 & $8,2 \%$ & 1 & $11,1 \%$ & \multirow[b]{2}{*}{0,771} \\
\hline & Femenino & 49 & $89,1 \%$ & 15 & $100,0 \%$ & & 56 & $91,8 \%$ & 8 & $88,9 \%$ & \\
\hline \multirow{4}{*}{$\begin{array}{l}\text { La vivienda } \\
\text { ocupada por este } \\
\text { hogar es }\end{array}$} & Arriendo & 41 & $74,5 \%$ & 12 & $80,0 \%$ & \multirow{4}{*}{0,323} & 47 & $77,0 \%$ & 6 & $66,7 \%$ & \multirow{4}{*}{0,488} \\
\hline & Familiar & 2 & $3,6 \%$ & 2 & $13,3 \%$ & & 4 & $6,6 \%$ & 0 & $0,0 \%$ & \\
\hline & Propia & 11 & $20,0 \%$ & 1 & $6,7 \%$ & & 9 & $14,8 \%$ & 3 & $33,3 \%$ & \\
\hline & Otra & 1 & $1,8 \%$ & 0 & $0,0 \%$ & & 1 & $1,6 \%$ & 0 & $0,0 \%$ & \\
\hline \multirow{4}{*}{$\begin{array}{c}\text { De dónde } \\
\text { provienen los } \\
\text { ingresos de este } \\
\text { hogar }\end{array}$} & Ingreso de capital & 2 & $3,7 \%$ & 0 & $0,0 \%$ & \multirow{4}{*}{0,222} & 1 & $1,7 \%$ & 1 & $11,1 \%$ & \multirow{4}{*}{0,023} \\
\hline & Ingreso ocasionales & 0 & $0,0 \%$ & 1 & $7,1 \%$ & & 0 & $0,0 \%$ & 1 & $11,1 \%$ & \\
\hline & Trabajo asalariado & 40 & $74,1 \%$ & 10 & $71,4 \%$ & & 44 & $74,6 \%$ & 6 & $66,7 \%$ & \\
\hline & Trabajo independiente & 12 & $22,2 \%$ & 3 & $21,4 \%$ & & 14 & $23,7 \%$ & 1 & $11,1 \%$ & \\
\hline \multirow{6}{*}{$\begin{array}{l}\text { Principal razón de } \\
\text { traslado de la } \\
\text { familia a su lugar } \\
\text { de residencia } \\
\text { actual }\end{array}$} & Adquisición de vivienda & 10 & $24,4 \%$ & 2 & $14,3 \%$ & \multirow{6}{*}{0,019} & 9 & $18,8 \%$ & 3 & $42,9 \%$ & \multirow{6}{*}{0,590} \\
\hline & Cambio de estado civil & 4 & $9,8 \%$ & 0 & $0,0 \%$ & & 3 & $6,3 \%$ & 1 & $14,3 \%$ & \\
\hline & Desplazado forzado & 5 & $12,2 \%$ & 0 & $0,0 \%$ & & 5 & $10,4 \%$ & 0 & $0,0 \%$ & \\
\hline & Trabajo & 14 & $34,1 \%$ & 7 & $50,0 \%$ & & 18 & $37,5 \%$ & 3 & $42,9 \%$ & \\
\hline & \multirow{2}{*}{$\begin{array}{l}\text { Finalización del contrato de } \\
\text { arrendamiento } \\
\text { Otras }\end{array}$} & 6 & $14,6 \%$ & 0 & $0,0 \%$ & & 6 & $12,5 \%$ & 0 & $0,0 \%$ & \\
\hline & & 2 & $4,9 \%$ & 5 & $35,7 \%$ & & 7 & $14,6 \%$ & 0 & $0,0 \%$ & \\
\hline \multirow{4}{*}{$\begin{array}{l}\text { Último nivel } \\
\text { educativo aprobado } \\
\text { por el adulto que } \\
\text { diligencia la } \\
\text { encuesta }\end{array}$} & Primaria & 14 & $25,5 \%$ & 1 & $7,1 \%$ & \multirow{4}{*}{0,436} & 12 & $20,0 \%$ & 3 & $33,3 \%$ & \multirow{4}{*}{0,69} \\
\hline & Secundaria & 28 & $50,9 \%$ & 10 & $71,4 \%$ & & 33 & $55,0 \%$ & 5 & $55,6 \%$ & \\
\hline & Técnico & 10 & $18,2 \%$ & 2 & $14,3 \%$ & & 11 & $18,3 \%$ & 1 & $11,1 \%$ & \\
\hline & Superior o universitario & 3 & $5,5 \%$ & 1 & $7,1 \%$ & & 4 & $6,7 \%$ & 0 & $0,0 \%$ & \\
\hline \multirow{4}{*}{ Tipo de familia } & Familia nuclear & 35 & $48,6 \%$ & 12 & $54,5 \%$ & \multirow{4}{*}{0,348} & 41 & $50,6 \%$ & 6 & $46,2 \%$ & \\
\hline & Familia Extensa & 6 & $8,3 \%$ & 1 & $4,5 \%$ & & 6 & $7,4 \%$ & 1 & $7,7 \%$ & 0992 \\
\hline & Familia monoparental & 13 & $18,1 \%$ & 1 & $4,5 \%$ & & 12 & $14,8 \%$ & 2 & $15,4 \%$ & 0,992 \\
\hline & Sin información & 18 & $25,0 \%$ & 8 & $36,4 \%$ & & 22 & $27,2 \%$ & 4 & $30,8 \%$ & \\
\hline
\end{tabular}

$\mathrm{P}^{*}$ : Chi-cuadrado

Fuente: Elaboración propia

En la Tabla 18 se puede evidenciar las variables que no presenta distribución normal validada por medio del estadístico de distribución normal de Kolmogorov-Smirnov, donde todos los ítems que evalúan la resiliencia presentan valores de significación inferior a 0,05 , comprobando la no normalidad de las variables. Por otro lado, la prueba estadística de $U$ de Mann-Whitney logró identificar que no existe significancia estadística en quienes son resilientes y en quienes no, esta información se comprueba en la edad del adulto que diligenció la encuesta ( $\left.\mathrm{p}^{* * * *} 0,287\right)$; Edad del estudiante ( $\mathrm{p}^{* * * *}$ : 
0,093); Cantidad de miembros que conforman el hogar ( $\left.p^{* * * *}: 0,445\right)$; Cuantos aportan al ingreso del hogar $\left(p^{* * * *}: 0,923\right)$.

Tabla 18. Promedios, distribución normal y variabilidad de cada una de las categorías de la resiliencia y valoración de la diferencia de las variables cuantitativas de los niños y niñas de cuarto y quinto de primaria del Colegio CEDID Ciudad Bolívar, 2019.

\begin{tabular}{|c|c|c|c|c|c|c|c|}
\hline \multirow[b]{2}{*}{ Variables cuantitativas } & \multirow[b]{2}{*}{$\begin{array}{l}\text { Resiliencia } \\
\text { Final }\end{array}$} & \multirow[b]{2}{*}{$\mathbf{P}^{\star}$} & \multicolumn{3}{|c|}{ Rangos } & \multirow[b]{2}{*}{$\begin{array}{c}\text { U de } \\
\text { Mann- } \\
\text { Whitney }\end{array}$} & \multirow[b]{2}{*}{$\mathbf{p}^{\star \star \star \star}$} \\
\hline & & & $\mathbf{n}$ & $\begin{array}{c}\text { Rango } \\
\text { promedio }\end{array}$ & $\begin{array}{l}\text { Suma } \\
\text { de } \\
\text { rangos }\end{array}$ & & \\
\hline $\begin{array}{l}\text { Edad del adulto que } \\
\text { diligencia la encuesta }\end{array}$ & $\begin{array}{l}\text { Bajo } \\
\text { Alto }\end{array}$ & 0,004 & $\begin{array}{c}62 \\
9\end{array}$ & $\begin{array}{l}35,0 \\
42,8\end{array}$ & $\begin{array}{c}2170,5 \\
385,5\end{array}$ & 217,5 & 0,287 \\
\hline Edad del estudiante & $\begin{array}{l}\text { Bajo } \\
\text { Alto }\end{array}$ & 0,000 & $\begin{array}{c}62 \\
9\end{array}$ & $\begin{array}{l}34,5 \\
46,0\end{array}$ & $\begin{array}{c}2142,0 \\
414,0\end{array}$ & 189 & 0,093 \\
\hline $\begin{array}{c}\text { Cantidad de miembros que } \\
\text { conforman el hogar }\end{array}$ & $\begin{array}{l}\text { Bajo } \\
\text { Alto }\end{array}$ & 0,000 & $\begin{array}{l}81 \\
13 \\
\end{array}$ & $\begin{array}{l}46,7 \\
52,7\end{array}$ & $\begin{array}{c}3779,5 \\
685,5 \\
\end{array}$ & 458,5 & 0,445 \\
\hline $\begin{array}{c}\text { Cuantos aportan al ingreso } \\
\text { del hogar }\end{array}$ & $\begin{array}{l}\text { Bajo } \\
\text { Alto }\end{array}$ & 0,000 & $\begin{array}{l}81 \\
13\end{array}$ & $\begin{array}{l}47,6 \\
46,8\end{array}$ & $\begin{array}{c}3856,0 \\
609,0\end{array}$ & 518 & 0,923 \\
\hline
\end{tabular}

$\mathrm{p}^{\star * * *}$ : Valor de $\mathrm{p}$ prueba estadística U de Mann-Whitney

Fuente: Elaboración Propia

Según los análisis realizados para comparar la resiliencia con las dimensiones pre test de la escala de personalidad creadora se identificó asociación entre la resiliencia pre - test y las dimensiones de fantasía e imaginación $(0,009)$, juegos intelectuales $(0,009)$ y total de instrumento de personalidad creadora $(0,029)$. Aunque existe asociación entre la resiliencia pre-test en las variables descritas anteriormente, los cambios que se presentan al observar estas variables con la resiliencia post-test no son favorables y no demuestran que sea efectiva la utilización de la intervención. 
Tabla 19. Estadístico de Chi- cuadrado de cada una de las categorías de resiliencia post-test y post -test y su asociación con las dimensiones del instrumento de personalidad creadora post-test medido en los niños y niñas del colegio CEDI, Ciudad Bolivar 2019.

\begin{tabular}{|c|c|c|c|c|c|c|c|c|c|c|c|}
\hline \multirow{3}{*}{ Dimensión } & \multirow{3}{*}{ Categoría } & \multicolumn{5}{|c|}{ Resiliencia Inicial } & \multicolumn{5}{|c|}{ Resiliencia Final } \\
\hline & & \multicolumn{2}{|c|}{ Bajo } & \multicolumn{2}{|c|}{ Alto } & \multirow{2}{*}{$\mathbf{P}^{\star}$} & \multicolumn{2}{|c|}{ Bajo } & \multicolumn{2}{|c|}{ Alto } & \multirow{2}{*}{$\mathbf{P}^{*}$} \\
\hline & & $\mathrm{n}$ & $\%$ & $\mathbf{n}$ & $\%$ & & $\mathbf{n}$ & $\%$ & $\mathbf{n}$ & $\%$ & \\
\hline \multirow{3}{*}{$\begin{array}{l}\text { Identificación } \\
\text { y solución de } \\
\text { problemas }\end{array}$} & Bajo & 8 & $11,1 \%$ & 0 & $0,0 \%$ & & 7 & $8,6 \%$ & 1 & $7,7 \%$ & \\
\hline & Medio & 25 & $34,7 \%$ & 6 & $27,3 \%$ & 0,096 & 30 & $37,0 \%$ & 1 & $7,7 \%$ & 0,156 \\
\hline & Alto & 39 & $54,2 \%$ & 16 & $72,7 \%$ & & 44 & $54,3 \%$ & 11 & $84,6 \%$ & \\
\hline \multirow{3}{*}{$\begin{array}{l}\text { Invención y } \\
\text { arte }\end{array}$} & Bajo & 23 & $31,9 \%$ & 6 & $27,3 \%$ & & 27 & $33,3 \%$ & 2 & $15,4 \%$ & \\
\hline & Medio & 39 & $54,2 \%$ & 12 & $54,5 \%$ & 0,155 & 44 & $54,3 \%$ & 7 & $53,8 \%$ & 0,849 \\
\hline & Alto & 10 & $13,9 \%$ & 4 & $18,2 \%$ & & 10 & $12,3 \%$ & 4 & $30,8 \%$ & \\
\hline \multirow{3}{*}{ Apertura } & Bajo & 19 & $26,4 \%$ & 2 & $9,1 \%$ & & 20 & $24,7 \%$ & 1 & $7,7 \%$ & \\
\hline & Medio & 23 & $31,9 \%$ & 8 & $36,4 \%$ & 0,393 & 26 & $32,1 \%$ & 5 & $38,5 \%$ & 0,225 \\
\hline & Alto & 30 & $41,7 \%$ & 12 & $54,5 \%$ & & 35 & $43,2 \%$ & 7 & $53,8 \%$ & \\
\hline \multirow{3}{*}{$\begin{array}{c}\text { Fantasia e } \\
\text { imaginación }\end{array}$} & Bajo & 20 & $27,8 \%$ & 2 & $9,1 \%$ & & 22 & $27,2 \%$ & 0 & $0,0 \%$ & \\
\hline & Medio & 33 & $45,8 \%$ & 12 & $54,5 \%$ & 0,009 & 40 & $49,4 \%$ & 5 & $38,5 \%$ & 0,186 \\
\hline & Alto & 19 & $26,4 \%$ & 8 & $36,4 \%$ & & 19 & $23,5 \%$ & 8 & $61,5 \%$ & \\
\hline \multirow{3}{*}{$\begin{array}{c}\text { Juegos } \\
\text { intelectuales }\end{array}$} & Bajo & 12 & $16,7 \%$ & 3 & $13,6 \%$ & & 15 & $18,5 \%$ & 0 & $0,0 \%$ & \\
\hline & Medio & 34 & $47,2 \%$ & 8 & $36,4 \%$ & 0,009 & 39 & $48,1 \%$ & 3 & $23,1 \%$ & 0,505 \\
\hline & Alto & 26 & $36,1 \%$ & 11 & $50,0 \%$ & & 27 & $33,3 \%$ & 10 & $76,9 \%$ & \\
\hline \multirow{3}{*}{$\begin{array}{c}\text { Total } \\
\text { instrumento } \\
\text { personalidad } \\
\text { creadora } \\
\end{array}$} & Bajo & 15 & $20,8 \%$ & 2 & $9,1 \%$ & & 17 & $21,0 \%$ & 0 & $0,0 \%$ & \\
\hline & Medio & 30 & $41,7 \%$ & 5 & $22,7 \%$ & 0,029 & 32 & $39,5 \%$ & 3 & $23,1 \%$ & 0,040 \\
\hline & Alto & 27 & $37,5 \%$ & 15 & $68,2 \%$ & & 32 & $39,5 \%$ & 10 & $76,9 \%$ & \\
\hline
\end{tabular}

$\mathrm{P}^{*}$ : Chi-cuadrado

Fuente: Elaboración propia

Los resultados presentes en la Tabla 19, nos muestran que existe relación entre la resiliencia después de la intervención con las dimensiones de identificación y solución de problemas $(0,005)$, apertura $(0,007)$, juegos intelectuales $(0,026)$ y total de instrumento de personalidad creadora $(0,006)$. Aunque todas estas asociaciones no presentan un cambio favorable después de la intervención para la resiliencia alta, el modelo de intervención utilizado puede reevaluarse en la intensión de fortalecer las dimensiones que no presentaron cambios a favor de esta. 
Tabla 20. Estadístico de Chi-cuadrado de cada una de las categorías de resiliencia post-test y post -test y su asociación con las dimensiones del instrumento de personalidad creadora pre -test medido en los niños y niñas del colegio CEDID Ciudad Bolivar 2018.

\begin{tabular}{|c|c|c|c|c|c|c|c|c|c|c|c|}
\hline \multirow{3}{*}{ Dimensión } & \multirow{3}{*}{ Categoría } & \multicolumn{5}{|c|}{ Resiliencia Inicial } & \multicolumn{5}{|c|}{ Resiliencia Final } \\
\hline & & \multicolumn{2}{|c|}{ Bajo } & \multicolumn{2}{|c|}{ Alto } & \multirow{2}{*}{$\mathbf{P}^{*}$} & \multicolumn{2}{|c|}{ Bajo } & \multicolumn{2}{|r|}{ Alto } & \multirow{2}{*}{$\mathbf{P}^{\star}$} \\
\hline & & $\mathbf{n}$ & $\%$ & $\mathbf{n}$ & $\%$ & & $\mathbf{n}$ & $\%$ & $\mathbf{n}$ & $\%$ & \\
\hline \multirow{3}{*}{$\begin{array}{l}\text { Identificación } \\
\text { y solución de } \\
\text { problemas }\end{array}$} & Baja & 21 & $29,2 \%$ & 1 & $4,5 \%$ & & 21 & $25,9 \%$ & 1 & $7,7 \%$ & \\
\hline & Media & 23 & $31,9 \%$ & 4 & $18,2 \%$ & 0,202 & 24 & $29,6 \%$ & 3 & $23,1 \%$ & 0,005 \\
\hline & Alta & 28 & $38,9 \%$ & 17 & $77,3 \%$ & & 36 & $44,4 \%$ & 9 & $69,2 \%$ & \\
\hline \multirow{4}{*}{$\begin{array}{l}\text { Invención y } \\
\text { arte }\end{array}$} & Baja & 24 & $33,3 \%$ & 5 & $22,7 \%$ & & 26 & $32,1 \%$ & 3 & $23,1 \%$ & \\
\hline & Media & 40 & $55,6 \%$ & 10 & $45,5 \%$ & 0,006 & 46 & $56,8 \%$ & 4 & $30,8 \%$ & 0,065 \\
\hline & Alta & 8 & $11,1 \%$ & 7 & $31,8 \%$ & & 9 & $11,1 \%$ & 6 & $46,2 \%$ & \\
\hline & Baja & 15 & $20,8 \%$ & 2 & $9,1 \%$ & & 17 & $21,0 \%$ & 0 & $0,0 \%$ & \\
\hline \multirow[t]{3}{*}{ Apertura } & Media & 32 & $44,4 \%$ & 4 & $18,2 \%$ & 0,074 & 32 & $39,5 \%$ & 4 & $30,8 \%$ & 0,007 \\
\hline & Alta & 25 & $34,7 \%$ & 16 & $72,7 \%$ & & 32 & $39,5 \%$ & 9 & $69,2 \%$ & \\
\hline & Baja & 21 & $29,2 \%$ & 3 & $13,6 \%$ & & 23 & $28,4 \%$ & 1 & $7,7 \%$ & \\
\hline \multirow{3}{*}{$\begin{array}{c}\text { Fantasía e } \\
\text { imaginación }\end{array}$} & Media & 26 & $36,1 \%$ & 8 & $36,4 \%$ & 0,041 & 31 & $38,3 \%$ & 3 & $23,1 \%$ & 0,270 \\
\hline & Alta & 25 & $34,7 \%$ & 11 & $50,0 \%$ & & 27 & $33,3 \%$ & 9 & $69,2 \%$ & \\
\hline & Baja & 10 & $13,9 \%$ & 1 & $4,5 \%$ & & 10 & $12,3 \%$ & 1 & $7,7 \%$ & \\
\hline \multirow{2}{*}{$\begin{array}{c}\text { Juegos } \\
\text { intelectuales }\end{array}$} & Media & 39 & $54,2 \%$ & 7 & $31,8 \%$ & 0,058 & 43 & $53,1 \%$ & 3 & $23,1 \%$ & 0,026 \\
\hline & Alta & 23 & $31,9 \%$ & 14 & $63,6 \%$ & & 28 & $34,6 \%$ & 9 & $69,2 \%$ & \\
\hline \multirow{3}{*}{$\begin{array}{c}\text { Total } \\
\text { instrumento }\end{array}$} & Baja & 13 & $18,1 \%$ & 0 & $0,0 \%$ & & 13 & $16,0 \%$ & 0 & $0,0 \%$ & \\
\hline & Media & 30 & $41,7 \%$ & 5 & $22,7 \%$ & 0,172 & 31 & $38,3 \%$ & 4 & $30,8 \%$ & 0,006 \\
\hline & Alta & 29 & $40,3 \%$ & 17 & $77,3 \%$ & & 37 & $45,7 \%$ & 9 & $69,2 \%$ & \\
\hline
\end{tabular}

Con el fin de identificar asociación entre el instrumento de personalidad creadora (juego) y cada una de las dimensiones que se agruparon y sus respectivas variables (ver Tabla 20), se identificó que para las características de los niños no existe relaciones dado que el valor de $p>0,05$, aunque para el caso de la edad el valor de p es igual a 0,057 lo cual puede indicar una relación con los juegos intelectuales. Para el caso de las fortalezas intrapsíquicas (ver Tabla 21) se identifica que para la impulsividad existe relación con la fantasía e imaginación, y para el caso de la afectividad tiene relación con la invención y arte, la apertura, la fantasía e imaginación y los juegos intelectuales dado que el valor de $p<0,05$, para el caso de las emociones positivas, la alegría y gratitud tienen relación con la invención y el arte, al igual que los juegos intelectuales, para el caso de la serenidad presenta relación con la invención y el arte. La simpatía tiene relación con la apertura y la fantasía e imaginación con 
valor de $p<0,05$. Para el caso del vínculo afectivo la afectividad tiene una asociación con la identificación y solución de problema.

Tabla 21. Estadístico de Chi- cuadrado de cada una de las categorías de juego y su asociación con variables de demográficas, familiares e instrumentos medidos en los niños y niñas del colegio CEDI, cuidad, Bolívar 2019.

\begin{tabular}{|c|c|c|c|c|c|}
\hline Dimensiones / Variables & $\begin{array}{c}\text { Identificación } \\
\text { y solución de } \\
\text { problemas }\end{array}$ & $\begin{array}{c}\text { Invención } \\
\text { y arte }\end{array}$ & Apertura & $\begin{array}{l}\text { Fantasía e } \\
\text { imaginación }\end{array}$ & $\begin{array}{c}\text { Juegos } \\
\text { Intelectuales }\end{array}$ \\
\hline \multicolumn{6}{|c|}{ Características de los niños y niñas } \\
\hline Edad del estudiante & 0,777 & 0,240 & 0,473 & 0,752 & 0,057 \\
\hline $\begin{array}{l}\text { Lugar de nacimiento del adulto } \\
\text { que diligencia la encuesta }\end{array}$ & 0,707 & 0,966 & 0,419 & 0,684 & 0,308 \\
\hline Sexo del estudiante & 0,344 & 0,481 & 0,165 & 0,884 & 0,477 \\
\hline $\begin{array}{l}\text { Víctima del conflicto armado } \\
\text { El adolescente tiene alguna }\end{array}$ & 0,917 & 0,394 & 0,437 & 0,107 & 0,263 \\
\hline $\begin{array}{l}\text { discapacidad, limitación } 0 \\
\text { capacidad diferente }\end{array}$ & 0,665 & 0,287 & 0,313 & 0,579 & 0,476 \\
\hline $\begin{array}{l}\text { El adolescente pertenece a } \\
\text { alguna etnia }\end{array}$ & 0,753 & 0,543 & 0,300 & 0,378 & 0,364 \\
\hline \multicolumn{6}{|l|}{ Fortalezas intrapsíquicas "Yo soy" } \\
\hline Impulsividad & 0,070 & 0,693 & 0,965 & 0,008 & 0,252 \\
\hline Autoestima & 0,440 & 0,072 & 0,307 & 0,156 & 0,781 \\
\hline Pensamiento Creativo & 0,124 & 0,197 & 0,646 & 0,217 & 0,763 \\
\hline Afectividad & 0,163 & 0,022 & 0,003 & 0,029 & 0,025 \\
\hline \multicolumn{6}{|c|}{ Habilidades para la acción- El otro- Alteridad "Yo puedo" } \\
\hline Asertividad & 0,168 & 0,433 & 0,393 & 0,583 & 0,985 \\
\hline \multicolumn{6}{|l|}{ Respuestas amortiguadoras } \\
\hline Adaptabilidad & 0,307 & 0,667 & 0,749 & 0,684 & 0,134 \\
\hline \multicolumn{6}{|l|}{ Emociones positivas } \\
\hline Alegría y gratitud & 0,766 & 0,008 & 0,137 & 0,022 & 0,001 \\
\hline Serenidad & 0,045 & 0,033 & 0,255 & 0,066 & 0,066 \\
\hline Simpatía & 0,187 & 0,384 & 0,001 & 0,001 & 0,719 \\
\hline Satisfacción personal & 0,988 & 0,321 & 0,075 & 0,911 & 0,101 \\
\hline \multicolumn{6}{|l|}{ Estilo parental } \\
\hline $\begin{array}{l}\text { Parentesco de quien diligencia la } \\
\text { encuesta }\end{array}$ & 0,961 & 0,190 & 0,747 & 0,347 & 0,547 \\
\hline Aceptación & 0,755 & 0,849 & 0,577 & 0,526 & 0,577 \\
\hline Control aceptado & 0,578 & 0,741 & 0,977 & 0,212 & 0,220 \\
\hline Control estricto & 0,687 & 0,184 & 0,971 & 0,073 & 0,096 \\
\hline \multicolumn{6}{|l|}{ Vínculo afectivo } \\
\hline Afectividad & 0,052 & 0,109 & 0,291 & 0,019 & 0,187 \\
\hline
\end{tabular}

En cuanto a la funcionalidad familiar (ver Tabla 22) no se presentó asociación con ninguna dimensión de juego, por otro lado, las condiciones familiares solo presentaron asociación entre la 
variable principal razón de traslado de la familia a su lugar de residencia actual con fantasía e imaginación valor de 0,025.

Tabla 22. Estadístico de Chi- cuadrado de cada una de las categorías de juego y su asociación con variables de demográficas, familiares e instrumentos medidos en los niños y niñas del colegio CEDI, cuidad, Bolívar 2019.

\begin{tabular}{|c|c|c|c|c|c|}
\hline Dimensiones / variables & $\begin{array}{l}\text { Identificación } \\
\text { y solución de } \\
\text { problemas }\end{array}$ & $\begin{array}{l}\text { Invención } \\
\text { y arte }\end{array}$ & Apertura & $\begin{array}{c}\text { Fantasía e } \\
\text { imaginación }\end{array}$ & $\begin{array}{l}\text { Juegos } \\
\text { Intelectuales }\end{array}$ \\
\hline \multicolumn{6}{|l|}{ Funcionalidad familiar } \\
\hline $\begin{array}{l}\text { Horas a la semana que usted dedica al acompañamiento } \\
\text { y realización de tareas del niño o de la niña }\end{array}$ & 0,825 & 0,968 & 0,758 & 0,799 & 0,057 \\
\hline $\begin{array}{l}\text { Horas a la semana que usted dedica a actividades } \\
\text { lúdicas y recreativas (como juegos y/o deportes) junto al } \\
\text { niño o a la niña }\end{array}$ & 0,355 & 0,581 & 0,093 & 0,729 & 0,316 \\
\hline $\begin{array}{l}\text { Actividades que usted realizó durante la última semana } \\
\text { con el niño o la niña }\end{array}$ & 0,433 & 0,977 & 0,760 & 0,745 & 0,341 \\
\hline \multicolumn{6}{|l|}{ Condiciones familiares } \\
\hline Parentesco de quien diligencia la encuesta & 0,961 & 0,190 & 0,747 & 0,347 & 0,547 \\
\hline Edad del adulto que diligencia la encuesta & 0,622 & 0,413 & 0,022 & 0,645 & 0,388 \\
\hline Lugar de nacimiento del adulto que diligencia la encuesta & 0,707 & 0,966 & 0,419 & 0,684 & 0,308 \\
\hline Género del adulto & 0,905 & 0,147 & 0,707 & 0,712 & 0,600 \\
\hline Tipo de afiliación & 0,551 & 0,512 & 0,450 & 0,578 & 0,411 \\
\hline Lugar de residencia & 0,628 & 0,274 & 0,269 & 0,380 & 0,478 \\
\hline Tipo de vivienda & 0,312 & 0,308 & 0,707 & 0,193 & 0,157 \\
\hline La vivienda ocupada por este hogar es & 0,317 & 0,537 & 0,605 & 0,585 & 0,502 \\
\hline Esta vivienda se encuentra en el & 0,991 & 0,483 & 0,455 & 0,231 & 0,633 \\
\hline Cantidad de miembros que conforman el hogar & 0,900 & 0,706 & 0,317 & 0,382 & 0,721 \\
\hline Tipo de familia & 0,797 & 0,102 & 0,600 & 0,616 & 0,197 \\
\hline Cuantos aportan al ingreso del hogar & 0,826 & 0,514 & 0,151 & 0,824 & 0,713 \\
\hline Ingreso mensual promedio del hogar & 0,863 & 0,270 & 0,746 & 0,610 & 0,832 \\
\hline De dónde provienen los ingresos de este hogar & 0,709 & 0,575 & 0,554 & 0,276 & 0,490 \\
\hline Tiempo que lleva este hogar viviendo en esta ciudad & 0,246 & 0,923 & 0,212 & 0,758 & 0,426 \\
\hline Tiempo que lleva este hogar viviendo en este barrio & 0,548 & 0,902 & 0,409 & 0,615 & 0,597 \\
\hline Lugar de procedencia del grupo familiar & 0,713 & 0,313 & 0,775 & 0,112 & 0,192 \\
\hline $\begin{array}{l}\text { Principal razón de traslado de la familia a su lugar de } \\
\text { residencia actual }\end{array}$ & 0,830 & 0,344 & 0,675 & 0,025 & 0,316 \\
\hline $\begin{array}{l}\text { ¿Se considera usted o algún miembro de su hogar } \\
\text { víctima del conflicto armado? }\end{array}$ & 0,868 & 0,543 & 0,786 & 0,119 & 0,774 \\
\hline $\begin{array}{l}\mathrm{Si} \text { la anterior respuesta fue afirmativa, ¿tiene } \\
\text { reconocimiento como víctima del conflicto armado? }\end{array}$ & 0,689 & 0,255 & 0,407 & 0,124 & 0,563 \\
\hline $\begin{array}{l}\text { Último nivel educativo aprobado por el adulto que } \\
\text { diligencia la encuesta }\end{array}$ & 0,957 & 0,921 & 0,943 & 0,419 & 0,772 \\
\hline $\begin{array}{l}\text { El menor nivel educativo aprobado por alguno de los } \\
\text { miembros de su hogar }\end{array}$ & 0,289 & 0,145 & 0,523 & 0,442 & 0,391 \\
\hline $\begin{array}{l}\text { El mayor nivel educativo aprobado por alguno de los } \\
\text { miembros de su hogar }\end{array}$ & 0,946 & 0,371 & 0,484 & 0,375 & 0,475 \\
\hline
\end{tabular}

$\mathrm{P}^{*}$ : Chi-cuadrado

Fuente: Elaboración propia 
Al finalizar la intervención desde el modelo RARE, estadísticamente se identificaron algunas mejoras en las fuentes ontosistémicas de la resiliencia infantil de los estudiantes de quinto, como lo son:

- En la categoría de fortalezas intrapsíquicas se encontró que el modelo logró que los estudiantes del grado quinto tuvieran una autoestima y pensamiento crítico moderado y no impulsivo, se puede asimilar a un grado un poco mayor de criticidad a medida que avanza la edad. Lo mismo, se encontró una relación entre resiliencia alta y afectividad.

- En la categoría de emociones positivas, después de la intervención se encontró que los estudiantes del grado quinto están en alto en los tres primeros constructos (Alegría, serenidad y simpatía)

- Para el caso de la dimensión de personalidad creadora (juego), para los constructos de identificación y solución de problemas y juegos intelectuales se identificó un leve aumento en el $50,0 \%$ de los datos después de la intervención y total del constructo de personalidad creadora.

- Se identifica que para la impulsividad existe relación con la fantasía e imaginación, y para el caso de la afectividad tiene relación con la invención y arte, la apertura, la fantasía e imaginación y los juegos intelectuales dado que el valor de $p<0,05$, para el caso de las emociones positivas, la alegría y gratitud tienen relación con la invención y el arte, al igual que los juegos intelectuales, para el caso de la serenidad presenta relación con la invención y el arte. La simpatía tiene relación con la apertura y la fantasía e imaginación con valor de $p<0,05$. Para el caso del vínculo afectivo la afectividad tiene una asociación con la identificación y solución de problema.

Lo anterior, permite demostrar que el modelo RARE cumplió con su apuesta: movilizar el Ethos creativo desde la morada interior, los hábitos y como cogito, pues se movilizaron en menor medida las posturas de la vida, las actitudes, los valores y los modos de pensar. 
Todo lo anterior demuestra que el juego como acto creativo es una buena herramienta para la promoción de la resiliencia, pues, aunque estadísticamente los resultados no son abrumadores, si se logra hacer una relación importante en los diferentes constructos trabajados.

Así mismo, se logra evidenciar que el juego sigue cumpliendo su función esencial: ser un lenguaje universal y la vida cotidiana de los niños y niñas y que al ser utilizado como medio para la promoción de la resiliencia, logra resultados interesantes para quienes lo juegan. En el modelo RARE el protagonista fue el juego y la resiliencia fue el resultado. 
7. CAPÍTULO 7. PROPUESTA DE

INTERVENCIÓN BASADA EN EL JUEGO 
"Yo pienso que lo primero que hay que garantizarles a los niños es un presente digno. Por ejemplo, en el tema del desplazamiento, el problema no es el hecho del desplazamiento, sino que el niño siga viviendo como desplazado. Cualquier persona que vaya a Soacha o a Cazucá se dará cuenta de que es muy difícil que ahí alguien pueda crecer y soñar con un futuro. Si no tenemos la capacidad de garantizarles un presente que les permita proyectar un futuro con esperanza no los podemos poner a revivir el pasado. No tiene la capacidad emocional para soportar esto" (Campo, 2014).

La cotidianidad en la localidad de Ciudad Bolívar se ve permeada por la inseguridad generalizada, el microtráfico, la delincuencia común, el pandillismo, la prostitución, los grupos desmovilizados que siguen delinquiendo y los "loteadores" piratas, además de carecer de servicios básicos como agua potable, alcantarillado, redes telefónicas, gas e infraestructura vial que facilite el ingreso a la zona.

En contexto, los y las niñas participantes del proceso fueron estudiantes de la Institución Educativa CEDID Ciudad Bolívar, la cual está ubicada en la Unidad de Planeación Zonal - UPZJerusalén, conformada por 15 barrios en los cuales habitan las familias. De manera ampliada la localidad Ciudad Bolívar es la tercera localidad de Bogotá más grande y con mayor superficie después de Sumapaz y Usme, e históricamente se ha caracterizado por ser un territorio que ha acogido y ha sido construido paso a paso por comunidades provenientes de distintas regiones del país a causa del desplazamiento forzado, o por la búsqueda de nuevas oportunidades en la capital, ubicándose así en la periferia de la ciudad. Actualmente la localidad, alberga un total de 616.455 habitantes un $8,5 \%$ de la población total de Bogotá, para los cuales están dispuestos 66 colegios oficiales, 106 colegios no oficiales o privados y 1 universidad. En este marco, según registros de la Secretaria de Educación del Distrito, para el 2019 de la matricula total de estudiantes de colegios oficiales de la localidad Ciudad Bolívar, 11.742 son víctimas del conflicto armado, y específicamente la institución educativa CEDID Ciudad Bolívar tiene un total de 746 estudiantes víctimas del conflicto, la segunda con más población de esta condición después de la institución educativa Sierra Morena que tiene un total de 955 estudiantes víctimas. 
Así se da la cotidianidad de los niños y niñas habitantes de la localidad de Ciudad Bolívar que participaron en la aplicación del modelo RARE: crecieron en un territorio difícil, hostil, precario, que no ofrece condiciones adecuadas para su desarrollo integral. Un territorio con alta presencia de organizaciones nacionales e internacionales de ayuda humanitaria, pero sin acceso a servicios básicos; un escenario con juego, pero sin espacios dignos para el mismo. Un espacio para construir, jugar y soñar.

El modelo RARE "Rayuela Resiliera" se ejecutó entre los meses de agosto y noviembre del año 2018 en la Institución Educativa Distrital CEDID - Sede Tanque Laguna, jornada mañana, ubicado en la localidad de Ciudad Bolívar - Bogotá, Colombia. La intervención con los estudiantes de $5^{\circ}$ grado fue priorizada por las directivas institucionales del plantel educativo y el equipo investigador, dado que esta población en particular se encuentra a puertas de cambios trascendentales en sus vidas como el inicio del bachillerato, lo cual significa que deberán asistir a otra sede y adquirir mayor capacidad de responsabilidad, autonomía y seguridad; y las dinámicas propias de la adolescencia, entre otras.

Las actividades desarrolladas se basan en la promoción de la resiliencia y su incidencia en las acciones o respuestas ante situaciones problemáticas de sus vidas, por lo que con ello se pretende validar un modelo psicosocial para la promoción de la resiliencia basado en el juego para niños y niñas denominado RARE "Rayuela Resiliera", donde variables como la personalidad creadora y los vínculos y tipologías de la crianza parental inciden o no en la capacidad de resiliencia de los y las estudiantes.

Se desarrollaron 8 talleres de trabajo, con encuentros de 3 horas semanales por cada curso, donde se implementaron diferentes temáticas para la atención psicosocial y la promoción de la resiliencia a partir del modelo ilustrado a continuación.

\subsection{Taller $N^{\circ}$ 1: caracterización y construcción de historia y personaje}

Descripción de la actividad: Se abre un espacio de diálogo, confianza, juego y reflexión para el reconocimiento de la historia de vida y características personales de cada estudiante, con la intención de identificar y caracterizar a la población. 


\section{Objetivo:}

- Caracterizar desde historias de vida los y las participantes del grado $5^{\circ}$ y construir desde referentes identitarios el personaje que les acompañará en el proceso de implementación del modelo de resiliencia.

Desarrollo: Se inicia la sesión con la presentación e identificación de cada estudiante y participante, al mencionar el nombre, edad y lugar de nacimiento de cada uno y cada una, de igual manera se presenta y explica el componente clave del proyecto RARE, entorno a los significados de la resiliencia y su importancia. Posteriormente se establecen acuerdos y normas de trabajo para la participación y desarrollo de esta y cada una de las siguientes sesiones. Seguido, se suministra a los niños y niñas el material necesario para dibujar un árbol que los represente según sus características, a partir de las siguientes indicaciones: Raíces: Dónde nació, cuándo nació, y elementos culturales que identifica como sus raíces. Cuál es su lengua materna y qué es lo que más recuerda de la infancia 0 de cuando era más niño. Tronco: Quiénes son sus familiares, dónde nacieron sus familiares, si viven o no con ellos, cuáles son las enseñanzas de su familia que arraigan su vida y le permiten sostenerse. Ramas en el árbol: Ubica qué hace actualmente, cuáles son sus diferentes talentos y gustos, su mascota, y cuáles son esas cosas que disfruta hacer que le llevan a expandir su vida. Ramas en el piso: Ubica que ha sido lo más triste que le ha sucedido, y los elementos que le generan temor, miedo e inseguridad. Frutos: Ubica los sueños y metas que tiene. A dónde quiere llegar y esas apuestas que dan sentido a su vida. Qué quiere ser cuando sea grande y cuál es su principal fortaleza. Finalmente, se permite la socialización de los árboles, haciendo énfasis en las reflexiones, preguntas, similitudes y diferencias que manifiestan los niños y niñas.

Análisis: Para el desarrollo de la primera sesión de trabajo fue indispensable el reconocimiento, la creación de vínculos y la construcción de confianza entre las y los estudiantes con los moderadores, por lo que la empatía y el carisma por parte de los mismos a la hora de relacionarse, jugar y aprender son elementos claves que posibilitan el cumplimiento de los objetivos propuestos en consideración al manejo de grupo. Los niños y niñas se muestran muy animados, sinceros, confiados y abiertos a la hora de expresar los elementos y características propias de sus personalidades e historias de vida, por lo que la participación es activa y permanente. En este primer acercamiento fue evidente la buena disposición de los dos grupos por participar en el proyecto al experimentar procesos 
de aprendizaje distintos a los académicos tradicionales. Finalmente, a la hora de socializar y reflexionar sobre las enseñanzas del día se pudo comprender que la mayoría de los niños y niñas tienen fuertes lazos con sus familiares y amigos y han experimentado tristezas como la soledad al extrañar a sus padres producto de las largas jornadas de trabajo que ellos deben desempeñar, el fallecimiento de un ser querido, una mascota o una separación, lo cual incide en sus niveles de resiliencia, independencia y autoestima.

Dificultades: Dentro de lo esperado, se pudo evidenciar algunas falencias en la capacidad de escucha activa y seguimiento de instrucciones por parte de algunos estudiantes, lo cual dificulta el manejo del tiempo y el cumplimiento oportuno de las actividades.

\section{Conclusiones y recomendaciones:}

- La sesión permitió la caracterización parcial de los niños y niñas, sin embargo, es necesario seguir desarrollando diferentes encuentros que permitan mayor comprensión y conocimiento de la población.

- El trabajo en equipo, la escucha activa, el seguimiento de instrucciones y la construcción de confianza son elementos indispensables para dar continuidad al proceso.

- Se debe ser más enfático en el manejo del tiempo y la cantidad de actividades a desarrollar desde la planeación metodológica, con el fin de no saturar la sesión ni dejar ejercicios por desarrollar.

\subsection{Taller $\mathrm{N}^{\circ}$ 2: Reciprocidad y construcción de confianza}

Descripción de la actividad: La sesión se centra en el objeto vinculante "Balón" al desarrollar espacios de interacción y juego que les permita a los niños y niñas relacionarse consigo mismos y con los demás desde la cooperatividad y el respeto mutuo.

\section{Objetivo:}

- Posibilitar diferentes espacios de juego con el balón que permita desarrollar procesos de confianza mutua, reciprocidad, y acuerdo en colectividades. 
Desarrollo: Se da inicio a la sesión con la actividad "Yo soy" donde a partir del uso y creación de escarapelas se invita a los niños y niñas escribir sus nombres como un ejercicio de reflexión alrededor del derecho al nombre, la identidad y el buen trato. Para continuar, se comunica el sentido primordial del taller alrededor del objeto vinculante "balón", por lo que se abre un espacio de diálogo sobre la historia, características, usos y expectativas sobre las actividades desarrolladas entorno a balones, como por ejemplo los juegos y deportes que invitan al trabajo en equipo, la solidaridad y la construcción de confianza. Así, se realiza una lluvia de ideas sobre juegos con balones o pelotas, se seleccionan algunos de ellos y se procede a jugar, con la intención de poner a prueba la relación entre teoría y práctica sobre la capacidad de relación, reciprocidad, confianza y trabajo en equipo que pueden desarrollar los niños y niñas a la hora de jugar, desde los imaginarios que ellos mismos tienen. Posterior al juego, se crea un espacio en forma de círculo donde todas y todos tendrán la oportunidad de expresar voluntariamente los aprendizajes y opiniones sobre lo ocurrido durante la sesión.

Análisis: Durante la segunda sesión de trabajo se pudo evidenciar que la falta de reconocimiento y unión entre los integrantes genera distanciamiento e individualismo dificultando el trabajo en equipo, por lo que su capacidad de respetar la diferencia, de aprender de otros y de adaptarse al cambio aún está en construcción, de igual manera, entre ellos y ellas no son cuidadosos pues no reconocen al otro durante el juego, no son capaces de escucharse ni respetarse y se les dificulta seguir instrucciones y normas para el juego limpio. Las actitudes violentas de algunos compañeros, especialmente en los varones, generan descontento y desunión en el grupo, donde distinciones por edad y por sexo como la organización y la participación, dejan en claro que las niñas suelen ser segregadas y aisladas a la hora de jugar, al igual que los integrantes más jóvenes del grupo suelen ser violentados por sus compañeros de mayor edad; por ende, no se evidencian indicios suficientes o significativos de reciprocidad y construcción de confianza para la resiliencia colectiva o comunitaria.

Finalmente, la sesión les permitió a los niños y niñas deconstruir imaginarios sobre el juego al contrarrestar la teoría y la práctica tras comprar lo que ellos y ellas consideran que pueden aprender y desarrollar al jugar de manera colectiva versus lo que aprendieron y vivenciaron durante la actividad, demostrando así que el juego en sí mismo no es elemento suficiente para desarrollar 
empatía, confianza y respeto, por lo que es necesaria la buena disposición y el bagaje cultural que cada uno y cada una puede aportar para el disfrute grupal y a su vez individual.

Dificultades: Se dificultó el manejo de grupo al aire libre o en espacios poco usuales pues los niños y niñas tienden a ignorar a la moderadora en consideración a su capacidad de escucha activa y el seguimiento de instrucciones.

En esta ocasión, la institución educativa programó actividades distintas a las acordadas con el equipo de trabajo en espacios alternos, lo que implicó readaptar la planeación en sintonía al cumplimiento de objetivos.

\section{Conclusiones y recomendaciones:}

- En uno de los grupos se pudo evidenciar que los niños y niñas no son tan cuidadosos como se esperaba al hacer del juego un escenario violento donde prima la competencia y el disfrute personal; en el otro curso se visibilizan mayores habilidades de juego en grupo, y a pesar de empujar o golpear en medio de las dinámicas propias del juego, mantienen la calma y procuran la diversión colectiva.

- La capacidad de liderazgo y autoridad en algunos de los niños y niñas puede ser utilizada para motivar y fomentar la participación de todo el curso, como una alianza o metodología estratégica de trabajo.

- El manejo del espacio es importante acordarlo con tiempo con los docentes para no interrumpir clases o delimitar espacios de trabajo.

\subsection{Taller $\mathrm{N}^{\circ}$ 3: Asertividad y afectividad}

Descripción de la actividad: La sesión ha sido diseñada para socializar los elementos claves del modelo RARE con los niños y niñas, a través de su apropiación y comprensión, y como juguete vinculante se crean "teléfonos" con vasos y cuerdas con la intención de poner a prueba su capacidad para comunicarse y relacionarse asertiva y afectivamente. 


\section{Objetivo:}

- Retomar la construcción del personaje del modelo "Beis", el árbol y la rayuela como elementos contextuales para el fortalecimiento de la resiliencia en los y las participantes.

- Construir el juguete del teléfono, enfatizar en los canales de comunicación consigo mismo y los demás desde el juego, así como en elementos de asertividad y diálogo intercultural.

Desarrollo: Para el desarrollo de la tercera sesión de trabajo se realiza un ejercicio de recuento con los integrantes sobre las actividades y experiencias desarrolladas anteriormente, acto seguido, se da a conocer la temática a trabajar durante el encuentro y las actividades propuestas. En primer lugar, se presentan y explican cada uno de los tres elementos que hacen parte del logo y modelo RARE: La rayuela o golosa, que representa el proceso de aprendizaje y juego a desarrollar sesión a sesión entorno a la resiliencia; Beis, quien es el personaje y amigo imaginario que acompañará el proceso, y que a su vez ha sido personalizado según las preferencias y características del curso; y por último, el árbol, que representa la historia y pertenencia de cada uno y cada una en el grupo. Una vez socializados los elementos, se forman 3 grupos de trabajo y se entrega el material necesario para decorar dichos objetos, haciendo alusión al sentido de identidad y cuidado que representa el construir colectivamente.

En segundo lugar, se entrega el material necesario para crear los teléfonos y se invita a los niños y niñas a conversar y reflexionar sobre la comunicación y las relaciones asertivas y afectivas; de igual manera, se ponen a prueba sus capacidades de transmisión de mensajes y actitudes positivas y agradables al jugar con los teléfonos. Finalmente, a partir de la lectura del cuento "Las palabras de Juan" se abre un espacio de diálogo para socializar las ideas, aprendizajes y sentimientos que surgieron durante la sesión.

Análisis: La sesión de trabajo fue muy diferente entre un curso y otro, por su parte 502 vivenció una sesión marcada por mucha armonía, por lo que las emociones no fueron individualizadas ni diferenciadoras; por el contrario, el grupo mostró una gran disposición de trabajo, alegría, positivismo y entusiasmo por las actividades a desarrollar. Se destacaron por su buen trabajo en equipo, compañerismo y solidaridad a la hora de decorar, jugar y reflexionar entre unos y otros, por lo que se considera que han demostrado actitudes resilientes individual y colectivamente, al 
mejorar sus dinámicas grupales y superar inconvenientes de las sesiones pasadas.

Por su parte en el curso 501 fue notorio que los niños y niñas tienen dificultades de comunicación y escucha no solo entre ellos como curso, sino que también evidencian comunicaciones poco asertivas y poco afectivas en casa, al punto de sentirse solos y tristes. Esto da cuenta del tipo de problemáticas y relaciones familiares, sociales y académicas que vivencian los y las estudiantes, donde se vuelve indispensable potenciar estrategias resilientes que les permita hacer frente a las situaciones que los hieren o lastiman.

Otro elemento que se destacó en el curso fue la falta de comprensión y reconocimiento de las diferentes formas de ser, hacer, pensar y sentir por la forma en que se relacionan unos con otros, entre las comunicaciones violentas, contestatarias, acusadoras y retadoras, y las frases y actitudes de desaprobación, reproche e intolerancia, se hace notoria la necesidad de potenciar el reconocimiento, cariño y respeto por el otro y la otra, así que, es posible que en el momento en que se fortalezca la identidad grupal mediante el reconocimiento de cada individuo como parte del todo, el curso se sentirá más unido y cohesionado, facilitando dinámicas grupales más sanas.

Dificultades: Diferentes imprevistos como la contención emocional, las actividades adicionales programadas por la institución educativa, y las dinámicas de trabajo que cada curso acostumbra a desarrollar, incidieron en el manejo del tiempo, el cumplimiento del planeador y la atención oportuna de los casos emergentes.

\section{Conclusiones y recomendaciones:}

- Las actividades manuales son muy bien recibidas por los niños y niñas ya que fomentan aspectos como el trabajo en equipo, la creatividad, la solidaridad, especialmente en el curso 501.

- El curso 502 no logró superar la estación de comunicación asertiva y afectiva de manera satisfactoria dado que no se escuchan ni comunican apropiadamente.

- Es necesario hacer seguimiento a los casos especiales que han ido manifestándose en el curso para procurar realizar una intervención completa con los niños y niñas, pues no es conveniente encontrar problemáticas y no solucionarlas. 


\subsection{Taller $\mathrm{N}^{\circ}$ 4: Autoestima, auto concepto y resistencia}

Descripción de la actividad: Como juguete vinculante se crean "muñecas quitapesares" las cuales desde su historia cultural y origen propician un encuentro de introspección con la intención de reconocer las situaciones que afectan negativamente a los niños y niñas y sus posibles potencialidades para solucionar dichas penas.

\section{Objetivo:}

- Facilitar espacios de introspección e interiorización que permitan entender las tristezas de cada participante y sus fortalezas para aprender a sobrellevarlas.

Desarrollo: La sesión inicia con la adecuación del espacio y la presentación de la temática del día; para ello, se da a conocer la historia de las muñecas quitapesares al leer la reseña informativa sobre su origen, y se explica que durante la sesión, cada niño y cada niña podrá crear su propia muñeca; acto seguido, se procede a crear y decorar las muñecas. A partir de la guía e instrucción de la psicóloga se invita a los niños y niñas realizar un ejercicio de introspección donde tendrán la oportunidad de pensar en las situaciones que les generan estrés, tristezas o penas, para posteriormente, generar la posibilidad de que cada uno y cada uno acepte y agradezca a la vida por los aprendizajes que le permite tener al enfrentar diferentes retos día a día, enfocando su mayor y mejor energía en las alternativas de solución que pueden brindar a ellos con tal de superarlos y ser resilientes ante las dificultades. Al finalizar el ejercicio de introspección la psicóloga invita a los niños y niñas a escribir una carta a la muñeca quitapesares donde depositaran sus penas y tristezas, con la intención de desahogarse y expresar sus emociones sanamente.

Luego de realizar las cartas se le entrega a cada integrante una silueta de un niño donde podrá decorarlo y caracterizarlo con las fortalezas y habilidades propias, para así reconocer las cualidades que les permite superar sus dificultades y ser resilientes ante la adversidad.

Por último, se abre un espacio de reflexión y análisis sobre lo vivenciado en la sesión entorno a las emociones y experiencias que cada integrante voluntariamente quiera compartir. 
Análisis: La sesión estuvo enmarcada en emociones de tristeza, frustración y dolor, y gran parte de los niños y niñas exteriorizaron su sentir mediante el llanto, fue evidente en sus rostros la preocupación y desilusión que les causan sus problemas, especialmente en el ámbito familiar, pues las indicaciones del ejercicio de introspección que se enmarcaron en la familia, fueron el detonante de las emociones.

Los niños y niñas identifican como problemáticas los vínculos familiares y el poco tiempo que comparten con sus padres; el manejo de emociones como el dolor, la tristeza y la soledad; las dificultades propias de la escuela como la superación de asignaturas y la aprobación del año escolar; la realización de eventos públicos como bailes, exposiciones y competencias deportivas; y las relaciones sociales, familiares y académicas. No obstante, también manifiestan deseos de superación de dichas problemáticas al ser mejores seres humanos, superar sus miedos, ser fuerte, valientes y respetuosos, y mejorar sus relaciones sociales.

Aunque, al finalizar la sesión gran parte de los y las estudiantes se muestran tranquilos y alegres de poder contar sus preocupaciones y tener sus muñecas quitapesares, se sentía tensión y angustia a nivel general, no obstante, las características personales y colectivas le permitió a la gran mayoría de estudiantes superar la sensación de tristeza individual y grupal para lograr resistir y modificar su estado de ánimo.

Dificultades: Dada la gran cantidad de actividades propuestas para el taller y la sensibilidad que éste evocaba, no fue posible desarrollar a cabalidad el total de ejercicios planeados, pues la contención de emociones no fue suficiente, dado que los niños y niñas se desbordaron más de lo esperado, al no contar con preguntas o indicaciones suficientes para que la psicóloga pudiera evocar las penas y preocupaciones de los y las estudiantes para después reactivar las emociones positivas en los mismo y así superar la tristeza, no obstante se entiende que lo ideal era aprovechar esa tristeza para escribir las cartas, como un ejercicio de desahogo, y luego con las siluetas y fortalezas recuperar el estado anímico del curso, pero las emociones sobrepasaron la planeación, de tal manera que fue necesario recuperar la sensación de alegría y tranquilidad en los niños y niñas obviando algunos elementos de la planeación por cuestiones de tiempo y manejo de grupo. 


\section{Conclusiones y recomendaciones:}

- Es importante tener en cuenta los resultados de esta sesión para la planeación de las temáticas próximas entorno a vínculos familiares, pues la mayoría de niños y niñas muestran dificultades emocionales alrededor de sus hogares.

- La sesión fue satisfactoria en la identificación de problemáticas y penas en los niños y niñas, recibieron y apreciaron positivamente el aporte cultural con la muñeca y fue una excusa bien guiada para el reconocimiento de emociones.

- A pesar de las problemáticas emocionales, el curso 502 cuenta con vínculos más sólidos y estables en comparación con sus pares de 501, lo que favoreció su capacidad de reponerse ante la sensación de tristeza causada al evocar las penas, y favoreció el apoyo, la solidaridad y la comprensión entre unos y otros.

\subsection{Taller $\mathrm{N}^{\circ}$ 5: Interdependencia e impulsividad}

Descripción de la actividad: La sesión se enfoca en la capacidad de hacer frente y resistir ante problemáticas que aquejen a los niños y niñas invitándolos a ser resilientes para poder sobrellevar y superar sus preocupaciones, para ello se utiliza el "costal" o "saco" como juguete vinculante, en un clásico juego de relevos.

\section{Objetivo:}

- Reconocer factores propios de impulsividad (Fortalezas para el logro persistente de objetivos), posibilitar mediante el juego la interdependencia humana para alcanzar metas colectivas, e identificar algunos referentes primarios de tutores de resiliencia.

Desarrollo: Haciendo uso de la imaginación y la fantasía se dice a los niños y niñas que Beis ha traído a la sesión las historias y experiencias de algunos modelos y ejemplos de resiliencia; para ello, se enseñan las imágenes de Mariana Pajón, Yerry Mina, Catherine Ibargüen y Nairo Quintana, como deportistas de alto rendimiento quienes a pesar de las dificultades que han sobrepasado a lo largo de sus vidas, han logrado desarrollar habilidades resilientes que les posibilita aprender y seguir adelante para ser seres humanos exitosos profesional y personalmente. Esta actividad se complementa al preguntar a los niños y niñas momentos 0 anécdotas de sus vidas en 
que han sido resilientes, persistentes y resistentes ante la adversidad y cómo han logrado seguir adelante; la mayoría de intervenciones se basan en situaciones de riesgo como accidentes físicos al escalar árboles, aprender a manejar bicicleta o patines o caídas y golpes durante el juego. Otras intervenciones dan cuenta de la resiliencia al sobreponerse de la muerte de un ser querido o mascota, una mudanza o la separación de los padres.

Con la identificación de experiencias entorno a la resiliencia se invita a los niños y niñas a aprender de las dificultades, a vivir con aceptación sus preocupaciones y a enfocarse en posibles soluciones que se encuentren a su alcance o que hagan de sus vidas más llevaderas y felices, teniendo como objetivos principales la paz, la tranquilidad y el bienestar propios al ser persistentes ante la adversidad.

Para continuar, se invita a los niños y niñas a experimentar de manera figurativa el significado de la resistencia, la persistencia y la resiliencia a través de un juego de relevos en el que todos y todas participaran; para ello se prepara una secuencia de actividades entre la carrera de costales, saltos en pareja como si fuesen sapitos, la carretilla y la competencia de pimpones con cucharas. Durante el ejercicio los y las estudiantes enfrentan diferentes obstáculos como el cansancio, la frustración y el trabajo en equipo.

El taller finaliza con un espacio de encuentro y compartir de experiencias, opiniones y sentimiento evocados durante la sesión.

Análisis: A lo largo de toda la sesión de trabajo se evidenció felicidad, alegría, gusto y compañerismo entre los y las estudiantes. Aún se hace notoria las dificultades de escucha y seguimiento de instrucciones, no obstante, se logra evidenciar avances en el manejo de emociones y la expresión de estas, pues sienten confianza en comunicar lo que sienten y piensan.

Así mismo, demostraron habilidades de resiliencia individual y colectiva, al motivarse y apoyarse unos a otros para poder disfrutar de la actividad y tardar el menor tiempo posible. No obstante, varios niños y niñas manifiestan no poder jugar diferentes etapas de la actividad pues sus compañeros no comparten los materiales o espacios entre todos y todas. Algunos de ellos lograron 
hablar con sus pares y negociar espacios de juego, otros buscaron ayuda con los adultos, quienes trataron de encontrar soluciones prácticas para algunos casos, y otros simplemente prefirieron no jugar o resignarse a las condiciones del ejercicio.

Dificultades: No se contó con todo el tiempo esperado para la realización de la sesión, por lo que fue necesario obviar algunos elementos metodológicos y priorizar el tiempo de juego.

\section{Conclusiones y recomendaciones:}

- El equipo de trabajo, la docente y los mismos estudiantes desean fomentar más espacios y actitudes de unión entre todos y todas, pues la actividad les permitió sentirse unidos al jugar como curso, pero al mismo tiempo evidenciar que aún hay elementos por mejorar, pues no todos y todas se sienten integrados e integradas plenamente.

- Se pudo evidenciar la capacidad resiliente en los niños y niñas de manera individual y colectiva, facilitando la comprensión y vivencia del concepto de manera cotidiana.

- Es necesario acordar espacios y tiempos de juego con relación a las actividades adicionales programadas por la institución educativa para facilitar el cumplimiento de objetivos.

\subsection{Taller $\mathrm{N}^{\circ}$ 6: Pensamiento crítico y sentido del humor}

Descripción de la actividad: La sesión se desarrolla en torno a la capacidad del pensamiento, los juegos de imaginación y el sentido del humor, para ello se utiliza como objeto vinculante un "acertijo" el cual invita a los niños y niñas a la concentración, la persistencia y el razonamiento.

\section{Objetivo:}

- Desarrollar estrategias que promuevan en los y las participantes el pensamiento crítico y el sentido del humor como elementos fundamentales para el fortalecimiento de la resiliencia.

Desarrollo: La sesión se inicia con la actividad rompehielo "Maremoto" donde a partir de diferentes instrucciones, los y las estudiantes deben cambiar de asiento entre unos y otros, con la intención de jugar, disfrutar y motivar las buenas energías. Para continuar, se invita a los niños y 
niñas a utilizar su imaginación para poder realizar un viaje a la playa, para ello, deberán descubrir la pista que les permite subirse al avión que los lleva hasta dicho lugar, al hacer uso del sentido del humor y el pensamiento crítico. Todos y todas deberán decir su nombre y un objeto que llevarán al viaje, y dependiendo del objeto que propongan tendrán la oportunidad de ir o no. El acertijo consiste en que dependiendo de la inicial de sus nombres deberán decir un objeto que comience con la misma letra; una vez todos y todas logren comprender el ejercicio se dice que puede viajar la totalidad del grupo y se culmina la actividad.

Seguido de lo anterior, se indica a los integrantes crear parejas y ubicarse en sus pupitres para poder realizar la próxima actividad de pensamiento crítico, donde deberán descubrir la casa en que vive el pececito en el clásico acertijo "Las casa de diferentes nacionalidades y el pececito", donde a partir de pistas como el color de la casa, la nacionalidad del su dueño, la ubicación de las residencias, la bebida favorita y la mascota de los dueños, se reta a los jugadores a ubicar la información de manera racional y organizada, para finalmente descubrir dónde vive el pez.

Una vez culminado el acertijo y descubierto el lugar de vivienda, se abre un espacio de diálogo y reflexión sobre lo vivenciado durante la sesión.

\section{Análisis:}

La sesión se desarrolló con normalidad, las emociones fueron muy positivas, se evidenció alegría, disfrute, solidaridad y trabajo en equipo por parte del curso.

El ejercicio de maremoto les permitió liberar energía y fomentar actitudes positivas, y a pesar del nivel de dificultad de los acertijos los niños y niñas intentan solucionarlos de manera persistente.

La actividad del acertijo sobre el pececito fue la que mayor dificultad representó para los y las estudiantes y aunque no lograron solucionarlo por sí mismos, intentaron hasta el último minuto hallar las respuestas y resultados correctos, tanto individual como colectivamente, demostrando su capacidad de persistencia y esfuerzo, características propias de la resiliencia.

Dificultades: Se presentaron dificultades como el manejo del tiempo y la falta de escucha 
por parte de los niños y niñas, lo cual demora el proceso y pone en riesgo el cumplimiento de los objetivos.

\section{Conclusiones y recomendaciones:}

- Los niños y niñas reconocen el sentido del humor y el pensamiento crítico como habilidades que les ayudan a superar problemáticas.

- Es visible el cambio, unión y mejoría al interior de los cursos.

- El apoyo de las docentes es un elemento vital que se ha destacado durante el proceso para el buen desarrollo de las sesiones.

\subsection{Taller $N^{\circ}$ 7: Vínculos familiares}

Descripción de la actividad: El taller ubica como juguete vinculante el teatro, donde a partir de la actuación y la puesta en escena los niños y niñas podrán dar a conocer la cotidianidad de sus dinámicas familiares, las tensiones, alegrías y soluciones en el diario vivir con sus padres, y así mismo identificar redes de apoyo familiares.

\section{Objetivo:}

- Reflexionar alrededor de los vínculos familiares identificando tutores de resiliencia y abordaje de situaciones cotidianas.

Desarrollo: Para iniciar la sesión y a modo de preparación se invita a los niños y niñas a participar de juego tradicional "El lobo está" como actividad rompehielos, donde a partir de la actuación se entra en personaje y se abre un espacio de confianza y respeto entre todos y todas con el fin de priorizar el juego, la diversión y el aprendizaje. Para continuar se propone el juego "Charadas" en el que los y las estudiantes deberán actuar diferentes personajes que deberán ser adivinados por sus compañeros quienes harán las veces de público, en primer lugar y de manera individual actuarán animales sin pronunciar sonidos, en segundo lugar y de manera grupal actuarán algunas películas de igual manera sin pronunciar palabras ni sonidos, y por último, de manera grupal actuarán algunas situaciones de la vida cotidiana como la navidad, la pérdida de una materia, el 
primer día de clases, entre otras.

Finalmente, la sesión culminó con el compartir de experiencias y opiniones sobre lo vivenciado durante la sesión de juego.

Análisis: Durante las actividades desarrolladas en el patio los y las estudiantes jugaron activa y participativamente, al punto en que la alegría se contagió a otros cursos que se integraron paulatinamente al juego. El éxito de la integración y el disfrute de la actividad rompió con límites estructurados como el tiempo, la edad o el curso, de tal manera que se extendió el ejercicio a otros cursos (segundo y tercero de primaria) y horarios (el descanso).

El haber desarrollado juegos tradicionales de la primera infancia les permitió a los niños y niñas comprender que la diversión, el disfrute y el aprendizaje, junto a la experiencia de jugar, estar con otras personas y sentirse a gusto individual y colectivamente, no es algo exclusivo de la edad, por lo que jugar (sin importar el juego) es una experiencia que se puede desarrollar en cualquier momento de la vida, y seguirá siendo gratificante y agradable.

La ausencia de adultos, padres de familia y figuras protectoras o de autoridad claras al interior de las escenas, puede reflejar la soledad o falta de acompañamiento que viven los niños y niñas, pues incluso al llegar a casa después del colegio lo único que manifiestan es ir a dormir sin compañía o interacción con nadie más; y, en la celebración de la navidad, solo fue posible identificar el rol de la familia en el cuento narrado por el grupo, pero enfatizando en que no comparten en familia y eso es lo que más desean.

La escena de la ruptura del plato demuestra que los niños han arraigado la violencia dentro de las respuestas propias a situaciones difíciles como errores, accidentes o equivocaciones. Se destaca que en algunas familias están presente el castigo físico como consecuencia de los malos actos 0 errores, y en otras los castigos están más ligados a la prohibición o abstención del juego 0 disfrute por parte de los niños y niñas. De igual manera, el común denominador en cada caso son los regaños o llamados de atención que alertan a los y las estudiantes sobre su mal comportamiento o equivocación. 
Un elemento de resiliencia adicional o diferente a los ya identificados en sesiones previas, es la disposición o ideal que tienen las niñas del curso 501 sobre el bachillerato; las niñas que actuaron esta situación cotidiana consideran que el bachillerato será una extensión de sus vidas durante la primaria, se muestran seguras y tranquilas ante el cambio, pero se destaca la madurez, independencia y autonomía que consideran podrán tener, pues al organizar una pijama después de clases, reflejan algunos de los intereses que se manifiestan en la adolescencia como el compartir con sus pares espacios de sus vidas distintos a la escuela, llevando la amistad a lugares como la casa, haciendo más íntimos y unidos sus lazos, vínculos y relaciones sociales, pues hasta el momento la amistad era algo que se quedaba en el interior del colegio.

Dificultades: En el curso 501 puede ser que las indicaciones durante el juego "Charadas" no se hayan explicado lo suficiente, por lo que no se prepararon el total de actos, tampoco se profundizó en la escena ni se vio mayor reflexión sobre las mismas, por lo que las actuaciones no fueron claras ni fáciles de entender.

\section{Conclusiones y recomendaciones:}

- En el curso 502 los niños y niñas reconocen vínculos emocionales importantes al interior de sus familias, en este caso a sus padres, mediante relaciones direccionadas por la autoridad, el respeto, en algunos casos el miedo, la afectividad y el tiempo en familia. Igualmente, las familias extensas también se muestran dentro de los vínculos significativos que constituyen como figuras dignas de amor y confianza en quienes apoyarse y con quienes compartir experiencias de vida.

Es notorio el miedo que sienten los niños y niñas de 502 por el cambio que involucra el bachillerato, pues temen ser rechazados, ignorados e incluso golpeados o maltratados, por lo que la imagen que tienen de esta nueva etapa está constituida por la violencia, la soledad y la inestabilidad.

- En el curso 501 no fue posible identificar claramente los vínculos familiares que se gestan al interior de sus familias, no obstante, sí fue evidente que los y las estudiantes reconocen la importancia y valor de la amistad como redes de apoyo o presión social que aprueban o desaprueban las acciones y sucesos en que se involucran desde sus cotidianidades. De esta manera, existe cierta familiaridad entre los y las estudiantes donde se gestan 
situaciones de cuidado y cariño, al igual que comportamientos violentos o poco tolerantes ante imprevistos, y dependiendo de la gravedad o culpabilidad en los sucesos se relacionan positiva o negativamente entre unos y otros.

- Los niños y niñas de 501 parecen estar preparados para cambios propios de la adolescencia, pues las dificultades que han vivenciado los ha vuelto más resilientes, pero es notoria la necesidad de acompañamiento, cariño y cuidado por parte de sus padres para superar afectiva y efectivamente dichos procesos.

\subsection{Taller $\mathrm{N}^{\circ}$ 8: Proyecto de vida}

Descripción de la actividad: La última sesión del proceso se direcciona hacia la construcción y socialización de los sueños y metas que motivan la resiliencia en los niños y niñas, identificando a través de "carteleras" los objetivos que los impulsan a seguir adelante y no desistir antes la adversidad.

\section{Objetivo:}

- Desarrollar estrategias que permitan a los niños y niñas visibilizar y comunicar sus sueños y metas a futuro, como elementos propios de los proyectos de vida que motivan la capacidad resiliente en cada integrante del curso.

Desarrollo: La sesión de juego inicial con un ejercicio de confianza y pertenencia donde se reflejan los lazos y vínculos creados entre ellos y ellas, para tal fin se ubican en el patio del colegio y se crea un círculo al hacer uso de la tela elástica, los y las estudiantes deberán ubicar la tela sobre su espalda de tal manera que cada uno y cada una pueda recostarse sobre la misma, sin el uso de sus manos, y mantenerse estables, pues el círculo les permitirá mantener el equilibrio procurando el bienestar y estabilidad de todos y todas; siempre y cuando, cada niño y cada niña mantenga su posición.

Una vez culminada la actividad, y demostrada su habilidad de trabajar en equipo, cuidar de cada integrante y confiar entre todos y todas, se permitirá la creación de juego libre, donde el curso 
de manera autónoma y democrática decidirá un juego que deseen desarrollar entre todos y todas, procurando la participación de cada estudiante y adulto.

Para continuar, a partir de material de reciclaje, pliegos de papel craf y elementos útiles para decorar cada niño y cada niña realizará en un pliego de papel craf una presentación de sus sueños y metas. Allí los y las estudiantes podrán escribir y dibujar todo aquello que los y las motiva a seguir adelante, lo que consideran son sus propósitos o proyecto de vida. Una vez cada estudiante termine su cartelera, el total de integrantes presentará a los demás participantes los sueños y metas plasmados.

Finalmente, se invita a los niños y niñas expresar sus pensamientos, ideas, sentimientos y aprendizajes recreados durante la sesión.

Análisis: Los proyectos de vida, sueños y metas de los niños y niñas se enfatizan en el cumplimiento y continuación de sus etapas escolares, ser profesionales, mejorar el bienestar de sus familias en consideración a sus lugares y tipos de vivienda, viajar por el mundo y conocer diferentes lugares y culturas, y por último tener una relación sólida, cariñosa y cuidadosa con la naturaleza, especialmente con los animales.

Es evidente la importancia que tienen los animales en la vida de los niños y niñas, lo cual los hace seres humanos sensibles, comprensivos y cuidadosos no solo de sí mismos, sus familias y compañeros, sino que su entorno, medio ambiente y otros seres vivos se hacen dignos de amor, respeto y cuidado por parte de cada uno.

Fue posible evidenciar características resilientes individuales y colectivas en las y los estudiantes al ser persistentes en cada ejercicio propuesto, y pesar del miedo a caer, las diferencias de estatura y las dudas, intentaron realizar cada actividad satisfactoriamente.

Esta última sesión se caracterizó por el buen trabajo en equipo, tolerancia, cuidado y respeto por lo diverso y diferente, y aunque la escucha activa ha sido una de las mayores dificultades, durante el encuentro fue evidente la buena comunicación y escucha entre cada miembro de la actividad. 
Dificultades: Fue notoria la baja asistencia por parte de los cursos, dado que algunos niños y niñas ya lograron pasar satisfactoriamente su año escolar, motivo por el cual algunos no van a clase, pues no deben habilitar ni recuperar materias. Llevar a cabo la aplicación de instrumentos al mismo tiempo que se desarrollaba la sesión incidió en la concentración, manejo del tiempo y participación de los niños y niñas, pues los distraía del proceso.

\section{Conclusiones y recomendaciones:}

- Los niños y niñas reconocen proyectos de vida sólidos, bien estructurados, reales y posibles: sueñan con culminar sus estudios académicos, ser profesionales, viajar por el mundo, ayudar a sus padres e incidir en su bienestar individual, familiar y social. Identifican estos objetivos como motores de resiliencia, los cuales impulsan la capacidad de respuesta y superación ante las problemáticas que se les presentan.

- En términos generales, fue evidente el proceso de fortalecimiento de la resiliencia individual y colectiva de los cursos, por lo que hubo incidencia positiva por parte del modelo RARE en la población y muestra seleccionada. En consideraciones de carácter cualitativo los y las estudiantes poseen mayor control de sus emociones y por ende de sus acciones y respuestas a estímulos o situaciones particulares; son capaces de identificar problemáticas y diferentes formas de actuar ante ellas; comprenden y reconocen las diferencias que los caracterizan y valoran los vínculos y lazos que crean con sus compañeros y compañeras, haciendo de estos tan significativos como familiares, por lo que procuran cuidar y protegerse unos a otros con tal de mantener esa sensación de unión y fortalecimiento colectivo. Finalmente, estos hallazgos son visibles para los estudiantes y participantes del proceso en la medida que consideran haber cambiado como grupo y como sujetos. 


\section{CAPÍTULO 8. DISCUSIÓN}


A continuación, se discutirán los resultados de la aplicación del modelo de promoción de la resiliencia con niños y niñas entre los 8 y los 12 años de la localidad de Ciudad Bolívar en la ciudad de Bogotá. El modelo es denominado "a la Ra, a la Re, a la RARE: Rayuela Resiliera", el cual está basado en el juego, y a su vez comprende la resiliencia como un proceso sistémico que depende de las fuentes onto, micro y macrosistémicas.

\subsection{Beis creció en la guerra.}

Las dimensiones de la violencia muestran que el conflicto armado colombiano es uno de los más complejos de la historia contemporánea de América Latina. Los niños y las niñas, los adolescentes, los jóvenes, los adultos e incluso las personas mayores del territorio colombiano han nacido y crecido inmersos en la violencia socio política del país o del llamado "conflicto armado", lo que representa una de las advertencias más evidentes frente al creciente impacto psicosocial que acaece sobre la población colombiana a lo largo y ancho del territorio, tanto en las zonas urbanas, pero con más recrudecimiento en las zonas rurales y los centros poblados apartados, convirtiéndose en una constante violación al goce efectivo de los derechos y al deterioro permanente de la calidad de vida y el aumento de las condiciones de vulnerabilidad y la pobreza.

Los niños y las niñas son las principales víctimas de los efectos del conflicto armado, que, aunque algunos no hayan nacido o crecido en medio de los combates, ellos y sus familias deben vivir a diario las consecuencias que la violencia dejó en sus vidas:

"Los niños y las niñas colombianos han nacido y crecido en medio de un conflicto intenso y degradado, algunos viven la guerra directamente, porque están en medio del fuego, porque deben empuñar las armas, observar la enemigo, recoger información y participar de manera activa en el conflicto, otros como espectadores de las "últimas noticias" y primicias de los medios de comunicación, espectadores de imágenes que invaden sus espacios y relaciones y que amenazan con arrebatar las figuras y lugares que les proveen afecto y seguridad" (Universidad Nacional de Colombia Sede Bogotá, 2003) 
Así pues, en el desarrollo del modelo RARE hubo una situación que llama la atención: tan sólo el $3 \%$ de las familias que participaron del estudio manifestaron ser víctimas del conflicto armado, frente a un $68 \%$ que indicaron que no pertenecen a dicha categorización. En contraste, durante el desarrollo del modelo los niños y niñas manifestaron que ellos no son las víctimas, que ese "papel" se lo dieron a algún familiar cercano.

Lo anterior, evidencia que en las familias de los niños y niñas la condición de ser víctima del conflicto armado aún no se tiene clara y mucho menos, se identifican los efectos legales y psicosociales que tiene tal reconocimiento; aún más, no se logra reconocer que existen efectos del orden emocional, relacional e incluso familiar, que ha atravesado la condición de vida de cada grupo.

Esto refleja en parte, lo que Martín-Baró (1984) denomina "efectos indirectos de la guerra", o lo que sería lo mismo, eso que sucede en las personas que no viven directamente la guerra o los hechos victimizantes de la misma, pero que, si se identifica como un factor transversal de la realidad del país, a partir de los relatos contados, de las noticias de los medios de comunicación, de la lectura de los diarios, o porque se vivenció, pero en ocasiones se prefiere callarlo o no se reconoció como un acontecimiento asociado al conflicto armado.

Ese desconocimiento de la consideración de "víctima del conflicto armado", sería uno de los efectos psicosociales de la guerra más evidentes, pues sin duda, la guerra causa los efectos más profundos por lo que tiene de crisis socioeconómica y de catástrofe y por lo que arrastra de irracionalidad y deshumanización. (Martín- Baró, Guerra y salud mental , 1984). Pareciera entonces que ser víctima de la guerra es solamente un "estatus" de algunos que la vivieron y el Estado les reconoció, pero se invisibiliza al ciudadano o ciudadana colombianos que padecieron la guerra y que, en sus lenguajes, formas de relacionamiento y encuentro con otros, se hace evidente que la guerra se naturalizó.

Lo anterior, sería pues, considerar que dicha naturalización llevaría a observar un aprendizaje social basado en la violencia y que hablar de la presencia de grupos armados, sería parte de la vida cotidiana. Esto a su vez, llevaría a considerar que el aprendizaje social de la violencia como forma de 
vida, ha afectado el bienestar o buen estar emocional de los niños y niñas colombianos, es decir, ha afectado la salud mental de quienes vivimos de manera directa o indirecta la guerra.

Dichas afectaciones emocionales se observaron en el comportamiento de algunos de los niños y niñas que participaron en la implementación del modelo RARE, por cuanto, sus formas de relacionamiento con pares son agresivas, se desconoce las diferencias del otro/otra, la resolución de conflictos solo tiene la vía de la violencia y el lenguaje es soez, además que en algunos casos se identificaron juegos de simulación entre pares, representando riñas, golpes y porte de armas.

De esta manera, se evidencia, por un lado, que, aunque los niños y niñas no se consideran como víctimas del conflicto armado, su comportamiento social ha reproducido lo que viven en casa y en la cotidianidad y de otro lado, que el conflicto armado permeó a la sociedad colombiana en general. Esto lleva a comprender que es un problema que ha de considerarse como una afectación en la salud mental, en el sentido del bienestar emocional y de otro lado, comprender la salud mental como una respuesta sistémica.

En este sentido la salud mental, es un efecto que no depende únicamente de las condiciones propias del individuo, sino que responde también a las condiciones en que se desarrolla la persona. Así pues, la salud mental se constituye como una dimensión de las relaciones entre las personas y los grupos más que un estado individual, aunque esa dimensión se enraíce de manera diferente en el organismo de cada uno de los individuos involucrados en esas relaciones, produciendo diversas manifestaciones (síntomas) y estados (síndromes) (Martín- Baró, Guerra y salud mental , 1984).

Sumado a lo anterior, los efectos psicosociales de la guerra no solamente acaecen en las condiciones individuales de las personas, sino que, además, es la respuesta a una serie de inequidades que llevan a las personas al deterioro de su bienestar emocional. En este sentido, la salud mental colombiana responde a una situación de violencia generalizada que hunde sus raíces en unas condiciones de injusticia estructural.

"Las primeras veces que entré en contactos con grupos de campesinos desplazados por la guerra sentí que mucho de su proceder mostraba trazas de delirio paranoide: estaban 
constantemente alertas, multiplicaban las instancias de vigilancia, no se fiaban de nadie desconocido, sospechaban de todos cuantos se acercaran a ellos, escrutaban los gestos y las palabras en busca de posibles peligros. $Y$, sin embargo, conocidas las circunstancias por las que habian pasado... uno llega a comprender que su comportamiento de hiperdesconfianza y alerta no constituía un delirio persecutorio..., sino el planteamiento más realista posible dada su situación vital". (Martín- Baró, Guerra y salud mental , 1984, pág. 506)

De esta manera y como lo menciona Martín- Baró, la guerra ha dejado en la población una alteración y confrontación de las relaciones sociales, pues dichas relaciones se vuelven violentas, polarizadas y mentirosas. La guerra ha puesto en evidencia numerosas crisis y trastornos personales en quienes ya no pueden descifrar las exigencias de su situación vital.

Sin embargo, se deben establecer tres categorías de análisis de las afectaciones de salud mental en los niños y niñas colombianos, pues los efectos no son uniformes en toda la población: la clase social, la cercanía o involucramiento con el conflicto armado y la temporalidad.

Frente a la clase social, es importante ver que son las poblaciones con más altas condiciones de pobreza y exclusión social, y en su mayoría los campesinos, los que sufren más el impacto bélico, además de ser los que están en situaciones de desempleo, de la ausencia de servicios del Estado y la crítica situación socio- económica. No quiere decir que los sectores medios y altos no reciban impacto de la guerra, al contrario, también lo reciben, pero en diferente grado y exposición. En cuanto a la cercanía o involucramiento de quienes combatieron o presenciaron los hechos victimizantes seguramente padecen diferentes afectaciones emocionales; y frente a la temporalidad, es sabido que los efectos psicosociales pueden ser inmediatos y otros se presentan a mediano y largo plazo.

Por otro lado, aunque no estuvieron cerca o involucrados a la guerra, los niños manifestaron que conocen personas (familiares o conocidos) que si lo estuvieron.

Y en la tercera categoría, sus formas de actuar evidencias el grado de aprendizaje social de la violencia. 
"Con todo, el grupo que más debe reclamar nuestra atención es el de los niños, aquellos que se encuentran construyendo su identidad y su horizonte de vida en el tejido de nuestras relaciones actuales. Ellos son los verdaderos "hijos de la guerra" y a nosotros nos corresponde la dificil tarea de cuidar que no estructuren su personalidad mediante el aprendizaje de la violencia, de la irracionalidad y de la mentira" (Martín- Baró, Guerra y salud mental , 1984, pág. 510).

De esta manera, es importante comprender que los niños y niñas colombianos son "hijos de la guerra", tanto los que en este momento atraviesan las tiernas edades infantiles como a los adultos que durante su infancia la vivimos.

Beis, el amigo imaginario de mi hijo, con el que en varias ocasiones he tenido la oportunidad de jugar en el juego del "como si", en ese juego imaginario que los niños y niñas juegan, también es un "hijo de la guerra". Los niños y niñas recrean en sus juegos de "como si" las formas de vida y la misma realidad social. Beis resulta ser cualquier niño o niña colombiano, al que cada uno le da una forma, un género, una vida, pero en la re-creación de la violenta cotidianidad.

\subsection{Para que Beis juegue, cree y sueñe}

Comprender el proceso de resiliencia que ha desarrollado un niño o niña que ha vivido la guerra colombiana y que se ha encontrado en exposición permanente a diferentes efectos psicosociales en ellos, ellas y sus familias, implica analizar diferentes vertientes, es decir, comprenderla como un proceso sistémico y comprender el entrelazamiento propio de dicho proceso. Entender la resiliencia infantil como proceso sistémico implicaría entonces un complejo análisis bivariado o multivariado donde se entrecrucen diferentes categorías y variables, así como su interrelacionamiento.

Así pues, la resiliencia infantil es la suma de las condiciones individuales (ontológicas), familiares (micro) y sociales (macro) donde crecen los niños y niñas, donde cada uno de los sistemas afecta positiva o negativamente el sostenimiento de los demás sistemas. 
"El contexto histórico en donde cada individuo elabora y realiza su existencia en las telarañas de las relaciones sociales. Asi pues, el autor propone cambiar la perspectiva de la salud mental y de los trastornos mentales, viéndolos no desde dentro hacia afuera, sino de afuera hacia adentro, no como la encarnación de un funcionamiento individual interno, sino como la materialización en una persona o grupo del carácter humanizador o alienante de una estructura de relaciones históricas" (Martín- Baró, Guerra y salud mental , 1984).

Haciendo referencia a la relación entre la vulnerabilidad y la adversidad, (Klotiarenco, Cáceres, \& Fontecilla, 1997) consideran que ningún elemento adverso es, por sí mismo, fuente de deterioro 0 daño inevitable para el niño. En general, la adversidad puede ser, si es que no contrarrestada, atenuada por medio del establecimiento de relaciones cuidadosas y cálidas entre los padres 0 cuidadores primarios y el niño.

Lo anterior sigue demostrando la importancia de tener una familia funcional al lado de los niños y niñas para que pueden elevar su resiliencia. Se requieren de cuidadores responsables que operen como tutores de resiliencia, es decir, que realicen su labor con amor, desde el fortalecimiento del vínculo, que jueguen con los niños y niñas y que les garanticen sus derechos básicos. Esto a su vez se ve permeado por las fuentes macrosistémicas de la resiliencia infantil, por cuanto, los padres y madres de los niños y niñas más vulnerables de la localidad de Ciudad Bolívar, para poder dar alimentación y un techo, deben prestar sus servicios no calificados de lo que obtienen muy pocos recursos para cumplir con su obligación. Es decir, también la ausencia de un Estado que garantice derechos, que propicie condiciones dignas de trabajo, que proteja a la infancia, afectan la resiliencia infantil. Las largas horas que deben laborar los adultos, reducen sus tiempos de cuidado y protección a sus hijos y en muchas ocasiones, relegan esta obligación a los niños mayores o a terceros.

Sin embargo, llama la atención que las familias de los niños que participaron en el modelo RARE en su mayoría cuentan con la presencia de papá y mamá en casa y aunque ambos tengan que trabajar y dediquen poco tiempo de juego a sus hijos, los niños consideran que su estilo parental es aceptado. 
Así pues, si bien los niños y niñas cuentan con unos buenos niveles de fuentes ontosistémicas de resiliencia infantil, es necesario que los modelos para su promoción realicen acciones de intervención con las demás fuentes (micro y macro), de manera que se busque en estos la promoción de factores protectores en favor de dicha resiliencia ontosistémica.

\title{
8.3.El modelo de promoción de la resiliencia desde el juego: intervención psicosocial para la construcción de paz
}

\begin{abstract}
"Eso es verdad. Tenemos una niñez muy fracturada. Quienes trabajamos con ellos tenemos un gran reto y muchísimo por hacer. Pero también hay que valorar que los niños son quienes tienen mejores índices de resiliencia. Eso quiere decir que todavía estamos a tiempo de trabajar con ellos y de acompañarlos en ese proceso de recuperación emocional. Por eso, cualquier cosa que hagamos tiene que ser muy estricta, muy rigurosa y muy técnica". (Campo, 2014)
\end{abstract}

El modelo de promoción de la resiliencia "RARE (Rayuela Resiliera)" es una propuesta de intervención psicosocial que, mediante el juego, busca elevar las fuentes ontosistémicas de la resiliencia infantil en niños y niñas que han estado expuestos al conflicto colombiano de manera indirecta.

En este sentido, es necesario partir del reconocimiento de que los niños y niñas víctimas del conflicto armado se han visto inmersos en diferentes situaciones de violencia, desde una forma tan clara y evidente como la guerra -pasando por torturas, asesinatos, desapariciones y delitos de diversa índole-, hasta las más sutiles como el lenguaje, que, con su fuerza simbólica, condena, discrimina 0 invisibiliza al individuo o a grupos de personas (Torres, 2004). Es decir, los niños y niñas que viven en el contexto colombiano, están creciendo y desarrollándose en escenarios en los que desafortunadamente la violencia se ha vuelto cotidiana y es por esto, que desde la intervención psicosocial se considera relevante abordar el tema de la resiliencia infantil, considerando su entorno social, su vida y sus características personales, con el objetivo de aportar en el fortalecimiento de los factores de autoprotección, ya que la habilidad para afrontar exitosamente las situaciones estresantes y los eventos adversos procede de la interacción de diversos elementos en la vida de niños y niñas. 
Partiendo de lo anterior, el modelo RARE consistió en ayudarles a descubrir sus propios recursos y los de su entorno cercano, identificando sus fortalezas personales, haciéndolas consientes, trayéndolas al lenguaje, jugando con ellas, de tal manera que estas autoafirmaciones sean para sí mismos contundentes y ayuden a fortalecer su idea de sí mismos y de los recursos que poseen para superar las adversidades.

Para el modelo RARE la promoción de la resiliencia infantil resulta de movilizar el Ethos creativo que se exalta y se manifiesta en gran medida en el juego y por ello la excusa para hacer el tratamiento es la rayuela resiliera, donde se hace una combinación de creatividad, superación de dificultades, de movilizar los hábitos y la esencia misma de cada niño y niña. Así pues, el modelo RARE pretendió ampliar las categorías o pilares ontosistémicos sobre los cuales se apalanca la resiliencia infantil.

En general, en la primera aplicación de los instrumentos en el grado quinto se encontró una mediana de emociones positivas moderadas, un autoconcepto positivo, la identificación de una disciplina laxa frente a la percepción de los estilos parentales y que los niños son moderadamente resilientes. Así mismo se idéntico en los niños y niñas una alta creatividad, participación, confianza y cariño hacia sus docentes y algunos compañeros. Sin embargo, se evidenció la necesidad de trabajar la escucha, el seguimiento de instrucciones, el trabajo en equipo y el cuidado del otro/a.

Esto lleva a pensar que los niveles de resiliencia de los niños y las niñas podrían ser adecuados o medios y logran con ellos enfrentarse a los retos de la vida. Es decir que, aunque Beis crezca en la guerra, juega, construye y sueña.

Frente a los resultados de la aplicación del modelo RARE es importante identificar que, aunque en varias de las categorías estadísticamente no se obtuvieron mejorías al final de la intervención, en el comportamiento y relacionamiento de los niños y niñas si se observaron cambios importantes. 
De esta manera, se valida lo que la autora de este documento ha señalado en diferentes escenarios académicos: para construir paz en Colombia, se requiere entrar a intervenir cada casa, es decir, se requiere intervenir a las familias, los padres y madres de los niños y niñas colombianos, para que comprendan el importante rol que han asumido en la crianza. Si en Colombia cada niño y niña creciera feliz y en entornos protectores, seguramente tendríamos menos exposición al dolor y a futuro tendríamos más adultos felices y allí está la verdadera construcción de paz, en los microsistemas del país.

Sin embargo, los resultados estadísticos del modelo RARE llevan a pensar que el impacto de no fue el deseado y que pueden existir otros factores que influencian la efectividad de la intervención, como el tiempo de ejecución y la estrategia implementada. Seguramente se requiere de un mayor tiempo de latencia o de exposición en el modelo y que se requiere de la intervención en los demás sistemas que intervienen en la promoción de la resiliencia infantil.

Esto se hizo evidente en la última sesión que se realizó con los niños y niñas y en la cual se le presentaron resultados a los padres y madres, allí se realizó un taller de vínculo afectivo y los padres manifestaron que no conocían de la importancia de contar con más tiempo y con mayor calidad en el compartir con sus hijos.

Así mismo, es necesario realizar acciones para vincular a los actores públicos que deciden las políticas públicas en favor de la infancia, así como en las comunidades aledañas a los colegios, para que se entiendan como actores protectores; de seguro, la intervención en el macrosistema ha de mejorar los niveles ontosistémicos de la resiliencia infantil.

Para que los niños y niñas sean resilientes, se requiere de mayor intervención psicosocial en ellos, en sus casas, en sus colegios, en sus barrios, en las localidades; pero esta intervención psicosocial le podrá apostar a la paz, cuando se diseñe desde los propios lenguajes en que transciende la vida, no solamente en los diseños de políticas públicas que se escriben desde la centralidad de Bogotá. 
La intervención psicosocial para los niños y niñas víctimas del conflicto armado colombiano debe ser pensada para cada uno de los contextos en los cuales se entra a interactuar con ellos y ellas. 


\section{CAPÍTULO 9. CONCLUSIONES}


Como se ha venido demostrando, esta investigación procuró demostrar que cuando un niño o niña víctimas del conflicto armado colombiano participan en una propuesta de atención psicosocial basada en juego, aumentan su resiliencia en mayor medida con respecto a otras propuestas de intervención. Para esto se diseñó el modelo "a la RA, a la RE, a la RARE: rayuela resiliera" o modelo RARE que logró demostrar también que a presencia del adulto significativo de la infancia o tutor resiliente determina unas mayores habilidades resilientes en los niños y las niñas.

Para ello se contó con la participación de 94 niños y niñas del Colegio CEDID de la localidad de Ciudad Bolívar de la ciudad de Bogotá, específicamente, de la sede de Tanque Laguna, los cuales, por consideraciones del diseño del estudio, fueron contemplados en dos grupos: uno, niños y niñas de grado quinto que participaron del modelo RARE y otro, de niños de cuarto grado de primaria que no participaron en el modelo. Para ello, se coordinó con las autoridades del colegio para ubicar la muestra de niños del grupo expuesto y el no expuesto.

Para poder medir la resiliencia infantil y el entramado teórico que se propuso para comprenderla como la suma de diferentes fuentes sistémicas, se tomaron 5 instrumentos que midieron 4 variables (fuentes ontosistémicas, fuentes microsistémicas, fuentes macrosistémicas y juego) y 10 dimensiones (Características de los niños y niñas, Fortalezas intrapsíquicas, Habilidades para la acción, Respuestas amortiguadoras, Emociones positivas, Estilo parental, Vínculo afectivo, Funcionalidad familiar, Determinantes sociales, el Juego como acto creativo). A su vez, cada una de las dimensiones evaluaba 60 constructos.

Una vez realizados los acuerdos con las directivas del colegio y la fundación Lúdica desarrollo humano y levantados los consentimientos informados de los padres y los asentimientos de los niños, se inicia la implementación del modelo RARE, donde los niños y niñas participaron de 9 sesiones de juego por un espacio de 4 meses.

Con lo anterior, este proyecto de investigación permite plantear las siguientes conclusiones: 


\subsection{Intervención psicosocial desde el juego y para el juego. Inversión pública en juego y como efecto colateral: la resiliencia}

El juego se reconoce como necesidad vital inherente al desarrollo infantil y por tanto como derecho indiscutible de todo ser humano, tal y como lo enuncia el artículo 31 de la Convención de los Derechos del Niño: "Los Estados Partes reconocen el derecho del niño y la niña al descanso y al esparcimiento, al juego y a las actividades recreativas propias de su edad y a participar libremente en la vida cultural y en las artes". (Organización de las Naciones Unidas ONU, 1989), lo cual posiciona al

juego en un ámbito político que transciende de lo discursivo a lo práctico desde el ejercicio activo y comprometido de los actores corresponsables de garantizar los derechos a niños y niñas; es decir, la familia, la sociedad y el Estado deben conjugar esfuerzos que generen escenarios de disfrute del juego.

El juego es un derecho que, garantizado en la vida de los niños y las niñas, motiva al Ethos creativo y con ello, es posible movilizar la autoestima, el pensamiento crítico, la afectividad. Además, se logran movilizar las emociones positivas como la alegría, la serenidad y la simpatía.

En esa medida gracias a la intervención social desde el juego, se podría aumentar los niveles de resiliencia infantil en el ser del niño y niña, basados en diseños de intervención con profesionales de diferentes disciplinas y en escenarios adecuados para ello. Se requiere, además, que los profesionales de las ciencias sociales se atrevan a vincular el juego como un medio y un fin en sí mismo.

En el estudio se encontró diferencias positivas entre los grupos expuestos y frente grupos control en constructos como simpatía, serenidad, alegría, invención y arte, impulsividad y resiliencia en general. Lo que evidencia que cuando un niño o niña participa en una propuesta de promoción de resiliencia como el modelo RARE, podría aumentar su resiliencia en sus fuentes ontosistémicas, considerando un mayor tiempo de latencia o al menos 6 meses.

Lo anterior demuestra que le modelo RARE no solamente generó espacios de diversión para los niños y niñas, sino también logró un espacio de promoción de resiliencia, de aprendizaje y 
socialización. Así mismo, se demuestra la necesidad de ampliar la intervención a los padres y madres y a los actores públicos del territorio.

También, este modelo sigue demostrando la necesidad de que los niños y niñas cuenten con espacios de calidad para el juego, no solamente en términos de espacios físicos, sino que se vincule el juego en espacios cotidianos como la familia, la escuela, la comunidad. En la localidad de Ciudad Bolívar los niños adolecen de espacios como parques o ludotecas, sus padres y madres tienen poco tiempo para jugar y los territorios son peligrosos, por ende, su derecho al juego se viene vulnerando de diferentes maneras.

Por su parte, también es necesario que los adultos que están alrededor de los niños y niñas comprendan al juego como un asunto serio; así pues, es necesario que los profesionales de las ciencias humanas, la educación, la salud, estudien más y mejor el juego y sus efectos y logren vincularlo como un lenguaje permanente en sus intervenciones.

"Elementos que, en la coyuntura actual de la sociedad colombiana, implican compromisos permanentes por tejer las transformaciones en el día a día, teniendo en cuenta los procesos de construcción de paz, esta paz no puede tener vida sin el ejercicio pleno de los derechos humanos, y sin tener en cuenta la importancia de promover relaciones de respeto, igualdad y creación colectiva en la diferencia" (Alayón-Torres, 2019).

De otro lado, es necesario que los gobiernos locales realicen inversión pública en el juego, como un asunto serio, que logra importantes efectos en los niños, niñas y sus familias. Como se demostró en el modelo RARE, la promoción de la resiliencia va resultando como efecto de una intervención psicosocial, pero para los niños, en RARE lo que importó fue la oportunidad de jugar.

"En épocas de conflicto, posconflicto y emergencias, el deporte, la recreación y el juego proporcionan esperanza y sentido de normalidad a niños y adolescentes de ambos sexos. Esas actividades también ayudan a que los pequeños que han sufrido traumas canalicen sanamente el dolor, el temor y la pérdida. De igual modo, ayudan a cicatrizar las heridas emocionales creando un ambiente seguro en el que los niños, niñas y adolescentes pueden 
expresar sus sentimientos, aprenden a confiar y establecen su autoestima y la confianza en sí mismo" (Fondo de las naciones unidas para la infancia- UNICEF-, 2004)

\subsection{Desarrollo local desde la infancia para la construcción de paz}

Como bien lo menciona Tonucci, se requiere de los niños y las niñas para salvar las ciudades, pues la planificación de éstas está concebida para una única fase de la vida de las personas, de adultos activos laboralmente, sin responsabilidades familiares, sin hijos. Como si los mismos planificadores de las ciudades no hubiesen pasado por la infancia.

Experiencias como la "Ciudad de los Niños", promovida por Francesco Tonucci, quien, desde su experiencia en Fanno, Italia, invita a pensar en ciudades estructuradas y creadas para ellos; Ciudades Amigas de la Infancia en España, donde UNICEF promueve la aplicación de la Convención sobre los Derechos del Niño en el ámbito de las Entidades Locales y la Red "La Ciudad de los niños", promovida por el Instituto de Ciencias y Tecnología de la Cognición del Consejo Nacional de Investigaciones de Roma, de la que hacen parte Medellín, Manizales y Bogotá.

En un mundo cada vez más urbano, el desafío para los gobiernos y especialmente para los alcaldes es garantizar ciudades sanas, seguras, hermosas, donde los niños puedan volver a jugar en las calles, que se garantice la tolerancia y donde podamos compartir los sueños con nuestros hijos. recogiendo las experiencias de países que han avanzado en escuchar a los niños y las niñas y reinvertir mejor los recursos públicos, pues es asumir una nueva forma de gobernar, es priorizar las acciones en los niños, niñas y adolescentes como protagonistas reales y con escenarios en los que puedan ser escuchados. Sus voces permiten fortalecer la ciudadanía, hacer ciudades más amigables y generar entornos urbanos protectores, donde se concentra la mayoría de la población infantil y

juvenil. Es pensar que este puede ser un mejor escenario para superar la pobreza y lograr la reconciliación del país, es pensar que desde los niños y las niñas se puede hacer un nuevo modelo de desarrollo local.

Las ciudades dejaron de ser territorios donde se veían a los niños y niñas jugar en la calle, ahora toma nuevos criterios de desarrollo la segregación y la especialización. El centro histórico ahora 
pertenece a los bancos, los centros comerciales y el ocio arrinconado a espacios privados. La casa ahora es el espacio para el descanso, la afectividad y la comunicación, la casa acoge la ciudad entera en un único espacio" (Tonucci, 2006)

En esta segregación llama la atención que los espacios públicos han sido absorbidos por los automóviles, poniendo barreras imposibles de superar para los niños y niñas. En pasados días, en Bogotá observé un letrero que decía "prohibido jugar pelota, bicicleta o correr, pues puede dañar los carros (coches)" y aquí me pregunté por el adulto que puso dicho letrero en una zona que era de uso compartido entre adultos y niños. ¿Por qué ese adulto privilegia sus derechos por encima de los de los niños?, ¿qué será del niño que fue hace algunos años?, ¿aún recordará sus travesuras y juegos callejeros?

La ciudad sigue siendo adulto céntrica, la planificación del desarrollo es adulto céntrica y más aún, las políticas públicas son adulto céntricas; las familias incluso son adulto céntricas, pues prefieren que un colegio enseñe a los pequeños a sumar y leer que, a jugar y escuchar sus emociones, pues ello es "perder tiempo y necesita prepararse para la adultez".

Como lo diría Tonucci (o Frato) los niños viven mal, pues no pueden vivir ninguna de las experiencias fundamentales para su desarrollo: la aventura, la investigación, el descubrimiento, la sorpresa, el riesgo o la superación de un obstáculo. ¡NO PUEDEN JUGAR! (Tonucci, 2006)

La ciudad se ha olvidado de los niños y han quedado relegados a espacios especialmente pensados para ellos, desde su habitación, hasta el parque con columpios o la ludoteca. Sin embargo, para los niños y niñas más vulnerables, ni siquiera cuentan con dichos espacios. En las zonas con mayor vulnerabilidad de Colombia, los parques infantiles se han convertido en el lugar de presencia permanente de venta y consumo de sustancias ilícitas, de pandillas y con ello, la ausencia absoluta de niños y niñas jugando. Si los niños permanecen en casa, deben atender los quehaceres domésticos, el cuidado de sus hermanos y tan solo algunas horas para crear y soñar, desde el juego.

"Devolver la autonomía a los niños será seguramente el mejor camino hacia la recuperación y la vida plena de las ciudades. Cuando los niños puedan ir solos a la escuela, salir a la calle a jugar 
con los amigos en los espacios públicos, también entonces los abuelos, las personas con discapacidad y los ciudadanos en general" (Tonucci, 2006, pág. 63) y aquí yace la verdadera construcción de paz, en el reencuentro de las poblaciones en la simpleza de la vida cotidiana en la calle. Para ello, es necesario también que los niños y niñas sean consultados en las decisiones públicas que les afecten: realizar ejercicios de participación infantil, aportar en la planificación de las políticas públicas y aportar en las decisiones de inversión pública en favor de los niños y niñas.

Dado lo anterior, se requiere también de espacios para acompañar su desarrollo y ofrecerles nuevas experiencias, descubrimientos y, en general, un enriquecimiento. Aquí tenemos un gran reto los adultos que pudiésemos acompañar la concreción y puesta en marcha de estos espacios, pues debemos comprender el juego infantil, entender que entramos como invitados y son los niños y niñas los protagonistas, volver a jugar y vincular el juego en las propuestas metodológicas.

Cuando logremos hacer un desarrollo local desde y para la infancia, podremos hablar de una nueva posibilidad en la construcción de paz, pues como dice Tonucci: los niños y niñas "con su presencia y sus juegos invadiendo los espacios públicos, son capaces de modificar los comportamientos de los adultos y obligarnos a respetar más el entorno en el que vivimos y en el que vivirán nuestros hijos y nuestros nietos" (Tonucci, 2006, pág. 67)

La construcción de una paz estable y duradera sigue siendo una utopía para Colombia, pues, aunque existan apuestas en las leyes, los gobiernos de turno modifican su comprensión; aún se requiere de una alta voluntad política para comprender que la verdadera paz no se gesta únicamente en acuerdos y que se requiere mayor inversión social en proyectos para "lo menos importante" como lo es el ocio y el juego.

Como líneas atrás se mencionó, para lograr la verdadera paz en Colombia se requiere que los adultos comprendamos que la infancia es el momento más importante de la vida, pues si los niños y niñas crecen felices y en entornos que los protejan, podremos asegurar un nuevo futuro.

Aún falta mucho por recorrer....

Por mi amada Colombia! 
10. CAPÍTULO 10. BIBLIOGRAFÍA 
Aguirre, A. M. (2010). Prácticas de crianza y su relación con rasgos resilientes de niños y niñas. Informe de tesis de maestría, Univer Nacional de Colombia, Bogotá. Obtenido de http://www.bdigital.unal.edu.co/2984/

Alayón-Torres, C. (2019). Estrategias pedagógicas de convivencia intercultural: Aportes a la prevención del racismo y la discriminación étnico- racial en Instituciones Educativas Distritales de Bogotá. Trabajo fin de máster , Universidad internacional de La Rioja.

Alvarán. (2013). Impactos psicosociales del desplazamiento forzado en Colombia, una propuesta de intervenciòn para niños y niñas. Tesis Doctoral, Universitat Jaume I, Castellón de la Plana, España.

Alvarán López, S., Rueda, S. M., Vieco, G., \& Gaviria, J. (2019). Validación del instrumento JJ63 para la medición de resiliencia en niños y adolescentes escolarizados en cinco instituciones públicas de Antioquia. Zona próxima.

Arriagada, F., Jara, P., \& Luengo, L. (2017). Nivel de resiliencia en familiares de personas hospitalizadas en cuidados intensivos y factores asociados. Ciencia y enfermería, 23(2), 3344. Obtenido de https://dx.doi.org/10.4067/S0717-95532017000200033

Asamblea General de las Naciones Unidas. (20 de Noviembre de 1989). Convención sobre los Derechos del Niño.

Asociación Centro de Desarrollo y Consultoría psicosocial Taller de vida. (2010). Resiliencia. En E. Castañeda, Desafíos para el presente: Conferencias "Primera infancia y conflicto armado en Colombia" (págs. 197 -219). Bogotá: Instituto Iberoamericano de Primera Infancia y Derechos de la Niñez IDIE \& Organización de Estados Iberoamericanos para la Educación, la ciencia y la cultura OEI.

Barudy, J., \& Dantagnan, M. (2008). La fiesta mágica y realista de la resiliencia infantil. Barcelona: Gedisa.

Bello, M. (2014). Por sobrevivir, no hubo tiempo para la tristeza. Revista Semana. Recuperado de https://especiales.semana.com/especiales/conflicto-salud-mental/por-sobrevivir-no-hubotiempo-para-la-tristeza.html

Bello, M., \& Ruiz Ceballo, S. (2002). Conflicto armado, niñez y juventud una perspectiva psicosocial. Bogotá: Universidad nacional de Colombia, fundación dos mundos.

Bójorquez, J, López, L., Hernández, M., \& Jiménez, E. (2013). Utilización del alfa de Cronbach para validar la confiabilidad de un instrumento de medición de satisfacción del estudiante en el uso de Software Minitab. Innovation in Engineering, Technology and Education for Competitiveness and Prosperity, 6, 1-9. Recuperado de https://www.researchgate.net/publication/317386341_Medicion_de_la_Confiabilidad_del_Apr endizaje_del_Programa_RStudio_Mediante_Alfa_de_Cronbach 
Burgos Alarcón, J. A., \& Uniminuto. (2015). Altos de la Florida; la montaña invisible e imbatible. (C. E. Muñoz, Ed.) Bogotá.

Bruner, J. (1997). La educación, puerta de la cultura. Madrid: visor.

Calderón, P. A., \& Piñeiro, N. (2003). Metodología de la investigación científica. Selección de lecturas. La Habana, Cuba.

Callois, R. (1986). Los juegos y los hombres: entre la máscara y el vértigo. México: Fondo de Cltura Económica.

Campo. (2014). jMás de 2 millones de niños víctimas! Revista Semana.

Carrero, C. T., \& Pinilla, H. Y. (2018). Promoción de la resiliencia en niños y niñas víctimas del conflicto armado: aportes desde las comunidades de diálogo. Investigación , Bogotá.

Centro Nacional de Memoria Histórica. (2013). GMH ¡Basta Ya! Colombia: memorias de guerra y dignidad. Bogotá: Imprenta Nacional.

Cervantes, W., Buenahora, Y., \& Fajardo Castillo, E. M. (2016). Emociones positivas y factores de riesgo psicosocial en contextos educativos vulnerables de la región caribe. Universidad Cooperativa de Colombia. Recuperado de http://repository.ucc.edu.co/handle/ucc/193

Corporación Juego y Niñez. (2014). Metodología NAVES, su ser y hacer-actualización. Bogotá: Corporación Juego y Niñez.

Corporación juego y niñez. (2014). Vínculo afectivo y juego. Bogotá.

Cyrulnik, B. (2005). Bajo el signo del vínculo. Barcelona: Gedisa.

Defensoría del pueblo. (2014). Voces y oportunidades para los niños, niñas y adolescentes en la construcción de paz en Colombia. Bogotá: Defensoría del Pueblo.

Duvignaud, J. (1997). El juego del juego. Buenos Aires: Fondo de cultura económica.

Egan, K. (1992). La Imaginacion En La Enseñanza. El Aprendizjae. Para Los Años Intermedios De La Escuela. Buenos Aires: Amorrortu Editores.

Escuela de Medicina UC - Pontificia Universidad Católica de Chile. (2007). Epidemiología analítica. Recuperado de http://escuela.med.puc.cl/recursos/recepidem/PDF/EPIANAL3.pdf

Fergusson , D., Horwood, L., \& Suniya S. , L. (2003). Resilience to Childhood Adversity: Results of a 21-Year Study. Cambridge University Press, 130-155. doi:10.1017/CBO9780511615788.008

Fondo de las naciones unidas para la infancia- UNICEF-. (2004). Deporte, recreación y juego. Nueva York. 
Fuentes, C. R., \& Torbay, Á. (2004). Desarrollar la creatividad desde los contextos educativos: un marco de reflexión sobre la mejora sociopersonal. Revista Iberoamericana sobre Calidad, Eficacia y Cambio en Educación, 2(1). Obtenido de http://www.redalyc.org/articulo.oa?id=55120112

Fundación Carlos Slim. (Abril de 2020). Educación inicial México. Obtenido de https://educacioninicial.mx/infografias/vinculo-afectivo-el-camino-hacia-la-resiliencia/

Gadamer, H.G. (1991). La actualidad de lo bello. Barcelona: Paidós

Garaigordobil, M., \& Pérez, J. I. (2005). Escala de personalidad creadora . Estudios de psicología, 345364.

Gardner, H. (1993). La mente no escolarizada. Como piensan los niños y cómo deberían pensar las escuelas. Paidos.

González, N. I., Valdez, J. L., \& Zavala, Y. (2008). Resiliencia en adolescentes mexicanos. Enseñanza e Investigación en Psicología, 13, 41-52.

Greco, C., Morelato, G., \& Ison, M. (2007). Emociones Positivas: Una herramienta psicológica para promocionar el proceso de resiliencia infantil. Psicodebate, 81-94. Obtenido de https://dspace.palermo.edu/ojs/index.php/psicodebate/article/view/429/209

Grotberg. (2006). La resiliencia en el mundo de hoy: como superar la adversidad. Barcelona: Gedisa.

Grotberg, E. (1995). A guide to promoting resilience in children: strenghening the human spirit (Vol. A). La Haya, Holanda: Bernard Van Leer Foundation.

Harris, P. (2005). El funcionamiento de la imaginación. Buenos Aires: Fondo de cultura económica.

Hernández, R., Fernández, C., \& Baptista, M. d. (2010). Metodología de la investigación (Quinta ed.). México: Mc Graw- Hill.

Huizinga, J. (1968). Homo Ludens. Buenos Aires: Emecé Editores.

ICBF, UNICEF y OIM. (2014). Impacto del conflicto armado en el estado psicosocial de los niños, niñas y adolescentes. Bogotá: ICBF.

Jaramillo, J. (2015). Construcción de una escala de determinantes sociales de la conducta resiliencia adolescente. Revista de la Facultad de Ciencias Médicas, Universidad de Cuenca, 1, 33, 3040.

Jaramillo, J. (2012). Instrumento de medición de resiliencia adolescente. Revista de la facultad de ciencias médicas de la Universidad de Cuenca, 12-15.

Jaramillo, J., Pozo, J. C., Quezada, I., \& Quispillo, C. (2011). Validación de la prueba JJ63 instrumento de medición de resiliencia adolescente en el colegio benigno malo de la ciudad de Cuenca. Cuenca: Universidad de Cuenca. 
Klotiarenco. (2000). Algunas particularidades metodológicas en los estudios sobre resiliencia. En M. A. kotliarenco, F. Mardones, A. Melillo, \& N. Suárez Ojeda, Actualizaciones en Resiliencia (págs. 53-72). Lanús: Ediciones de la UNLa.

Klotiarenco, M. A., Cáceres, I., \& Fontecilla, M. (1997). Estado de Arte en Resiliencia. Buenos Aires: Organización panamericana de la salud.

Kotliarenco, M. A., \& Cáceres, I. (2011). Estado del Arte en Resiliencia III . Diplomado Promoción de la Parentalidad Positiva: Estrategias de Evaluación e Intervención Ecosistémicas.

Kotliarenco, M., Mardones, F., Melillo, A., \& Suarez Ojeda, N. (2000). Actualizaciones en Resiliencia. Buenos Aires: Universidad Nacional de Lanús: Fundación Bernard van Leer.

Lucas, M. A. (2012). Pedagogía para una ciudadanía creativa. Tesis doctoral. Barcelona: Universidad de Barcelona.

Lourdy, C. (27 de agosto de 2016). Bienvenido el fin de la guerra. El Heraldo. Recuperado de https://cesarlorduy.com/bienvenido-el-fin-de-la-guerra/

Manciaux, M. (2003). La resiliencia : resistir y rehacerse. Barcelona: Gedisa.

Martín- Baró, I. (1984). Guerra y salud mental . ECA Estudios Centroamericanos, 503-514.

Manciaux, M. (2003). La resiliencia : resistir y rehacerse. Barcelona: Gedisa.

Mateu, R., García, M., Gil, J., \& Caballer, A. (2009). ¿Qué es la resiliencia?. Hacia un modelo integrador. Barcelona: Universitat Jaume.

Menoni, R., \& Klasse, E. (2007). Construyendo alternativas al dolor: Reflexiones sobre la resiliencia en barrio Casabo. Revista uruguaya de enfermería.

Montes, G. (1999). La frontera indómita. México: Fondo de cultura económica.

Montiel. (18 de Enero de 2015). Las huellas del conflicto armado en los niños y adolescentes colombianos. El País.

Morelato, G. (2014). Evaluación de factores de resiliencia en niños argentinos en condiciones de vulnerabilidad familiar. Univ. Psychol, 13(4), 1473-1488. doi:http://dx.doi.org/10.11144/Javeriana.UPSY13-4.efrn.

Munist, M., Santos, M., Kotliarenco, Suárez, \& Grotberg, I. F. (1998). Manual de identificación y promoción de la resiliencia en niños y adolescentes. Washington: Organización Panamericana de la Salud.

Organización de las Naciones Unidas. (2014). Los niños y los conflictos armados. New York.

Organización de las Naciones Unidas ONU. (1989). Convención de los derechos del niño. Artículo 31. 
Oros, L. B. (2006). Evaluación de la simpatía en niños de 6 y 7 años de edad. Libro de Ponencias del $X$ Congreso Nacional de Psicodiagnóstico, 345-349. Buenos Aires, Argentina

Oros, L. B. (2014). Nuevo cuestionario de emociones positivas para niños. Anales de psicología, 30(2), 522- 529. doi:http://dx.doi.org/10.6018/analesps.30.2.158361

Ospina, M. I., \& Sarmiento, P. (2010). Promoción de la resiliencia en la primera infancia un reto para el contexto escolar. Informe de trabajo de grado. Obtenido de https://repository.javeriana.edu.co/handle/10554/6670

Paniagua, R. E. (2015). Metodología para la validación de una escala o instrumento de medida. Universidad de Antioquia. Facultad Nacional de Salud Pública. Medellín, Colombia. Recuperado de http://www.udea.edu.co/wps/wcm/connect/udea/d76a0609-c62d-4dfb-83dc5313c2aed2f6/METODOLOG\%C3\%8DA+PARA+LA+VALIDACI\%C3\%93N+DE+UNA+ESCA LA.pdf?MOD=AJPERES

Pérez, R. E., Guevara, G. A., Canales, R., \& Matta, H. H. (2018). Funcionalidad familiar y resiliencia en adolescentes de una institución educativa de. XVI Coloquio Panamericano de Investigación en Enfermería. Cuba.

Piaget, J. (1932). El criterio moral. Barcelona: Martínez Roca.

Piaget, J. (1961). La formacion del simbolo en el niño. Mexico: Fondo de cultura económica.

Poletti, R., \& Dobbs, B. (2005). La resiliencia, el arte de resurgir a la vida. Buenos Aires: Lumen.

Pontificia Universidad Javeriana. (s.f.). Recuperado de http://cmap.javeriana.edu.co/servlet/SBReadResourceServlet?rid=1K6XH9QJQ-1HB851T$2 \mathrm{M} 6$

Pozo, J., Quezada, I., \& Quispillo, C. (2011). Validación de la prueba JJ63 instrumento de medición de resiliencia adolescente en el colegio benigno malo de la ciudad de Cuenca. Cuenca, Ecuador Puig, G., \& Rubio, J. L. (2011). Manual de resiliencia aplicada (Primera edición ed.). Barcelona: Gedisa.

Puig, G., \& Rubio, J. L. (2013). Manual de resiliencia aplicada. Barcelona: Gedisa.

Radke- Yarrow, M. y. (1992). Hard growing: children who survive. En A. y. Maten, Risk, and protective factors in the development of psychopathology. Cambridge: Cambridge University Press.

Richaud de Minzi, M. C. (2007). La percepción de estilos de relación con su padre y madre en niños y niñas de 8 a 12. Revista Iberoamericana de Diagnóstico y Evaluación, 1(23), 63-81.

Rodríguez. (2010). El enfoque ético de la acción sin daño. Bogotá: Universidad Nacional de Colombia.

Rodríguez, H. Y., Guzmán, L., \& Yela, N. D. (2012). Factores personales que influyen en el desarrollo de la resiliencia en niños y niñas en edades comprendidas entre 7 y 12 años que se desarrollan en extrema pobreza. Internacional journal psychological research, 98-107. Obtenido de http://www.scielo.org.co/pdf/ijpr/v5n2/v5n2a11.pdf 
Roldán, S. (s.f.). Sergio Roldán Blog. Recuperado el 1 de junio de 2016, de http://www.sergioroldan.co/blog/2013/07/antecedentes-de-la-politica-de-restitucion-detierras/

Ruiz-Ceballos, S. (2002). Impactos psicosociales de la participacion de niñ@s y jóvenes en el conflicto armado. En M. N. Bello \& S. Ruiz-Ceballos, Conflicto armado, niñez y juventud: Una perspectiva psicosocial (págs. 17-46). Bogotá, Colombia: Universidad Nacional de Colombia, Fundacion Dos Mundos

Sánchez, M. C. (2004). Guía para la formulación de proyectos de investigación. Bogotá: Alma Mater Magisterio.

Sousa, V.D., Driessnack, M., \& Costa, I.A. (2007). Revisión de diseños de investigación resaltantes para enfermería. Revista Latino-am Enfermagem. Recuperado de https://www.scielo.br/pdf/rlae/v15n3/es_v15n3a22.pdf

Tirado, M. I. (1998). El juego y el arte de ser humano (Segunda edición ed.). Medellín: Universidad de Antioquia.

Tonucci, F. (2006). La ciudad de los niños. ¿Por qué necesitamos de los niños para salvar las ciudades? I.T.(75). Recuperado de http://equidadparalainfancia.org/wpcontent/uploads/2016/05/Francesco-Tonucci.pdf

Torres, M. (2004). Violencia Social y Violencia de Género. Disponible en: http://www.americalatinagenera.org/es/index.php?option=com_content\&task=view\&id=905\& pub_id=215\&ml=1\&mlt=s\&tmpl=component.

Trilla, J., \& Novella, A. (2001). Educación y participación social en la infancia. Revista iberoamericana de educación N²6, 137 - 164.

Unidad administrativa especial de gestión de restitución de tierras despojadas. (2016). Guía para la aplicación del enfoque diferencial en el proceso de restitución de tierras. Bogotá: Unidad de restitución de tierras.

Unidad de Atención y Reparación Integral a Víctimas. (s.f.). Registro único de víctimas. Recuperado de http://rni.unidadvictimas.gov.co/RUV

Universidad de Alicante. (s.f.). Recuperado el 18 de 06 de 2016, de http://personal.ua.es/es/franciscofrances/materiales/tema4/observacin_interna_o_participante.html

Universidad de Antioquia, Grupo de Investigaciòn en Salud Mental de la Facultad Nacional de Salud Pùblica. (Abril de 2016). Ficha de registro de lìnea de investigación. Medellin, Antioquia, Colombia.

Universidad de Cuenca. (2015). Construcción de una escala de determinantes sociales de la conducta resiliente adolescente. Cuenca, Ecuador. 
Universidad Nacional de Colombia Sede Bogotá. (2003). Conflicto armado, niñez y juventud: una perspectiva psicosocial. (M. N. Bello, \& S. Ruiz Ceballos, Edits.) Bogotá: Universidad Nacional de Colombia.

Vanegas, J. A., Bolívar, C., \& Camacho, L. B. (2011). Significado del desplazamiento forzado por conflicto armado para niños y niñas. Fundamentos en Humanidades, XII(24), 163-189. Obtenido de http://www.redalyc.org/articulo.oa?id=18426920007

Vanistendael, S. (2005). La resiliencia: desde una inspiración hacia cambios prácticos. Madrid: $2^{\circ}$ Congreso internacional de los trastornos de comportamiento en niños.

Vigotsky, L. (1999). La imaginación y el arte en la infancia. Ensayo psicológico. Madrid: Ediciones Akal S.A.

Winnicott , D. (1991). Realidad y juego. Barcelona: Gedisa. 
11. ANEXOS 


\section{Anexo 1. Aval del comité de ética}
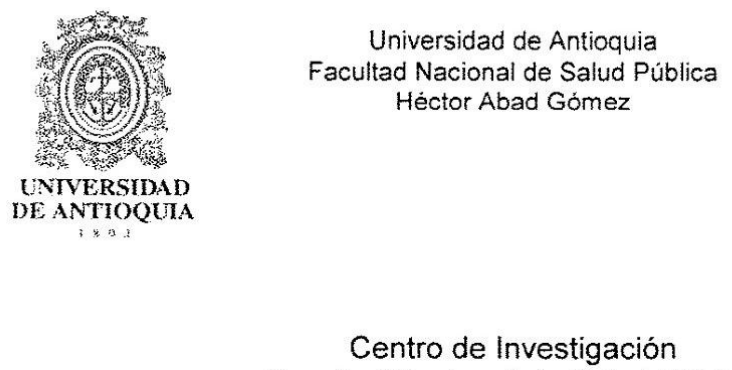

Certificación

El Comité de Ética de la Investigación de la Facultad Nacional de Salud Pública según el acta 154 del 08 de noviembre de 2016, avaló el proyecto de investigación titulado Modelo psicosocial de promoción de la resiliencia en la infancia campesina para la prevención de conductas problemáticas. Estudio de caso control. Contexto rural del municipio de Santo Domingo Antioquia. Colombia. 2016-2017.

El comité da aval al proyecto en la categoria riesgo mayor al minimo según la resolución 8430 del Ministerio de Salud.

El proyecto de investigación cuenta con consentimiento informado según lo establecido en los artículos 15 y 16 de la Resolución 8430 de 1993.

Si el proyecto de investigación no ha iniciado ejecución en un año después de la expedición del presente aval, se deberá remitir nuevamente al Comité de Ética para su renovación. Este aval es válido durante toda la vigencia del proyecto de investigación.

Dado en Medellin, el 10 de noviembre de 2016.
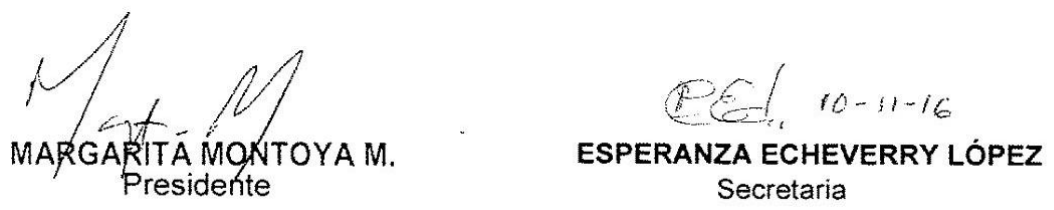

Centro de Investigación Facultad Nacional de Salud Pública

Calle 62 No. $52-59$ of. 232 Tel: 2196830

E-mail: eticasaludpublica@udea.edu.co 


\section{Anexo 2. Encuesta sociodemográfica}

\section{ENCUESTA SOCIODEMOGRÁFICA}

\section{Indicación:}

- Complete la información requerida mediante pregunta abierta

- Marque con una equis $(\mathrm{X})$ en las preguntas de selección múltiple

\section{A. Identificación}

A.1. Curso:

A.2. Número de la tarjeta de identidad o registro civil del niño o la niña:

A.3. Parentesco de quien diligencia la encuesta:

A.4. Edad del adulto que diligencia la encuesta:
a. Padre
b. Madre
c. Tutor legal
d. Otro:

A.5. Edad del niño o de la niña:

A.6. Fecha de nacimiento del adulto que diligencia la encuesta:

A.7. Fecha de nacimiento del niño o de la niña:

A.8. Lugar de nacimiento del adulto que diligencia la encuesta:

A.9. Lugar de nacimiento del niño o de la niña:

A.10. Género del adulto:

A.11. Género del niño o de la niña:

A.12. El niño o de la niña es víctima del conflicto armado:

a. $\mathrm{Si}$

b. No

A.13. El niño o de la niña tiene alguna discapacidad, limitación 0 capacidad diferente:

A.14. El niño o la niña pertenece a alguna etnia:
a. $\mathrm{Si}$
$\circ \quad$ ¿Cuál?
b. No
a. $\mathrm{Si}$
○ ¿Cuál?
b. No

A.15. El niño o de la niña se encuentra afiliado a:
a. SISBEN - Nivel:
c. Ninguno
b. EPS - ¿Cuál?

\section{B. Caracterización socioeconómica del hogar}




\begin{tabular}{|c|c|}
\hline $\begin{array}{l}\text { B.1. Lugar de residencia: } \\
\text { a. Localidad: } \\
\text { b. Barrio: }\end{array}$ & $\begin{array}{l}\text { B.2. Tipo de vivienda: } \\
\text { a. Casa } \\
\text { b. Apartamento } \\
\text { c. Casa Lote }\end{array}$ \\
\hline $\begin{array}{l}\text { B.3. La vivienda ocupada por este hogar es: } \\
\text { a. Propia } \\
\text { b. En arriendo } \\
\text { c. Otra: }\end{array}$ & 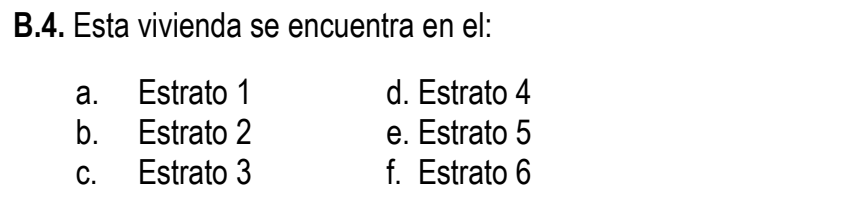 \\
\hline \multirow[t]{2}{*}{ B.5. Cantidad de miembros que conforman el hogar: } & \multirow{3}{*}{$\begin{array}{l}\text { B.6. Miembros que conforman el hogar (puede poner el número } \\
\text { de X necesarias) } \\
\begin{array}{lll}\text { a. Papá } & \text { e. Tíos/as } & \text { i. Hermanastros/as } \\
\text { b. Mamá } & \text { f. Primos/as } & \text { j. Otro(s): } \\
\text { c. Hijos/as } & \text { g. Padrastro } \\
\text { d. Abuelos/as } & \text { h. Madrastra }\end{array}\end{array}$} \\
\hline & \\
\hline $\begin{array}{l}\text { B.7. Cantidad de miembros que aportan al ingreso mensual del } \\
\text { hogar: }\end{array}$ & \\
\hline $\begin{array}{l}\text { B.8. Ingreso mensual promedio del hogar: } \\
\begin{aligned} \text { a. } & \text { Menos de } \$ 100.000 \\
\text { b. } & \text { De } \$ 100.000 \text { a } \$ 350.000 \\
\text { c. } & \text { De } \$ 350.001 \text { a } \$ 700.000 \\
\text { d. } & \text { De } \$ 700.001 \text { a } \$ 1.000 .000 \\
\text { e. } & \text { De } \$ 1.000 .001 \text { a } \$ 2.000 .000 \\
\text { f. } & \text { De } \$ 2.000 .001 \text { a } \$ 3.500 .000 \\
\text { g. } & \text { De } \$ 3.500 .001 \text { a } \$ 5.000 .000 \\
\text { h. } & \text { Más de } \$ 5.000 .000 \\
\text { i. } & \text { No sabe } / \text { No responde }\end{aligned}\end{array}$ & $\begin{array}{l}\text { B.9. De dónde provienen los ingresos de este hogar: } \\
\begin{array}{l}\text { a. Trabajo asalariado } \\
\text { b. Trabajo independiente } \\
\text { c. Pensiones (jubilación, invalidez, vejez, etc.) } \\
\text { d. Dineros provenientes de otros hogares e. } \\
\text { e. Ingresos de capital (arriendos, utilidades e intereses) } \\
\text { f. Ingresos ocasionales (venta de bienes, lotería, etc.) }\end{array}\end{array}$ \\
\hline $\begin{array}{l}\text { B.10. Tiempo que lleva este hogar viviendo en esta ciudad: } \\
\text { a. Menos de } 1 \text { año } \\
\text { b. Entre } 1 \text { y menos de } 3 \text { años } \\
\text { c. Entre } 3 \text { y } 5 \text { años } \\
\text { d. Más de } 5 \text { años }\end{array}$ & $\begin{array}{l}\text { B.11. Tiempo que lleva este hogar viviendo en este barrio: } \\
\text { a. Menos de } 1 \text { año } \\
\text { b. Entre } 1 \text { y menos de } 3 \text { años } \\
\text { c. Entre } 3 \text { y } 5 \text { años } \\
\text { d. Más de } 5 \text { años }\end{array}$ \\
\hline $\begin{array}{l}\text { B.12.Lugar de procedencia del grupo familiar: } \\
\text { a. País: } \\
\text { b. Departamento: } \\
\text { c. Municipio o Ciudad: } \\
\text { d. Barrio: }\end{array}$ & $\begin{array}{l}\text { B.13.Principal razón de traslado de la familia a su lugar de } \\
\text { residencia actual: } \\
\text { a. Trabajo } \\
\text { b. Adquisición de vivienda } \\
\text { c. Cambio de estado civil } \\
\text { d. Finalización del contrato de arrendamiento } \\
\text { e. Disminución de ingresos } \\
\text { f. Aumento de ingresos } \\
\text { g. Problemas con los vecinos } \\
\text { h. Desastre natural } \\
\text { i. Desplazamiento forzado } \\
\text { j. Amenazas } \\
\text { k. Otra: }\end{array}$ \\
\hline B.14. ¿Se considera usted o algún miembro de su hogar víctima & B.15. Si la anterior respuesta fue afirmativa, ¿tiene reconocimiento \\
\hline
\end{tabular}


del conflicto armado?

a. Si

b. No como víctima del conflicto armado?

(Por ejemplo: carta de desplazamiento, registro único de víctimas RUV)
a. Si
b. no

\section{Caracterización educativa y cultural del hogar}

C.1. Último nivel educativo aprobado por el adulto que diligencia la encuesta:
a. Preescolar
e. Superior o Universitario
b. Primaria
f. Posgrado
c. Secundaria
g. Ninguno
d. Técnico

C.3. El mayor nivel educativo aprobado por alguno de los miembros de su hogar:
a. Preescolar
b. Primaria
e. Superior o Universitario
c. Secundaria
f. Posgrado
d. Técnico
g. Ninguno

C.5. Horas a la semana que usted dedica a actividades lúdicas y recreativas (como juegos y/o deportes) junto al niño 0 a la niña:
a. Menos de 3 horas semanales
b. De 3 a 6 horas semanales
c. De 6 a 10 horas semanales
d. Más de 10 horas semanales

C.2. El menor nivel educativo aprobado por alguno de los miembros de su hogar:
a. Preescolar
e. Superior o Universitario
b. Primaria
f. Posgrado
c. Secundaria
g. Ninguno
d. Técnico

C.4. Horas a la semana que usted dedica al acompañamiento y realización de tareas del niño o de la niña:
a. Menos de 3 horas semanales
b. De 3 a 6 horas semanales
c. De 6 a 10 horas semanales
d. Más de 10 horas semanales

C.6. Actividades que usted realizó durante la última semana con el niño o la niña:
a. Labores académicas (tareas, lecturas, proyectos)
b. Labores del hogar ( limpieza, mantenimiento, cocina)
c. Juegos o deportes
d. Visitar familiares y/o amigos
e. Viajes
f. Otro:

\section{Observaciones}


Anexo 3. Instrumento de medición de resiliencia

"RAYUELA RESILIERA": MODELO VALIDADO DE PROMOCION DE LA RESILIENCIA EN NINOS Y NIRAS

\begin{tabular}{|l|l|}
\hline & Cuestionario JJ63: RESILIENCIA EN ADOLESCENTES \\
Jaramillo, 2014
\end{tabular}

\begin{tabular}{|c|c|c|c|c|c|c|}
\hline \multirow{2}{*}{ PREGUNTAS } & \multicolumn{5}{|c|}{ RESPUESTAS } & \multirow{2}{*}{$\begin{array}{l}\text { Puntaje } \\
\text { parcial }\end{array}$} \\
\hline & $\begin{array}{c}\text { Casi } \\
\text { nunca }\end{array}$ & $\begin{array}{l}\text { Pocas } \\
\text { veces }\end{array}$ & A veces & $\begin{array}{l}\text { Muchas } \\
\text { veces }\end{array}$ & $\begin{array}{c}\text { Casi } \\
\text { siempre }\end{array}$ & \\
\hline \multicolumn{7}{|l|}{$\begin{array}{l}\text { 1. ¿Cuándo alguien de la familia tiene un problema, tú } \\
\text { ayudas? }\end{array}$} \\
\hline \multicolumn{7}{|l|}{ 2. ¿En tu casa predomina la armonia? } \\
\hline \multicolumn{7}{|l|}{$\begin{array}{l}\text { 3. } i \text { Puedes conversar de lo que sea sin temor dentro de tu } \\
\text { famila? }\end{array}$} \\
\hline \multicolumn{7}{|l|}{$\begin{array}{l}\text { 4. ¿Ante un problema, eres capaz de pecir ayuda a alguien de } \\
\text { tu familia? }\end{array}$} \\
\hline \multicolumn{7}{|l|}{$\begin{array}{l}\text { 5. ¿Demuestras el cariño que les tienes a los miembros de tu } \\
\text { familia? }\end{array}$} \\
\hline \multicolumn{7}{|l|}{$\begin{array}{l}\text { 6. ¿En tu familia se distribuyen las responsabiidades entre } \\
\text { todos? }\end{array}$} \\
\hline \multicolumn{7}{|l|}{$\begin{array}{l}\text { 7. ¿Aceptas los defectos de los demás miembros de tu } \\
\text { familia? }\end{array}$} \\
\hline \multicolumn{7}{|l|}{ 8. ¿Te sientes orgullosola de la persona que eres? } \\
\hline \multicolumn{7}{|l|}{ 9. Sientes que eres querido en casa? } \\
\hline \multicolumn{7}{|l|}{ 10. ¿Sientes que te apoyan en lo que te propones? } \\
\hline \multicolumn{7}{|l|}{ 11. ¿Te consideras atractivola? } \\
\hline \multicolumn{7}{|l|}{$\begin{array}{l}12 \text { ¿Estás contento con la figura corporal y apariencia que } \\
\text { tenes? }\end{array}$} \\
\hline \multicolumn{7}{|l|}{ 13. ¿Quisieras cambiar alguna parte de tu cuenpo? } \\
\hline \multicolumn{7}{|l|}{$\begin{array}{l}\text { 14. ¿Te duelen las opiniones de tus amigos cuando están en } \\
\text { tu contra? }\end{array}$} \\
\hline \multicolumn{7}{|l|}{$\begin{array}{l}\text { 15. ¿Si la conducta de otra persona te molesta, le pides que } \\
\text { camkie su comportamiento contigo? }\end{array}$} \\
\hline \multicolumn{7}{|l|}{ 16. ¿Le dices a tu familia cuando te molesta algo? } \\
\hline \multicolumn{7}{|l|}{$\begin{array}{l}\text { 17. ¿Cuándo te piden un favor que no deseas hacer ¿dices } \\
\text { simplemente "no" y te quedas tranquilo? }\end{array}$} \\
\hline \multicolumn{7}{|l|}{ 18. ¿Expresas tus deseos de realizar algo con facilidad? } \\
\hline \multicolumn{7}{|l|}{ 19. ¿Expresas likremente tu enfado o descontento? } \\
\hline \multicolumn{7}{|l|}{ 20. ¿Reclamas algo cuando es injusto? } \\
\hline \multicolumn{7}{|l|}{$\begin{array}{l}\text { 21. ¿Cuándo le prestas algo a alguien y olvidan devolverlo, le } \\
\text { recuerdas? }\end{array}$} \\
\hline \multicolumn{7}{|l|}{22 ¿Cuándo sucede algo inesperado ¿lo superas rápido? } \\
\hline \multicolumn{7}{|l|}{ 23. ¿Cuándo algo te sale mal, lo aceptas con facilidad? } \\
\hline \multicolumn{7}{|l|}{$\begin{array}{l}\text { 24. ¿Si tienes problemas con tus familiares, lo resuelves } \\
\text { rápidamente? }\end{array}$} \\
\hline $\begin{array}{l}\text { 25. ¿En las materias que no te gustan sacas buenas } \\
\text { calificaciones? }\end{array}$ & & & & & & \\
\hline
\end{tabular}


"RAYUELA RESILIERA": MODELO VALIDADO DE PROMOCION DE LA RESILIENCIA EN NIROS Y NIRAS

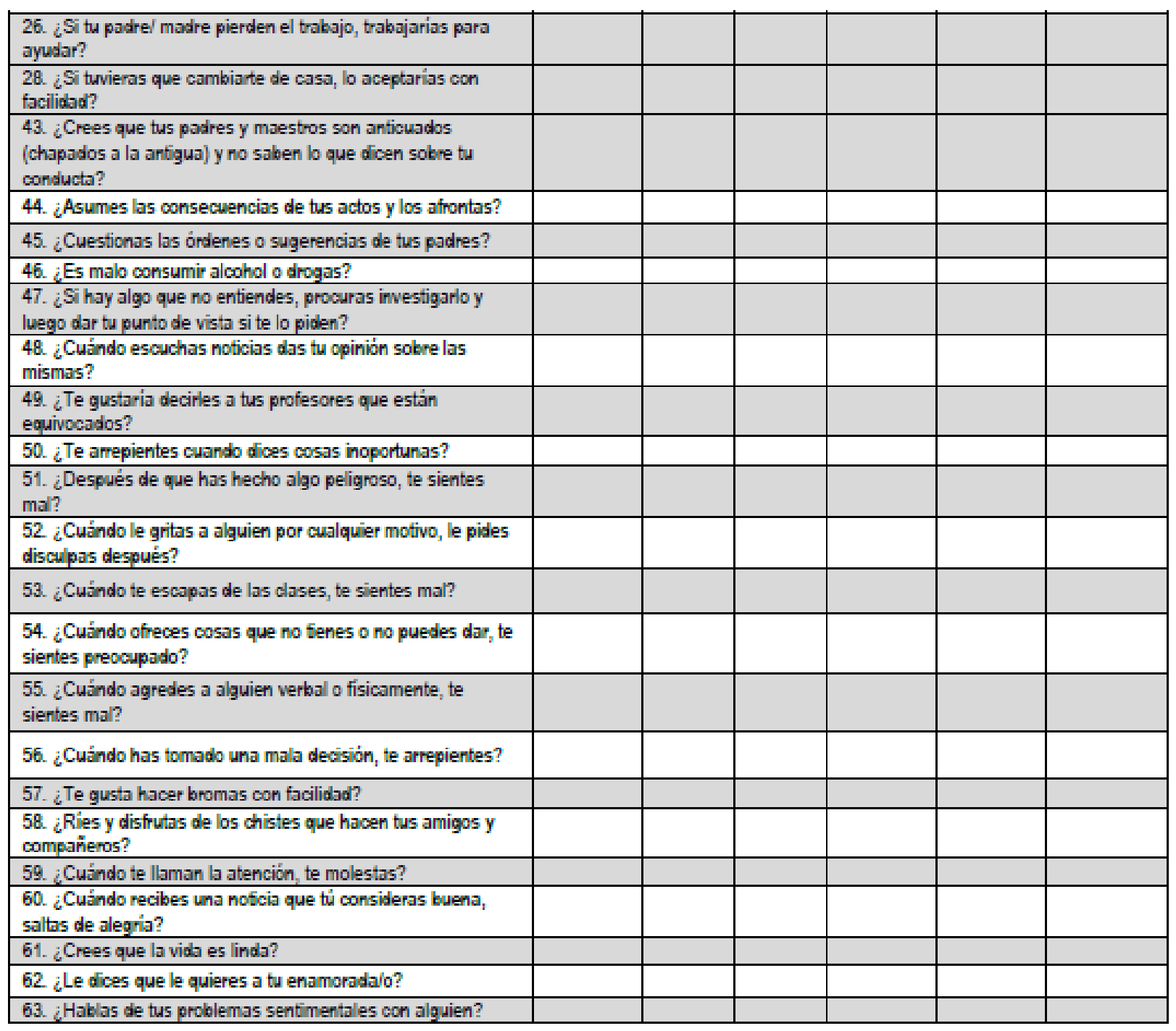


Anexo 4. Autorización del autor para la utilización del instrumento de medición de resiliencia

Cuenca, 29 de julio de 2016

Sandra Milena Alvarán López,

Trabajadora Social Universidad Nacional de Colombia

Docente Investigadora Universidad de Antioquia

Facultad Nacional de Salud Pública

Grupo de Investigación y Desarrollo Académico en Salud Mental (GISAME)

Su despacho.-

De mi consideración:

Con un cordial saludo me dirijo a Usted, para confirmarle mi autorización al uso del Test denominado Instrumento de Medición de la Resiliencia Adolescente "JJ63". Su persona puede adaptarlo y/o realizar los cambios que crea conveniente para mejorar su utilización.

Sin más por el momento me despido de usted.

Atentamente,

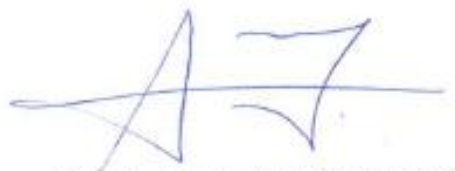

Dr. Julio Alfredo Jaramillo Oyervide

Docente de la Cátedra de Psicología

de la Facultad de Ciencias Médicas

de la Universidad de Cuenca. 
Anexo 5. Instrumento de percepción de estilos parentales

\begin{tabular}{l}
$\begin{array}{l}\text { ESCALA DE PERCEPCIÓN DE LA RELACIÓN CON LOS PADRES PARA NIÑOS Y NIÑAS. } \\
\text { BASADA EN EL MODELO SCHAEFER, DE MINZI (2007) }\end{array}$ \\
\hline Curso: \\
\hline
\end{tabular}

Instrucciones

Lee las siguientes frases e indica con una señal $(X)$ en qué medida te las puedes aplicar a ti mismo

\begin{tabular}{|c|c|c|c|}
\hline Afimación ylo pregunta & SI & $\begin{array}{l}\text { MASO } \\
\text { MENOS }\end{array}$ & NO \\
\hline 1. A mi mamá le qusta hablar y estar conmigo la mayor parte del tiempo & & & \\
\hline 2. Mi mamá controla que llegue a casa a horario. & & & \\
\hline 3. Mi mamá me dice que me quiere mucho & & & \\
\hline 4. Mi mamá siempre quiere saber todo el tiempo dónde estoy y lo que hago & & & \\
\hline 5. Mi mamá decide con qué amigos puedo juntarme. & & & \\
\hline 6. Mi mamá se preocupa poco si yo me porto mal. & & & \\
\hline 7. Mi mamá me deja salir todas las veces que yo quiera. & & & \\
\hline 8. Mi mamá me hace sentir la persona más importante de su vida & & & \\
\hline 9. Mi mamá se mete en mis cosas. & & & \\
\hline 10. Mi mamá cree que castigándome va a corregir mi mal comportamiento. & & & \\
\hline 11. Mi mamá siempre escucha lo que yo opino y pienso. & & & \\
\hline 12. Mi mamá está siempre pendiente de lo que yo hago en la escuela y en el tiempo libre & & & \\
\hline $\begin{array}{l}\text { 13. Mi mamá siempre me dice las cosas que hace por mi, me echa en cara todo lo que tiene } \\
\text { que hacer por mi culpa. }\end{array}$ & & & \\
\hline 14. Mi mamá quiere controlar todo lo que yo haga. & & & \\
\hline 15. Mi mamá le importa cuando hago algo que no debo. & & & \\
\hline 16. Mi mamá me deja hacer lo que quiera. & & & \\
\hline 17. Mi mamá me protege cuando tengo miedo. & & & \\
\hline 18. Mi mamá insiste con que tengo que hacer todo lo que me dice. & & & \\
\hline 19. Mi papá me castiga cuando no le hago caso. & & & \\
\hline 20. Mi mamá a menudo tiene largas charlas conmigo sobre el por qué de las cosas. & & & \\
\hline $\begin{array}{l}\text { 21. Mi mamá me dice que, si realmente la quiero, me tengo que portar bien para no amargarle } \\
\text { la vida. }\end{array}$ & & & \\
\hline 22. Mi mamá insiste en que haga mis tareas. & & & \\
\hline $\begin{array}{l}\text { 23. Si insisto, mi mamá afloja y puedo quedarme levantado hasta más tarde los dias de } \\
\text { semana. }\end{array}$ & & & \\
\hline $\begin{array}{l}\text { 24. Mi mamá dice que portarse mal es muy grave y puedo tener problemas cuando sea } \\
\text { grande. }\end{array}$ & & & \\
\hline 25. Mi mamá, si hago algo que le duele, deja de hablarme hasta que me disculpe. & & & \\
\hline 26. Mi mamá se muestra orgullosa de lo que yo hago. & & & \\
\hline 27. Mi mamá quiere que me quede en casa para saber lo que yo hago & & & \\
\hline 28. Mi mamá hace que yo cumpla lo que me manda. & & & \\
\hline 29. A mi mamá le interesa lo que yo hago. & & & \\
\hline $\begin{array}{l}\text { 30. Mi mamá, cuando fallo en algo, no quiere saber nada conmigo hasta que yo encuentro la } \\
\text { forma de reconciliarme. }\end{array}$ & & & \\
\hline 31. Mi mamá me deja ir a jugar cuando quiero. & & & \\
\hline $\begin{array}{l}\text { 32. Mi mamá, cuando me porto mal, se preocupa porque voy a sufrir las co } \\
\text { cuando sea grande. }\end{array}$ & & & \\
\hline
\end{tabular}


Anexo 6. Autorización de la autora para la utilización del instrumento de percepción de estilos parentales

$10 / 6 / 2020$

Gmall - asludoa deade Colombla y pregunta

M Gmail

Cindy Tatiana Carrero Torres <tatianacarrerogegmail.com>

\section{Saludos desde Colombia y pregunta \\ 7 mensajes}

Tatiana Carrero Torres \&tatianacarrero@gmail.com>

Para: fachuin7@uap.edu.ar

9 de abril de $2018,20: 48$

Respetada Gabriela, reciba un cordial saludo. He revisado su articulo ESTILOS PARENTALES Y CREATIVIDAD EN NIN̈OS ESCOLARIZADOS, publicado en la revista Psicoperspectivas.

Estoy interesada en aplicar la adaptación que realizaron de la "Escala Argentina de Percepción de la Relación con los Padres para niños de Richaud de Minzi basada en el modelo Schaefer, la prueba de figuras del Test de Pensamiento Creativo de Torrance Forma B y la Escala de Personalidad Creadora heteroevaluación de Garaigordobil'. Podría informarme por favor qué debo hacer para obtener la autorización y la información completa para la aplicación.

Gracias.

Cindy Tatiana Carrero Torres

Trabajadora Social

Magister en Cooperación al Desarrollo

Doctoranda en Desarrollo Local y Cooperación

Tel. (057) 3002644453

Gabriela Krumm <gabrielakrummgdoc.uap.edu.ar>

Para: Tatiana Carrero Torres <tatianacarreroggmail.com>

12 de abril de $2018,10: 15$

Estimada Treing

El CRPBI adaptado es de la. Dez. Rishrnd y se ha usado en vanas pablenciones $y$ los items que re agreguron (direstamente del cuestionaro original en ingles) pan el estudio expecifico que se reslizo extin en el artisulo. Fijate por google academico si eacoutras algua publicacion con el "CRPBI Richand" o Escrin Argentina de Percepción prreatal

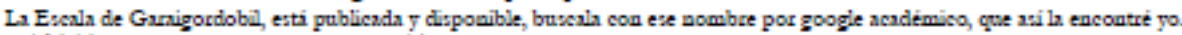

El TTCT re puede comprar por Scholastic Testing Service, ali te da las forman, wi como sil lo queses verbal o de figurn.

Espero que la informacion te sen de utilidad.

Saludos cordiales

Dra. Gabciela Krumm

[El texoo ctado esta ocuanol

Tatiana Carrero Torres «tatianacarrero@gmail.com>

Para: minzigciudad.com.ar

7 de mayo de $2018,20: 02$

Respetada Dra. Maria Cristina Richaud de Minzi, reciba un cordial saludo. He revisado su artículo "La percepción de estilos de relación con su padre y madre en niños y niñas de 8 a 12 años"., publicado en la Revista lberoamericana de Evaluación Psicológica, 2007, Vol 1, No 23.

Estoy interesada en aplicar la Escala Argentina de Percepción de la Relación con los Padres para niños basada en el modelo Schaefer o incluso la versión abreviada versión abreviada de Ghiglione \& Richaud de Minzi, 2009 de 18 ítems. Podría informarme por favor qué debo hacer para obtener la autorización y la información completa para la aplicación.

Gracias.

[El texto ctado etat ocuetol

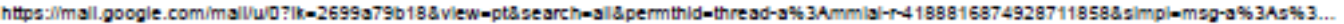


Tatiana Carrero Torres <tatianacarrero@gmail.com>

7 de mayo de 2018, 20:30

Para: mrichaud@conicet.gov.ar

[El texto cítado está oculto]

Tatiana Carrero Torres <tatianacarrero@gmail.com>

16 de mayo de $2018,8: 48$

Para: Gabriela Krumm <gabrielakrumm@doc.uap.edu.ar

Cc: Sandra Milena Alvarán <smalvaranl@gmail.com>

Estimada Dra. Gabriela, gracias por su respuesta y orientación.

Tengo una solicitud adicional, no he logrado respuesta de la Dra. Richaud para la autorización, por lo que prefiero aplicar la adaptación que ustedes hicieron para su investigación. Así pues, ¿me podrias autorizar la utilización de la adaptación que han hecho al CRPBI de la Dra. Richaud? y en tal caso, ¿me podrías compartir el instrumento y el baremo de puntuación?

Quedo atenta a tu respuesta y reitero mis agradecimientos por la orientación!

[El texto citado está oculto]

Gabriela Liliana Krumm <gabriela.krumm@uap.edu.ar>

Para: Tatiana Carrero Torres <tatianacarrero@gmail.com>

16 de mayo de $2018,16: 58$

Cc: Sandra Milena Alvarán <smalvaranl@gmail.com>

\section{Estimada Tatiana}

Ahí te lo envío. Los baremos no los tengo porque no se sacaron, ya que se utilizan para comparaciones individuales de los puntajes.

Saludos cordiales

\section{Dra. Gabriela Krumm}

De: Tatiana Carrero Torres <tatianacarrero@gmail.com>

Enviado: miércoles, 16 de mayo de 2018 10:48:28

Para: Gabriela Krumm

Cc: Sandra Milena Alvarán

Asunto: Re: Saludos desde Colombia y pregunta

[El texto citado está oculto]

望) CRPBI adaptado.docx

$18 \mathrm{~K}$ 
Anexo 7. EPC: Escala de personalidad creadora

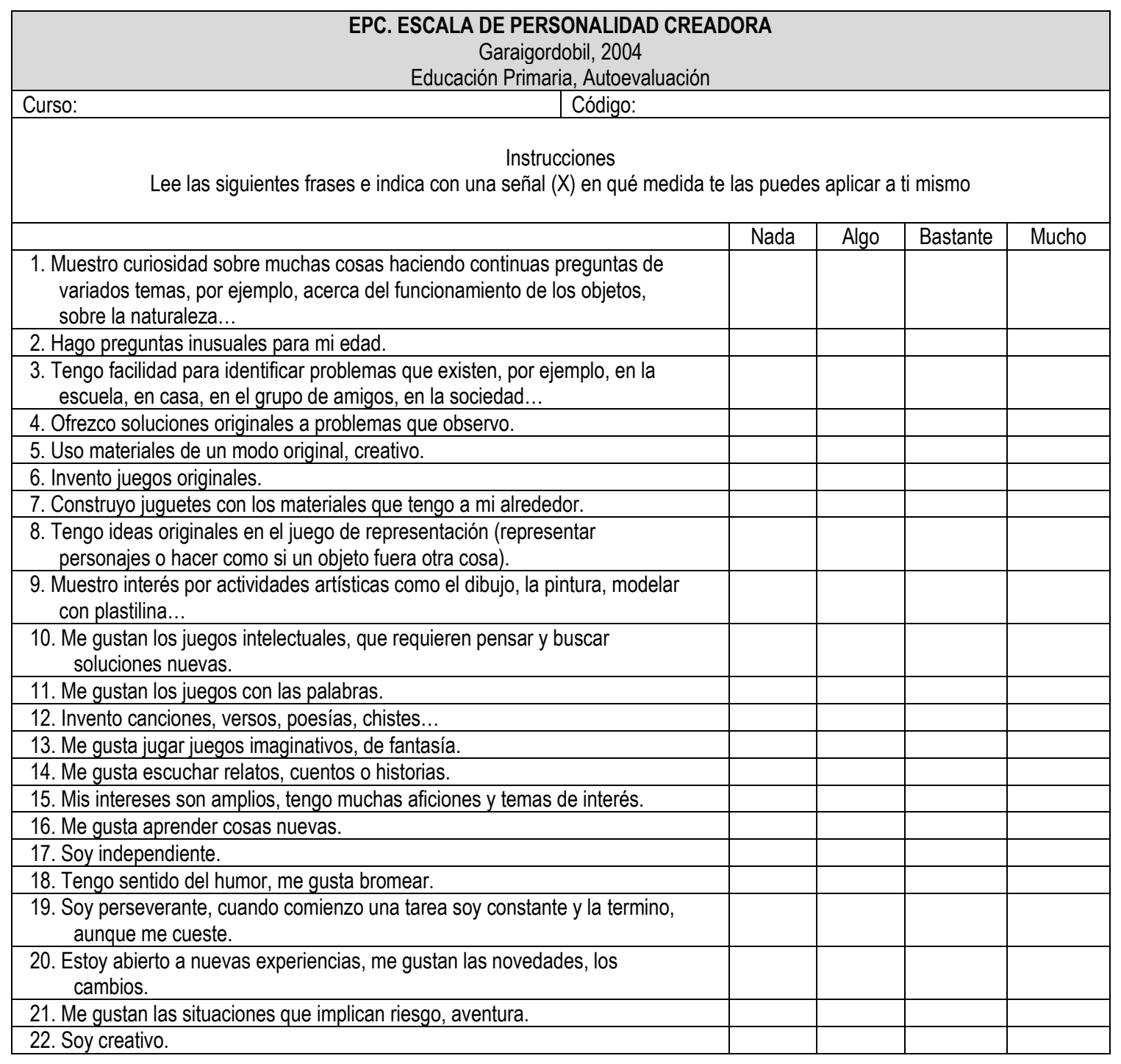

\section{Normas de aplicación, corrección e interpretación}

La versión de autoevaluación se administra de forma colectiva y cada persona debe reflexionar en qué medida se puede aplicar los contenidos de esas frases a sí mismo. En la hetero-aplicación se solicita a padres y profesores que lean las frases e indiquen en qué medida se pueden aplicar a su alumno $o$ a su hijo. 
Para la corrección, debido a que las frases se plantean en términos positivos o dicho de otro modo hacen referencia a conductas o rasgos de personalidad característicos de sujetos creadores, se puntúa con 0, 1, 203 puntos respectivamente en función del grado de intensidad de aplicación del contenido de la frase (nada, algo, bastante, mucho). Para interpretar las puntuaciones directas puede utilizarse el baremo elaborado con una muestra de 139 niños de 10 a 12 años de edad (véase tabla 2).

Tabla 23. Tabla de transformación de puntuaciones directas en percentiles para varones y mujeres en la escala de personalidad creadora EPC

\begin{tabular}{ccccccc}
\hline & \multicolumn{6}{c}{ Puntuación Directa } \\
\hline Puntuación & \multicolumn{2}{c}{ Autoevaluación } & \multicolumn{2}{c}{ Padres } & \multicolumn{2}{c}{ Profesores } \\
\cline { 2 - 7 } Percentil & $\mathrm{V}$ & $\mathrm{M}$ & $\mathrm{V}$ & $\mathrm{M}$ & $\mathrm{V}$ & $\mathrm{M}$ \\
\hline 1 & 12 & 18 & 12 & 14 & 5 & 8 \\
10 & 25 & 29 & 19 & 25 & 13 & 16 \\
20 & 29 & 32 & 23 & 31 & 21 & 22 \\
30 & 30 & 34 & 29 & 33 & 26 & 26 \\
40 & 33 & 36 & 32 & 36 & 30 & 29 \\
50 & 34 & 38 & 35 & 39 & 32 & 33 \\
60 & 36 & 41 & 38 & 41 & 36 & 38 \\
70 & 40 & 43 & 43 & 43 & 39 & 40 \\
80 & 43 & 46 & 47 & 47 & 44 & 45 \\
90 & 49 & 52 & 50 & 54 & 47 & 48 \\
99 & 66 & 61 & 55 & 61 & 54 & 60 \\
\hline
\end{tabular}

Fuente: Garaigordobil (2004). 
Anexo 8. Autorización de la autora para la utilización de la EPC: Escala de personalidad creadora

\author{
Saludos desde Colombia y pregunta \\ 6 mensajes \\ Tatiana Carrero Torres «tatianacarrero@gmail.com> \\ Para: maite.garaigordobilgehu.es \\ creadora: estudio psicométrico exploratorio". \\ la información completa para la aplicación. \\ Gracias. \\ Cindy Tatiana Carrero Torres \\ Trabajadora Social \\ Magister en Cooperación al Desarrollo \\ Doctoranda en Desarrollo Local y Cooperación \\ Tel. (057) 3002644453
}

7 de mayo de $2018,20: 25$

Respetada Dra. Maite Garaigordobil, reciba un cordial saludo. He revisado su artículo "Escala de personalidad

Estoy interesada en aplicar la EPC. Podría informarme por favor qué debo hacer para obtener la autorización y

MAITE GARAIGORDOBIL <maite garaigordobil@ehu.eus>

8 de mayo de $2018,1: 00$

Para: Tatiana Carrero Torres <tatianacarrero@gmail.com>

Estimada Tatiana,

Tiene mi permiso para utilizar mi escala. Espero le sea de interés. Quedo a su disposición si le surge alguna duda.

Un cordial saludo,

Maite

Maite Garaigordobil Landazabal

Catedrática de Evaluación y Diagnóstico Psicológicos

Dpto. Personalidad, Evaluación y Tratamientos Psicológicos.

Directora del Master Oficial en Psicología General Sanitaria.

Facultad de Psicología. Universidad del Pais Vasco.

Avda de Tolosa 70. 20018 Donostia-San Sebastián.

Tfno: 943 - 015634; Fax: 943 - 015670

E-mail: maite.garaigordobilgehu.eus

http:l/orcid.org/0000-0002-8621-6245

http:l/www. sc.ehu.es/garaigordobil

https://www.researchgate.net/profile/Maite_Garaigordobil/publications

http///scholar.google.es/citations?user=uc./s7kAAAA.J\&hl=es

Tatiana Carrero Torres <tatianacarreroggmail.com> escribió:

Respetada Dra. Maite Garaigordobil, reciba un cordial saludo. He revisado su articulo "Escala de personalidad creadora: estudio psicométrico exploratorio" $"$. *

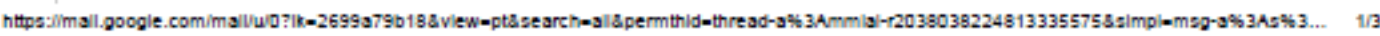




\section{Anexo 9. Cuestionario de emociones positivas}

\begin{tabular}{|c|c|c|c|c|}
\hline \multicolumn{5}{|c|}{$\begin{array}{l}\text { CUESTIONARIO INFANTIL DE EMOCIONES POSITIVAS } \\
\text { Oros, } 2014\end{array}$} \\
\hline Curso: & \multicolumn{4}{|l|}{ Código: } \\
\hline \multicolumn{5}{|c|}{ Instrucciones } \\
\hline \multicolumn{5}{|c|}{$\begin{array}{l}\text { Por favor responde las frases que aparecen más abajo haciendo una cruz }(\mathrm{x}) \text { en la casilla que corresponda: } \\
\text { Si, Más o menos, o No. } \\
\text { No hay respuestas correctas o incorrectas, sólo es importante que seas honesto. Muchas Gracias. }\end{array}$} \\
\hline & & sí & $\begin{array}{l}\text { MÁSO } \\
\text { MENOS }\end{array}$ & NO \\
\hline \multicolumn{5}{|l|}{ 1. Soy una persona alegre } \\
\hline \multicolumn{5}{|c|}{ 2. Estoy agradecido con varias personas, por lo que hacen por mí } \\
\hline \multicolumn{5}{|c|}{ 3. La mayor parte de los días me siento en paz } \\
\hline \multicolumn{5}{|c|}{ 4. Valoro cuando los demás me ayudan } \\
\hline \multicolumn{5}{|l|}{ 5. Soy bastante tranquilo } \\
\hline \multicolumn{5}{|c|}{ 6. Me pongo muy mal si veo que alguien se lastima } \\
\hline \multicolumn{5}{|c|}{ 7. Si veo llorar a un/a nene/a me dan ganas de llorar a mí también } \\
\hline \multicolumn{5}{|l|}{ 8. Me quiero mucho a mí mismo } \\
\hline \multicolumn{5}{|c|}{ 9. Soluciono mis problemas con mucha tranquilidad } \\
\hline \multicolumn{5}{|l|}{ 10. Me gusta devolver favores } \\
\hline \multicolumn{5}{|c|}{ 11. Cuando alguien está solo y aburrido me dan ganas de acercarme y jugar con él } \\
\hline \multicolumn{5}{|c|}{ 12. Me divierto mucho con las cosas que hago } \\
\hline \multicolumn{5}{|l|}{ 13. Soy muy feliz } \\
\hline \multicolumn{5}{|l|}{ 14. Casi siempre estoy relajado } \\
\hline \multicolumn{5}{|c|}{ 15. Siempre que puedo, devuelvo los favores que recibo } \\
\hline \multicolumn{5}{|l|}{ 16. Siento que soy muy valioso } \\
\hline \multicolumn{5}{|c|}{ 17. Aunque tenga problemas, igual mantengo la calma } \\
\hline \multicolumn{5}{|l|}{ 18. Casi siempre la paso bien } \\
\hline \multicolumn{5}{|c|}{ 19. Me quedo tranquilo aunque no pueda hacer lo que me gusta } \\
\hline \multicolumn{5}{|l|}{ 20. Siento que soy importante } \\
\hline \multicolumn{5}{|c|}{ 21. Si alguien está llorando me dan ganas de abrazarlo o consolarlo } \\
\hline \multicolumn{5}{|l|}{ 22. Me gusta agradecerle a la gente } \\
\hline 23. Casi siempre estoy contento/a & & & & \\
\hline
\end{tabular}


Anexo 10. Autorización de la autora para la utilización del cuestionario de emociones positivas

De: Laura Oros <lauraorosb@gmail.com>
Fecha: 30 de enero de $2018,12: 17$
Asunto: RE: Solicitud de información
Para: SANDRA ALVARAN <smalvaranl@gmail.com>

Estimada Sandra:

La información completa está en el articulo que te adjunto. Anexo también la prueba.

En Argentina aún no hemos elaborado los baremos para la interpretación individual de los puntajes (estamos trabajando en ello). pero te paso aquí abajo los valores provisorios a partir de los casos que hemos recogido (corresponden a la corrección global del test):

Desde el valor 24 hasta el 52 se consideran puntajes bajos de emocionalidad positiva.

Desde el 53 hasta el 57 puntajes moderadamente bajos.

Desde el 58 hasta el 61 puntajes moderadamente altos.

Desde el 62 en adelante puntajes elevados.

El valor promedio en una muestra de más de 1000 niños de ambos sexos con edades comprendidas entre los 8 y los 12 años fue de: $56,83(\mathrm{DE}=7.08)$ que correspondería a un puntaje moderadamente alto.

Desde luego que estos datos pueden variar culturalmente por lo que te recomiendo calcular tus propios baremos.

Espero que te sirva,

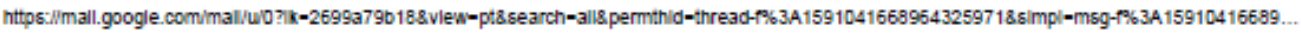

10/6/2020

Gmall - Fwd: Sollctud de informacion

Saludos cordiales,

Laura

De: SANDRA ALVARAN [mailto:smalvaranl@gmail.com]

Enviado el: martes, 30 de enero de 2018 11:44

Para: Laura Oros <lauraorosb@gmail.com>

Asunto: Solicitud de información

Un saludo desde Colombia.

Estoy interesada en aplicar el cuestionario de emociones positivas para niños. Podría informarme por favor qué debo hacer para obtener la autorización y la información completa para la aplicación.

Gracias.

Sandra Milena Alvarán López

Trabajadora Social Universidad Nacional de Colombia

Docente Investigadora Universidad de Antioquia

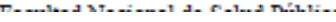


Anexo 11. Diccionario de variables.

\begin{tabular}{|c|c|c|c|c|c|}
\hline \multicolumn{6}{|c|}{ Diccionario de datos } \\
\hline$\#$ & Variable & Etiqueta & Naturaleza & $\begin{array}{l}\text { Nivel de } \\
\text { medición }\end{array}$ & Valores \\
\hline 1 & Código & $\begin{array}{l}\text { Documento de identidad del } \\
\text { estudiante }\end{array}$ & Cualitativa & Nominal & No aplica \\
\hline 2 & Tipo_Población & $\begin{array}{l}\text { Tipo de poblacion "Cuarto control y } \\
\text { Quinto expuestos" }\end{array}$ & Cualitativa & Nominal & \begin{tabular}{|l|}
1 Control \\
2 Expuestos \\
\end{tabular} \\
\hline 3 & Nombre_Estudiante & Nombre del estudiante & Cualitativa & Nominal & No aplica \\
\hline 4 & Consentimiento & $\begin{array}{l}\text { Se le entrego el consentimiento a } \\
\text { los padres o acudiente para su firma }\end{array}$ & Cualitativa & Nominal & \begin{tabular}{|l|}
$1 \mathrm{Si}$ \\
$2 \mathrm{No}$ \\
$99 \mathrm{Sin}$ informacion
\end{tabular} \\
\hline 5 & Entrego_Encuesta & $\begin{array}{l}\text { Primera entrega encuestas } 7 \text { de } \\
\text { septiembre del } 2017\end{array}$ & Cualitativa & Nominal & \begin{tabular}{|l|}
$1 \mathrm{Si}$ \\
$2 \mathrm{No}$ \\
$99 \mathrm{Sin}$ informacion \\
\end{tabular} \\
\hline 6 & Curso & Grado actual del estudiante & Cualitativa & Nominal & \begin{tabular}{|l|}
1 Cuarto grupo 401 \\
2 Cuarto grupo 402 \\
3 Quinto grupo 501 \\
4 Quinto grupo 502 \\
\end{tabular} \\
\hline 7 & Parentesco & $\begin{array}{l}\text { Parentesco de quien diligencia la } \\
\text { encuesta }\end{array}$ & Cualitativa & Nominal & \begin{tabular}{|l|}
1 Madre \\
2 Padre \\
3 Otros \\
99 Sin informacion \\
\end{tabular} \\
\hline 8 & Edad_Adulto & $\begin{array}{l}\text { Edad del adulto que diligencia la } \\
\text { encuesta }\end{array}$ & Cuantitativa & Discreta & Edad en años cumplidos \\
\hline 9 & Edad_Estudiante & Edad del estudiante & Cuantitativa & Continua & Edad en años cumplidos \\
\hline 10 & Lugar_Nacimiento_Adulto & $\begin{array}{l}\text { Lugar de nacimiento del adulto que } \\
\text { diligencia la encuesta }\end{array}$ & Cualitativa & Nominal & No aplica \\
\hline 11 & Lugar_Nacimiento_Niño & $\begin{array}{l}\text { Lugar de nacimiento del niño o de la } \\
\text { niña }\end{array}$ & Cualitativa & Nominal & No aplica \\
\hline 12 & $\begin{array}{c}\text { Sexo_Adulto_Responsabl } \\
\mathrm{e}\end{array}$ & Género del adulto & Cualitativa & Ordinal & \begin{tabular}{|l|}
1 Masculino \\
2 Femenino \\
99 Sin información \\
\end{tabular} \\
\hline 13 & Sexo_Estudiante & Sexo del estudiante & Cualitativa & Nominal & $\begin{array}{l}1 \text { Masculino } \\
2 \text { Femenino } \\
99 \text { Sin información }\end{array}$ \\
\hline 14 & Victima_Conflicto_Armado & Victima del complicto armado & Cualitativa & Nominal & \begin{tabular}{|l|}
$1 \mathrm{Si}$ \\
$2 \mathrm{No}$ \\
$99 \mathrm{Sin}$ informacion \\
\end{tabular} \\
\hline 15 & Discapacidad & $\begin{array}{l}\text { El adolecente tiene alguna } \\
\text { discapacidad, limitación o capacidad } \\
\text { diferente }\end{array}$ & Cualitativa & Nominal & \begin{tabular}{|l|}
$1 \mathrm{Si}$ \\
$2 \mathrm{No}$ \\
$99 \mathrm{Sin}$ informacion \\
\end{tabular} \\
\hline 16 & Etnia & $\begin{array}{l}\text { El adolecente pertenece a alguna } \\
\text { etnia }\end{array}$ & Cualitativa & Ordinal & \begin{tabular}{|l|}
$1 \mathrm{Si}$ \\
$2 \mathrm{No}$ \\
$99 \mathrm{Sin}$ informacion \\
\end{tabular} \\
\hline 17 & Sisben_EPS & Tipo de afiliacion & Cualitativa & Nominal & No aplica \\
\hline 18 & Residencia & Lugar de residencia & Cualitativa & Nominal & No aplica \\
\hline 19 & Tipo_Vivienda & Tipo de vivienda & Cualitativa & Nominal & \begin{tabular}{|l|}
1 Apartamento \\
2 Casa \\
3 Inquilinato \\
99 Sin informacion \\
\end{tabular} \\
\hline 20 & Propiedad_Vivenda & $\begin{array}{l}\text { La vivienda ocupada por este hogar } \\
\text { es }\end{array}$ & Cualitativa & Nominal & \begin{tabular}{|l|}
1 Arriendo \\
2 Familiar \\
3 Propia \\
4 Otra \\
99 Sin informacion \\
\end{tabular} \\
\hline 21 & Estrato & Esta vivienda se encuentra en el & Cualitativa & Ordinal & \begin{tabular}{|l|}
1 Estrato 1 \\
2 Estrato 2 \\
3 Estrato 3 \\
99 Sin informacion \\
\end{tabular} \\
\hline
\end{tabular}




\begin{tabular}{|c|c|c|c|c|c|}
\hline 22 & $\begin{array}{c}\text { Cantidad_Miembros_Hog } \\
\text { ar }\end{array}$ & $\begin{array}{l}\text { Cantidad de miembros que } \\
\text { conforman el hogar }\end{array}$ & Cuantitativa & Discreta & $\begin{array}{l}\text { Numero personas que viven en } \\
\text { el hogar }\end{array}$ \\
\hline 23 & Tipo_familia & Tipo de familia & Cualitativa & Nominal & \begin{tabular}{|l|}
1 Familia nuclear \\
2 Familia Extensa \\
3 Familia monoparental \\
99 Sin información \\
\end{tabular} \\
\hline 24 & $\begin{array}{c}\text { Miem_Apor_Ingre_Mensu } \\
\text { al }\end{array}$ & $\begin{array}{l}\text { Cuantos aportan al ingreso del } \\
\text { hogar }\end{array}$ & Cuantitativa & Discreta & \\
\hline 25 & $\begin{array}{c}\text { Ingreso_Mensual_Promed } \\
\text { io }\end{array}$ & $\begin{array}{l}\text { Ingreso mensual promedio del } \\
\text { hogar }\end{array}$ & Cualitativa & Nominal & $\begin{array}{l}1 \text { Entre } 100.000 \text { y } 350.000 \\
2 \text { Entre } 350.001 \text { y } 749.999 \\
3 \text { Entre } 700.000 \text { y } 1.000 .000 \\
4 \text { Entre } 1.000 .000 \text { y } 2.000 .000 \\
5 \text { No sabe/ No responde } \\
6 \text { Mas de } 5000001 \\
\end{array}$ \\
\hline 26 & Proveniencia_Ingresos & $\begin{array}{l}\text { De dónde provienen los ingresos de } \\
\text { este hogar }\end{array}$ & Cualitativa & Ordinal & $\begin{array}{l}1 \text { Ingreso de capital } \\
2 \text { Ingreso ocasionales } \\
3 \text { Trabajo asalariado } \\
4 \text { Trabajo independiente } \\
99 \text { Sin información } \\
\end{array}$ \\
\hline 27 & Tiempo_Perm_ciudad & $\begin{array}{l}\text { Tiempo que lleva este hogar } \\
\text { viviendo en esta ciudad }\end{array}$ & Cualitativa & Ordinal & $\begin{array}{l}1 \text { Menos de } 1 \text { año } \\
2 \text { Entre } 1 \text { y menos de } 3 \text { años } \\
3 \text { Entre } 3 \text { y } 5 \text { años } \\
4 \text { Mas de } 5 \text { años }\end{array}$ \\
\hline 28 & Tiempo_Perm_Barrio & $\begin{array}{l}\text { Tiempo que lleva este hogar } \\
\text { viviendo en este barrio }\end{array}$ & Cualitativa & Nominal & $\begin{array}{l}1 \text { Menos de } 1 \text { año } \\
2 \text { Entre } 1 \text { y menos de } 3 \text { años } \\
3 \text { Entre } 3 \text { y } 5 \text { años } \\
4 \text { Mas de } 5 \text { años }\end{array}$ \\
\hline 29 & Lugar_Procedencia & $\begin{array}{l}\text { Lugar de procedencia del grupo } \\
\text { familiar }\end{array}$ & Cualitativa & Nominal & No aplica \\
\hline 30 & Razón_Traslado & $\begin{array}{l}\text { Principal razón de traslado de la } \\
\text { familia a su lugar de residencia } \\
\text { actual }\end{array}$ & Cualitativa & Nominal & $\begin{array}{l}1 \text { Adquisición de vivienda } \\
2 \text { Cambio de estado civil } \\
3 \text { Desplazado forzado } \\
4 \text { Trabajo } \\
5 \text { Finalización del contrato de } \\
\text { arrendamiento } \\
6 \text { Otras }\end{array}$ \\
\hline 31 & $\begin{array}{c}\text { Se_con_victi_Con_Armad } \\
0\end{array}$ & $\begin{array}{l}\text { ¿Se considera usted o algún } \\
\text { miembro de su hogar víctima del } \\
\text { conflicto armado? }\end{array}$ & Cualitativa & Nominal & \begin{tabular}{|l|}
$1 \mathrm{Si}$ \\
$2 \mathrm{No}$ \\
$99 \mathrm{Sin}$ informacion \\
\end{tabular} \\
\hline 32 & Cual & $\begin{array}{l}\text { Si la anterior respuesta fue } \\
\text { afirmativa, ¿tiene reconocimiento } \\
\text { como víctima del conflicto armado? }\end{array}$ & Cualitativa & Nominal & No aplica \\
\hline 33 & Nivel_Educativo_Adulto & $\begin{array}{l}\text { Último nivel educativo aprobado por } \\
\text { el adulto que diligencia la encuesta }\end{array}$ & Cualitativa & Nominal & \begin{tabular}{|l}
1 Primaria \\
2 Secundaria \\
3 Técnico \\
4 Superior o universitario \\
99 Sin información
\end{tabular} \\
\hline 34 & Menor_Nivel_Educativo & $\begin{array}{l}\text { El menor nivel educativo aprobado } \\
\text { por alguno de los miembros de su } \\
\text { hogar }\end{array}$ & Cualitativa & Nominal & $\begin{array}{l}\text { Primaria } \\
2 \text { Secundaria } \\
3 \text { Técnico } \\
4 \text { Superior o universitario } \\
99 \text { Sin informacion } \\
\end{array}$ \\
\hline 35 & Mayor_Nivel_Educativo & $\begin{array}{l}\text { El mayor nivel educativo aprobado } \\
\text { por alguno de los miembros de su } \\
\text { hogar }\end{array}$ & Cualitativa & Ordinal & $\begin{array}{l}1 \text { Primaria } \\
2 \text { Secundaria } \\
3 \text { Técnico } \\
4 \text { Superior o universitario } \\
99 \text { Sin informacion }\end{array}$ \\
\hline 36 & $\underset{\text { dé }}{\text { Horas_Sema_Acomp_Aca }}$ & $\begin{array}{l}\text { Horas a la semana que usted } \\
\text { dedica al acompañamiento y } \\
\text { realización de tareas del niño o de } \\
\text { la niña }\end{array}$ & Cualitativa & Nominal & $\begin{array}{l}1 \text { Menos de } 3 \text { horas a la } \\
\text { semana } \\
2 \text { De } 3 \text { a } 6 \text { horas a la semana } \\
3 \text { De } 6 \text { a } 10 \text { horas a la semana } \\
4 \text { Mas de } 10 \text { Horas a la semana } \\
99 \text { Sin informacion } \\
\end{array}$ \\
\hline 37 & $\begin{array}{c}\text { Horas_Sema_Acti_Ludore } \\
\text { creativas }\end{array}$ & $\begin{array}{l}\text { Horas a la semana que usted } \\
\text { dedica a actividades lúdicas y } \\
\text { recreativas (como juegos y/o } \\
\text { deportes) junto al niño o a la niña }\end{array}$ & Cualitativa & Nominal & $\begin{array}{l}1 \text { Menos de } 3 \text { horas a la } \\
\text { semana } \\
2 \text { De } 3 \text { a } 6 \text { horas a la semana } \\
3 \text { De } 6 \text { a } 10 \text { horas a la semana } \\
4 \text { Mas de } 10 \text { Horas a la semana } \\
99 \text { Sin informacion }\end{array}$ \\
\hline
\end{tabular}




\begin{tabular}{|c|c|c|c|c|c|}
\hline 38 & $\begin{array}{c}\text { Actividades_Realiante_Ult } \\
\text { ima_sema }\end{array}$ & $\begin{array}{l}\text { Actividades que usted realizó } \\
\text { durante la última semana con el } \\
\text { niño o la niña }\end{array}$ & Cualitativa & Nominal & $\begin{array}{l}1 \text { Labores academicas } \\
2 \text { Labores del hogar } \\
3 \text { Visitar Familiares o amigos } \\
4 \text { Viajar } \\
5 \text { Juegos } \\
99 \text { Sin informacion }\end{array}$ \\
\hline 39 & EP_Pretest_P1 & 1. Soy una persona alegre & Cualitativa & Ordinal & $\begin{array}{l}1 \mathrm{Si} \\
2 \text { Mas o menos } \\
3 \text { No }\end{array}$ \\
\hline 40 & EP_Pretest_P2 & $\begin{array}{l}\text { 2. Estoy agradecido con varias } \\
\text { personas, por lo que hacen por mí }\end{array}$ & Cualitativa & Ordinal & \begin{tabular}{|l}
$1 \mathrm{Si}$ \\
$2 \mathrm{Mas}$ o menos \\
$3 \mathrm{No}$ \\
\end{tabular} \\
\hline 41 & EP_Pretest_P3 & $\begin{array}{l}\text { 3. La mayor parte de los días me } \\
\text { siento en paz }\end{array}$ & Cualitativa & Ordinal & $\begin{array}{l}1 \mathrm{Si} \\
2 \text { Mas o menos } \\
3 \text { No }\end{array}$ \\
\hline 42 & EP_Pretest_P4 & $\begin{array}{l}\text { 4. Valoro cuando los demás me } \\
\text { ayudan }\end{array}$ & Cualitativa & Ordinal & $\begin{array}{l}1 \mathrm{Si} \\
2 \text { Mas o menos } \\
3 \text { No } \\
\end{array}$ \\
\hline 43 & EP_Pretest_P5 & 5. Soy bastante tranquilo & Cualitativa & Ordinal & \begin{tabular}{|l|}
$1 \mathrm{Si}$ \\
$2 \mathrm{Mas}$ o menos \\
$3 \mathrm{No}$ \\
\end{tabular} \\
\hline 44 & EP_Pretest_P6 & $\begin{array}{l}\text { 6. Me pongo muy mal si veo que } \\
\text { alguien se lastima }\end{array}$ & Cualitativa & Ordinal & \begin{tabular}{|l}
$1 \mathrm{Si}$ \\
$2 \mathrm{Mas}$ o menos \\
$3 \mathrm{No}$ \\
\end{tabular} \\
\hline 45 & EP_Pretest_P7 & $\begin{array}{l}\text { 7. Si veo llorar a un/a nene/a me } \\
\text { dan ganas de llorar a mí también }\end{array}$ & Cualitativa & Ordinal & $\begin{array}{l}\text { Si } \\
2 \text { Mas o menos } \\
3 \text { No }\end{array}$ \\
\hline 46 & EP_Pretest_P8 & 8. Me quiero mucho a mí mismo & Cualitativa & Ordinal & \begin{tabular}{|l|}
$1 \mathrm{Si}$ \\
$2 \mathrm{Mas}$ o menos \\
$3 \mathrm{No}$ \\
\end{tabular} \\
\hline 47 & EP_Pretest_P9 & $\begin{array}{l}\text { 9. Soluciono mis problemas con } \\
\text { mucha tranquilidad }\end{array}$ & Cualitativa & Ordinal & \begin{tabular}{|l}
$1 \mathrm{Si}$ \\
$2 \mathrm{Mas}$ o menos \\
$3 \mathrm{No}$ \\
\end{tabular} \\
\hline 48 & EP_Pretest_P10 & 10. Me gusta devolver favores & Cualitativa & Ordinal & $\begin{array}{l}1 \mathrm{Si} \\
2 \mathrm{Mas} \text { o menos } \\
3 \mathrm{No}\end{array}$ \\
\hline 49 & EP_Pretest_P11 & $\begin{array}{l}\text { 11. Cuando alguien está solo y } \\
\text { aburrido me dan ganas de } \\
\text { acercarme y jugar con él }\end{array}$ & Cualitativa & Ordinal & $\begin{array}{l}\mathrm{Si} \\
2 \mathrm{Mas} \text { o menos } \\
3 \mathrm{No} \\
\end{array}$ \\
\hline 50 & EP_Pretest_P12 & $\begin{array}{l}\text { 12. Me divierto mucho con las cosas } \\
\text { que hago }\end{array}$ & Cualitativa & Ordinal & \begin{tabular}{|l}
$1 \mathrm{Si}$ \\
2 Mas o menos \\
3 No \\
\end{tabular} \\
\hline 51 & EP_Pretest_P13 & 13. Soy muy feliz & Cualitativa & Ordinal & \begin{tabular}{|l|}
$1 \mathrm{Si}$ \\
$2 \mathrm{Mas}$ o menos \\
$3 \mathrm{No}$ \\
\end{tabular} \\
\hline 52 & EP_Pretest_P14 & 14. Casi siempre estoy relajado & Cualitativa & Ordinal & $\begin{array}{l}\mathrm{Si} \\
2 \mathrm{Mas} \text { o menos } \\
3 \mathrm{No} \\
\end{array}$ \\
\hline 53 & EP_Pretest_P15 & $\begin{array}{l}\text { 15. Siempre que puedo, devuelvo } \\
\text { los favores que recibo }\end{array}$ & Cualitativa & Ordinal & \begin{tabular}{|l}
$1 \mathrm{Si}$ \\
2 Mas o menos \\
3 No \\
\end{tabular} \\
\hline 54 & EP_Pretest_P16 & 16. Siento que soy muy valioso & Cualitativa & Ordinal & \begin{tabular}{|l|}
$1 \mathrm{Si}$ \\
$2 \mathrm{Mas}$ o menos \\
$3 \mathrm{No}$ \\
\end{tabular} \\
\hline 55 & EP_Pretest_P17 & $\begin{array}{l}\text { 17. Aunque tenga problemas, igual } \\
\text { mantengo la calma }\end{array}$ & Cualitativa & Ordinal & $\begin{array}{l}\text { 1 Si } \\
2 \text { Mas o menos } \\
3 \text { No }\end{array}$ \\
\hline 56 & EP_Pretest_P18 & 18. Casi siempre la paso bien & Cualitativa & Ordinal & $\begin{array}{l}1 \mathrm{Si} \\
2 \mathrm{Mas} \text { o menos } \\
3 \mathrm{No} \\
\end{array}$ \\
\hline 57 & EP_Pretest_P19 & $\begin{array}{l}\text { 19. Me quedo tranquilo aunque no } \\
\text { pueda hacer lo que me gusta }\end{array}$ & Cualitativa & Ordinal & \begin{tabular}{|l|}
$1 \mathrm{Si}$ \\
$2 \mathrm{Mas}$ o menos \\
$3 \mathrm{No}$ \\
\end{tabular} \\
\hline 58 & EP_Pretest_P20 & 20. Siento que soy importante & Cualitativa & Ordinal & \begin{tabular}{|l}
$1 \mathrm{Si}$ \\
$2 \mathrm{Mas}$ o menos \\
$3 \mathrm{No}$
\end{tabular} \\
\hline 59 & EP_Pretest_P21 & $\begin{array}{l}\text { 21. Si alguien está llorando me dan } \\
\text { ganas de abrazarlo o consolarlo }\end{array}$ & Cualitativa & Ordinal & $\begin{array}{l}1 \mathrm{Si} \\
2 \mathrm{Mas} \text { o menos } \\
3 \mathrm{No} \\
\end{array}$ \\
\hline
\end{tabular}




\begin{tabular}{|c|c|c|c|c|c|}
\hline 60 & EP_Pretest_P22 & 22. Me gusta agradecerle a la gente & Cualitativa & Ordinal & $\begin{array}{l}1 \mathrm{Si} \\
2 \mathrm{Mas} \text { o menos } \\
3 \mathrm{No}\end{array}$ \\
\hline 61 & EP_Pretest_P23 & 23. Casi siempre estoy contento/a & Cualitativa & Ordinal & $\begin{array}{l}1 \mathrm{Si} \\
2 \text { Mas o menos } \\
3 \mathrm{No}\end{array}$ \\
\hline 62 & $\begin{array}{c}\text { PD_Pre_test_AlegriayGrat } \\
\text { itud }\end{array}$ & Puntaje Alegria y gratitud Inicial & Cuantitativa & Discreta & No aplica \\
\hline 63 & PD_Pre_test_Serenidad & Puntaje Serenidad Inicial & Cuantitativa & Discreta & No aplica \\
\hline 64 & PD_Pre_test_Simpatia & Puntaje Simpatia Inicial & Cuantitativa & Discreta & No aplica \\
\hline 65 & $\begin{array}{c}\text { PD_Pre_test_Satisfacción } \\
\text { personal }\end{array}$ & Puntaje Satisfaccion personal Inicial & Cuantitativa & Discreta & No aplica \\
\hline 66 & $\begin{array}{c}\text { Escala_Pre_test_Alegriay } \\
\text { Gratitud }\end{array}$ & Alegria y gratitud Inicial (Agrupado) & Cualitativa & Ordinal & $\begin{array}{l}1 \text { Bajo } \\
2 \text { Medio } \\
3 \text { Alto }\end{array}$ \\
\hline 67 & $\begin{array}{c}\text { Escala_Pre_test_Serenida } \\
\text { d }\end{array}$ & Serenidad Inicial (Agrupado) & Cualitativa & Ordinal & $\begin{array}{l}1 \text { Bajo } \\
2 \text { Medio } \\
3 \text { Alto }\end{array}$ \\
\hline 68 & Escala_Pre_test_Simpatia & Simpatia Inicial (Agrupado) & Cualitativa & Ordinal & $\begin{array}{l}1 \text { Bajo } \\
2 \text { Medio } \\
3 \text { Alto }\end{array}$ \\
\hline 69 & $\begin{array}{c}\text { Escala_Pre_test_Satisfac } \\
\text { ciónpersonal }\end{array}$ & $\begin{array}{l}\text { Satisfaccion personal Inicial } \\
\text { (Agrupado) }\end{array}$ & Cualitativa & Ordinal & $\begin{array}{l}\text { Bajo } \\
2 \text { Medio } \\
3 \text { Alto } \\
\end{array}$ \\
\hline 70 & PC_Pretest_P1 & $\begin{array}{l}\text { 1. Muestro curiosidad sobre muchas } \\
\text { cosas haciendo continuas } \\
\text { preguntas de variados temas, por } \\
\text { ejemplo, acerca del funcionamiento } \\
\text { de los objetos, sobre la naturaleza... }\end{array}$ & Cualitativa & Ordinal & $\begin{array}{l}0 \text { Nada } \\
1 \text { Algo } \\
2 \text { Bastante } \\
3 \text { Mucho }\end{array}$ \\
\hline 71 & PC_Pretest_P3 & $\begin{array}{l}\text { 3. Tengo facilidad para identificar } \\
\text { problemas que existen, por ejemplo, } \\
\text { en la escuela, en casa, en el grupo } \\
\text { de amigos, en la sociedad... } \\
\end{array}$ & Cualitativa & Ordinal & $\begin{array}{l}0 \text { Nada } \\
1 \text { Algo } \\
2 \text { Bastante } \\
3 \text { Mucho } \\
\end{array}$ \\
\hline 72 & PC_Pretest_P4 & $\begin{array}{l}\text { 4. Ofrezco soluciones originales a } \\
\text { problemas que observo. }\end{array}$ & Cualitativa & Ordinal & $\begin{array}{l}0 \text { Nada } \\
1 \text { Algo } \\
2 \text { Bastante } \\
3 \text { Mucho } \\
\end{array}$ \\
\hline 73 & PC_Pretest_P5 & $\begin{array}{l}\text { 5. Uso materiales de un modo } \\
\text { original, creativo. }\end{array}$ & Cualitativa & Ordinal & $\begin{array}{l}0 \text { Nada } \\
1 \text { Algo } \\
2 \text { Bastante } \\
3 \text { Mucho } \\
\end{array}$ \\
\hline 74 & PC_Pretest_P6 & 6. Invento juegos originales. & Cualitativa & Ordinal & $\begin{array}{l}0 \text { Nada } \\
1 \text { Algo } \\
2 \text { Bastante } \\
3 \text { Mucho }\end{array}$ \\
\hline 75 & PC_Pretest_P7 & $\begin{array}{l}\text { 7. Construyo juguetes con los } \\
\text { materiales que tengo a mi } \\
\text { alrededor. }\end{array}$ & Cualitativa & Ordinal & $\begin{array}{l}0 \text { Nada } \\
1 \text { Algo } \\
2 \text { Bastante } \\
3 \text { Mucho } \\
\end{array}$ \\
\hline 76 & PC_Pretest_P8 & $\begin{array}{l}\text { 8. Tengo ideas originales en el } \\
\text { juego de representación } \\
\text { (representar personajes o hacer } \\
\text { como si un objeto fuera otra cosa). }\end{array}$ & Cualitativa & Ordinal & $\begin{array}{l}0 \text { Nada } \\
1 \text { Algo } \\
2 \text { Bastante } \\
3 \text { Mucho } \\
\end{array}$ \\
\hline 77 & PC_Pretest_P9 & $\begin{array}{l}\text { 9. Muestro interés por actividades } \\
\text { artísticas como el dibujo, la pintura, } \\
\text { modelar con plastilina... }\end{array}$ & Cualitativa & Ordinal & $\begin{array}{l}0 \text { Nada } \\
1 \text { Algo } \\
2 \text { Bastante } \\
3 \text { Mucho } \\
\end{array}$ \\
\hline 78 & PC_Pretest_P10 & $\begin{array}{l}\text { 10. Me gustan los juegos } \\
\text { intelectuales, que requieren pensar } \\
\text { y buscar soluciones nuevas. }\end{array}$ & Cualitativa & Ordinal & $\begin{array}{l}0 \text { Nada } \\
1 \text { Algo } \\
2 \text { Bastante } \\
3 \text { Mucho } \\
\end{array}$ \\
\hline 79 & PC_Pretest_P11 & $\begin{array}{l}\text { 11. Me gustan los juegos con las } \\
\text { palabras. }\end{array}$ & Cualitativa & Ordinal & $\begin{array}{l}0 \text { Nada } \\
1 \text { Algo } \\
2 \text { Bastante } \\
3 \text { Mucho } \\
\end{array}$ \\
\hline
\end{tabular}




\begin{tabular}{|c|c|c|c|c|c|}
\hline 80 & PC_Pretest_P12 & $\begin{array}{l}\text { 12. Invento canciones, versos, } \\
\text { poesías, chistes... }\end{array}$ & Cualitativa & Ordinal & $\begin{array}{l}0 \text { Nada } \\
1 \text { Algo } \\
2 \text { Bastante } \\
3 \text { Mucho }\end{array}$ \\
\hline 81 & PC_Pretest_P13 & $\begin{array}{l}\text { 13. Me gusta jugar juegos } \\
\text { imaginativos, de fantasía. }\end{array}$ & Cualitativa & Ordinal & $\begin{array}{l}0 \text { Nada } \\
1 \text { Algo } \\
2 \text { Bastante } \\
3 \text { Mucho }\end{array}$ \\
\hline 82 & PC_Pretest_P14 & $\begin{array}{l}\text { 14. Me gusta escuchar relatos, } \\
\text { cuentos o historias. }\end{array}$ & Cualitativa & Ordinal & \begin{tabular}{|l|}
0 Nada \\
1 Algo \\
2 Bastante \\
3 Mucho \\
\end{tabular} \\
\hline 83 & PC_Pretest_P15 & $\begin{array}{l}\text { 15. Mis intereses son amplios, tengo } \\
\text { muchas aficiones y temas de } \\
\text { interés. }\end{array}$ & Cualitativa & Ordinal & \begin{tabular}{|l|}
0 Nada \\
1 Algo \\
2 Bastante \\
3 Mucho
\end{tabular} \\
\hline 84 & PC_Pretest_P16 & $\begin{array}{l}\text { 16. Me gusta aprender cosas } \\
\text { nuevas. }\end{array}$ & Cualitativa & Ordinal & \begin{tabular}{|l|}
0 Nada \\
1 Algo \\
2 Bastante \\
3 Mucho \\
\end{tabular} \\
\hline 85 & PC_Pretest_P17 & 17. Soy independiente. & Cualitativa & Ordinal & $\begin{array}{l}0 \text { Nada } \\
1 \text { Algo } \\
2 \text { Bastante } \\
3 \text { Mucho }\end{array}$ \\
\hline 86 & PC_Pretest_P18 & $\begin{array}{l}\text { 18. Tengo sentido del humor, me } \\
\text { gusta bromear. }\end{array}$ & Cualitativa & Ordinal & $\begin{array}{l}0 \text { Nada } \\
1 \text { Algo } \\
2 \text { Bastante } \\
3 \text { Mucho }\end{array}$ \\
\hline 87 & PC_Pretest_P19 & $\begin{array}{l}\text { 19. Soy perseverante, cuando } \\
\text { comienzo una tarea soy constante y } \\
\text { la termino, aunque me cueste. }\end{array}$ & Cualitativa & Ordinal & $\begin{array}{l}0 \text { Nada } \\
1 \text { Algo } \\
2 \text { Bastante } \\
3 \text { Mucho }\end{array}$ \\
\hline 88 & PC_Pretest_P20 & $\begin{array}{l}\text { 20. Estoy abierto a nuevas } \\
\text { experiencias, me gustan las } \\
\text { novedades, los cambios. }\end{array}$ & Cualitativa & Ordinal & $\begin{array}{l}0 \text { Nada } \\
1 \text { Algo } \\
2 \text { Bastante } \\
3 \text { Mucho }\end{array}$ \\
\hline 89 & PC_Pretest_P21 & $\begin{array}{l}\text { 21. Me gustan las situaciones que } \\
\text { implican riesgo, aventura. }\end{array}$ & Cualitativa & Ordinal & $\begin{array}{l}0 \text { Nada } \\
1 \text { Algo } \\
2 \text { Bastante } \\
3 \text { Mucho }\end{array}$ \\
\hline 90 & PC_Pretest_P22 & 22. Soy creativo. & Cualitativa & Ordinal & $\begin{array}{l}0 \text { Nada } \\
1 \text { Algo } \\
2 \text { Bastante } \\
3 \text { Mucho }\end{array}$ \\
\hline 91 & $\begin{array}{l}\text { PD_pre_test_Identificació } \\
\text { nysolucióndeproblemas }\end{array}$ & $\begin{array}{l}\text { Puntaje Identificacion y solucion de } \\
\text { problemas Inicial }\end{array}$ & Cuantitativa & Discreta & No aplica \\
\hline 92 & PD_pre_test_Invenciónyar & Puntaje Invencion y arte Inicial & Cuantitativa & Discreta & No aplica \\
\hline 93 & PD_pre_test_Apertura & Puntaje Apertura Inicial & Cuantitativa & Discreta & No aplica \\
\hline 94 & $\begin{array}{l}\text { PD_pre_test_Fantasiaeim } \\
\text { aginación }\end{array}$ & $\begin{array}{l}\text { Puntaje Fantasia e imaginacion } \\
\text { Inicial }\end{array}$ & Cuantitativa & Discreta & No aplica \\
\hline 95 & $\begin{array}{l}\text { PD_pre_test_Juegosintele } \\
\text { ctuales }\end{array}$ & Puntaje Juegos intelectuales Inicial & Cuantitativa & Discreta & No aplica \\
\hline 96 & PD_pre_test_total & Puntaje Total Inicial & Cuantitativa & Discreta & No aplica \\
\hline 97 & $\begin{array}{l}\text { Escala_pre_test_Identifica } \\
\text { ciónysolucióndeproblemas }\end{array}$ & $\begin{array}{l}\text { Identificacion y solucion de } \\
\text { problemas Inicial (Agrupado) }\end{array}$ & Cualitativa & Ordinal & $\begin{array}{l}1 \text { Bajo } \\
2 \text { Medio } \\
3 \text { Alto }\end{array}$ \\
\hline 98 & $\begin{array}{c}\text { Escala_pre_test_Invenció } \\
\text { nyarte }\end{array}$ & Invencion y arte Inicial (Agrupado) & Cualitativa & Ordinal & \begin{tabular}{|l|}
1 Bajo \\
2 Medio \\
3 Alto
\end{tabular} \\
\hline 99 & Escala_pre_test_Apertura & Apertura Inicial (Agrupado) & Cualitativa & Ordinal & $\begin{array}{l}1 \text { Bajo } \\
2 \text { Medio } \\
3 \text { Alto }\end{array}$ \\
\hline
\end{tabular}




\begin{tabular}{|c|c|c|c|c|c|}
\hline 100 & $\begin{array}{c}\text { Escala_pre_test_Fantasia } \\
\text { eimaginación }\end{array}$ & $\begin{array}{l}\text { Fantasia e imaginacion Inicial } \\
\text { (Agrupado) }\end{array}$ & Cualitativa & Ordinal & $\begin{array}{l}1 \text { Bajo } \\
2 \text { Medio } \\
3 \text { Alto }\end{array}$ \\
\hline 101 & $\begin{array}{c}\text { Escala_pre_test_JuegosIn } \\
\text { telectuales }\end{array}$ & $\begin{array}{l}\text { Juegos intelectuales Inicial } \\
\text { (Agrupado) }\end{array}$ & Cualitativa & Ordinal & $\begin{array}{l}1 \text { Bajo } \\
2 \text { Medio } \\
3 \text { Alto }\end{array}$ \\
\hline 102 & Escala_pre_test_Total & Total Inicial (Agrupado) & Cualitativa & Ordinal & $\begin{array}{l}1 \text { Bajo } \\
2 \text { Medio } \\
3 \text { Alto }\end{array}$ \\
\hline 103 & EP_pretest_P110 & $\begin{array}{l}\text { 1. A mi mamá le gusta hablar y } \\
\text { estar conmigo la mayor parte del } \\
\text { tiempo }\end{array}$ & Cualitativa & Ordinal & $\begin{array}{l}1 \text { Bajo } \\
2 \text { Medio } \\
3 \text { Alto }\end{array}$ \\
\hline 104 & EP_pretest_P211 & $\begin{array}{l}\text { 2. Mi mamá controla que llegue a } \\
\text { casa a horario. }\end{array}$ & Cualitativa & Ordinal & $\begin{array}{l}1 \text { Bajo } \\
2 \text { Medio } \\
3 \text { Alto }\end{array}$ \\
\hline 105 & EP_pretest_P312 & $\begin{array}{l}\text { 3. Mi mamá me dice que me quiere } \\
\text { mucho }\end{array}$ & Cualitativa & Ordinal & $\begin{array}{l}1 \text { Bajo } \\
2 \text { Medio } \\
3 \text { Alto }\end{array}$ \\
\hline 106 & EP_pretest_P413 & $\begin{array}{l}\text { 4. Mi mamá siempre quiere saber } \\
\text { todo el tiempo dónde estoy y lo que } \\
\text { hago }\end{array}$ & Cualitativa & Ordinal & $\begin{array}{l}1 \text { Bajo } \\
2 \text { Medio } \\
3 \text { Alto }\end{array}$ \\
\hline 107 & EP_pretest_P514 & $\begin{array}{l}\text { 5. Mi mamá decide con qué amigos } \\
\text { puedo juntarme. }\end{array}$ & Cualitativa & Ordinal & $\begin{array}{l}\text { Bajo } \\
2 \text { Medio } \\
3 \text { Alto }\end{array}$ \\
\hline 108 & EP_pretest_P615 & $\begin{array}{l}\text { 6. Mi mamá se preocupa poco si yo } \\
\text { me porto mal. }\end{array}$ & Cualitativa & Ordinal & $\begin{array}{l}1 \text { Bajo } \\
2 \text { Medio } \\
3 \text { Alto }\end{array}$ \\
\hline 109 & EP_pretest_P716 & $\begin{array}{l}\text { 7. Mi mamá me deja salir todas las } \\
\text { veces que yo quiera. }\end{array}$ & Cualitativa & Ordinal & $\begin{array}{l}\text { Bajo } \\
2 \text { Medio } \\
3 \text { Alto }\end{array}$ \\
\hline 110 & EP_pretest_P817 & $\begin{array}{l}\text { 8. Mi mamá me hace sentir la } \\
\text { persona más importante de su vida }\end{array}$ & Cualitativa & Ordinal & $\begin{array}{l}1 \text { Bajo } \\
2 \text { Medio } \\
3 \text { Alto } \\
\end{array}$ \\
\hline 111 & EP_pretest_P918 & 9. Mi mamá se mete en mis cosas. & Cualitativa & Ordinal & $\begin{array}{l}1 \text { Bajo } \\
2 \text { Medio } \\
3 \text { Alto }\end{array}$ \\
\hline 112 & EP_pretest_P1019 & $\begin{array}{l}\text { 10. Mi mamá cree que } \\
\text { castigándome va a corregir mi mal } \\
\text { comportamiento. }\end{array}$ & Cualitativa & Ordinal & $\begin{array}{l}1 \text { Bajo } \\
2 \text { Medio } \\
3 \text { Alto }\end{array}$ \\
\hline 113 & EP_pretest_P1120 & $\begin{array}{l}\text { 11. Mi mamá siempre escucha lo } \\
\text { que yo opino y pienso. }\end{array}$ & Cualitativa & Ordinal & $\begin{array}{l}1 \text { Bajo } \\
2 \text { Medio } \\
3 \text { Alto } \\
\end{array}$ \\
\hline 114 & EP_pretest_P1221 & $\begin{array}{l}\text { 12. Mi mamá está siempre } \\
\text { pendiente de lo que yo hago en la } \\
\text { escuela y en el tiempo libre }\end{array}$ & Cualitativa & Ordinal & $\begin{array}{l}1 \text { Bajo } \\
2 \text { Medio } \\
3 \text { Alto }\end{array}$ \\
\hline 115 & EP_pretest_P1322 & $\begin{array}{l}\text { 13. Mi mamá siempre me dice las } \\
\text { cosas que hace por mí, me echa en } \\
\text { cara todo lo que tiene que hacer por } \\
\text { mi culpa. }\end{array}$ & Cualitativa & Ordinal & $\begin{array}{l}1 \text { Bajo } \\
2 \text { Medio } \\
3 \text { Alto }\end{array}$ \\
\hline 116 & EP_pretest_P1423 & $\begin{array}{l}\text { 14. Mi mamá quiere controlar todo } \\
\text { lo que yo haga. }\end{array}$ & Cualitativa & Ordinal & $\begin{array}{l}1 \text { Bajo } \\
2 \text { Medio } \\
3 \text { Alto } \\
\end{array}$ \\
\hline 117 & EP_pretest_P1524 & $\begin{array}{l}\text { 15. Mi mamá le importa cuando } \\
\text { hago algo que no debo. }\end{array}$ & Cualitativa & Ordinal & $\begin{array}{l}1 \text { Bajo } \\
2 \text { Medio } \\
3 \text { Alto } \\
\end{array}$ \\
\hline 118 & EP_pretest_P1625 & $\begin{array}{l}\text { 16. Mi mamá me deja hacer lo que } \\
\text { quiera. }\end{array}$ & Cualitativa & Ordinal & $\begin{array}{l}1 \text { Bajo } \\
2 \text { Medio } \\
3 \text { Alto }\end{array}$ \\
\hline 119 & EP_pretest_P1726 & $\begin{array}{l}\text { 17. Mi mamá me protege cuando } \\
\text { tengo miedo. }\end{array}$ & Cualitativa & Ordinal & $\begin{array}{l}1 \text { Bajo } \\
2 \text { Medio } \\
3 \text { Alto } \\
\end{array}$ \\
\hline 120 & EP_pretest_P1827 & $\begin{array}{l}\text { 18. Mi mamá insiste con que tengo } \\
\text { que hacer todo lo que me dice. }\end{array}$ & Cualitativa & Ordinal & $\begin{array}{l}1 \text { Bajo } \\
2 \text { Medio } \\
3 \text { Alto } \\
\end{array}$ \\
\hline 121 & EP_pretest_P1928 & $\begin{array}{l}\text { 19. Mi papá me castiga cuando no } \\
\text { le hago caso. }\end{array}$ & Cualitativa & Ordinal & $\begin{array}{l}1 \text { Bajo } \\
2 \text { Medio } \\
3 \text { Alto }\end{array}$ \\
\hline
\end{tabular}




\begin{tabular}{|c|c|c|c|c|c|}
\hline 122 & EP_pretest_P2029 & $\begin{array}{l}\text { 20. Mi mamá a menudo tiene largas } \\
\text { charlas conmigo sobre el por qué de } \\
\text { las cosas. }\end{array}$ & Cualitativa & Ordinal & $\begin{array}{l}1 \text { Bajo } \\
2 \text { Medio } \\
3 \text { Alto }\end{array}$ \\
\hline 123 & EP_pretest_P2130 & $\begin{array}{l}\text { 21. Mi mamá me dice que, si } \\
\text { realmente la quiero, me tengo que } \\
\text { portar bien para no amargarle la } \\
\text { vida. }\end{array}$ & Cualitativa & Ordinal & $\begin{array}{l}1 \text { Bajo } \\
2 \text { Medio } \\
3 \text { Alto }\end{array}$ \\
\hline 124 & EP_pretest_P2231 & $\begin{array}{l}\text { 22. Mi mamá insiste en que haga } \\
\text { mis tareas. }\end{array}$ & Cualitativa & Ordinal & $\begin{array}{l}1 \text { Bajo } \\
2 \text { Medio } \\
3 \text { Alto }\end{array}$ \\
\hline 125 & EP_pretest_P2332 & $\begin{array}{l}\text { 23. Si insisto, mi mamá afloja y } \\
\text { puedo quedarme levantado hasta } \\
\text { más tarde los días de semana. }\end{array}$ & Cualitativa & Ordinal & $\begin{array}{l}\text { 1 Bajo } \\
2 \text { Medio } \\
3 \text { Alto }\end{array}$ \\
\hline 126 & EP_pretest_P24 & $\begin{array}{l}\text { 24. Mi mamá dice que portarse mal } \\
\text { es muy grave y puedo tener } \\
\text { problemas cuando sea grande. }\end{array}$ & Cualitativa & Ordinal & $\begin{array}{l}\text { 1 Bajo } \\
2 \text { Medio } \\
3 \text { Alto }\end{array}$ \\
\hline 127 & EP_pretest_P25 & $\begin{array}{l}\text { 25. Mi mamá, si hago algo que le } \\
\text { duele, deja de hablarme hasta que } \\
\text { me disculpe. }\end{array}$ & Cualitativa & Ordinal & $\begin{array}{l}1 \text { Bajo } \\
2 \text { Medio } \\
3 \text { Alto }\end{array}$ \\
\hline 128 & EP_pretest_P26 & $\begin{array}{l}\text { 26. Mi mamá se muestra orgullosa } \\
\text { de lo que yo hago. }\end{array}$ & Cualitativa & Ordinal & \begin{tabular}{|l|}
1 Bajo \\
2 Medio \\
3 Alto \\
\end{tabular} \\
\hline 129 & EP_pretest_P27 & $\begin{array}{l}\text { 27. Mi mamá quiere que me quede } \\
\text { en casa para saber lo que yo hago }\end{array}$ & Cualitativa & Ordinal & $\begin{array}{l}\text { 1 Bajo } \\
2 \text { Medio } \\
3 \text { Alto }\end{array}$ \\
\hline 130 & EP_pretest_P28 & $\begin{array}{l}\text { 28. Mi mamá hace que yo cumpla lo } \\
\text { que me manda. }\end{array}$ & Cualitativa & Ordinal & $\begin{array}{l}1 \text { Bajo } \\
2 \text { Medio } \\
3 \text { Alto }\end{array}$ \\
\hline 131 & EP_pretest_P29 & $\begin{array}{l}\text { 29. A mi mamá le interesa lo que yo } \\
\text { hago. }\end{array}$ & Cualitativa & Ordinal & $\begin{array}{l}1 \text { Bajo } \\
2 \text { Medio } \\
3 \text { Alto }\end{array}$ \\
\hline 132 & EP_pretest_P30 & $\begin{array}{l}\text { 30. Mi mamá, cuando fallo en algo, } \\
\text { no quiere saber nada conmigo } \\
\text { hasta que yo encuentro la forma de } \\
\text { reconciliarme. }\end{array}$ & Cualitativa & Ordinal & $\begin{array}{l}1 \text { Bajo } \\
2 \text { Medio } \\
3 \text { Alto }\end{array}$ \\
\hline 133 & EP_pretest_P31 & $\begin{array}{l}\text { 31. Mi mamá me deja ir a jugar } \\
\text { cuando quiero. }\end{array}$ & Cualitativa & Ordinal & \begin{tabular}{|l|}
1 Bajo \\
2 Medio \\
3 Alto \\
\end{tabular} \\
\hline 134 & EP_pretest_P32 & \begin{tabular}{|l|} 
32. Mi mamá, cuando me porto mal, \\
se preocupa porque voy a sufrir las \\
consecuencias cuando sea grande. \\
\end{tabular} & Cualitativa & Ordinal & \begin{tabular}{|l|}
1 Bajo \\
2 Medio \\
3 Alto \\
\end{tabular} \\
\hline 135 & $\begin{array}{c}\text { PD_pre_test_Dimensión_ } \\
\text { Aceptación }\end{array}$ & Aceptacion Inicial & Cuantitativa & Discreta & No aplica \\
\hline 136 & $\begin{array}{l}\text { PD_pre_test_Dimensión_ } \\
\text { ControlAceptado }\end{array}$ & Control aceptado Inicial & Cuantitativa & Discreta & No aplica \\
\hline 137 & $\begin{array}{c}\text { PD_pre_test_Dimensión_ } \\
\text { Controlestricto }\end{array}$ & Control estricto Inicial & Cuantitativa & Discreta & No aplica \\
\hline 138 & $\begin{array}{l}\text { totaldelas3anterioresFacto } \\
\text { raceptaciónvscontrolestrict }\end{array}$ & Factor Aceptacion Inicial & Cuantitativa & Discreta & No aplica \\
\hline 139 & $\begin{array}{c}\text { PD_pre_test_Factor_Cont } \\
\text { rolpatologico }\end{array}$ & Contol patologico Inicial & Cuantitativa & Discreta & No aplica \\
\hline 140 & $\begin{array}{c}\text { PD_pre_test_Factor_Auto } \\
\text { nomiaextrema }\end{array}$ & Autonomia Extrema Inicial & Cuantitativa & Discreta & No aplica \\
\hline 141 & $\begin{array}{c}\text { Escala_pre_test_Dimensi } \\
\text { ón_Aceptación }\end{array}$ & Aceptacion Inicial (Agrupado) & Cualitativa & Ordinal & $\begin{array}{l}\text { 1 Bajo } \\
2 \text { Medio } \\
3 \text { Alto }\end{array}$ \\
\hline 142 & $\begin{array}{l}\text { PD_pre_test_Dimensión_ } \\
\text { ControlAceptado33 }\end{array}$ & Control aceptado Inicial (Agrupado) & Cualitativa & Ordinal & $\begin{array}{l}1 \text { Bajo } \\
2 \text { Medio } \\
3 \text { Alto }\end{array}$ \\
\hline 143 & $\begin{array}{l}\text { PD_pre_test_Dimensión_ } \\
\text { Controlestricto34 }\end{array}$ & Control Estricto Inicial (Agrupado) & Cualitativa & Ordinal & $\begin{array}{l}1 \text { Bajo } \\
2 \text { Medio } \\
3 \text { Alto }\end{array}$ \\
\hline 144 & $\begin{array}{l}\text { totaldelas3anterioresFacto } \\
\text { raceptaciónvscontrolestrict } \\
\text { A }\end{array}$ & control estrict Inicial (Agrupado) & Cualitativa & Ordinal & $\begin{array}{l}1 \text { Bajo } \\
2 \text { Medio } \\
3 \text { Alto }\end{array}$ \\
\hline
\end{tabular}




\begin{tabular}{|c|c|c|c|c|c|}
\hline 145 & $\begin{array}{l}\text { PD_pre_test_Factor_Cont } \\
\text { rolpatologico36 }\end{array}$ & Control patologico Inicial (Agrupado) & Cualitativa & Ordinal & $\begin{array}{l}1 \text { Bajo } \\
2 \text { Medio } \\
3 \text { Alto }\end{array}$ \\
\hline 146 & $\begin{array}{l}\text { PD_pre_test_Factor_Auto } \\
\text { nomiaextrema37 }\end{array}$ & $\begin{array}{l}\text { Autonomia Extrema Inicial } \\
\text { (Agrupado) }\end{array}$ & Cualitativa & Ordinal & $\begin{array}{l}1 \text { Bajo } \\
2 \text { Medio } \\
3 \text { Alto } \\
\end{array}$ \\
\hline 147 & JJ63_pretest_P1 & $\begin{array}{l}\text { ¿Cuando alguien de la familia tiene } \\
\text { un problema, tú ayudas?_inicial }\end{array}$ & Cualitativa & Ordinal & $\begin{array}{l}1 \text { Casi nunca } \\
2 \text { Pocas veces } \\
3 \text { A veces } \\
4 \text { Muchas veces } \\
5 \text { Casi siempre } \\
\end{array}$ \\
\hline 148 & JJ63_pretest_P2 & $\begin{array}{l}\text { ¿En tu casa predomina la } \\
\text { armonía?_inicial }\end{array}$ & Cualitativa & Ordinal & \begin{tabular}{|l}
1 Casi nunca \\
2 Pocas veces \\
3 A veces \\
4 Muchas veces \\
5 Casi siempre
\end{tabular} \\
\hline 149 & JJ63_pretest_P3 & $\begin{array}{l}\text { ¿Puedes conversar de lo que sea } \\
\text { sin temor dentro de tu } \\
\text { familia?_inicial }\end{array}$ & Cualitativa & Ordinal & $\begin{array}{l}1 \text { Casi nunca } \\
2 \text { Pocas veces } \\
3 \text { A veces } \\
4 \text { Muchas veces } \\
5 \text { Casi siempre }\end{array}$ \\
\hline 150 & JJ63_pretest_P4 & $\begin{array}{l}\text { ¿Ante un problema, eres capaz de } \\
\text { pedir ayuda a alguien de tu familia? } \\
\text { _inicial }\end{array}$ & Cualitativa & Ordinal & $\begin{array}{l}1 \text { Casi nunca } \\
2 \text { Pocas veces } \\
3 \text { A veces } \\
4 \text { Muchas veces } \\
5 \text { Casi siempre } \\
\end{array}$ \\
\hline 151 & JJ63_pretest_P5 & $\begin{array}{l}\text { ¿Demuestras el cariño que les } \\
\text { tienes a los miembros de tu } \\
\text { familia?_inicial }\end{array}$ & Cualitativa & Ordinal & $\begin{array}{l}\text { Casi nunca } \\
2 \text { Pocas veces } \\
3 \text { A veces } \\
4 \text { Muchas veces } \\
5 \text { Casi siempre }\end{array}$ \\
\hline 152 & JJ63_pretest_P6 & $\begin{array}{l}\text { ¿En tu familia se distribuyen las } \\
\text { responsabilidades entre todos? } \\
\text { _inicial }\end{array}$ & Cualitativa & Ordinal & $\begin{array}{l}1 \text { Casi nunca } \\
2 \text { Pocas veces } \\
3 \text { A veces } \\
4 \text { Muchas veces } \\
5 \text { Casi siempre }\end{array}$ \\
\hline 153 & JJ63_pretest_P7 & $\begin{array}{l}\text { ¿Aceptas los defectos de los demás } \\
\text { miembros de tu familia?_inicial }\end{array}$ & Cualitativa & Ordinal & $\begin{array}{l}1 \text { Casi nunca } \\
2 \text { Pocas veces } \\
3 \text { A veces } \\
4 \text { Muchas veces } \\
5 \text { Casi siempre } \\
\end{array}$ \\
\hline 154 & JJ63_pretest_P8 & $\begin{array}{l}\text { ¿Te sientes orgulloso/a de la } \\
\text { persona que eres? inicial }\end{array}$ & Cualitativa & Ordinal & $\begin{array}{l}1 \text { Casi nunca } \\
2 \text { Pocas veces } \\
3 \text { A veces } \\
4 \text { Muchas veces } \\
5 \text { Casi siempre }\end{array}$ \\
\hline 155 & JJ63_pretest_P9 & $\begin{array}{l}\text { ¿Sientes que eres querido en } \\
\text { casa? inicial }\end{array}$ & Cualitativa & Ordinal & $\begin{array}{l}1 \text { Casi nunca } \\
2 \text { Pocas veces } \\
3 \text { A veces } \\
4 \text { Muchas veces } \\
5 \text { Casi siempre }\end{array}$ \\
\hline 156 & JJ63_pretest_P10 & $\begin{array}{l}\text { ¿Sientes que te apoyan en lo que te } \\
\text { propones? inicial }\end{array}$ & Cualitativa & Ordinal & $\begin{array}{l}1 \text { Casi nunca } \\
2 \text { Pocas veces } \\
3 \text { A veces } \\
4 \text { Muchas veces } \\
5 \text { Casi siempre }\end{array}$ \\
\hline 157 & JJ63_pretest_P11 & ¿Te consideras atractivo/a? _inicial & Cualitativa & Ordinal & $\begin{array}{l}1 \text { Casi nunca } \\
2 \text { Pocas veces } \\
3 \text { A veces } \\
4 \text { Muchas veces } \\
5 \text { Casi siempre }\end{array}$ \\
\hline 158 & JJ63_pretest_P12 & $\begin{array}{l}\text { ¿Estás contento con la figura } \\
\text { corporal y apariencia que tienes? } \\
\text { _inicial }\end{array}$ & Cualitativa & Ordinal & $\begin{array}{l}1 \text { Casi nunca } \\
2 \text { Pocas veces } \\
3 \text { A veces } \\
4 \text { Muchas veces } \\
5 \text { Casi siempre }\end{array}$ \\
\hline 159 & JJ63_pretest_P13 & $\begin{array}{l}\text { ¿Quisieras cambiar alguna parte de } \\
\text { tu cuerpo? inicial }\end{array}$ & Cualitativa & Ordinal & $\begin{array}{l}1 \text { Casi nunca } \\
2 \text { Pocas veces } \\
3 \text { A veces } \\
\end{array}$ \\
\hline
\end{tabular}




\begin{tabular}{|c|c|c|c|c|c|}
\hline & & & & & $\begin{array}{l}4 \text { Muchas veces } \\
5 \text { Casi siempre }\end{array}$ \\
\hline 160 & JJ63_pretest_P14 & $\begin{array}{l}\text { ¿Te duelen las opiniones de tus } \\
\text { amigos cuando están en tu contra? } \\
\text { _inicial }\end{array}$ & Cualitativa & Ordinal & $\begin{array}{l}1 \text { Casi nunca } \\
2 \text { Pocas veces } \\
3 \text { A veces } \\
4 \text { Muchas veces } \\
5 \text { Casi siempre }\end{array}$ \\
\hline 161 & JJ63_pretest_P15 & $\begin{array}{l}\text { ¿Si la conducta de otra persona te } \\
\text { molesta, le pides que cambie su } \\
\text { comportamiento contigo?_inicial }\end{array}$ & Cualitativa & Ordinal & \begin{tabular}{|l}
1 Casi nunca \\
2 Pocas veces \\
3 A veces \\
4 Muchas veces \\
5 Casi siempre
\end{tabular} \\
\hline 162 & JJ63_pretest_P16 & $\begin{array}{l}\text { ¿Le dices a tu familia cuando te } \\
\text { molesta algo?_inicial }\end{array}$ & Cualitativa & Ordinal & $\begin{array}{l}1 \text { Casi nunca } \\
2 \text { Pocas veces } \\
3 \text { A veces } \\
4 \text { Muchas veces } \\
5 \text { Casi siempre }\end{array}$ \\
\hline 163 & JJ63_pretest_P17 & $\begin{array}{l}\text { ¿Cuándo te piden un favor que no } \\
\text { deseas hacer ¿dices simplemente } \\
\text { "no" y te quedas tranquilo?_inicial }\end{array}$ & Cualitativa & Ordinal & $\begin{array}{l}1 \text { Casi nunca } \\
2 \text { Pocas veces } \\
3 \text { A veces } \\
4 \text { Muchas veces } \\
5 \text { Casi siempre }\end{array}$ \\
\hline 164 & JJ63_pretest_P18 & $\begin{array}{l}\text { ¿Expresas tus deseos de realizar } \\
\text { algo con facilidad?_inicial }\end{array}$ & Cualitativa & Ordinal & $\begin{array}{l}1 \text { Casi nunca } \\
2 \text { Pocas veces } \\
3 \text { A veces } \\
4 \text { Muchas veces } \\
5 \text { Casi siempre }\end{array}$ \\
\hline 165 & JJ63_pretest_P19 & $\begin{array}{l}\text { ¿Expresas libremente tu enfado o } \\
\text { descontento?_inicial }\end{array}$ & Cualitativa & Ordinal & $\begin{array}{l}1 \text { Casi nunca } \\
2 \text { Pocas veces } \\
3 \text { A veces } \\
4 \text { Muchas veces } \\
5 \text { Casi siempre }\end{array}$ \\
\hline 166 & JJ63_pretest_P20 & $\begin{array}{l}\text { ¿Reclamas algo cuando es } \\
\text { injusto?_inicial }\end{array}$ & Cualitativa & Ordinal & $\begin{array}{l}1 \text { Casi nunca } \\
2 \text { Pocas veces } \\
3 \text { A veces } \\
4 \text { Muchas veces } \\
5 \text { Casi siempre }\end{array}$ \\
\hline 167 & JJ63_pretest_P21 & $\begin{array}{l}\text { ¿Cuándo le prestas algo a alguien y } \\
\text { olvidan devolverlo, le } \\
\text { recuerdas?_inicial }\end{array}$ & Cualitativa & Ordinal & $\begin{array}{l}1 \text { Casi nunca } \\
2 \text { Pocas veces } \\
3 \text { A veces } \\
4 \text { Muchas veces } \\
5 \text { Casi siempre }\end{array}$ \\
\hline 168 & JJ63_pretest_P22 & $\begin{array}{l}\text { ¿Cuándo sucede algo inesperado } \\
\text { ¿lo superas rápido?_inicial }\end{array}$ & Cualitativa & Ordinal & \begin{tabular}{|l}
1 Casi nunca \\
2 Pocas veces \\
3 A veces \\
4 Muchas veces \\
5 Casi siempre \\
\end{tabular} \\
\hline 169 & JJ63_pretest_P23 & $\begin{array}{l}\text { ¿Cuándo algo te sale mal, lo } \\
\text { aceptas con facilidad?_inicial }\end{array}$ & Cualitativa & Ordinal & $\begin{array}{l}1 \text { Casi nunca } \\
2 \text { Pocas veces } \\
3 \text { A veces } \\
4 \text { Muchas veces } \\
5 \text { Casi siempre }\end{array}$ \\
\hline 170 & JJ63_pretest_P24 & $\begin{array}{l}\text { ¿Si tienes problemas con tus } \\
\text { familiares, lo resuelves } \\
\text { rápidamente? _inicial }\end{array}$ & Cualitativa & Ordinal & $\begin{array}{l}1 \text { Casi nunca } \\
2 \text { Pocas veces } \\
3 \text { A veces } \\
4 \text { Muchas veces } \\
5 \text { Casi siempre }\end{array}$ \\
\hline 171 & JJ63_pretest_P25 & $\begin{array}{l}\text { ¿En las materias que no te gustan } \\
\text { sacas buenas calificaciones?_inicial }\end{array}$ & Cualitativa & Ordinal & \begin{tabular}{|l}
1 Casi nunca \\
2 Pocas veces \\
3 A veces \\
4 Muchas veces \\
5 Casi siempre
\end{tabular} \\
\hline 172 & JJ63_pretest_P26 & $\begin{array}{l}\text { ¿Si tu padre/ madre pierden el } \\
\text { trabajo, trabajarías para } \\
\text { ayudar?_inicial }\end{array}$ & Cualitativa & Ordinal & $\begin{array}{l}1 \text { Casi nunca } \\
2 \text { Pocas veces } \\
3 \text { A veces } \\
4 \text { Muchas veces } \\
5 \text { Casi siempre }\end{array}$ \\
\hline 173 & JJ63_pretest_P27 & $\begin{array}{l}\text { ¿Si te emborrachas, pides } \\
\text { disculpas a tus padres al día } \\
\text { siguiente? inicial }\end{array}$ & Cualitativa & Ordinal & $\begin{array}{l}1 \text { Casi nunca } \\
2 \text { Pocas veces } \\
3 \text { A veces }\end{array}$ \\
\hline
\end{tabular}




\begin{tabular}{|c|c|c|c|c|c|}
\hline & & & & & $\begin{array}{l}4 \text { Muchas veces } \\
5 \text { Casi siempre }\end{array}$ \\
\hline 174 & JJ63_pretest_P28 & $\begin{array}{l}\text { ¿Si tuvieras que cambiarte de casa, } \\
\text { lo aceptarías con facilidad?_inicial }\end{array}$ & Cualitativa & Ordinal & $\begin{array}{l}1 \text { Casi nunca } \\
2 \text { Pocas veces } \\
3 \text { A veces } \\
4 \text { Muchas veces } \\
5 \text { Casi siempre } \\
\end{array}$ \\
\hline 175 & JJ63_pretest_P43 & $\begin{array}{l}\text { ¿Crees que tus padres y maestros } \\
\text { son anticuados (chapados a la } \\
\text { antigua) y no saben lo que dicen } \\
\text { sobre tu conducta?_inicial }\end{array}$ & Cualitativa & Ordinal & $\begin{array}{l}1 \text { Casi nunca } \\
2 \text { Pocas veces } \\
3 \text { A veces } \\
4 \text { Muchas veces } \\
5 \text { Casi siempre }\end{array}$ \\
\hline 176 & JJ63_pretest_P44 & $\begin{array}{l}\text { ¿Asumes las consecuencias de tus } \\
\text { actos y los afrontas?_inicial }\end{array}$ & Cualitativa & Ordinal & $\begin{array}{l}1 \text { Casi nunca } \\
2 \text { Pocas veces } \\
3 \text { A veces } \\
4 \text { Muchas veces } \\
5 \text { Casi siempre }\end{array}$ \\
\hline 177 & JJ63_pretest_P45 & $\begin{array}{l}\text { ¿Cuestionas las órdenes o } \\
\text { sugerencias de tus padres?_inicial }\end{array}$ & Cualitativa & Ordinal & $\begin{array}{l}1 \text { Casi nunca } \\
2 \text { Pocas veces } \\
3 \text { A veces } \\
4 \text { Muchas veces } \\
5 \text { Casi siempre }\end{array}$ \\
\hline 178 & JJ63_pretest_P46 & $\begin{array}{l}\text { ¿Es malo consumir alcohol o } \\
\text { drogas?_inicial }\end{array}$ & Cualitativa & Ordinal & $\begin{array}{l}1 \text { Casi nunca } \\
2 \text { Pocas veces } \\
3 \text { A veces } \\
4 \text { Muchas veces } \\
5 \text { Casi siempre }\end{array}$ \\
\hline 179 & JJ63_pretest_P47 & $\begin{array}{l}\text { ¿Si hay algo que no entiendes, } \\
\text { procuras investigarlo y luego dar tu } \\
\text { punto de vista si te lo piden?_inicial }\end{array}$ & Cualitativa & Ordinal & $\begin{array}{l}1 \text { Casi nunca } \\
2 \text { Pocas veces } \\
3 \text { A veces } \\
4 \text { Muchas veces } \\
5 \text { Casi siempre }\end{array}$ \\
\hline 180 & JJ63_pretest_P48 & $\begin{array}{l}\text { ¿Cuándo escuchas noticias das tu } \\
\text { opinión sobre las mismas?_inicial }\end{array}$ & Cualitativa & Ordinal & $\begin{array}{l}1 \text { Casi nunca } \\
2 \text { Pocas veces } \\
3 \text { A veces } \\
4 \text { Muchas veces } \\
5 \text { Casi siempre }\end{array}$ \\
\hline 181 & JJ63_pretest_P49 & $\begin{array}{l}\text { ¿Te gustaría decirles a tus } \\
\text { profesores que están } \\
\text { equivocados?_inicial }\end{array}$ & Cualitativa & Ordinal & $\begin{array}{l}1 \text { Casi nunca } \\
2 \text { Pocas veces } \\
3 \text { A veces } \\
4 \text { Muchas veces } \\
5 \text { Casi siempre }\end{array}$ \\
\hline 182 & JJ63_pretest_P50 & $\begin{array}{l}\text { ¿Te arrepientes cuando dices cosas } \\
\text { inoportunas? _inicial }\end{array}$ & Cualitativa & Ordinal & $\begin{array}{l}1 \text { Casi nunca } \\
2 \text { Pocas veces } \\
3 \text { A veces } \\
4 \text { Muchas veces } \\
5 \text { Casi siempre }\end{array}$ \\
\hline 183 & JJ63_pretest_P51 & $\begin{array}{l}\text { ¿Después de que has hecho algo } \\
\text { peligroso, te sientes mal?_inicial }\end{array}$ & Cualitativa & Ordinal & $\begin{array}{l}1 \text { Casi nunca } \\
2 \text { Pocas veces } \\
3 \text { A veces } \\
4 \text { Muchas veces } \\
5 \text { Casi siempre }\end{array}$ \\
\hline 184 & JJ63_pretest_P52 & $\begin{array}{l}\text { ¿Cuándo le gritas a alguien por } \\
\text { cualquier motivo, le pides disculpas } \\
\text { después?_inicial }\end{array}$ & Cualitativa & Ordinal & $\begin{array}{l}1 \text { Casi nunca } \\
2 \text { Pocas veces } \\
3 \text { A veces } \\
4 \text { Muchas veces } \\
5 \text { Casi siempre }\end{array}$ \\
\hline 185 & JJ63_pretest_P53 & $\begin{array}{l}\text { ¿Cuándo te escapas de las clases, } \\
\text { te sientes mal?_inicial }\end{array}$ & Cualitativa & Ordinal & $\begin{array}{l}1 \text { Casi nunca } \\
2 \text { Pocas veces } \\
3 \text { A veces } \\
4 \text { Muchas veces } \\
5 \text { Casi siempre }\end{array}$ \\
\hline 186 & JJ63_pretest_P54 & $\begin{array}{l}\text { ¿Cuándo ofreces cosas que no } \\
\text { tienes o no puedes dar, te sientes } \\
\text { preocupado?_inicial }\end{array}$ & Cualitativa & Ordinal & $\begin{array}{l}1 \text { Casi nunca } \\
2 \text { Pocas veces } \\
3 \text { A veces } \\
4 \text { Muchas veces } \\
5 \text { Casi siempre }\end{array}$ \\
\hline 187 & JJ63_pretest_P55 & $\begin{array}{l}\text { ¿Cuándo agredes a alguien } \\
\text { verbalmente o físicamente, te } \\
\text { sientes mal? inicial }\end{array}$ & Cualitativa & Ordinal & $\begin{array}{l}1 \text { Casi nunca } \\
2 \text { Pocas veces } \\
3 \text { A veces }\end{array}$ \\
\hline
\end{tabular}




\begin{tabular}{|c|c|c|c|c|c|}
\hline & & & & & $\begin{array}{l}4 \text { Muchas veces } \\
5 \text { Casi siempre } \\
\end{array}$ \\
\hline 188 & JJ63_pretest_P56 & $\begin{array}{l}\text { ¿Cuándo has tomado una mala } \\
\text { decisión, te arrepientes?_inicial }\end{array}$ & Cualitativa & Ordinal & $\begin{array}{l}1 \text { Casi nunca } \\
2 \text { Pocas veces } \\
3 \text { A veces } \\
4 \text { Muchas veces } \\
5 \text { Casi siempre } \\
\end{array}$ \\
\hline 189 & JJ63_pretest_P57 & $\begin{array}{l}\text { ¿Te gusta hacer bromas con } \\
\text { facilidad?_inicial }\end{array}$ & Cualitativa & Ordinal & $\begin{array}{l}1 \text { Casi nunca } \\
2 \text { Pocas veces } \\
3 \text { A veces } \\
4 \text { Muchas veces } \\
5 \text { Casi siempre } \\
\end{array}$ \\
\hline 190 & JJ63_pretest_P58 & $\begin{array}{l}\text { ¿Ríes y disfrutas de los chistes que } \\
\text { hacen tus amigos y } \\
\text { compañeros?_inicial }\end{array}$ & Cualitativa & Ordinal & $\begin{array}{l}1 \text { Casi nunca } \\
2 \text { Pocas veces } \\
3 \text { A veces } \\
4 \text { Muchas veces } \\
5 \text { Casi siempre } \\
\end{array}$ \\
\hline 191 & JJ63_pretest_P59 & $\begin{array}{l}\text { ¿Cuándo te llaman la atención, te } \\
\text { molestas?_inicial }\end{array}$ & Cualitativa & Ordinal & $\begin{array}{l}\text { Casi nunca } \\
2 \text { Pocas veces } \\
3 \text { A veces } \\
4 \text { Muchas veces } \\
5 \text { Casi siempre } \\
\end{array}$ \\
\hline 192 & JJ63_pretest_P60 & $\begin{array}{l}\text { ¿Cuándo recibes una noticia que tú } \\
\text { consideras buena, saltas de } \\
\text { alegría?_inicial }\end{array}$ & Cualitativa & Ordinal & $\begin{array}{l}1 \text { Casi nunca } \\
2 \text { Pocas veces } \\
3 \text { A veces } \\
4 \text { Muchas veces } \\
5 \text { Casi siempre } \\
\end{array}$ \\
\hline 193 & JJ63_pretest_P61 & ¿Crees que la vida es linda?_inicial & Cualitativa & Ordinal & $\begin{array}{l}1 \text { Casi nunca } \\
2 \text { Pocas veces } \\
3 \text { A veces } \\
4 \text { Muchas veces } \\
5 \text { Casi siempre } \\
\end{array}$ \\
\hline 194 & JJ63_pretest_P62 & $\begin{array}{l}\text { ¿Le dices que le quieres a tu } \\
\text { enamorada/o?_inicial }\end{array}$ & Cualitativa & Ordinal & $\begin{array}{l}1 \text { Casi nunca } \\
2 \text { Pocas veces } \\
3 \text { A veces } \\
4 \text { Muchas veces } \\
5 \text { Casi siempre } \\
\end{array}$ \\
\hline 195 & JJ63_pretest_P63 & $\begin{array}{l}\text { ¿Hablas de tus problemas } \\
\text { sentimentales con alguien?_inicial }\end{array}$ & Cualitativa & Ordinal & $\begin{array}{l}1 \text { Casi nunca } \\
2 \text { Pocas veces } \\
3 \text { A veces } \\
4 \text { Muchas veces } \\
5 \text { Casi siempre } \\
\end{array}$ \\
\hline 196 & $\begin{array}{c}\text { Puntaje_funcio_fami_incia } \\
\text { I }\end{array}$ & Funcionalidad Familiar inicial & Cuantitativa & Discreta & No aplica \\
\hline 197 & Puntaje_Autoes_inicial & Autoestima Inicial & Cuantitativa & Discreta & No aplica \\
\hline 198 & Puntaje_aserti_inicial & Asertividad inicial & Cuantitativa & Discreta & No aplica \\
\hline 199 & Puntaje_adap_inicial & $\begin{array}{l}\text { Adaptabilidad a situaciones nuevas } \\
\text { inicial }\end{array}$ & Cuantitativa & Discreta & No aplica \\
\hline 200 & Puntaje_pensa_inicial & $\begin{array}{l}\text { Capacidad de pensamiento crítico } \\
\text { inicial }\end{array}$ & Cuantitativa & Discreta & No aplica \\
\hline 201 & Puntaje_impul_inicial & Impulsividad inicial & Cuantitativa & Discreta & No aplica \\
\hline 202 & Puntaje_afecti_inicial & Afectividad inicial & Cuantitativa & Discreta & No aplica \\
\hline 203 & Puntaje_resil_inicial & Resiliencia general inicial & Cuantitativa & Discreta & No aplica \\
\hline 204 & Recor_funcio_fami_incial & $\begin{array}{l}\text { Funcionalidad Familiar inicial } \\
\text { (agrupado) }\end{array}$ & Cualitativa & Ordinal & $\begin{array}{l}1 \text { Familia funcional } \\
2 \text { Familia moderadamente } \\
\text { funcional } \\
3 \text { Familia disfuncional } \\
4 \text { Familia severamente } \\
\text { disfuncional }\end{array}$ \\
\hline 205 & Recor_Autoes_inicial & Autoestima Inicial (agrupado) & Cualitativa & Ordinal & $\begin{array}{l}1 \text { Autoestima adecuada } \\
2 \text { Autoestima moderadamente }\end{array}$ \\
\hline
\end{tabular}




\begin{tabular}{|c|c|c|c|c|c|}
\hline & & & & & $\begin{array}{l}\text { adecuada } \\
3 \text { Autoestima deficiente } \\
4 \text { Autoestima severamente } \\
\text { deficiente }\end{array}$ \\
\hline 206 & Recor_aserti_inicial & Asertividad inicial (agrupado) & Cualitativa & Ordinal & $\begin{array}{l}1 \text { Asertivo/a } \\
2 \text { Moderadamente asertivo/ } \\
3 \text { Asertivo/a esporádico } \\
4 \text { No asertivo/a }\end{array}$ \\
\hline 207 & Recor_adap_inicial & $\begin{array}{l}\text { Adaptabilidad a situaciones nuevas } \\
\text { inicial (agrupado) }\end{array}$ & Cualitativa & Ordinal & $\begin{array}{l}\text { 1 Adaptabilidad adecuada } \\
2 \text { Adaptabilidad } \\
\text { moderadamente adecuada } \\
3 \text { Adaptabilidad inadecuada } \\
4 \text { Adaptabilidad severamente } \\
\text { inadecuada }\end{array}$ \\
\hline 208 & Recor_pensa_inicial & $\begin{array}{l}\text { Capacidad de pensamiento crítico } \\
\text { inicial (agrupado) }\end{array}$ & Cualitativa & Ordinal & $\begin{array}{l}1 \text { Pensamiento crítico } \\
2 \text { Pensamiento moderadamente } \\
\text { crítico } \\
3 \text { Pensamiento poco crítico } \\
4 \text { Pensamiento acrítico } \\
\end{array}$ \\
\hline 209 & Recor_impul_inicial & Impulsividad inicial (agrupado) & Cualitativa & Ordinal & $\begin{array}{l}1 \text { No impulsivo/a } \\
2 \text { Impulsivo ocasional } \\
3 \text { Moderadamente impulsivo } \\
4 \text { Impulsivo/a } \\
\end{array}$ \\
\hline 210 & Recor_afecti_inicial & Afectividad inicial (agrupado) & Cualitativa & Ordinal & $\begin{array}{l}1 \text { Afectivo/a } \\
2 \text { Moderadamente afectivo/a } \\
3 \text { Afectivo/a ocasional } \\
4 \text { No afectivo/a }\end{array}$ \\
\hline 211 & Recor_resil_inicial & $\begin{array}{l}\text { Resiliencia general inicial } \\
\text { (agrupado) }\end{array}$ & Cualitativa & Ordinal & $\begin{array}{l}1 \text { Resiliente } \\
2 \text { Moderadamente resiliente } \\
3 \text { Levemente resiliente } \\
4 \text { No resiliente }\end{array}$ \\
\hline 212 & EP_Posttest_P1 & 1. Soy una persona alegre & Cualitativa & Ordinal & $\begin{array}{l}1 \mathrm{Si} \\
2 \mathrm{Mas} \text { o menos } \\
3 \mathrm{No}\end{array}$ \\
\hline 213 & EP_Posttest_P2 & $\begin{array}{l}\text { 2. Estoy agradecido con varias } \\
\text { personas, por lo que hacen por mí }\end{array}$ & Cualitativa & Ordinal & $\begin{array}{l}\text { 1 Si } \\
2 \text { Mas o menos } \\
3 \text { No }\end{array}$ \\
\hline 214 & EP_Posttest_P3 & $\begin{array}{l}\text { 3. La mayor parte de los días me } \\
\text { siento en paz }\end{array}$ & Cualitativa & Ordinal & $\begin{array}{l}1 \mathrm{Si} \\
2 \mathrm{Mas} \text { o menos } \\
3 \mathrm{No}\end{array}$ \\
\hline 215 & EP_Posttest_P4 & $\begin{array}{l}\text { 4. Valoro cuando los demás me } \\
\text { ayudan }\end{array}$ & Cualitativa & Ordinal & $\begin{array}{l}\text { 1 Si } \\
2 \text { Mas o menos } \\
3 \text { No } \\
\end{array}$ \\
\hline 216 & EP_Posttest_P5 & 5. Soy bastante tranquilo & Cualitativa & Ordinal & \begin{tabular}{l|}
$1 \mathrm{Si}$ \\
$2 \mathrm{Mas}$ o menos \\
$3 \mathrm{No}$ \\
\end{tabular} \\
\hline 217 & EP_Posttest_P6 & $\begin{array}{l}\text { 6. Me pongo muy mal si veo que } \\
\text { alguien se lastima }\end{array}$ & Cualitativa & Ordinal & $\begin{array}{l}\text { 1 Si } \\
2 \text { Mas o menos } \\
3 \text { No }\end{array}$ \\
\hline 218 & EP_Posttest_P7 & $\begin{array}{l}\text { 7. Si veo llorar a un/a nene/a me } \\
\text { dan ganas de llorar a mí también }\end{array}$ & Cualitativa & Ordinal & $\begin{array}{l}1 \mathrm{Si} \\
2 \mathrm{Mas} \text { o menos } \\
3 \mathrm{No} \\
\end{array}$ \\
\hline 219 & EP_Posttest_P8 & 8. Me quiero mucho a mí mismo & Cualitativa & Ordinal & $\begin{array}{l}1 \mathrm{Si} \\
2 \mathrm{Mas} \text { o menos } \\
3 \mathrm{No}\end{array}$ \\
\hline 220 & EP_Posttest_P9 & $\begin{array}{l}\text { 9. Soluciono mis problemas con } \\
\text { mucha tranquilidad }\end{array}$ & Cualitativa & Ordinal & $\begin{array}{l}\text { Si } \\
2 \text { Mas o menos } \\
3 \text { No }\end{array}$ \\
\hline 221 & EP_Posttest_P10 & 10. Me gusta devolver favores & Cualitativa & Ordinal & $\begin{array}{l}1 \mathrm{Si} \\
2 \mathrm{Mas} \text { o menos } \\
3 \mathrm{No}\end{array}$ \\
\hline 222 & EP_Posttest_P11 & $\begin{array}{l}\text { 11. Cuando alguien está solo y } \\
\text { aburrido me dan ganas de } \\
\text { acercarme y jugar con él }\end{array}$ & Cualitativa & Ordinal & $\begin{array}{l}1 \mathrm{Si} \\
2 \mathrm{Mas} \text { o menos } \\
3 \mathrm{No}\end{array}$ \\
\hline 223 & EP_Posttest_P12 & $\begin{array}{l}\text { 12. Me divierto mucho con las cosas } \\
\text { que hago }\end{array}$ & Cualitativa & Ordinal & $\begin{array}{l}1 \mathrm{Si} \\
2 \mathrm{Mas} \text { o menos } \\
3 \mathrm{No}\end{array}$ \\
\hline
\end{tabular}




\begin{tabular}{|c|c|c|c|c|c|}
\hline 224 & EP_Posttest_P13 & 13. Soy muy feliz & Cualitativa & Ordinal & $\begin{array}{l}1 \mathrm{Si} \\
2 \text { Mas o menos } \\
3 \text { No }\end{array}$ \\
\hline 225 & EP_Posttest_P14 & 14. Casi siempre estoy relajado & Cualitativa & Ordinal & $\begin{array}{l}1 \mathrm{Si} \\
2 \mathrm{Mas} \text { o menos } \\
3 \mathrm{No}\end{array}$ \\
\hline 226 & EP_Posttest_P15 & $\begin{array}{l}\text { 15. Siempre que puedo, devuelvo } \\
\text { los favores que recibo }\end{array}$ & Cualitativa & Ordinal & $\begin{array}{l}\mathrm{Si} \\
2 \mathrm{Mas} \text { o menos } \\
3 \mathrm{No}\end{array}$ \\
\hline 227 & EP_Posttest_P16 & 16. Siento que soy muy valioso & Cualitativa & Ordinal & $\begin{array}{l}\mathrm{Si} \\
2 \mathrm{Mas} \text { o menos } \\
3 \mathrm{No}\end{array}$ \\
\hline 228 & EP_Posttest_P17 & $\begin{array}{l}\text { 17. Aunque tenga problemas, igual } \\
\text { mantengo la calma }\end{array}$ & Cualitativa & Ordinal & $\begin{array}{l}1 \mathrm{Si} \\
2 \text { Mas o menos } \\
3 \text { No }\end{array}$ \\
\hline 229 & EP_Posttest_P18 & 18. Casi siempre la paso bien & Cualitativa & Ordinal & $\begin{array}{l}\text { 1 Si } \\
2 \text { Mas o menos } \\
3 \text { No }\end{array}$ \\
\hline 230 & EP_Posttest_P19 & $\begin{array}{l}\text { 19. Me quedo tranquilo aunque no } \\
\text { pueda hacer lo que me gusta }\end{array}$ & Cualitativa & Ordinal & \begin{tabular}{|l|}
$1 \mathrm{Si}$ \\
$2 \mathrm{Mas}$ o menos \\
$3 \mathrm{No}$ \\
\end{tabular} \\
\hline 231 & EP_Posttest_P20 & 20. Siento que soy importante & Cualitativa & Ordinal & $\begin{array}{l}\text { 1 Si } \\
2 \text { Mas o menos } \\
3 \text { No }\end{array}$ \\
\hline 232 & EP_Posttest_P21 & $\begin{array}{l}\text { 21. Si alguien está llorando me dan } \\
\text { ganas de abrazarlo o consolarlo }\end{array}$ & Cualitativa & Ordinal & $\begin{array}{l}1 \mathrm{Si} \\
2 \text { Mas o menos } \\
3 \mathrm{No}\end{array}$ \\
\hline 233 & EP_Posttest_P22 & 22. Me gusta agradecerle a la gente & Cualitativa & Ordinal & \begin{tabular}{|l|}
$1 \mathrm{Si}$ \\
$2 \mathrm{Mas}$ o menos \\
$3 \mathrm{No}$ \\
\end{tabular} \\
\hline 234 & EP_Posttest_P23 & 23. Casi siempre estoy contento/a & Cualitativa & Ordinal & $\begin{array}{l}1 \mathrm{Si} \\
2 \mathrm{Mas} \text { o menos } \\
3 \mathrm{No}\end{array}$ \\
\hline 235 & $\begin{array}{c}\text { PD_post_test_AlegriayGra } \\
\text { titud }\end{array}$ & Puntaje Alegria y gratitud Final & Cuantitativa & Discreta & No aplica \\
\hline 236 & PD_post_test_Serenidad & Puntaje Serenidad Final & Cuantitativa & Discreta & No aplica \\
\hline 237 & PD_post_test_Simpatia & Puntaje Simpatia Final & Cuantitativa & Discreta & No aplica \\
\hline 238 & $\begin{array}{c}\text { PD_post_test_Satisfacció } \\
\text { npersonal }\end{array}$ & Puntaje Satisfaccion personal Final & Cuantitativa & Discreta & No aplica \\
\hline 239 & $\begin{array}{c}\text { Escala_post_test_Alegriay } \\
\text { Gratitud }\end{array}$ & Alegria y gratitud Final (Agrupado) & Cualitativa & Ordinal & $\begin{array}{l}1 \text { Bajo } \\
2 \text { Medio } \\
3 \text { Alto }\end{array}$ \\
\hline 240 & $\begin{array}{c}\text { Escala_post_test_Serenid } \\
\text { ad }\end{array}$ & Serenidad Final (Agrupado) & Cualitativa & Ordinal & $\begin{array}{l}1 \text { Bajo } \\
2 \text { Medio } \\
3 \text { Alto }\end{array}$ \\
\hline 241 & $\begin{array}{c}\text { Escala_post_test_Simpati } \\
\text { a }\end{array}$ & Simpatia Final (Agrupado) & Cualitativa & Ordinal & $\begin{array}{l}1 \text { Bajo } \\
2 \text { Medio } \\
3 \text { Alto } \\
\end{array}$ \\
\hline 242 & $\begin{array}{c}\text { Escala_post_test_Satisfac } \\
\text { ciónpersonal }\end{array}$ & $\begin{array}{l}\text { Satisfaccion personal Final } \\
\text { (Agrupado) }\end{array}$ & Cualitativa & Ordinal & $\begin{array}{l}1 \text { Bajo } \\
2 \text { Medio } \\
3 \text { Alto }\end{array}$ \\
\hline 243 & PC_Posttest_P1 & $\begin{array}{l}\text { 1. Muestro curiosidad sobre muchas } \\
\text { cosas haciendo continuas } \\
\text { preguntas de variados temas, por } \\
\text { ejemplo, acerca del funcionamiento } \\
\text { de los objetos, sobre la naturaleza... }\end{array}$ & Cualitativa & Ordinal & $\begin{array}{l}0 \text { Nada } \\
1 \text { Algo } \\
2 \text { Bastante } \\
3 \text { Mucho }\end{array}$ \\
\hline 244 & PC_Posttest_P2 & $\begin{array}{l}\text { 3. Tengo facilidad para identificar } \\
\text { problemas que existen, por ejemplo, } \\
\text { en la escuela, en casa, en el grupo } \\
\text { de amigos, en la sociedad... } \\
\end{array}$ & Cualitativa & Ordinal & $\begin{array}{l}0 \text { Nada } \\
1 \text { Algo } \\
2 \text { Bastante } \\
3 \text { Mucho } \\
\end{array}$ \\
\hline 245 & PC_Posttest_P3 & $\begin{array}{l}\text { 4. Ofrezco soluciones originales a } \\
\text { problemas que observo. }\end{array}$ & Cualitativa & Ordinal & $\begin{array}{l}0 \text { Nada } \\
1 \text { Algo } \\
2 \text { Bastante } \\
3 \text { Mucho }\end{array}$ \\
\hline 246 & PC_Posttest_P4 & $\begin{array}{l}\text { 5. Uso materiales de un modo } \\
\text { original, creativo. }\end{array}$ & Cualitativa & Ordinal & $\begin{array}{l}0 \text { Nada } \\
1 \text { Algo }\end{array}$ \\
\hline
\end{tabular}




\begin{tabular}{|c|c|c|c|c|c|}
\hline & & & & & $\begin{array}{l}2 \text { Bastante } \\
3 \text { Mucho }\end{array}$ \\
\hline 247 & PC_Posttest_P5 & 6. Invento juegos originales. & Cualitativa & Ordinal & $\begin{array}{l}0 \text { Nada } \\
1 \text { Algo } \\
2 \text { Bastante } \\
3 \text { Mucho } \\
\end{array}$ \\
\hline 248 & PC_Posttest_P6 & $\begin{array}{l}\text { 7. Construyo juguetes con los } \\
\text { materiales que tengo a mi } \\
\text { alrededor. }\end{array}$ & Cualitativa & Ordinal & $\begin{array}{l}0 \text { Nada } \\
1 \text { Algo } \\
2 \text { Bastante } \\
3 \text { Mucho }\end{array}$ \\
\hline 249 & PC_Posttest_P7 & $\begin{array}{l}\text { 8. Tengo ideas originales en el } \\
\text { juego de representación } \\
\text { (representar personajes o hacer } \\
\text { como si un objeto fuera otra cosa). }\end{array}$ & Cualitativa & Ordinal & $\begin{array}{l}0 \text { Nada } \\
1 \text { Algo } \\
2 \text { Bastante } \\
3 \text { Mucho }\end{array}$ \\
\hline 250 & PC_Posttest_P8 & $\begin{array}{l}\text { 9. Muestro interés por actividades } \\
\text { artísticas como el dibujo, la pintura, } \\
\text { modelar con plastilina... }\end{array}$ & Cualitativa & Ordinal & $\begin{array}{l}0 \text { Nada } \\
1 \text { Algo } \\
2 \text { Bastante } \\
3 \text { Mucho }\end{array}$ \\
\hline 251 & PC_Posttest_P9 & $\begin{array}{l}\text { 10. Me gustan los juegos } \\
\text { intelectuales, que requieren pensar } \\
\text { y buscar soluciones nuevas. }\end{array}$ & Cualitativa & Ordinal & $\begin{array}{l}0 \text { Nada } \\
1 \text { Algo } \\
2 \text { Bastante } \\
3 \text { Mucho }\end{array}$ \\
\hline 252 & PC_Posttest_P10 & $\begin{array}{l}\text { 11. Me gustan los juegos con las } \\
\text { palabras. }\end{array}$ & Cualitativa & Ordinal & $\begin{array}{l}0 \text { Nada } \\
1 \text { Algo } \\
2 \text { Bastante } \\
3 \text { Mucho }\end{array}$ \\
\hline 253 & PC_Posttest_P11 & $\begin{array}{l}\text { 12. Invento canciones, versos, } \\
\text { poesías, chistes... }\end{array}$ & Cualitativa & Ordinal & $\begin{array}{l}0 \text { Nada } \\
1 \text { Algo } \\
2 \text { Bastante } \\
3 \text { Mucho }\end{array}$ \\
\hline 254 & PC_Posttest_P12 & $\begin{array}{l}\text { 13. Me gusta jugar juegos } \\
\text { imaginativos, de fantasía. }\end{array}$ & Cualitativa & Ordinal & $\begin{array}{l}0 \text { Nada } \\
1 \text { Algo } \\
2 \text { Bastante } \\
3 \text { Mucho }\end{array}$ \\
\hline 255 & PC_Posttest_P13 & $\begin{array}{l}\text { 14. Me gusta escuchar relatos, } \\
\text { cuentos o historias. }\end{array}$ & Cualitativa & Ordinal & $\begin{array}{l}0 \text { Nada } \\
1 \text { Algo } \\
2 \text { Bastante } \\
3 \text { Mucho }\end{array}$ \\
\hline 256 & PC_Posttest_P14 & $\begin{array}{l}\text { 15. Mis intereses son amplios, tengo } \\
\text { muchas aficiones y temas de } \\
\text { interés. }\end{array}$ & Cualitativa & Ordinal & $\begin{array}{l}0 \text { Nada } \\
1 \text { Algo } \\
2 \text { Bastante } \\
3 \text { Mucho }\end{array}$ \\
\hline 257 & PC_Posttest_P15 & $\begin{array}{l}\text { 16. Me gusta aprender cosas } \\
\text { nuevas. }\end{array}$ & Cualitativa & Ordinal & $\begin{array}{l}0 \text { Nada } \\
1 \text { Algo } \\
2 \text { Bastante } \\
3 \text { Mucho }\end{array}$ \\
\hline 258 & PC_Posttest_P16 & 17. Soy independiente. & Cualitativa & Ordinal & $\begin{array}{l}0 \text { Nada } \\
1 \text { Algo } \\
2 \text { Bastante } \\
3 \text { Mucho }\end{array}$ \\
\hline
\end{tabular}




\begin{tabular}{|c|c|c|c|c|c|}
\hline 259 & PC_Posttest_P17 & $\begin{array}{l}\text { 18. Tengo sentido del humor, me } \\
\text { gusta bromear. }\end{array}$ & Cualitativa & Ordinal & $\begin{array}{l}0 \text { Nada } \\
1 \text { Algo } \\
2 \text { Bastante } \\
3 \text { Mucho }\end{array}$ \\
\hline 260 & PC_Posttest_P18 & $\begin{array}{l}\text { 19. Soy perseverante, cuando } \\
\text { comienzo una tarea soy constante y } \\
\text { la termino, aunque me cueste. }\end{array}$ & Cualitativa & Ordinal & $\begin{array}{l}0 \text { Nada } \\
1 \text { Algo } \\
2 \text { Bastante } \\
3 \text { Mucho }\end{array}$ \\
\hline 261 & PC_Posttest_P19 & $\begin{array}{l}\text { 20. Estoy abierto a nuevas } \\
\text { experiencias, me gustan las } \\
\text { novedades, los cambios. }\end{array}$ & Cualitativa & Ordinal & \begin{tabular}{|l|}
0 Nada \\
1 Algo \\
2 Bastante \\
3 Mucho
\end{tabular} \\
\hline 262 & PC_Posttest_P20 & $\begin{array}{l}\text { 21. Me gustan las situaciones que } \\
\text { implican riesgo, aventura. }\end{array}$ & Cualitativa & Ordinal & \begin{tabular}{|l|}
0 Nada \\
1 Algo \\
2 Bastante \\
3 Mucho
\end{tabular} \\
\hline 263 & PC_Posttest_P21 & 22. Soy creativo. & Cualitativa & Ordinal & \begin{tabular}{|l|}
0 Nada \\
1 Algo \\
2 Bastante \\
3 Mucho \\
\end{tabular} \\
\hline 264 & $\begin{array}{c}\text { PD_post_test_Identificació } \\
\text { nysolucióndeproblemas }\end{array}$ & $\begin{array}{l}\text { Puntaje Identificacion y solucion de } \\
\text { problemas Final }\end{array}$ & Cuantitativa & Discreta & No aplica \\
\hline 265 & $\begin{array}{l}\text { PD_post_test_Invencióny } \\
\text { arte }\end{array}$ & Puntaje Invencion y arte Final & Cuantitativa & Discreta & No aplica \\
\hline 266 & PD_post_test_Apertura & Puntaje Apertura Final & Cuantitativa & Discreta & No aplica \\
\hline 267 & $\begin{array}{c}\text { PD_post_test_Fantasiaei } \\
\text { maginación }\end{array}$ & $\begin{array}{l}\text { Puntaje Fantasia e imaginacion } \\
\text { Final }\end{array}$ & Cuantitativa & Discreta & No aplica \\
\hline 268 & $\begin{array}{c}\text { PD_post_test_Juegosintel } \\
\text { ectuales }\end{array}$ & Puntaje Juegos intelectuales Final & Cuantitativa & Discreta & No aplica \\
\hline 269 & PD_post_test_total & Puntaje Total Final & Cuantitativa & Discreta & No aplica \\
\hline 270 & $\begin{array}{c}\text { Escala_post_test_Identific } \\
\text { aciónysolucióndeproblema } \\
\text { s }\end{array}$ & $\begin{array}{l}\text { Identificacion y solucion de } \\
\text { problemas Final(Agrupado) }\end{array}$ & Cualitativa & Ordinal & $\begin{array}{l}\text { Bajo } \\
2 \text { Medio } \\
3 \text { Alto } \\
\end{array}$ \\
\hline 271 & $\begin{array}{c}\begin{array}{c}\text { Escala_post_test_Invenci } \\
\text { ónyarte }\end{array} \\
\end{array}$ & Invencion y arte Final(Agrupado) & Cualitativa & Ordinal & \begin{tabular}{|l|}
1 Bajo \\
2 Medio \\
3 Alto \\
\end{tabular} \\
\hline 272 & $\begin{array}{c}\text { Escala_post_test_Apertur } \\
\text { a }\end{array}$ & Apertura Final(Agrupado) & Cualitativa & Ordinal & \begin{tabular}{|l|}
1 Bajo \\
2 Medio \\
3 Alto \\
\end{tabular} \\
\hline 273 & $\begin{array}{c}\text { Escala_post_test_Fantasi } \\
\text { aeimaginación }\end{array}$ & $\begin{array}{l}\text { Fantasia e imaginacion } \\
\text { Final(Agrupado) }\end{array}$ & Cualitativa & Ordinal & \begin{tabular}{|l|}
1 Bajo \\
2 Medio \\
3 Alto \\
\end{tabular} \\
\hline 274 & $\begin{array}{c}\text { Escala_post_test_Juegosl } \\
\text { ntelectuales }\end{array}$ & $\begin{array}{l}\text { Juegos intelectuales } \\
\text { Final(Agrupado) }\end{array}$ & Cualitativa & Ordinal & \begin{tabular}{|l|}
1 Bajo \\
2 Medio \\
3 Alto \\
\end{tabular} \\
\hline 275 & Escala_post_test_Total & Total Final(Agrupado) & Cualitativa & Ordinal & \begin{tabular}{|l|}
1 Bajo \\
2 Medio \\
3 Alto \\
\end{tabular} \\
\hline 276 & EP_Posttest_P138 & $\begin{array}{l}\text { 1. A mi mamá le gusta hablar y } \\
\text { estar conmigo la mayor parte del } \\
\text { tiempo }\end{array}$ & Cualitativa & Ordinal & \begin{tabular}{|l|}
1 Bajo \\
2 Medio \\
3 Alto \\
\end{tabular} \\
\hline 277 & EP_Posttest_P239 & $\begin{array}{l}\text { 2. Mi mamá controla que llegue a } \\
\text { casa a horario. }\end{array}$ & Cualitativa & Ordinal & \begin{tabular}{|l|}
1 Bajo \\
2 Medio \\
3 Alto \\
\end{tabular} \\
\hline
\end{tabular}




\begin{tabular}{|c|c|c|c|c|c|}
\hline 278 & EP_Posttest_P340 & $\begin{array}{l}\text { 3. Mi mamá me dice que me quiere } \\
\text { mucho }\end{array}$ & Cualitativa & Ordinal & \begin{tabular}{|l}
1 Bajo \\
2 Medio \\
3 Alto
\end{tabular} \\
\hline 279 & EP_Posttest_P441 & $\begin{array}{l}\text { 4. Mi mamá siempre quiere saber } \\
\text { todo el tiempo dónde estoy y lo que } \\
\text { hago }\end{array}$ & Cualitativa & Ordinal & \begin{tabular}{|l|} 
1 Bajo \\
2 Medio \\
3 Alto \\
\end{tabular} \\
\hline 280 & EP_Posttest_P542 & $\begin{array}{l}\text { 5. Mi mamá decide con qué amigos } \\
\text { puedo juntarme. }\end{array}$ & Cualitativa & Ordinal & $\begin{array}{l}\text { Bajo } \\
2 \text { Medio } \\
3 \text { Alto }\end{array}$ \\
\hline 281 & EP_Posttest_P643 & $\begin{array}{l}\text { 6. Mi mamá se preocupa poco si yo } \\
\text { me porto mal. }\end{array}$ & Cualitativa & Ordinal & \begin{tabular}{|l|} 
1 Bajo \\
2 Medio \\
3 Alto
\end{tabular} \\
\hline 282 & EP_Posttest_P744 & $\begin{array}{l}\text { 7. Mi mamá me deja salir todas las } \\
\text { veces que yo quiera. }\end{array}$ & Cualitativa & Ordinal & \begin{tabular}{|l|} 
1 Bajo \\
2 Medio \\
3 Alto \\
\end{tabular} \\
\hline 283 & EP_Posttest_P845 & $\begin{array}{l}\text { 8. Mi mamá me hace sentir la } \\
\text { persona más importante de su vida }\end{array}$ & Cualitativa & Ordinal & $\begin{array}{l}1 \text { Bajo } \\
2 \text { Medio } \\
3 \text { Alto }\end{array}$ \\
\hline 284 & EP_Posttest_P946 & 9. Mi mamá se mete en mis cosas. & Cualitativa & Ordinal & $\begin{array}{l}\text { 1 Bajo } \\
2 \text { Medio } \\
3 \text { Alto }\end{array}$ \\
\hline 285 & EP_Posttest_P1047 & $\begin{array}{l}\text { 10. Mi mamá cree que } \\
\text { castigándome va a corregir mi mal } \\
\text { comportamiento. }\end{array}$ & Cualitativa & Ordinal & $\begin{array}{l}\text { 1 Bajo } \\
2 \text { Medio } \\
3 \text { Alto }\end{array}$ \\
\hline 286 & EP_Posttest_P1148 & $\begin{array}{l}\text { 11. Mi mamá siempre escucha lo } \\
\text { que yo opino y pienso. }\end{array}$ & Cualitativa & Ordinal & \begin{tabular}{|l|} 
1 Bajo \\
2 Medio \\
3 Alto \\
\end{tabular} \\
\hline 287 & EP_Posttest_P1249 & $\begin{array}{l}\text { 12. Mi mamá está siempre } \\
\text { pendiente de lo que yo hago en la } \\
\text { escuela y en el tiempo libre }\end{array}$ & Cualitativa & Ordinal & \begin{tabular}{|l|} 
1 Bajo \\
2 Medio \\
3 Alto \\
\end{tabular} \\
\hline 288 & EP_Posttest_P1350 & $\begin{array}{l}\text { 13. Mi mamá siempre me dice las } \\
\text { cosas que hace por mí, me echa en } \\
\text { cara todo lo que tiene que hacer por } \\
\text { mi culpa. }\end{array}$ & Cualitativa & Ordinal & $\begin{array}{l}1 \text { Bajo } \\
2 \text { Medio } \\
3 \text { Alto }\end{array}$ \\
\hline 289 & EP_Posttest_P1451 & $\begin{array}{l}\text { 14. Mi mamá quiere controlar todo } \\
\text { lo que yo haga. }\end{array}$ & Cualitativa & Ordinal & \begin{tabular}{|l|} 
1 Bajo \\
2 Medio \\
3 Alto \\
\end{tabular} \\
\hline 290 & EP_Posttest_P1552 & $\begin{array}{l}\text { 15. Mi mamá le importa cuando } \\
\text { hago algo que no debo. }\end{array}$ & Cualitativa & Ordinal & \begin{tabular}{|l|} 
1 Bajo \\
2 Medio \\
3 Alto \\
\end{tabular} \\
\hline 291 & EP_Posttest_P1653 & $\begin{array}{l}\text { 16. Mi mamá me deja hacer lo que } \\
\text { quiera. }\end{array}$ & Cualitativa & Ordinal & \begin{tabular}{|l|} 
1 Bajo \\
2 Medio \\
3 Alto
\end{tabular} \\
\hline 292 & EP_Posttest_P1754 & $\begin{array}{l}\text { 17. Mi mamá me protege cuando } \\
\text { tengo miedo. }\end{array}$ & Cualitativa & Ordinal & $\begin{array}{l}\text { Bajo } \\
2 \text { Medio } \\
3 \text { Alto }\end{array}$ \\
\hline 293 & EP_Posttest_P1855 & $\begin{array}{l}\text { 18. Mi mamá insiste con que tengo } \\
\text { que hacer todo lo que me dice. }\end{array}$ & Cualitativa & Ordinal & \begin{tabular}{|l|}
1 Bajo \\
2 Medio \\
3 Alto \\
\end{tabular} \\
\hline 294 & EP_Posttest_P1956 & $\begin{array}{l}\text { 19. Mi papá me castiga cuando no } \\
\text { le hago caso. }\end{array}$ & Cualitativa & Ordinal & \begin{tabular}{|l|}
1 Bajo \\
2 Medio \\
3 Alto
\end{tabular} \\
\hline 295 & EP_Posttest_P2057 & $\begin{array}{l}\text { 20. Mi mamá a menudo tiene largas } \\
\text { charlas conmigo sobre el por qué de } \\
\text { las cosas. }\end{array}$ & Cualitativa & Ordinal & \begin{tabular}{|l|} 
1 Bajo \\
2 Medio \\
3 Alto \\
\end{tabular} \\
\hline 296 & EP_Posttest_P2158 & $\begin{array}{l}\text { 21. Mi mamá me dice que, si } \\
\text { realmente la quiero, me tengo que } \\
\text { portar bien para no amargarle la } \\
\text { vida. }\end{array}$ & Cualitativa & Ordinal & $\begin{array}{l}1 \text { Bajo } \\
2 \text { Medio } \\
3 \text { Alto }\end{array}$ \\
\hline 297 & EP_Posttest_P2259 & $\begin{array}{l}\text { 22. Mi mamá insiste en que haga } \\
\text { mis tareas. }\end{array}$ & Cualitativa & Ordinal & \begin{tabular}{|l|} 
1 Bajo \\
2 Medio \\
3 Alto
\end{tabular} \\
\hline 298 & EP_Posttest_P2360 & $\begin{array}{l}\text { 23. Si insisto, mi mamá afloja y } \\
\text { puedo quedarme levantado hasta } \\
\text { más tarde los días de semana. }\end{array}$ & Cualitativa & Ordinal & \begin{tabular}{|l|} 
1 Bajo \\
2 Medio \\
3 Alto \\
\end{tabular} \\
\hline 299 & EP_Posttest_P24 & $\begin{array}{l}\text { 24. Mi mamá dice que portarse mal } \\
\text { es muy grave y puedo tener } \\
\text { problemas cuando sea grande. }\end{array}$ & Cualitativa & Ordinal & \begin{tabular}{|l|} 
1 Bajo \\
2 Medio \\
3 Alto
\end{tabular} \\
\hline
\end{tabular}




\begin{tabular}{|c|c|c|c|c|c|}
\hline 300 & EP_Posttest_P25 & $\begin{array}{l}\text { 25. Mi mamá, si hago algo que le } \\
\text { duele, deja de hablarme hasta que } \\
\text { me disculpe. }\end{array}$ & Cualitativa & Ordinal & $\begin{array}{l}1 \text { Bajo } \\
2 \text { Medio } \\
3 \text { Alto }\end{array}$ \\
\hline 301 & EP_Posttest_P26 & $\begin{array}{l}\text { 26. Mi mamá se muestra orgullosa } \\
\text { de lo que yo hago. }\end{array}$ & Cualitativa & Ordinal & $\begin{array}{l}1 \text { Bajo } \\
2 \text { Medio } \\
3 \text { Alto }\end{array}$ \\
\hline 302 & EP_Posttest_P27 & $\begin{array}{l}\text { 27. Mi mamá quiere que me quede } \\
\text { en casa para saber lo que yo hago }\end{array}$ & Cualitativa & Ordinal & $\begin{array}{l}1 \text { Bajo } \\
2 \text { Medio } \\
3 \text { Alto }\end{array}$ \\
\hline 303 & EP_Posttest_P28 & $\begin{array}{l}\text { 28. Mi mamá hace que yo cumpla lo } \\
\text { que me manda. }\end{array}$ & Cualitativa & Ordinal & $\begin{array}{l}1 \text { Bajo } \\
2 \text { Medio } \\
3 \text { Alto }\end{array}$ \\
\hline 304 & EP_Posttest_P29 & $\begin{array}{l}\text { 29. A mi mamá le interesa lo que yo } \\
\text { hago. }\end{array}$ & Cualitativa & Ordinal & $\begin{array}{l}1 \text { Bajo } \\
2 \text { Medio } \\
3 \text { Alto }\end{array}$ \\
\hline 305 & EP_Posttest_P30 & $\begin{array}{l}\text { 30. Mi mamá, cuando fallo en algo, } \\
\text { no quiere saber nada conmigo } \\
\text { hasta que yo encuentro la forma de } \\
\text { reconciliarme. }\end{array}$ & Cualitativa & Ordinal & $\begin{array}{l}1 \text { Bajo } \\
2 \text { Medio } \\
3 \text { Alto }\end{array}$ \\
\hline 306 & EP_Posttest_P31 & $\begin{array}{l}\text { 31. Mi mamá me deja ir a jugar } \\
\text { cuando quiero. }\end{array}$ & Cualitativa & Ordinal & $\begin{array}{l}1 \text { Bajo } \\
2 \text { Medio } \\
3 \text { Alto }\end{array}$ \\
\hline 307 & EP_Posttest_P32 & $\begin{array}{l}\text { 32. Mi mamá, cuando me porto mal, } \\
\text { se preocupa porque voy a sufrir las } \\
\text { consecuencias cuando sea grande. }\end{array}$ & Cualitativa & Ordinal & $\begin{array}{l}\text { Bajo } \\
2 \text { Medio } \\
3 \text { Alto } \\
\end{array}$ \\
\hline 308 & $\begin{array}{c}\text { PD_Post_test_Dimensión } \\
\text { _Aceptación }\end{array}$ & Aceptacion Final & Cuantitativa & Discreta & No aplica \\
\hline 309 & $\begin{array}{c}\text { PD_Post_test_Dimensión } \\
\text { _ControlAceptado }\end{array}$ & Control aceptado Final & Cuantitativa & Discreta & No aplica \\
\hline 310 & $\begin{array}{l}\text { PD_Post_test_Dimensión } \\
\text { _Controlestricto }\end{array}$ & Control estricto Final & Cuantitativa & Discreta & No aplica \\
\hline 311 & $\begin{array}{l}\text { totaldelas3anterioresFacto } \\
\text { raceptaciónvscontrolestrict } \\
\text { B }\end{array}$ & Factor Aceptacion Final & Cuantitativa & Discreta & No aplica \\
\hline 312 & $\begin{array}{c}\text { PD_Post_test_Factor_Co } \\
\text { ntrolpatologico }\end{array}$ & Contol patologico Final & Cuantitativa & Discreta & No aplica \\
\hline 313 & $\begin{array}{l}\text { PD_Post_test_Factor_Aut } \\
\text { onomiaextrema }\end{array}$ & Autonomia Extrema Final & Cuantitativa & Discreta & No aplica \\
\hline 314 & $\begin{array}{l}\text { Escala_Post_test_Dimens } \\
\text { ión_Aceptación }\end{array}$ & Aceptacion Final (Agrupado) & Cualitativa & Ordinal & $\begin{array}{l}1 \text { Bajo } \\
2 \text { Medio } \\
3 \text { Alto }\end{array}$ \\
\hline 315 & $\begin{array}{l}\text { PD_Post_test_Dimensión } \\
\text { _ControlAceptado62 }\end{array}$ & Control aceptado Final (Agrupado) & Cualitativa & Ordinal & $\begin{array}{l}1 \text { Bajo } \\
2 \text { Medio } \\
3 \text { Alto }\end{array}$ \\
\hline 316 & $\begin{array}{l}\text { PD_Post_test_Dimensión } \\
\text { _Controlestricto63 }\end{array}$ & Control Estricto Final (Agrupado) & Cualitativa & Ordinal & $\begin{array}{l}\text { Bajo } \\
2 \text { Medio } \\
3 \text { Alto } \\
\end{array}$ \\
\hline 317 & $\begin{array}{c}\text { totaldelas3anterioresFacto } \\
\text { raceptaciónvscontrolestrict } \\
\text { C C }\end{array}$ & $\begin{array}{l}\text { totaldelas3anterioresFactoraceptaci } \\
\text { ónvscontrolestrict Final (Agrupado) }\end{array}$ & Cualitativa & Ordinal & $\begin{array}{l}1 \text { Bajo } \\
2 \text { Medio } \\
3 \text { Alto }\end{array}$ \\
\hline 318 & $\begin{array}{l}\text { PD_Post_test_Factor_Co } \\
\text { ntrolpatologico65 }\end{array}$ & Control patologico Final (Agrupado) & Cualitativa & Ordinal & $\begin{array}{l}\text { Bajo } \\
2 \text { Medio } \\
3 \text { Alto } \\
\end{array}$ \\
\hline 319 & $\begin{array}{l}\text { PD_Post_test_Factor_Aut } \\
\text { onomiaextrema66 }\end{array}$ & $\begin{array}{l}\text { Autonomia Extrema Final } \\
\text { (Agrupado) }\end{array}$ & Cualitativa & Ordinal & $\begin{array}{l}\text { Bajo } \\
2 \text { Medio } \\
3 \text { Alto }\end{array}$ \\
\hline 320 & JJ63_Posttest_P1 & $\begin{array}{l}\text { ¿Cuando alguien de la familia tiene } \\
\text { un problema, tú ayudas?_inicial }\end{array}$ & Cualitativa & Ordinal & $\begin{array}{l}\text { Casi nunca } \\
2 \text { Pocas veces } \\
3 \text { A veces } \\
4 \text { Muchas veces } \\
5 \text { Casi siempre } \\
\end{array}$ \\
\hline 321 & JJ63_Posttest_P2 & $\begin{array}{l}\text { ¿En tu casa predomina la } \\
\text { armonía?_inicial }\end{array}$ & Cualitativa & Ordinal & $\begin{array}{l}1 \text { Casi nunca } \\
2 \text { Pocas veces } \\
3 \text { A veces } \\
4 \text { Muchas veces } \\
5 \text { Casi siempre }\end{array}$ \\
\hline
\end{tabular}




\begin{tabular}{|c|c|c|c|c|c|}
\hline 322 & JJ63_Posttest_P3 & $\begin{array}{l}\text { ¿Puedes conversar de lo que sea } \\
\text { sin temor dentro de tu } \\
\text { familia?_inicial }\end{array}$ & Cualitativa & Ordinal & $\begin{array}{l}1 \text { Casi nunca } \\
2 \text { Pocas veces } \\
3 \text { A veces } \\
4 \text { Muchas veces } \\
5 \text { Casi siempre }\end{array}$ \\
\hline 323 & JJ63_Posttest_P4 & $\begin{array}{l}\text { ¿Ante un problema, eres capaz de } \\
\text { pedir ayuda a alguien de tu familia? } \\
\text { _nicial }\end{array}$ & Cualitativa & Ordinal & $\begin{array}{l}\text { Casi nunca } \\
2 \text { Pocas veces } \\
3 \text { A veces } \\
4 \text { Muchas veces } \\
5 \text { Casi siempre } \\
\end{array}$ \\
\hline 324 & JJ63_Posttest_P5 & $\begin{array}{l}\text { ¿Demuestras el cariño que les } \\
\text { tienes a los miembros de tu } \\
\text { familia? inicial }\end{array}$ & Cualitativa & Ordinal & $\begin{array}{l}1 \text { Casi nunca } \\
2 \text { Pocas veces } \\
3 \text { A veces } \\
4 \text { Muchas veces } \\
5 \text { Casi siempre } \\
\end{array}$ \\
\hline 325 & JJ63_Posttest_P6 & $\begin{array}{l}\text { ¿En tu familia se distribuyen las } \\
\text { responsabilidades entre todos? } \\
\text { _nicial }\end{array}$ & Cualitativa & Ordinal & \begin{tabular}{|l} 
Casi nunca \\
2 Pocas veces \\
3 A veces \\
4 Muchas veces \\
5 Casi siempre
\end{tabular} \\
\hline 326 & JJ63_Posttest_P7 & $\begin{array}{l}\text { ¿Aceptas los defectos de los demás } \\
\text { miembros de tu familia?_inicial }\end{array}$ & Cualitativa & Ordinal & $\begin{array}{l}\text { Casi nunca } \\
2 \text { Pocas veces } \\
3 \text { A veces } \\
4 \text { Muchas veces } \\
5 \text { Casi siempre }\end{array}$ \\
\hline 327 & JJ63_Posttest_P8 & $\begin{array}{l}\text { ¿Te sientes orgulloso/a de la } \\
\text { persona que eres?_inicial }\end{array}$ & Cualitativa & Ordinal & \begin{tabular}{|l} 
Casi nunca \\
2 Pocas veces \\
3 A veces \\
4 Muchas veces \\
5 Casi siempre
\end{tabular} \\
\hline 328 & JJ63_Posttest_P9 & $\begin{array}{l}\text { ¿Sientes que eres querido en } \\
\text { casa? inicial }\end{array}$ & Cualitativa & Ordinal & \begin{tabular}{|l}
1 Casi nunca \\
2 Pocas veces \\
3 A veces \\
4 Muchas veces \\
5 Casi siempre \\
\end{tabular} \\
\hline 329 & JJ63_Posttest_P10 & $\begin{array}{l}\text { ¿Sientes que te apoyan en lo que te } \\
\text { propones? inicial }\end{array}$ & Cualitativa & Ordinal & \begin{tabular}{|l|}
1 Casi nunca \\
2 Pocas veces \\
3 A veces \\
4 Muchas veces \\
5 Casi siempre \\
\end{tabular} \\
\hline 330 & JJ63_Posttest_P11 & ¿Te consideras atractivo/a? _inicial & Cualitativa & Ordinal & $\begin{array}{l}1 \text { Casi nunca } \\
2 \text { Pocas veces } \\
3 \text { A veces } \\
4 \text { Muchas veces } \\
5 \text { Casi siempre } \\
\end{array}$ \\
\hline 331 & JJ63_Posttest_P12 & $\begin{array}{l}\text { ¿Estás contento con la figura } \\
\text { corporal y apariencia que tienes? } \\
\text { inicial }\end{array}$ & Cualitativa & Ordinal & $\begin{array}{l}1 \text { Casi nunca } \\
2 \text { Pocas veces } \\
3 \text { A veces } \\
4 \text { Muchas veces } \\
5 \text { Casi siempre } \\
\end{array}$ \\
\hline 332 & JJ63_Posttest_P13 & $\begin{array}{l}\text { ¿Quisieras cambiar alguna parte de } \\
\text { tu cuerpo? _inicial }\end{array}$ & Cualitativa & Ordinal & \begin{tabular}{|l|}
1 Casi nunca \\
2 Pocas veces \\
3 A veces \\
4 Muchas veces \\
5 Casi siempre \\
\end{tabular} \\
\hline 333 & JJ63_Posttest_P14 & $\begin{array}{l}\text { ¿Te duelen las opiniones de tus } \\
\text { amigos cuando están en tu contra? } \\
\text { _inicial }\end{array}$ & Cualitativa & Ordinal & \begin{tabular}{|l}
1 Casi nunca \\
2 Pocas veces \\
3 A veces \\
4 Muchas veces \\
5 Casi siempre \\
\end{tabular} \\
\hline
\end{tabular}




\begin{tabular}{|c|c|c|c|c|c|}
\hline 334 & JJ63_Posttest_P15 & $\begin{array}{l}\text { ¿Si la conducta de otra persona te } \\
\text { molesta, le pides que cambie su } \\
\text { comportamiento contigo?_inicial }\end{array}$ & Cualitativa & Ordinal & $\begin{array}{l}1 \text { Casi nunca } \\
2 \text { Pocas veces } \\
3 \text { A veces } \\
4 \text { Muchas veces } \\
5 \text { Casi siempre }\end{array}$ \\
\hline 335 & JJ63_Posttest_P16 & $\begin{array}{l}\text { ¿Le dices a tu familia cuando te } \\
\text { molesta algo?_inicial }\end{array}$ & Cualitativa & Ordinal & $\begin{array}{l}1 \text { Casi nunca } \\
2 \text { Pocas veces } \\
3 \text { A veces } \\
4 \text { Muchas veces } \\
5 \text { Casi siempre }\end{array}$ \\
\hline 336 & JJ63_Posttest_P17 & $\begin{array}{l}\text { ¿Cuándo te piden un favor que no } \\
\text { deseas hacer ¿dices simplemente } \\
\text { "no" y te quedas tranquilo?_inicial }\end{array}$ & Cualitativa & Ordinal & $\begin{array}{l}\text { Casi nunca } \\
2 \text { Pocas veces } \\
3 \text { A veces } \\
4 \text { Muchas veces } \\
5 \text { Casi siempre }\end{array}$ \\
\hline 337 & JJ63_Posttest_P18 & $\begin{array}{l}\text { ¿Expresas tus deseos de realizar } \\
\text { algo con facilidad?_inicial }\end{array}$ & Cualitativa & Ordinal & $\begin{array}{l}1 \text { Casi nunca } \\
2 \text { Pocas veces } \\
3 \text { A veces } \\
4 \text { Muchas veces } \\
5 \text { Casi siempre }\end{array}$ \\
\hline 338 & JJ63_Posttest_P19 & $\begin{array}{l}\text { ¿Expresas libremente tu enfado o } \\
\text { descontento?_inicial }\end{array}$ & Cualitativa & Ordinal & $\begin{array}{l}1 \text { Casi nunca } \\
2 \text { Pocas veces } \\
3 \text { A veces } \\
4 \text { Muchas veces } \\
5 \text { Casi siempre }\end{array}$ \\
\hline 339 & JJ63_Posttest_P20 & $\begin{array}{l}\text { ¿Reclamas algo cuando es } \\
\text { injusto?_inicial }\end{array}$ & Cualitativa & Ordinal & $\begin{array}{l}1 \text { Casi nunca } \\
2 \text { Pocas veces } \\
3 \text { A veces } \\
4 \text { Muchas veces } \\
5 \text { Casi siempre }\end{array}$ \\
\hline 340 & JJ63_Posttest_P21 & $\begin{array}{l}\text { ¿Cuándo le prestas algo a alguien y } \\
\text { olvidan devolverlo, le } \\
\text { recuerdas?_inicial }\end{array}$ & Cualitativa & Ordinal & $\begin{array}{l}1 \text { Casi nunca } \\
2 \text { Pocas veces } \\
3 \text { A veces } \\
4 \text { Muchas veces } \\
5 \text { Casi siempre }\end{array}$ \\
\hline 341 & JJ63_Posttest_P22 & $\begin{array}{l}\text { ¿Cuándo sucede algo inesperado } \\
\text { ¿lo superas rápido?_inicial }\end{array}$ & Cualitativa & Ordinal & $\begin{array}{l}1 \text { Casi nunca } \\
2 \text { Pocas veces } \\
3 \text { A veces } \\
4 \text { Muchas veces } \\
5 \text { Casi siempre }\end{array}$ \\
\hline 342 & JJ63_Posttest_P23 & $\begin{array}{l}\text { ¿Cuándo algo te sale mal, lo } \\
\text { aceptas con facilidad?_inicial }\end{array}$ & Cualitativa & Ordinal & $\begin{array}{l}1 \text { Casi nunca } \\
2 \text { Pocas veces } \\
3 \text { A veces } \\
4 \text { Muchas veces } \\
5 \text { Casi siempre }\end{array}$ \\
\hline 343 & JJ63_Posttest_P24 & $\begin{array}{l}\text { ¿Si tienes problemas con tus } \\
\text { familiares, lo resuelves } \\
\text { rápidamente? inicial }\end{array}$ & Cualitativa & Ordinal & $\begin{array}{l}1 \text { Casi nunca } \\
2 \text { Pocas veces } \\
3 \text { A veces } \\
4 \text { Muchas veces } \\
5 \text { Casi siempre }\end{array}$ \\
\hline 344 & JJ63_Posttest_P25 & $\begin{array}{l}\text { ¿En las materias que no te gustan } \\
\text { sacas buenas calificaciones?_inicial }\end{array}$ & Cualitativa & Ordinal & $\begin{array}{l}\text { Casi nunca } \\
2 \text { Pocas veces } \\
3 \text { A veces } \\
4 \text { Muchas veces } \\
5 \text { Casi siempre }\end{array}$ \\
\hline 345 & JJ63_Posttest_P26 & $\begin{array}{l}\text { ¿Si tu padre/ madre pierden el } \\
\text { trabajo, trabajarías para } \\
\text { ayudar?_inicial }\end{array}$ & Cualitativa & Ordinal & $\begin{array}{l}1 \text { Casi nunca } \\
2 \text { Pocas veces } \\
3 \text { A veces } \\
4 \text { Muchas veces } \\
5 \text { Casi siempre }\end{array}$ \\
\hline 346 & JJ63_Posttest_P27 & $\begin{array}{l}\text { ¿Si te emborrachas, pides } \\
\text { disculpas a tus padres al día } \\
\text { siguiente?_inicial }\end{array}$ & Cualitativa & Ordinal & $\begin{array}{l}1 \text { Casi nunca } \\
2 \text { Pocas veces } \\
3 \text { A veces } \\
4 \text { Muchas veces } \\
5 \text { Casi siempre }\end{array}$ \\
\hline 347 & JJ63_Posttest_P28 & $\begin{array}{l}\text { ¿Si tuvieras que cambiarte de casa, } \\
\text { lo aceptarías con facilidad?_inicial }\end{array}$ & Cualitativa & Ordinal & $\begin{array}{l}1 \text { Casi nunca } \\
2 \text { Pocas veces } \\
3 \text { A veces } \\
4 \text { Muchas veces } \\
5 \text { Casi siempre }\end{array}$ \\
\hline
\end{tabular}




\begin{tabular}{|c|c|c|c|c|c|}
\hline 348 & JJ63_Posttest_P43 & $\begin{array}{l}\text { ¿Crees que tus padres y maestros } \\
\text { son anticuados (chapados a la } \\
\text { antigua) y no saben lo que dicen } \\
\text { sobre tu conducta?_inicial }\end{array}$ & Cualitativa & Ordinal & $\begin{array}{l}1 \text { Casi nunca } \\
2 \text { Pocas veces } \\
3 \text { A veces } \\
4 \text { Muchas veces } \\
5 \text { Casi siempre }\end{array}$ \\
\hline 349 & JJ63_Posttest_P44 & $\begin{array}{l}\text { ¿Asumes las consecuencias de tus } \\
\text { actos y los afrontas?_inicial }\end{array}$ & Cualitativa & Ordinal & $\begin{array}{l}1 \text { Casi nunca } \\
2 \text { Pocas veces } \\
3 \text { A veces } \\
4 \text { Muchas veces } \\
5 \text { Casi siempre }\end{array}$ \\
\hline 350 & JJ63_Posttest_P45 & $\begin{array}{l}\text { ¿Cuestionas las órdenes o } \\
\text { sugerencias de tus padres?_inicial }\end{array}$ & Cualitativa & Ordinal & $\begin{array}{l}1 \text { Casi nunca } \\
2 \text { Pocas veces } \\
3 \text { A veces } \\
4 \text { Muchas veces } \\
5 \text { Casi siempre }\end{array}$ \\
\hline 351 & JJ63_Posttest_P46 & $\begin{array}{l}\text { ¿Es malo consumir alcohol o } \\
\text { drogas?_inicial }\end{array}$ & Cualitativa & Ordinal & $\begin{array}{l}1 \text { Casi nunca } \\
2 \text { Pocas veces } \\
3 \text { A veces } \\
4 \text { Muchas veces } \\
5 \text { Casi siempre }\end{array}$ \\
\hline 352 & JJ63_Posttest_P47 & $\begin{array}{l}\text { ¿Si hay algo que no entiendes, } \\
\text { procuras investigarlo y luego dar tu } \\
\text { punto de vista si te lo piden?_inicial }\end{array}$ & Cualitativa & Ordinal & $\begin{array}{l}1 \text { Casi nunca } \\
2 \text { Pocas veces } \\
3 \text { A veces } \\
4 \text { Muchas veces } \\
5 \text { Casi siempre }\end{array}$ \\
\hline 353 & JJ63_Posttest_P48 & $\begin{array}{l}\text { ¿Cuándo escuchas noticias das tu } \\
\text { opinión sobre las mismas?_inicial }\end{array}$ & Cualitativa & Ordinal & $\begin{array}{l}1 \text { Casi nunca } \\
2 \text { Pocas veces } \\
3 \text { A veces } \\
4 \text { Muchas veces } \\
5 \text { Casi siempre }\end{array}$ \\
\hline 354 & JJ63_Posttest_P49 & $\begin{array}{l}\text { ¿Te gustaría decirles a tus } \\
\text { profesores que están } \\
\text { equivocados?_inicial }\end{array}$ & Cualitativa & Ordinal & $\begin{array}{l}1 \text { Casi nunca } \\
2 \text { Pocas veces } \\
3 \text { A veces } \\
4 \text { Muchas veces } \\
5 \text { Casi siempre }\end{array}$ \\
\hline 355 & JJ63_Posttest_P50 & $\begin{array}{l}\text { ¿Te arrepientes cuando dices cosas } \\
\text { inoportunas? inicial }\end{array}$ & Cualitativa & Ordinal & $\begin{array}{l}1 \text { Casi nunca } \\
2 \text { Pocas veces } \\
3 \text { A veces } \\
4 \text { Muchas veces } \\
5 \text { Casi siempre }\end{array}$ \\
\hline 356 & JJ63_Posttest_P51 & $\begin{array}{l}\text { ¿Después de que has hecho algo } \\
\text { peligroso, te sientes mal?_inicial }\end{array}$ & Cualitativa & Ordinal & $\begin{array}{l}1 \text { Casi nunca } \\
2 \text { Pocas veces } \\
3 \text { A veces } \\
4 \text { Muchas veces } \\
5 \text { Casi siempre }\end{array}$ \\
\hline 357 & JJ63_Posttest_P52 & $\begin{array}{l}\text { ¿Cuándo le gritas a alguien por } \\
\text { cualquier motivo, le pides disculpas } \\
\text { después?_inicial }\end{array}$ & Cualitativa & Ordinal & $\begin{array}{l}1 \text { Casi nunca } \\
2 \text { Pocas veces } \\
3 \text { A veces } \\
4 \text { Muchas veces } \\
5 \text { Casi siempre }\end{array}$ \\
\hline 358 & JJ63_Posttest_P53 & $\begin{array}{l}\text { ¿Cuándo te escapas de las clases, } \\
\text { te sientes mal?_inicial }\end{array}$ & Cualitativa & Ordinal & $\begin{array}{l}1 \text { Casi nunca } \\
2 \text { Pocas veces } \\
3 \text { A veces } \\
4 \text { Muchas veces } \\
5 \text { Casi siempre }\end{array}$ \\
\hline 359 & JJ63_Posttest_P54 & $\begin{array}{l}\text { ¿Cuándo ofreces cosas que no } \\
\text { tienes o no puedes dar, te sientes } \\
\text { preocupado?_inicial }\end{array}$ & Cualitativa & Ordinal & $\begin{array}{l}1 \text { Casi nunca } \\
2 \text { Pocas veces } \\
3 \text { A veces } \\
4 \text { Muchas veces } \\
5 \text { Casi siempre }\end{array}$ \\
\hline 360 & JJ63_Posttest_P55 & $\begin{array}{l}\text { ¿Cuándo agredes a alguien } \\
\text { verbalmente o físicamente, te } \\
\text { sientes mal?_inicial }\end{array}$ & Cualitativa & Ordinal & $\begin{array}{l}1 \text { Casi nunca } \\
2 \text { Pocas veces } \\
3 \text { A veces } \\
4 \text { Muchas veces } \\
5 \text { Casi siempre }\end{array}$ \\
\hline 361 & JJ63_Posttest_P56 & $\begin{array}{l}\text { ¿Cuándo has tomado una mala } \\
\text { decisión, te arrepientes?_inicial }\end{array}$ & Cualitativa & Ordinal & $\begin{array}{l}1 \text { Casi nunca } \\
2 \text { Pocas veces } \\
3 \text { A veces } \\
4 \text { Muchas veces } \\
5 \text { Casi siempre }\end{array}$ \\
\hline
\end{tabular}




\begin{tabular}{|c|c|c|c|c|c|}
\hline 362 & JJ63_Posttest_P57 & $\begin{array}{l}\text { ¿Te gusta hacer bromas con } \\
\text { facilidad?_inicial }\end{array}$ & Cualitativa & Ordinal & $\begin{array}{l}1 \text { Casi nunca } \\
2 \text { Pocas veces } \\
3 \text { A veces } \\
4 \text { Muchas veces } \\
5 \text { Casi siempre }\end{array}$ \\
\hline 363 & JJ63_Posttest_P58 & $\begin{array}{l}\text { ¿Ríes y disfrutas de los chistes que } \\
\text { hacen tus amigos y } \\
\text { compañeros?_inicial }\end{array}$ & Cualitativa & Ordinal & $\begin{array}{l}1 \text { Casi nunca } \\
2 \text { Pocas veces } \\
3 \text { A veces } \\
4 \text { Muchas veces } \\
5 \text { Casi siempre }\end{array}$ \\
\hline 364 & JJ63_Posttest_P59 & $\begin{array}{l}\text { ¿Cuándo te llaman la atención, te } \\
\text { molestas?_inicial }\end{array}$ & Cualitativa & Ordinal & $\begin{array}{l}1 \text { Casi nunca } \\
2 \text { Pocas veces } \\
3 \text { A veces } \\
4 \text { Muchas veces } \\
5 \text { Casi siempre }\end{array}$ \\
\hline 365 & JJ63_Posttest_P60 & $\begin{array}{l}\text { ¿Cuándo recibes una noticia que tú } \\
\text { consideras buena, saltas de } \\
\text { alegría?_inicial }\end{array}$ & Cualitativa & Ordinal & $\begin{array}{l}1 \text { Casi nunca } \\
2 \text { Pocas veces } \\
3 \text { A veces } \\
4 \text { Muchas veces } \\
5 \text { Casi siempre } \\
\end{array}$ \\
\hline 366 & JJ63_Posttest_P61 & ¿Crees que la vida es linda?_inicial & Cualitativa & Ordinal & $\begin{array}{l}1 \text { Casi nunca } \\
2 \text { Pocas veces } \\
3 \text { A veces } \\
4 \text { Muchas veces } \\
5 \text { Casi siempre } \\
\end{array}$ \\
\hline 367 & JJ63_Posttest_P62 & $\begin{array}{l}\text { ¿Le dices que le quieres a tu } \\
\text { enamorada/o?_inicial }\end{array}$ & Cualitativa & Ordinal & $\begin{array}{l}1 \text { Casi nunca } \\
2 \text { Pocas veces } \\
3 \text { A veces } \\
4 \text { Muchas veces } \\
5 \text { Casi siempre }\end{array}$ \\
\hline 368 & JJ63_Posttest_P63 & $\begin{array}{l}\text { ¿Hablas de tus problemas } \\
\text { sentimentales con alguien?_inicial }\end{array}$ & Cualitativa & Ordinal & $\begin{array}{l}1 \text { Casi nunca } \\
2 \text { Pocas veces } \\
3 \text { A veces } \\
4 \text { Muchas veces } \\
5 \text { Casi siempre } \\
\end{array}$ \\
\hline 369 & Puntaje_funcio_fami_Final & Funcionalidad Familiar final & Cuantitativa & Discreta & No aplica \\
\hline 370 & Puntaje_Autoes_Final & Autoestima final & Cuantitativa & Discreta & No aplica \\
\hline 371 & Puntaje_aserti_Final & Asertividad final & Cuantitativa & Discreta & No aplica \\
\hline 372 & Puntaje_adap_Final & $\begin{array}{l}\text { Adaptabilidad a situaciones } \\
\text { nuevasfinal }\end{array}$ & Cuantitativa & Discreta & No aplica \\
\hline 373 & Puntaje_pensa_Final & $\begin{array}{l}\text { Capacidad de pensamiento crítico } \\
\text { final ) }\end{array}$ & Cuantitativa & Discreta & No aplica \\
\hline 374 & Puntaje_impul_Final & Impulsividad final & Cuantitativa & Discreta & No aplica \\
\hline 375 & Puntaje_afecti_Final & Afectividad final & Cuantitativa & Discreta & No aplica \\
\hline 376 & Puntaje_resil_Final & Resiliencia general final & Cuantitativa & Discreta & No aplica \\
\hline 377 & Recor_funcio_fami_Final & $\begin{array}{l}\text { Funcionalidad Familiar final } \\
\text { (agrupado) }\end{array}$ & Cualitativa & Ordinal & $\begin{array}{l}1 \text { Familia funcional } \\
2 \text { Familia moderadamente } \\
\text { funcional } \\
3 \text { Familia disfuncional } \\
4 \text { Familia severamente } \\
\text { disfuncional }\end{array}$ \\
\hline 378 & Recor_Autoes_Final & Autoestima final (agrupado) & Cualitativa & Ordinal & $\begin{array}{l}1 \text { Autoestima adecuada } \\
2 \text { Autoestima moderadamente } \\
\text { adecuada } \\
3 \text { Autoestima deficiente } \\
4 \text { Autoestima severamente } \\
\text { deficiente }\end{array}$ \\
\hline 379 & Recor_aserti_Final & Asertividad final (agrupado) & Cualitativa & Ordinal & $\begin{array}{l}1 \text { Asertivo/a } \\
2 \text { Moderadamente asertivo/ } \\
3 \text { Asertivo/a esporádico } \\
4 \text { No asertivo/a }\end{array}$ \\
\hline 380 & Recor_adap_Final & $\begin{array}{l}\text { Adaptabilidad a situaciones } \\
\text { nuevasfinal (agrupado) }\end{array}$ & Cualitativa & Ordinal & $\begin{array}{l}1 \text { Adaptabilidad adecuada } \\
2 \text { Adaptabilidad } \\
\text { moderadamente adecuada } \\
3 \text { Adaptabilidad inadecuada } \\
4 \text { Adaptabilidad severamente } \\
\text { inadecuada }\end{array}$ \\
\hline
\end{tabular}




\begin{tabular}{|c|c|c|c|c|c|}
\hline 381 & Recor_pensa_Final & $\begin{array}{l}\text { Capacidad de pensamiento crítico } \\
\text { final (agrupado) }\end{array}$ & Cualitativa & Ordinal & $\begin{array}{l}1 \text { Pensamiento crítico } \\
2 \text { Pensamiento moderadamente } \\
\text { crítico } \\
3 \text { Pensamiento poco crítico } \\
4 \text { Pensamiento acrítico } \\
\end{array}$ \\
\hline 382 & Recor_impul_Final & Impulsividad final (agrupado) & Cualitativa & Ordinal & $\begin{array}{l}1 \text { No impulsivo/a } \\
2 \text { Impulsivo ocasional } \\
\text { Moderadamente impulsivo } \\
4 \text { Impulsivo/a }\end{array}$ \\
\hline 383 & Recor_afecti_Final & Afectividad final (agrupado) & Cualitativa & Ordinal & $\begin{array}{l}1 \text { Afectivo/a } \\
2 \text { Moderadamente afectivo/a } \\
3 \text { Afectivo/a ocasional } \\
4 \text { No afectivo/a } \\
\end{array}$ \\
\hline 384 & Recor_resil_Final & Resiliencia general final (agrupado) & Cualitativa & Ordinal & $\begin{array}{l}1 \text { Resiliente } \\
2 \text { Moderadamente resiliente } \\
3 \text { Levemente resiliente } \\
4 \text { No resiliente }\end{array}$ \\
\hline
\end{tabular}


Anexo 12. Consentimiento informado para los padres y asentimiento informado

\section{CONSENTIMIENTO INFORMADO}

Curso

Identificación de los responsables del estudio:

- Cindy Tatiana Carrero Torres (Líder de Investigación)

- Lorena Acuña Pinilla (Auxiliar de investigación)

- Yuli Pulido (Auxiliar de investigación)

- Catherine Alayón (Auxiliar de investigación)

\section{INFORMACIÓN PARA EL NIÑO O LA NIÑA}

Las personas responsables de la investigación me han explicado en qué consiste esta actividad. Me han dicho que en cualquier momento puedo decir si quiero o no hacer parte del estudio. También me han dejado preguntar lo que no entiendo y me han contestado satisfactoriamente.

Si decido participar debo:

- Contestar las preguntas que me hacen, siempre y cuando yo quiera y esté en condiciones de hacerlo.

- Responder honestamente las preguntas que me hacen.

ACEPTO: SI

NO

Firma del niño(a) 
Bogotá D.C., 13 de agosto de 2018

\section{CIRCULAR PARA PADRES DE FAMILIA O CUIDADORES}

\section{Estimado padre-madre de familia o cuidador responsable:}

Al grupo de investigación del proyecto "Rayuela Resiliera": Modelo Validado De Promoción De La Resiliencia En Niños Y Niñas, le interesa mejorar las condiciones de vida de los niños que habitan en la Localidad de Ciudad Bolívar. Para lograrlo, llevaremos a cabo actividades que buscan mejor en los niños sus habilidades emocionales, para que sean más fuertes frente a las adversidades o situaciones difíciles que se les presente, o lo que se llamaría "resiliencia" (que es la capacidad de aprender de los errores y sobreponerse al dolor). Para el logro de lo propuesto, se han escogido los niños de la Escuela Tanque Laguna grado $5^{\circ}$ jornada mañana.

A los niños se les aplicará una encuesta de 63 preguntas y luego se realizarán talleres lúdicos durante los meses de setiembre y octubre de 2018, los días jueves (502) y viernes (501) durante su horario habitual de clase, complementando el currículo de las clases de ética y valores, religión y educación artística, según sea el caso. Durante la encuesta y los talleres lúdicos su hijo estará acompañado por profesionales terapeutas capacitados para hacer contención emocional y que además responderán todas sus inquietudes.

La participación de su hijo (a) es libre, voluntaria y anónima, no tiene ningún costo, no representa ningún riesgo para su salud física o mental, es confidencial, no recibirá ninguna compensación económica.

Los datos recolectados serán manejados únicamente por el equipo de investigación, sólo tendrán acceso a la información el equipo de investigadoras, y esta información será sólo rebelada en caso de así usted requerirlo.

En la investigación, las instituciones no tienen ninguna responsabilidad, dado que ésta es desarrollada exclusivamente por el equipo de investigadoras. El Colegio CEDID Ciudad Bolívar- Escuela Tanque Laguna se vincula y avala la aplicación de los cuestionarios y la implementación de los talleres, con la autorización de los padres y de los niños y niñas. Usted podrá retirar voluntariamente este consentimiento en cualquier momento. Si hay discrepancia entre los apoderados del menor, no se considerará la participación del menor en la investigación.

Para cualquier información referente al estudio puede contactar a las siguientes investigadoras: Tatiana Carrero Torres, Tel: 300 2644453, e-mail: tatianacarrero@gmail.com, Auxiliares de Investigación: Lorena Acuña Pinilla, Cel 3118889836 e-mail: Lorena.9658@gmail.com, Yuli Pulido, cel 3123897908, e-mail yulypulido@ludica.cc y Catherine Alayón Cel 3012402777 . En caso de requerir comunicarse con una persona externa al grupo de investigación, podrán comunicarse con el director de Fundación Lúdica Daniel Diaz Cel: 3152604757.

Las investigadoras participarán en la próxima reunión de padres de familia que cite el colegio y allí también podrán despejar dudas al respecto.

Si desea que su hijo o hija participe, debe firmar la siguiente hoja y enviarla en la agenda del niño, antes del día jueves 16 de agosto de 2018.

\section{MIL GRACIAS POR SU ATENCIÓN Y COLABORACIÓN}




\section{CONSENTIMIENTO INFORMADO}

Manifiesto que no he recibido presiones verbales, escritas y/o gestuales para permitir la participación de mi hijo en el estudio y los talleres lúdicos de "rayuela resiliera": modelo validado de promoción de la resiliencia en niños y niñas". Que dicha decisión la tomé en pleno uso de mis facultades mentales, sin encontrarme bajo efectos de medicamentos, drogas o bebidas alcohólicas de forma consciente, autónoma y libre. Su firma (o huella digital) indica que usted ha permitido voluntariamente que el menor participe en este estudio habiendo leído (o escuchado) la información anterior y de común acuerdo entre las personas que tienen la patria potestad del menor participante.

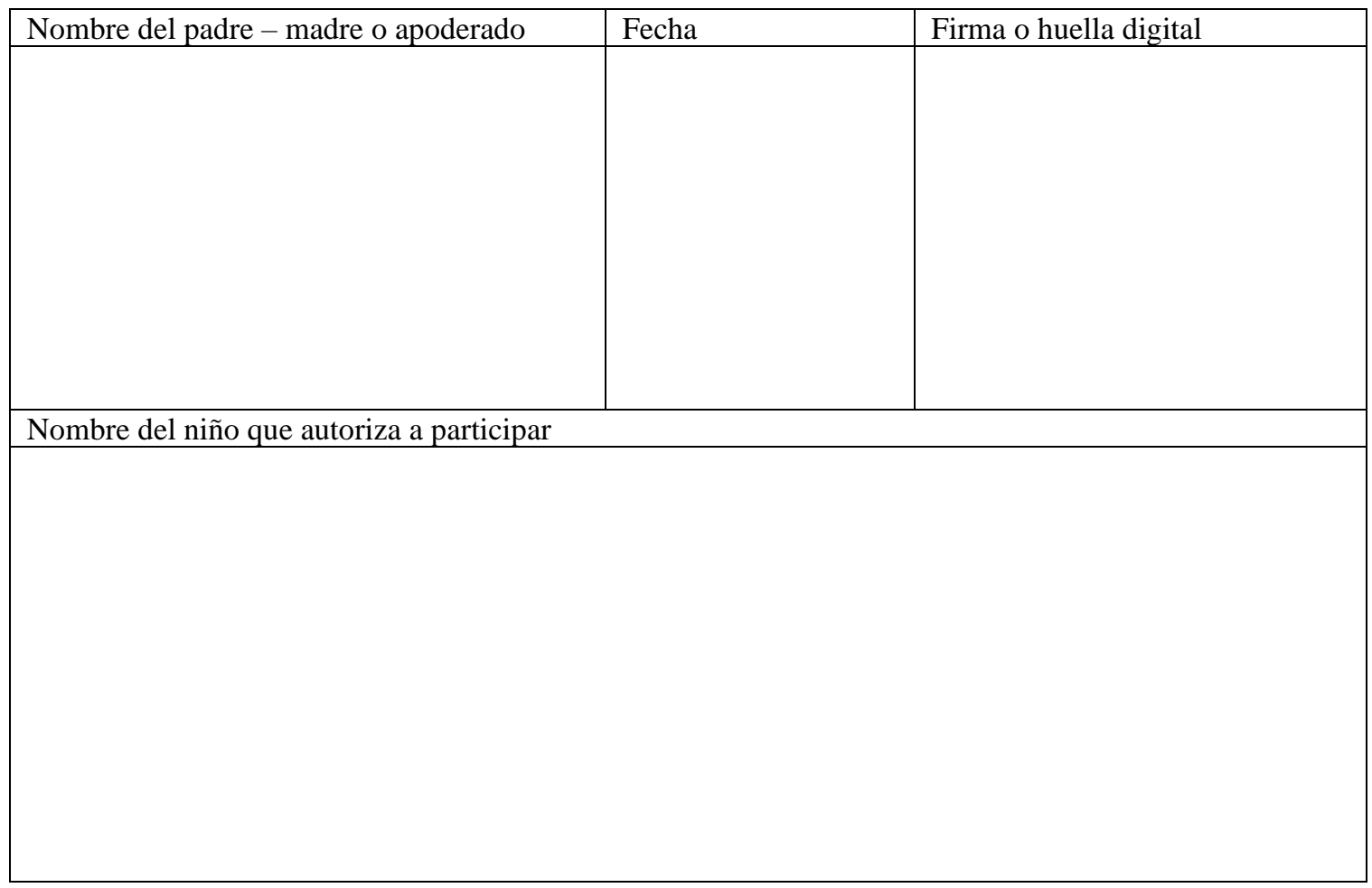

